\title{
Apuntes de investigación educativa
}

Alicia Aleli Chaparro Caso-López, Juan Carlos Rodríguez Macías y Juan Carlos Pérez Morán (COORDINADORES)

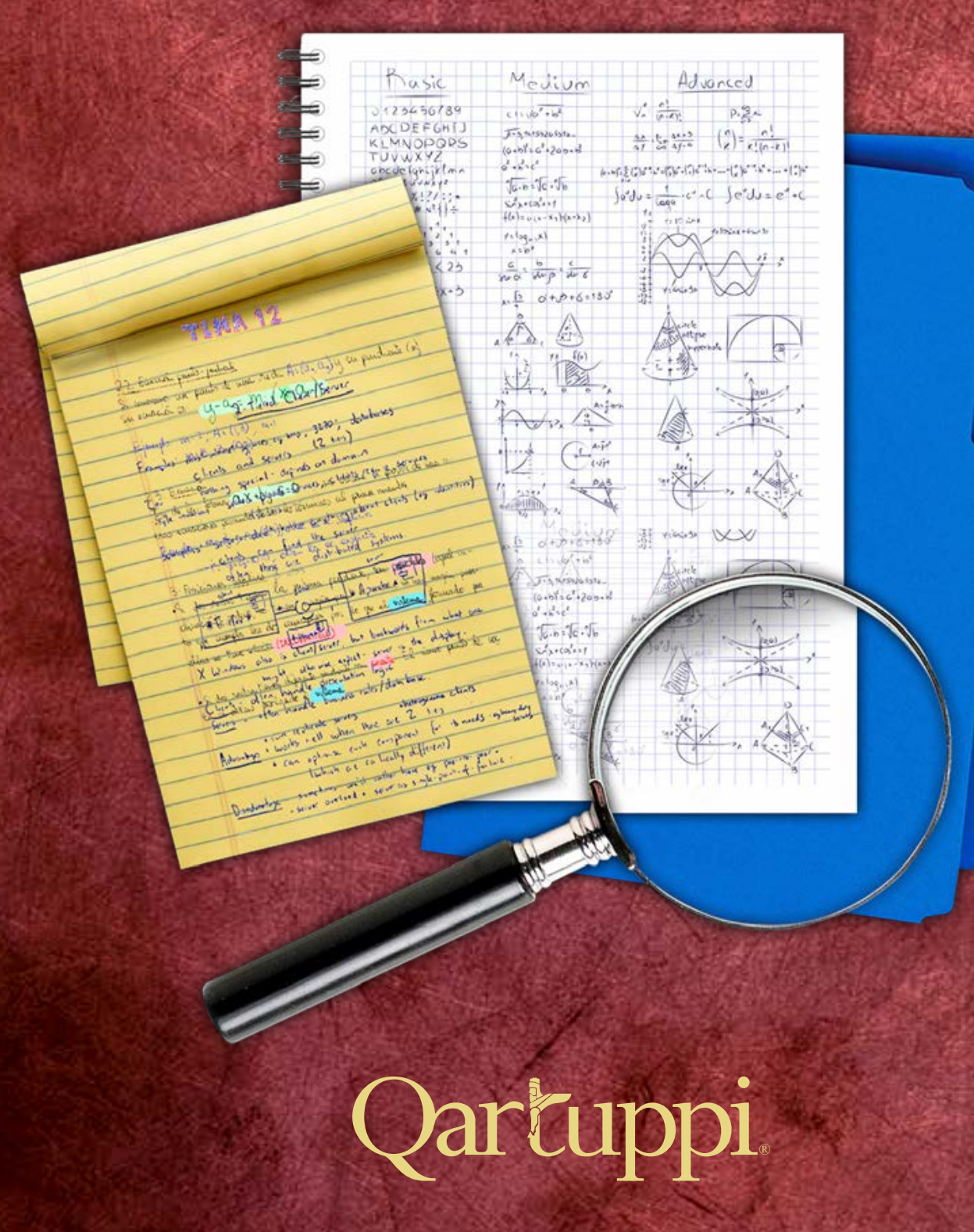




\section{Apuntes de investigación educativa}

Alicia Alelí Chaparro Caso-López, Juan Carlos Rodríguez Macías y Juan Carlos Pérez Morán (COORDINADORES) 
Esta obra ha sido dictaminada por:

Rubí Surema Peniche Cetzal, Universidad Autónoma de Aguascalientes

Mónica Fulgencio Juárez, Universidad Michoacana de San Nicolás de Hidalgo Ana María Méndez Puga, Universidad Michoacana de San Nicolás de Hidalgo

Apuntes de investigación educativa

1era. edición, abril 2019

ISBN 978-607-98270-9-0

DOI 10.29410/QTP.19.05

D.R. @ 2019. Qartuppi, S. de R.L. de C.V.

Villa Turca 17, Villas del Mediterráneo

Hermosillo, Son. 83220 México

http://www.qartuppi.com

Edición y Dlseño: Qartuppi, S. de R.L. de C.V.

Diseño de portada: Stefanya Ríos Padilla

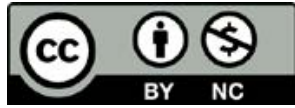

Esta obra posee una Licencia Creative Commons Atribución-NoComercial 4.0 Internacional. 


\section{Índice}

6 Prólogo

Coral González Barbera

PRIMERA PARTE: EDUCACIÓN BÁSICA

13 Capítulo 1 - Aprendizaje de la escritura

Alicia Alelí Chaparro Caso-López e Irma Gloria Arregui Eaton

47 Capítulo 2 - Aprendizaje de las matemáticas

Alicia Alelí Chaparro Caso-López y César Gómez-Monarrez

72 Capítulo 3 - Relevancia de la interacción en el aula desde la perspectiva psicológica

Amy Nayeli Vargas Ceseña, Alicia Alelí Chaparro Caso-López

y Juan Carlos Rodríguez Macías

92 Capítulo 4 - Efectividad de prácticas directivas en contextos escolares vulnerables

Genoveva Gutiérrez Ruiz, Noé Mora Osuna y Alicia Alelí Chaparro Caso-López

110 Capítulo 5 - Evaluación del diseño de la prueba de matemáticas de primaria (06) del PLANEA ELCE 2015 Juan Carlos Pérez-Morán, Juan Carlos Rodríguez Macías, Ramsés Vázquez Lira y Alina Alejandra Ramos Vargas 
SEGUNDA PARTE: EDUCACIÓN SUPERIOR

134 Capítulo 6 - Relación Universidad-desarrollo tecnológico en el marco de la sociedad y la economía del conocimiento Rodolfo García-Galván y Juan Carlos Rodríguez Macías

167 Capítulo 7 -Cumplir con los otros: una revisión documental sobre la colaboración UABC-Tercer Sector Ricardo Lindquist Sánchez, Rodolfo García-Galván y Alicia Alelí Chaparro Caso-López

188 Capítulo 8 - Contexto institucional de la cooperación IES-sector productivo: marco general para México y Baja California Marcela Morales Páez, Rodolfo García-Galván y Juan Carlos Rodríguez Macías

210 Capítulo 9 - La cooperación tecnocientífica IES-SP en Baja California desde la percepción de los profesores-investigadores Marcela Morales Páez, Juan Carlos Vázquez Almaraz y Juan Carlos Rodríguez Macías

224 Capítulo 10 - ¿Qué valoran los empleadores en los egresados de educación superior en Baja California?

Dalia Lizzett Acosta Cárdenas, Juan Carlos Rodríguez Macías, Rodolfo García-Galván y Alicia Alelí Chaparro Caso-López

238 Capítulo 11- Análisis del procedimiento para evaluar programas educativos en la educación superior de México a partir del modelo CIPP de Stufflebeam Nancy Noemí Gutiérrez Anguiano, Leticia Berenice Castillo García, Alicia Alelí Chaparro Caso-López y Rodolfo García-Galván 


\section{Prólogo}

Escribir el prólogo de un libro es un verdadero honor y una enorme responsabilidad, puesto que se trata de convencer al lector de que las páginas que siguen son merecedoras de su tiempo y esfuerzo. En este caso, ambas sensaciones, honor y responsabilidad, las comparte quien suscribe, pero la tarea de convencer al lector resulta extremadamente fácil debido al interés que suscita cada capítulo en sí mismo, desde su título hasta sus referencias.

El Instituto de Investigación y Desarrollo Educativo (IIDE) de la Universidad Autónoma de Baja California es, sin duda, el principal referente en materia de investigación educativa del Estado y uno de los primeros en México. En los más de 26 años desde su creación, se han realizado cientos de investigaciones y se ha formado a numerosas cohortes de estudiantes de posgrado.

Como bien es sabido, la universidad tiene varias misiones, las cuales han ido cambiando desde su creación con el devenir de los tiempos y los intereses de la sociedad. Sin embargo, es indudable que los centros universitarios actuales deben cumplir con dos objetivos principales: formar a sus estudiantes y difundir conocimientos científicos y rigurosos logrados con sus investigaciones. El IIDE por sus peculiares características, es un ejemplo de cómo integrar ambos objetivos.

Apuntes de investigación educativa es una prueba irrefutable de la anterior afirmación. Se trata de la compilación de estudios y revisiones documentales, diseñados y llevados a cabo por estudiantes e investigadores del IIDE, bajo el amparo de sus programas de posgrado de Maestría o Doctorado en Ciencias Educativas. Es pues, el producto final de procesos de formación e investigación desarrollados íntegramenteen el instituto. 
Los citados trabajos, en forma de capítulos, se agrupan bajo dos temáticas; por una parte, los cinco primeros, abordan cuestiones relacionadas con la etapa básica y obligatoria del sistema educativo. Por otra, los seis restantes, se centran en aspectos vinculados con la educación superior.

Los dos primeros capítulos, de estructura similar, se centran respectivamente en los aprendizajes más importantes de los primeros años del sistema educativo puesto que son el cimiento en el que apoyar muchos otros: la escritura y las matemáticas. Tras una extensa revisión bibliográfica, se repasan ambos procesos de aprendizaje y los problemas más frecuentes que se desprenden de los citados procesos. Cabe destacar que, tanto el capítulo 1 (Chaparro y Arregui) como el 2 (Chaparro y Gómez-Monarrez), hacen hincapié en la evaluación, análisis y corrección de los principales errores cometidos. Aportan informaciones muy completas sobre ambos procesos de aprendizaje y permiten extraer conclusiones que afectan de manera directa a su enseñanza así, aunque el núcleo central es el aprendizaje, se puede afirmar que serán de interés y utilidad para todos aquellos implicados en el proceso de enseñanza-aprendizaje de la escritura o de las operaciones fundamentales de matemáticas, especialmente para docentes y padres.

Los capítulos 3 y 4, a pesar de tener estructura y objetivos diferentes presentan un denominador común: ambos profundizan en cuestiones vinculadas con las relaciones interpersonales que se establecen en los centros educativos de la etapa básica.

En el capítulo 3 (Vargas, Chaparro y Rodríguez) se presenta una revisión del estado del arte referida a la interacción en el aula entre estudiantes y estudiantes-docentes. Asimismo, se exponen los paradigmas que, desde la Psicología, han surgido para explicar las interacciones en el contexto educativo y de qué manera pueden influir en el desarrollo emocional e incluso en el desempeño académico de los estudiantes. Tras leerlo, cualquier docente tendrá herramientas para enfrentarse a su práctica diaria, siendo consciente de que numerosas investigaciones concuerdan en dos ideas: (1) que una interacción positiva y responsable con los estudiantes influye de manera decisiva la consecución de aprendizajes significativos y (2) que lograr una interrelación entre estudiantes basada en el respeto y el buen clima ayudará a tener estudiantes más motivados en su aula. 
El capítulo 4 (Gutiérrez, Mora y Chaparro) se centra en una figura esencial de las escuelas de educación básica: el director o directora. Basándose en la literatura sobre el tema, se destaca la importancia que las prácticas directivas tienen en todos los contextos educativos $\mathrm{y}$, especialmente en los contextos más desfavorecidos y vulnerables. La conclusión fundamental se basa en la idea de que las labores directivas sólo tendrán un efecto positivo en los estudiantes si se adaptan al contexto sociocultural y económico en el que se ubica la escuela. Este breve trabajo hará reflexionar a quienes lideran las escuelas puesto que les permitirá analizar sus tareas y funciones bajo el prisma del contexto en el que se encuentran inmersas.

Por último, en esta primera parte del libro se incluye un quinto capítulo (Pérez-Morán, Rodríguez, Vázquez y Ramos) con un enfoque totalmente diferente puesto que se presenta un interesante análisis de contenido de ítems liberados de una importante prueba que pretende medir los conocimientos matemáticos de los estudiantes mexicanos de $6^{\circ}$ de Educación Primaria. Partiendo del llamado Modelo para la Evaluación del Diseño Universal (Thompson, Johnstone y Thurlow, 2002) y mediante una metodología basada en dos procedimientos, panel de expertos y protocolos verbales con estudiantes, presenta un pormenorizado análisis llegando a resultados enormemente interesantes sobre los ítems concretos sobre los que trabaja. Este capítulo puede ser muy clarificador y relevante para los encargados de diseñar las pruebas a gran escala que, en ocasiones, tienen implicaciones de gran impacto para estudiantes e instituciones. Además, puede ayudar a todos aquellos que diseñan pruebas para evaluar contenidos a un grupo reducido de estudiantes, ya que se aborda cuestiones que cualquier docente debería tener en cuenta al elaborar sus exámenes.

La segunda parte compila seis capítulos más, cuyo factor común es la Educación Superior. El primero de ellos, el capítulo 6 (García-Galván y Rodríguez) presenta una discusión teórica y conceptual sobre la relación de la universidad con su entorno. Los autores buscan de una manera sencilla mostrar al lector las diferentes aristas que comprenden los procesos implicados en la relación entre estos dos entes: universidad y sociedad. 
El capítulo 7 (Lindquist, García-Galván y Chaparro), parte de la preocupación por conocer de qué manera la Universidad Autónoma de Baja California está colaborando con el Ilamado Tercer Sector. Para llegar a la principal conclusión, consistente en que hay que seguir trabajando en estrechar la colaboración puesto que aún es muy superflua, hace un interesante repaso por el origen y evolución de la universidad, deteniéndose en las funciones que se le ha otorgado a lo largo de la historia hasta concretar en la importancia de colaborar con el Tercer Sector (elemento que también se detiene a explicar). Cualquier persona vinculada con la universidad o con organizaciones y comunidades sociales, disfrutará del enfoque y revisión de este capítulo.

De manera complementaria, el capítulo 8 (Morales, García-Galván y Rodríguez) se centra en la relación o cooperación entre las instituciones universitarias y el sector productivo o empresarial. Revisando el concepto de institución y analizando los modos existentes de colaboración con las empresas, se sintetizan las principales normativas, nacionales y estatales, que rigen actualmente este tipo de colaboración. El principal hallazgo que extraen es que, la legislación, sobre el papel, contempla elementos y fuentes de colaboración de gran relevancia para ambos estamentos, universidad y empresas, sin embargo, no todos están implementados en la práctica. Los profesionales encargados de las prácticas externas de los estudiantes, los que ocupan cargos de gestión vinculados con la relación entre estudios universitarios y sector productivo, ya sea en la universidad o en la empresa, reflexionarán con la lectura del capítulo sobre su labor y el modo de desarrollarla para favorecer esta necesaria colaboración.

En el Capítulo 9 (Morales, Vázquez y Rodríguez) se presenta un estudio empírico realizado con profesores investigadores, sobre las condiciones y procesos relacionados con la cooperación tecnocientífica (CT) entre las instituciones de educación superior y el sector productivo. Entre los hallazgos relevantes destaca que, en general, existe una predisposición positiva hacia la realización de actividades de CT. El estudio da cuenta de la necesidad de que el gobierno adopte una actitud de mayor apoyo hacia la CT, tanto a través de financiamiento directo como de la generación de políticas públicas que coadyuven al fortalecimiento de esta. Por lo tanto, el estudio presentado en este capítulo puede resultar relevante para los interesados el tema de la cooperación tecnocientífica. 
En el capítulo 10 (Acosta, Rodríguez, García-Galván y Chaparro) se aborda, en esencia, la misma cuestión que el capítulo 8, pero concretando en las valoraciones de algunos empleadores del estado de Baja California. Basándose en entrevistas semiestructuradas a encargados de recursos humanos de tres importantes empresas, recogen información sobre los procesos de selección, las características que buscan de los futuros empleados y la opinión que les merece la Educación Superior en cuanto a la formación que consigue en sus egresados. Entre las interesantes conclusiones destaca la importancia que los empleadores otorgan, no tanto a los conocimientos de los solicitantes, que los presuponen, como a las actitudes que demuestran y destacan la responsabilidad, el compromiso, la iniciativa y la capacidad para resolver problemas, entre otras. Este capítulo puede resultar de especial interés para aquellos estudiantes o recién egresados de la universidad que se encuentran en el proceso de búsqueda de empleo.

Para finalizar, el capítulo 11 (Gutiérrez, Castillo, Chaparro y García-Galván) se centra en un campo esencial de la evaluación, la evaluación de programas. Tomando como referencia uno de los modelos teóricos más conocidos y valorados, el modelo CIPP de Stufflebeam, analiza los procesos que siguen los dos organismos encargados de la evaluación de los programas y planes de estudios de todas las instituciones universitarias mexicanas, el CIEES y el COPAES. El fundamental hallazgo que se desprende de la comparación y el análisis llevado a cabo es que, en esencia, ambos organismos cumplen con las etapas y fases que el modelo teórico de referencia apunta. El lector interesado en la calidad universitaria, así como en el diseño y evaluación de planes de estudios, disfrutará de una excelente integración del modelo teórico citado y de los modelos prácticos implementados en la actualidad para la evaluación de programas de Educación Superior en México.

Sin otra pretensión que potenciar la motivación hacia la lectura de este libro de investigación que compila diversos intereses vinculados con la educación básica y superior, no me queda más que la satisfacción que produce la sensación de imaginar que lo habré logrado. 
Mis felicitaciones al IIDE y en especial a todos y cada uno de los autores de esta obra y a aquellos que, sin ser autores, hacen posible la edición anual de trabajos de posgrado que contribuyen a la difusión y dan visibilidad a investigaciones educativas en el ámbito nacional e internacional.

Dra. Coral González Barbera Profesora de Métodos de Investigación y Diagnóstico en Educación Facultad de Educación Universidad Complutense de Madrid 


\section{Primera parte: Educación básica}




\section{Capítulo 1}

\section{Aprendizaje de la escritura}

Alicia Alelí Chaparro Caso-López e Irma Gloria Arregui Eaton

La escritura es una habilidad intrínsecamente ligada a la lectura, ambas actividades componen la lengua escrita (Berruezo, 2004). Según Cuetos (1991) la escritura implica cuatro procesos: (1) planificación del mensaje, (2) construcción de las estructuras sintácticas, (3) selección de palabras, y (4) procesos motores; cada uno de ellos está compuesto por distintos subprocesos. Por lo tanto, de acuerdo con el autor, para escribir se necesita tener conocimiento de los códigos de lenguaje, habilidad de convertir los fonemas en grafemas, conocimiento del sistema grafémico, una adecuada motricidad fina, habilidad espacial para juntar las letras formando palabras y separar los espacios entre las mismas.

La escritura puede clasificarse de diversas formas. Por ejemplo, Sánchez (2006) afirmó que existen tres modalidades de lenguaje escrito: (1) escritura espontánea, (2) escritura al dictado, y (3) escritura a la copia. Por su parte, Rosino (2009) señaló que la escritura se puede diferenciar a partir de los procesos implicados en la escritura de palabras y la composición de textos. En el primer proceso sólo se requiere la aplicación de las normas ortográficas, mientras que el segundo es más complejo e implica la necesidad de dar coherencia al conjunto de palabras escritas para generar un significado. Así, también, se puede clasificar en escritura productiva (copia de textos) y reproductiva (dictado). Berruezo (2004) señaló que independientemente de la modalidad de escritura, ésta siempre es una actividad gnoso-práxica. 


\section{Procesos implicados en la escritura}

La literatura sobre el proceso de aprendizaje de la escritura muestra varios aspectos que se involucran en la escritura de las palabras y textos. Arnaiz y Ruiz (2001) mencionaron que escribir no es sólo reproducir signos. Para que la escritura se dé se requiere poner en marcha procesos de tipo lingüístico-cognoscitivo y perceptivo-motor (Correig, 2000; Jiménez y Artiles, 1990). A este respecto, Rosino (2009) señaló que para que los niños empiecen a escribir se necesitan muchas horas de práctica. Según este autor se trata de una actividad compleja que demanda de un grado alto de abstracción. En la enseñanza inicial de la escritura se requiere principalmente de mostrar a los niños las letras y sus diferencias para que logren discriminarlas e identificar sus correspondencias sonoras. Posteriormente, los niños aprenden a identificar las señales contextuales dentro del texto, donde las propias palabras actúan como señales que ayudan a decodificar cada palabra. En último lugar, las palabras se asocian a los conceptos que éstas representan, los cuales se almacenan en la memoria a largo plazo, donde se almacena todas palabras que conocemos, así como el conocimiento lingüístico de las mismas.

Jiménez y Artiles (1990) en un estudio sobre aprendizaje de la lecto-escritura señalaron que tanto la lectura como la escritura son aprendizajes que demandan habilidades cognitivas y lingüísticas. Además, concluyeron que estas son las habilidades con mayor peso en la adquisición de la lectoescritura, tal como la del dominio del sistema fonológicoy semántico, así como el razonamiento conceptual, sí pueden integrarse mejor desde la perspectiva de un modelo psicolingüisitco-cognitivo. Según este modelo, la lectoescritura es un proceso lingüístico-cognoscitivo y su adquisición va a depender de un conjunto de experiencias lingüísticas, metalingüísticas y de conocimiento del mundo.

Aprender a leer y escribir implica también un componente visiográfico en donde se deben relacionar los fonemas (sonidos) y los grafemas (representaciones gráficas). Sin embargo, como planteó Rosino (2009), la escritura puede darse por dos rutas, la fonológica y léxica u ortográfica:

La ruta fonológica conocida también como indirecta o no léxica, en la que la palabra escrita se genera a través de la utilización de mecanismos de conversión o reglas 
de correspondencia fonema-grafema; una vez que el niño logra identificar las unidades fonemáticas de la palabra. Es decir, el niño necesita separar la palabra en fonemas y buscar la conexión de cada fonema con su grafema. Esta ruta es la que los niños controlan mejor, dado que es el primer objetivo que se cubre en el aprendizaje de la escritura. Sin embargo, es importante señalar que esto ocurre en los niños de habla hispana quienes inician el aprendizaje de la escritura a través de la ruta fonológica, pero no así en los niños de habla inglesa como se verá más adelante.

Escribir por la ruta fonológica o indirecta es un proceso arduo y complejo que implica el dominio de una serie importante de aprendizajes básicos. Esta estrategia de escritura está altamente influida por la pronunciación, lo que implica que todos los errores de lenguaje oral que comete un sujeto son errores que serán directamente transferidos a la escritura. Por tanto, muchos de los errores de escritura, son más concretamente errores de habla, que sólo desaparecerán del lenguaje escrito, cuando sean previamente eliminados del lenguaje oral.

La ruta ortográfica conocida también como visual o léxica implica la utilización de los conocimientos sobre las representaciones ortográficas de las palabras que previamente se han aprendido. En este caso, el aprendiz puede presentar errores ortográficos derivados de las palabras homófonas, en cuyos casos el niño deberá aprender la regla ortográfica aplicada a cada una (ejemplo: casa, caza) y palabras irregulares o excepcionales escritas en inglés (ejemplo: web) que fonológicamente pueden ser apropiadas, pero estar incorrectamente escritas. El proceso de escritura por esta vía tiene que volverse automático, para así lograr el dominio de la forma más compleja de la escritura que es la composición de textos.

La ruta ortográfica inicia igual que la ruta fonológica con la activación del significado en el sistema semántico, pero el siguiente paso no es ya la activación de la representación correspondiente en el léxico fonológico, sino la activación de una representación ortográfica de la palabra acumulada en un almacén de memoria denominado léxico ortográfico. 
Valle (1989) describió las características de las rutas fonológica y ortográfica según sus propiedades y funciones. La escritura fonológica (también llamada no léxica) tiene las siguientes características:

1. Insensibilidad a la frecuencia, porque se supone que en este modo de escritura (ruta no léxica) cada fonema se convierte en la letra o grafema correspondiente. Por lo tanto, si el sujeto conoce dichas equivalencias, las aplicará indistintamente y con igual exactitud independientemente de que las palabras sean frecuentes o infrecuentes.

2. La regularidad es un factor importante: se cometerán menores errores con palabras regulares (palabras que conservan la relación fonema-grafema) que con irregulares. Estas últimas no se escribirían bien más que por azar, si el sujeto utiliza la ruta fonológica; por el sonido es imposible distinguir entre $b$ y $v$.

3. Las pseudo palabras se escribirán mejor que las palabras. Esta predicción puede parecer un tanto extraña a primera vista, pero es completamente lógica. La razón es la siguiente: sólo hay una forma posible de escribir correctamente la palabra según las reglas de la Real Academia de la Lengua, mientras que las pseudopalabras no tienen una forma ortográfica establecida, por lo tanto, cualquier grafía que transcriba el sonido debe considerarse como aceptable.

4. La longitud es importante. Cuanto más larga es una palabra, mayor es el número de veces que hay que aplicar las reglas de la conversión fonemas-grafemas (CFG) y, por tanto, mayor la probabilidad de cometer un error (p. 48).

Por otra parte, el mismo Valle (1989, p. 49) también describe las características de escritura en la ruta ortográfica (léxica):

1. Insensibilidad a la regularidad de las palabras. El número de faltas cometidas sería aproximadamente el mismo, independientemente de si se trata de palabras regulares, es decir, aquellas en las que se conservan la conversión fonema-grafema como de irregulares. La razón es que el concepto de regularidad no tiene nada que ver con la vista, sino con las relaciones fonema-grafema; es decir, si se sabe cómo se escribe una palabra, no importa que ésta sea regular o irregular. 
2. Gran sensibilidad a la frecuencia, por tanto, el número de errores será tanto menor cuanto mayor es la frecuencia. Ya que se trata de reproducir formas visuales y lógicamente, cuantas más veces se han visto dichas formas mejor será el conocimiento que poseemos y menor la probabilidad de cometer errores.

3. Diferencias significativas entre la escritura de palabras y de pseudoplabras, siendo mucho mejor la primera que la segunda.

4. Insensibilidad a la longitud. En las posiciones más extremas, la longitud no debe afectar en absoluto, la corrección en la escritura léxica. Sin embargo, podemos tener conocimiento parcial de cómo se escribe una palabra, por ejemplo, podemos saber que tiene una " $\mathrm{h}$ ", pero no saber exactamente dónde. Si esto es así, entonces, cuanto más larga sea una palabra mayor será la probabilidad de que el conocimiento parcial nos induzca al error.

Sin embargo, no es clara la forma como ambas rutas interactúan. Como señalaron García-Orza, Madrazo-Lazcano y Viñals-Álvarez (2002) las dos rutas pueden trabajar al mismo tiempo en un espacio denominado almacén grafémico. No obstante, se generan problemas cuando el sujeto tiene que escribir alguna palabra que conoce pero que resulta irregular, como puede ser la palabra whisky, en cuyo caso, puede llegar a imponerse la representación ortográfica. Por lo tanto, cuando se escriben oraciones se utiliza más la ruta fonológica.

\section{El idioma como factor de aprendizaje}

De acuerdo con los planteamientos de Leal, Matute y Zarabozo (2005), en las diferentes lenguas y sistemas de escritura, existen variaciones en las relaciones entre las formas visuales y el sonido. La lectura por definición es de material escrito, por lo que inevitablemente hablar de lectura implica retomar los sistemas de escritura. Las dos rutas utilizadas como estrategias de aprendizaje descritas anteriormente son aplicables de acuerdo con las reglas del español, el cual se considera que cuenta con un sistema transparente de escritura. No obstante, la situación de aplicación de cada una de las rutas cambia en 
función del idioma. Valle (1989) afirmó que en los idiomas con sistemas transportes o superficiales, existe correspondencia consistente entre grafemas y fonemas que hace posible leer cualquier palabra vista desde la primera vez; mientras que en idiomas con sistemas logográficos o en alfabéticos con relaciones no unívocas (múltiples) entre grafemas y fonemas es baja la probabilidad de leer una palabra nueva correctamente, a estos el autor les Ilamó sistemas opacos o profundos, un ejemplo de éstos es el idioma inglés.

Al respecto, Viñals, Vega y Álvarez-Duque (2003) señalaron que en el inglés predominan las conversiones no univocas entre fonemas y grafemas, por lo que es frecuente que se escriban palabras irregulares que no siguen las reglas de conversión de los grafemas en fonemas, por ejemplo, en inglés buy se pronuncia /bai/ y mint se pronuncia /mint/. El inglés, por lo tanto, es un idioma con un sistema de escritura con relaciones no unívocas en el que se utiliza más la ruta ortográfica.

Asimismo, Signorini y Borzone de Manrique (2003) afirmaron que el conocimiento teórico y empírico acerca de la lengua inglesa han mostrado que la información fonológica es una condición necesaria, pero no suficiente para el dominio de la lectura. El inglés cuenta con numerosas palabras irregulares, es decir, no se conserva la relación fonema-grafema. De acuerdo con los autores, en inglés se requiere una fuente adicional de información para el procesamiento de palabras escritas, es decir, el conocimiento de patrones visuales ortográficos específicos que ayuden a identificar una a una las palabras que forman el texto escrito.

Por otra parte, como planteó Valle (1989), el lenguaje español se considera un sistema transparente de escritura (aunque tiene características de opacidad) ya que posee varios fonemas que puede ser transcritos gráficamente de más de una forma: /b/

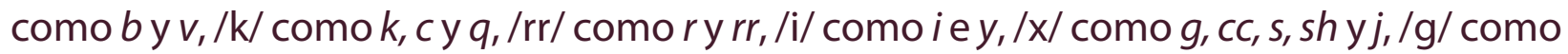
gy gu; y otros problemas de pronunciación como la distinción entre lle y (pollo, poyo). En consecuencia, de acuerdo con el autor, es posible decir que en español escribir sin faltas de ortografía sólo se logra por la ruta visual, por lo que la ruta fonológica sólo se use de forma auxiliar o cuando se enfrentan a palabras que no tienen sentido. Por ejemplo, en un estudio con niños españoles de cinco años Cuetos (1989) encontró que estos eran capaces de escribir más del $90 \%$ de las pseudopalabras bisílabas que se les dictaba. 
En consecuencia, el aprendizaje de la escritura en los idiomas inglés y español es diferente, por lo tanto, como plantearon Signorini y Borzone de Manrique (2003), los modelos de aprendizaje de lectura y escritura que se han elaborado en inglés no pueden aplicarse al español. En estos modelos se considera que en inglés las estrategias fonológicas son un medio fundamental y necesario para formar representaciones ortográficas indispensables tanto para escribir como para leer. Sin embargo, en español los niños pueden aprender a leer sin que necesariamente exista una representación ortográfica estable. Por lo que la calidad de tales representaciones ortográficas constituye una condición indispensable para la escritura convencional pero no para la lectura.

Estudios como el de Leal et al. (2005) muestran que la alta frecuencia de errores ortográficos en textos escritos por niños con y sin problemas de escritura confirman la baja transparencia en la relación fonema-grafema en español de México. Concluyendo que, si el sistema ortográfico del español fuera transparente en estricto sentido, no habría errores ortográficos. Por lo tanto, el dominio de la ortografía es difícil de alcanzar para los niños mexicanos, al grado que la alta frecuencia de errores ortográficos no es un rasgo distintivo de los niños con problemas de escritura. El sistema ortográfico del español es asimétrico con un mayor número de correspondencias unívocas grafemafonema, más relacionadas con la lectura, que fonema-grafema propias de la escritura. En español es más fácil leer que escribir.

\section{Problemas de escritura}

Cuando se inicia el aprendizaje de cualquier sistema de escritura, es común que los aprendices cometan errores. Sin embargo, cuando estos errores se hacen recurrentes y no se corrigen naturalmente con el desarrollo de la madurez motriz y cognoscitiva, es probable que se presente un trastorno de la escritura (Berruezo, 2004; Leal et al., 2005). Existen varios tipos de trastornos de la escritura y cada uno de ellos muestra diferentes características y factores asociados a su desarrollo. Los tres más comunes son la disgrafía, la agrafía y la disortografía. 


\section{Disgrafía}

Este trastorno es de tipo funcional y afecta la calidad de la escritura. Hidalgo (2009) haciendo una revisión de la literatura especializada, relativa al concepto, encontró diferentes definiciones del mismo término. Hay autores que la definen como "las deficiencias en la adquisición o en la ejecución de la escritura", otros la definen como "dificultades o incapacidades para la transcripción correcta de los sonidos", "mala letra", "trastornos que afecta a la simbolización y/o a la forma de la letra", "cuando la calidad de la escritura es deficiente, siendo así sin que exista ningún tipo de déficit neurológico, ni intelectual que explique esta deficiencia".

Berruezo (2004) señaló que la disgrafía se produce en personas cuya inteligencia está dentro de los límites de la normalidad, que no presentan daños sensoriales o neurológicos graves y que tienen una estimulación pedagógica adecuada. En los niños disgráficos se producen deficiencias en el procesamiento neurológico que afectan las acciones implicadas en la escritura como son el ajuste espacial y el inicio de la acción muscular. Viñals et al. (2003) presentaron una descripción de los tipos de disgrafía:

1. Disgrafía fonológica. En la que los sujetos tienen problemas con la escritura de pseudopalabras y poco familiares, mientras que tienen una escritura adecuada de palabras familiares. Las personas con este tipo de disgrafía tienden a escribir las pseudopalabras como palabras reales, fenómeno conocido como lexicalización. Los disgráficos fonológicos tienen problemas en la ruta fonológica y dependen únicamente de la ruta léxica para la escritura de las palabras.

2. Disgrafía superficial. Se describe como una alteración de la ruta léxica. Las personas con este trastorno tienen problemas para representar las palabras del léxico que son de baja frecuencia. Los sujetos tienen problemas con las reglas ortográficas, escribiendo palabras que coinciden con su sonido, pero no tienen una grafía adecuada.

3. Disgrafía profunda. Es una combinación de la disgrafía superficial y fonológica severa. Las personas son incapaces de escribir pseudopalabras, cometen errores derivativos y algunas lexicalizaciones. Muestran errores semánticos en la escritura, 
la cual está repleta de errores fonológicos, ortográficos y errores de omisión/ sustitución de letras y sílabas. En este trastorno existe deficiencia tanto en la ruta fonológica como ortográfica.

4. Disgrafía apráxica. Se caracteriza por alteraciones de los patrones motores de escritura, pudiendo afectar a todos o sólo algunos patrones. Las personas omiten, sustituyen o producen letras de forma incorrecta.

5. Disgrafía aferente. En la que las personas tienden a duplicar letras o trozos de estas. Su escritura tiende a inclinarse hacia abajo. La posible explicación que se da a estos trastornos es que los sujetos tienen incapacidad para integrar la información sobre los movimientos procedentes de la visión y de las sensaciones propioceptivas como retro alimentación de este proceso (Ellis y Young, 1988, como se citó en Viñals et al., 2003). Es como si escribieran sin ver y sentir sus propios movimientos.

6. Alteración del deletreo. En donde los sujetos son capaces de escribir perfectamente, pero incapaces de deletrear. Los sujetos olvidan los nombres de las letras a causa de una lesión neurológica, provocando problemas con la denominación de algunas letras.

Hidalgo (2009) mencionó que la clasificación de disgrafía más aceptada desde la perspectiva cognoscitiva distingue dos tipos de disgrafías.

1. Disgrafía adquirida. Es un trastorno que implica que las personas después de haber aprendido a escribir adecuadamente pierden en menor o mayor grado esta habilidad como consecuencia de un traumatismo o accidente cerebral. Dentro de este tipo de disgrafías se ubican la afasia dinámica central, en donde existe dificultad de planificación del mensaje tanto oral como escrito y el agramatismo o dificultad en la construcción de estructura sintáctica de las oraciones. Se incluyen también dentro de esta clasificación las disgrafías centrales que afectan a nivel léxico o de producción escrita las palabras junto a las disgrafías periféricas, que involucran dificultades en los procesos motores posteriores a la recuperación de 
las palabras. Las disgrafías adquiridas centrales se caracterizan por una alteración de una de las rutas para acceder al léxico o en ambas. Las disgrafías semánticas se caracterizan por la dificultad para comprender el significado de palabras escritas en el dictado. Las disgrafías periféricas implican trastornos motores y causadas por una lesión en procesos posteriores al acceso al léxico.

2. Disgrafía evolutiva. Son dificultades en el aprendizaje inicial de la escritura sin que exista una razón objetiva para ello, pues los sujetos muestran todos los elementos necesarios para el aprendizaje de la escritura como la escolarización adecuada, capacidad intelectual y desarrollo emocional normal, sin problemas en procesos perceptivos o motores.

Además de la disgrafía, un problema de escritura que puede llegar a mostrar algunas personas son las dificultades motoras. Como el mismo Hidalgo (2009) lo planteó, generalmente, este tipo de problemas indican una falta de consolidación del aprendizaje de los patrones motores de las letras en sus diferentes formas, lo que lleva a los niños a mezclar mayúsculas y minúsculas, a confundir letras semejantes, a mostrar un trazo o tamaño inadecuado (demasiado grande o diminuto), a torcer las líneas horizontales, etc. Las deficiencias en la coordinación motriz que afectan sólo al trazo y no al recuerdo de sus patrones motores, no se consideran como dificultades de aprendizaje sino como trastornos de la coordinación.

\section{Agrafía}

Las disgrafías no son los únicos trastornos de la escritura que pueden manifestarse. Existen además una serie de problemas de escritura, conocidos como agrafías, asociados a lesiones de diferentes zonas cerebrales y que ocasionan a su vez diferentes tipos de error en la escritura. Sánchez (2006, pp. 40-41) presentó una descripción de los diferentes tipos de trastorno ocasionados por daños en distintas zonas cerebrales:

1. Lesiones en la región temporal izquierda. Hay alteración del oído fonemático y afasia sensorial. No pueden escribir letras aisladas al dictado, tienen fallas en la elección 
del sonido escuchado y dificultades para escribir sílabas con estructura acústica compleja. Las articulaciones que realizan son inútiles como ayuda; en la escritura de palabras consolidadas tienen éxito, pero hay omisión de sonidos próximos. No pueden destacar ciertos sonidos aislados del flujo de las consonantes y permutan en la ubicación de los sonidos.

2. Alteraciones de la base cinestésica del lenguaje verbal (afasia motriz aferente). Hay escritura de letras aisladas, muestran articulaciones difusas y existe dificultad en el proceso de la escritura. La sustitución articulatoria y la negativa de escribir un sonido son síntomas con los que puede establecerse que hay alteración en la base cinestésica de la escritura. Las huellas cinestésicas que se tienen al escribir en silencio son defectuosas.

3. Alteraciones en la escritura cuando existe afasia motriz eferente (áreas inferiores de la zona premotriz del hemisferio izquierdo). Se altera la fluidez en la escritura; pueden escribir letras al dictado en forma aislada, pero no pueden hacerlo con sílabas complejas o palabras. Pierden el orden debido de las letras y las cambian de ubicación.

4. Lesiones en las regiones occipital, temporoccipital y parieto-occipital del hemisferio izquierdo. Hay dificultades para recodificar el sistema de fonemas hallados y pasarlos a grafemas. Se observan alteraciones visoespaciales, problemas para escribir la letra necesaria, algunos elementos aislados que forman la letra se escriben en relaciones espaciales inadecuadas y las letras se escriben en espejo (copia y dictado).

5. Lesiones en las áreas frontales. No hay alteraciones específicas de la escritura en forma directa.

Sánchez (2006, p. 41) también clasificó los tipos de agrafias:

1. Agrafias afásicas

a. Agrafia en la afasia de Broca. La escritura es escasa, difícil, torpe, abreviada y agramatical, con parafasias literales, repeticiones y omisiones de letras; estas últimas están pobremente formadas. 
b. Agrafia en la afasia de Wernicke. Paragrafías literales y verbales con neologismos abundantes y paragramatismo escrito.

c. Agrafia en la afasia de conducción (Luria, motora aferente). Mejor escritura espontánea que empeora en el dictado. Hay paragrafias literales al escribir palabras fonológicamente complejas, sustituciones literales, adiciones y omisiones de letras en una sola palabra. Asimismo, hay autocorrección, pero el paciente no recuerda cómo se escribe, se realiza lento y escribe más letras que palabras. Cuando tiene agrafia apráxica no puede escribir las letras porque ha olvidado los movimientos necesarios.

\section{Agrafias no afásicas}

a. Agrafia apráxica. En la que se observan errores de ortografía y reiteraciones de letras. La apraxia se observa en la escritura a la copia, en la espontánea y al dictado.

b. Agrafia visoespacial. Se distingue por reiteraciones de rasgos y letras (aspectos espaciales) y por aumento del margen izquierdo (negligencia espacial unilateral). Se observa en caso de lesiones del hemisferio derecho. Alrededor del $50 \%$ de los pacientes con lesiones prerrolándicas y $75 \%$ con lesiones retrorrolándicas tienen dificultades en la escritura. Los hispanoparlantes con lesiones derechas pueden manifestar disortografía, que va de leve a grave. Los pacientes con lesiones derechas cambian la caligrafía, después del daño cerebral, de cursiva a caligrafía de molde, y escriben cada letra como una unidad separada, como si se produjera una desautomatización motora. Lo mismo sucede con la firma, que es un acto automático.

c. Agrafia motora. Las alteraciones motoras en la escritura son resultado de las lesiones del sistema nervioso central que implican a los núcleos basales, al cerebelo y a las vías corticoespinales, o de lesiones que afectan los nervios periféricos y la estructura mecánica de la mano. 


\section{Otras alteraciones en la escritura}

a. Hemiagrafia. La sección del cuerpo calloso como tratamiento para controlar la epilepsia o por remoción de un tumor altera la escritura con la mano izquierda y deja intacta la habilidad para escribir con la mano derecha.

b. Estados de confusión. Los pacientes pueden hablar, comprender órdenes, repetir, denominar y leer, pero son incapaces de expresarse en forma escrita.

\section{Disortografía}

Este problema de escritura es menos grave que los de la disgrafía y agrafía, no es de tipo funcional, y se relaciona con los estudiantes que tienen problemas para aprender la ortografía, mostrando errores asociados con la escritura de la palabra, pero no con el trazo o su grafía (García Vidal 1989, como se citó en López, 2016). Los niños con problemas de disortografía no necesariamente tienen dificultades de la lectura. López (2016), basada en otros autores (Tsvetkova, 1977 y Luria, 1980), presenta una descripción de los tipos de disortografía (pp. 19-20):

- Temporal: relacionada con la percepción del ritmo, presentando dificultades en la percepción de los aspectos fonéticos de la cadena hablada y su correspondiente transcripción, así como la separación y unión de sus elementos

- Perceptivo-cinestésica: relacionada con dificultades en la articulación de los fonemas y la discriminación auditiva de estos. Son frecuentes los errores de sustitución de las letras "r" por "I"

- Disortocinética: dificultad para ordenar y secuenciar las grafías. Errores de unión y fragmentación de palabras

- Visoespacial: relacionada con la percepción visual de ciertas letras, produciéndose errores de rotación de letras (b por d, p por q), sustituciones de grafemas con formas similares (a por o, o $m$ por $n$ )

- Dinámica: dificultad en la expresión escrita es aspectos como la gramática, el orden de los elementos en una oración o la concordancia entre género y número.

- Semántica: el alumno altera el análisis conceptual de las palabras

- Cultural: dificultad en el aprendizaje de las reglas de ortografía 
Respecto a la disortografía, López (2016) cita cuatro posibles causas:

1. Problemas perceptuales: deficiencias en la percepción y/o la memoria visual o auditiva. Esto impacta en la discriminación auditiva de los fonemas y en la memoria auditiva, lo que afecta la memoria visual implicada en la ortografía.

2. Bajo nivel de inteligencia: lo que limita la realización de operaciones de tipo lógicointelectual.

3. Problemas lingüísticos: esto puede estar asociado a dificultades de articulaciones, lo que ocasiona una mala articulación de un fonema o la sustitución incorrecta de éstos. Según la autora, esto puede deberse a que hay una deficiencia de vocabulario o de conocimientos.

4. Problemas afectivos-emocionales: se dice que una pobre motivación aumenta la probabilidad de cometer errores cuando se escribe.

\section{Evaluación de los errores en escritura}

Para evaluar la escritura que producen los estudiantes ante diferentes tareas: copia, dictado o producción es necesario, además de evaluar los aciertos, analizar los errores que éstos cometen. La evaluación de los errores en escritura permite contar con información que dé cuenta de los aspectos de la escritura que generan más conflicto a los estudiantes y proponer así estrategias adecuadas para su corrección. Pero, además, la evaluación de los errores permite identificar posibles trastornos cuyo origen puede deberse a alguna alteración neurológica, en cuyo caso se necesitará apoyo específico para mejorar la escritura de los estudiantes.

En la investigación sobre escritura, varios autores han descrito diferentes formas para su evaluación. Por ejemplo, Jiménez y Artiles (1990) propusieron un análisis de las tareas de dictado de frases, evaluaron dos niveles de la ejecución de los estudiantes caligráfico y ortográfico. En cada nivel establecieron criterios de ejecución, desglosando cada criterio en los diferentes tipos de respuesta que podían dar los estudiantes: 


\section{Caligrafía}

1. Rapidez de la escritura al dictado.
a. Sólo escribe letras sueltas o alguna palabra.
b. Escribe textos muy incompletos. Faltan más de la mitad de las palabras.
c. Textos bastante incompletos. Faltan más de dos palabras.
d. Texto completo, pero faltando una o dos palabras o sílabas.
e. Texto completo.

2. Precisión en la grafía de base.
a. Pocas letras y muchas faltas.
b. Hace bien algunas letras, pero tiene muchos errores en las grafías.
c. Acomoda las grafías, pero aparecen algunas mal o enlaces raros.
d. Acomoda las grafías, pero con letras separadas o enlaces raros.
e. Grafías y enlaces apropiados.

3. Proporcionalidad en la escritura.
a. Pocas letras y muchas faltas.
b. Hay variaciones llamativas.
c. Regularidad en el tamaño y distancia de las palabras.

4. Dominio del trazo y acomodación a pautas horizontales o inclinación personal.
a. Letra vibrante y temblorosa sin poderse acomodar a las pautas.
b. Mala acomodación a las pautas horizontales y a la pendiente personal.
c. Acomodación a las pautas y pendientes personales con errores.
d. Pendiente constante y regularidad en el apoyo de las pautas.

5. Fluidez, legibilidad, personalización y limpieza en la escritura.
a. Letra vacilante, temblorosa e impersonal.
b. Escritura trabajosa con letra estereotipada o de aprendizaje.
c. Letra fluida pero poco legible.
d. Letra fluida, legible y personal. 


\section{Ortografía}

1. Ruptura o unión de contextos independientes.
a. Parece que no conoce las leyes de unión y ruptura de contextos.
b. Rompe o une bastantes contextos sin razón.
c. Rompe algunos contextos en escritura muy incompleta.
d. Rompe algunos contextos en texto completo.
e. Buena ruptura y unión de palabras en texto completo.

2. Sustitución fónica, sustitución gráfica, confusión deletras simétricas, agregaciones, omisiones, traslaciones, contaminaciones y mezcla de letras y sílabas.
a. Dominante y típico.
b. Frecuente.
c. Algunas veces y en textos incompletos.
d. Algunas veces en texto completo.
e. Texto adecuado.

Hidalgo (2009) indicó los errores más frecuentes que pueden encontrarse en el proceso de escritura en función de los trastornos que los originan:

1. Proporcionalidad. Se presenta sobre todo en la fase de aprendizaje. Este error es una tendencia a realizar las letras en dimensiones diferentes. Es común observar que conforme el niño crece va reduciendo el tamaño de la letra.

2. Paralelismo. Falta de paralelismo entre grafemas o entre líneas.

3. Procesos motores. Los principales trastornos que surgen en el aspecto motriz son de tres tipos:

a. Referentes a los alógrafos (confusión de alógrafos, mezcla de letras mayúsculas y minúsculas, mezcla de diferentes escrituras, adición u omisión de rasgos, etc.).

b. Referentes a los patrones motores (letras mal trazadas, letras excesivamente grandes o excesivamente pequeñas, letras muy inclinadas, rasgos de letras desproporcionados, etc.). 
c. Referentes a la organización general (líneas inclinadas, espacios muy grandes entre líneas, palabras amontonadas, márgenes demasiado amplios, etc.). La utilización incorrecta de los alógrafos se tiende a presentar cuando se introducen las letras mayúsculas, ya que los niños todavía no distinguen bien en qué condiciones se usan estas letras y en qué condiciones las minúsculas, produciendo errores al mezclar unas y otras en una misma palabra.

4. Otros trastornos. Apoyaduras o temblores; modificaciones relacionadas con la direccionalidad (trazos curvos de letras hechos en el sentido de las manecillas del reloj).

Santana (1985) evaluó la calidad de la escritura espontánea con base en tres criterios:

1. Productividad morfológica. Hacía referencia al número de letras, palabras y signos morfológicos escritos por los sujetos.

2. Complejidad morfológica. Integrada por la complejidad de la sílaba y de la palabra. La primera se determina dividiendo la cantidad de letras entre el número de sílabas. Por otra parte, la complejidad de la palabra se calcula a través de los índices de letras/palabras y de sílabas/palabras.

3. Precisión morfológica. Se evaluó a partir de los errores morfológicos. Se consideraron dos tipos generales de errores morfológicos:

a. Errores de deletreo, podían presentarse en la letra, sílaba o palabra. A nivel letras se calcularon: el número de omisiones, adiciones, sustituciones e inversiones de letra dentro de una misma sílaba, así como el número total de errores de letra. A nivel de sílaba se calculó el número de omisiones, adiciones, sustituciones, inversiones y separaciones. A nivel de palabra se contó el número de separaciones y el número de uniones incorrectas.

b. Errores de signo, incluían errores de acentuación, de punto morfológico, de diéresis y de guión. Así mismo, se contó el número de omisiones, de adiciones y de inversiones. 
Bornas, Servera, Llabrés y Matas (2000) propusieron una forma de evaluación centrada en la observación directa de la escritura de diferentes letras en los niños. En su registro midieron seis categorías de errores en la ejecución: inicio incorrecto, cambio de dirección, trazo continuo, interrupción de dos o más segundos, volver hacia atrás (repasar) y otros errores (realizar un trazo de grosor o tamaño desproporcionado, hacer la letra a la inversa, etc.).

Valle (1989) analizando la escritura de palabras regulares e irregulares propuso la siguiente clasificación de los errores:

1. Errores puramente ortográficos. Por definición, sólo pueden aparecer en palabras reales, también nombradas palabras irregulares. Podrían definirse como aquellos errores que, conservando el sonido de la palabra dictada, no conversan la grafía prescrita.

2. Errores fonológicos. Estos pueden darse tanto en palabras como en pseudopalabras. En general, conversan la pronunciación de la palabra dictada o la cambian ligeramente debido a una mala aplicación de las reglas de Conversión Fonema-Grafema, por ejemplo, escribir "címica" o "cimaca" en vez de "química". Estos errores se deben a generalizaciones o particularizaciones de las reglas de Conversión Fonema-Grafema.

3. Omisiones. Cuando no se escribe la palabra dictada. El grado de solapamiento en el número de omisiones de palabras y pseudopalabras pudiera indicar un deficiente o no suficiente desarrollado léxico ortográfico.

4. Lexicalizaciones. Escribir no palabras como palabras. Es decir, escribir que tienen un sonido con una grafía que da como resultado una palabra que el sujeto encuentra en su almacén semántico.

5. Conversiones de palabras en pseudopalabras. Fenómeno contrario al anterior. Los errores que podían (debían) incluirse en 1. o 2. no se contabilizan en este tipo.

6. Sustituciones de fonema. Un fonema que al escribirlo se convierte en un grafema que cuando se lee pierde el sonido original. Ejemplo: /paso/ en "vaso". Sólo se contabilizaban errores de este tipo cuando las sustituciones no encajan en alguna de las categorías anteriores. 
En un estudio realizado en México, Leal et al. (2005) señalaron que no todos los errores que los niños escriben son puramente ortográficos, por lo que establecieron una categorización de los errores de escritura agrupándolos en seis clases:

Clase I. Errores asociados a la conciencia fonológica, que se manifiestan en la omisión de letras o segmentos. Ejemplo: conejito en lugar de conejitos, nive en lugar de nieve. Clase II. Errores asociados a la integridad del sistema fonológico, en el que el niño tiene confusión de dos fonemas originado por la forma de articulación o por el proceso fonológico que pueda llevar a un fonema a otro. Ejemplo: conejido en lugar de conejito.

Clase III. Errores asociados a procesos visomotores, que se manifiestan en la confusión de dos letras que guardan una relación de simetría axial o lateral. Ejemplo: lodo en lugar de lobo.

Clase IV. Errores ortográficos de palabra homófona. Ejemplo: lovo en lugar de lobo.

Clase V. Errores ortográficos en una palabra heterófona. Ejemplo: gitarra en lugar de guitarra.

Clase VI. Errores varios de escritura que afectan la palabra o lexema. Ejemplo: torpezar en lugar de tropezar.

De las seis clases solamente dos son errores ortográficos (clases IV y V).

Las clasificaciones de los errores revisadas hasta aquí corresponden a investigaciones realizadas en español. Sin embargo, en otros idiomas como el ruso también se han evaluado los errores de escritura. Akhutina (2002) identificó los siguientes errores en niños de primaria que mostraban dificultades en la escritura:

1. Omisión y sustitución de vocales acentuadas, entre otras.

2. Imposibilidad de la formación del hábito de la escritura ideográfica.

3. Tendencia a la escritura fonética.

4. Dificultades para orientarse en la hoja del cuaderno y para encontrar el inicio de la línea y para mantenerla. 
5. Oscilaciones constantes de la inclinación y la altura de las letras y ausencia del respeto de la proporción de los elementos de las letras.

6. Escritura separada de letras dentro de las palabras.

7. Dificultades en la actualización de la imagen gráfica y motora de la letra necesaria (sustituciones de letras manuscritas por letras de imprenta).

8. Escritura en espejo.

9. Alteración del orden de las letras.

10. Unión o separación de las palabras.

\section{Análisis en el tipo de errores}

Así como se han propuesto diferentes formas de evaluar la escritura, se han realizado diferentes hallazgos en función del tipo de errores que los niños cometen. Un primer resultado que puede puntualizarse aquí es el de Valle (1989), quien concluyó que en todos los niveles de educación básica se cometen más errores en palabras irregulares que regulares. En la escritura fonológica, sólo las palabras irregulares son problemáticas y dado el uso de la irregularidad en el español, aún una escritura mediada fonológicamente va a producir aciertos en un $50 \%$ de los casos de la escritura de estas palabras irregulares, ya que se trata de una decisión binaria (por ejemplo: escribir con $b$ o $v$ ). Por lo tanto, aun asumiendo que se tuviera un desconocimiento ortográfico total, no se producirá un $100 \%$ de errores, sino que el porcentaje oscilará alrededor del $25 \%$. Valle afirmó que la razón es que el $50 \%$ son palabras irregulares que no representan un problema para alguien que conoce las reglas de la Conversión Fonema-Grafema y aproximadamente un $50 \%$ del $50 \%$ restante de las palabras irregulares se escribirán correctamente por azar.

Leal et al. (2005) al comparar la escritura de niños sin problemas de escritura y con problemas de escritura concluyeron que los niños sin problemas de escritura siguen más un patrón relacionado a la transparencia, es decir, cometieron menos errores cuando los fonemas que debían representar eran más transparentes. Encontraron que la mayoría de los errores ocurren en la asignación de los grafemas a fonemas que aceptan sólo un fonema, dos fonemas o seis fonemas. Los problemas de escritura de los niños 
son de orden fonológico. Estos niños tienen un sistema fonológico intacto, lo que es demostrado por la proporción que existe entre los errores no ortográficos y ortográficos.

Los niños con problemas de lecto-escritura tienen otros problemas que no sólo limitan el dominio de las características ortográficas de nuestro sistema, sino que también el reconocimiento de los grafemas y, sobre todo, de los fonemas, incluyendo su ubicación dentro de la palabra. Los niños con problemas de escritura y niños sin problemas de escritura encontraron que, aunque los dos grupos cometen muchos errores ortográficos de las clases IV y V no se encontraron diferencias estadísticamente significativas entre los niños con problemas de escritura y los niños sin problemas de escritura, concluyendo que los problemas ortográficos son comunes en los dos grupos. Sin embargo, comparando los errores ortográficos (clases IV y V) y no ortográficos (clases I, II, III y VI) en ambos grupos encontraron que los niños sin problemas de escritura cometen casi tres errores ortográficos por cada error no ortográfico, mientras que la proporción en los niños con problemas de escritura es casi de uno a uno. Los niños con problemas de escritura tienen el doble de errores fonológicos que los niños sin problemas de escritura, y catorce veces más errores visomotores. En los niños sin problemas de escritura, los errores de sustitución son más bien de tipo ortográfico que fonológico. Los fonemas /b/ y /s/ son en los que se cometieron mayor cantidad de errores.

Valle (1989) mencionó que, aunque a simple vista las omisiones parecen indicar una falla en la ruta visual (léxica) como fonológica (no léxica), en realidad las omisiones pueden ser consecuencia de otro tipo de factores de tipo atencional o incluso pragmático, que poco tienen que ver con los procesos específicos de la escritura. Por su parte, Santana (1985) evaluando la producción espontánea de los estudiantes en la escritura de textos encontró una relativa independencia entre la productividad, complejidad y precisión del texto. Asimismo, estableció que el aprendizaje del deletreo y el aprendizaje de los signos morfológicos ocurren en momentos distintos del desarrollo.

A través del desarrollo, el niño va modificando el uso de las estrategias de escritura y, por lo tanto, se presenta una variación en el tipo de errores que se cometen según la edad. Valle (1989), realizando una comparación de los errores cometidos por niños en $2^{\circ}$, 
$4^{\circ}, 6^{\circ}$ y $8^{\circ}$ grado de educación básica en España, encontró que la distribución de errores es distinta según la frecuencia de uso en las palabras y varía según se trate de palabras o pseudopalabras. Tanto en $2^{\circ}$ como en $4^{\circ}$ grado, pero especialmente en $2^{\circ}$, el número de errores fue mayor en las palabras que en las pseudopalabras, mientras que en $8^{\circ}$ ocurre al revés. Lo que indica que en el estudio de Valle al parecer los niños más pequeños utilizan la ruta ortográfica y los mayores la fonológica. Este resultado puede resultar confuso, pues para la escritura de las palabras se supone el uso de la ruta ortográfica mientras que para las pseudopalabras la ruta es fonológica y la ruta fonológica es la que los niños utilizan cuando se inicia el aprendizaje de la lecto-escritura.

En otro estudio sobre los errores en diferentes edades, Santana (1985) realizó una comparación de la morfología de los errores que cometen los niños de educación básica. En su estudio analizó los errores cometidos en letras, sílabas y palabras. Encontró que los errores específicos de letra tienden a disminuir a lo largo de los tres primeros años escolares. Además, encontró que la proporción de omisiones y de inversiones de letra es diferente entre cada uno de los grados escolares. Asimismo, sus resultados también mostraron diferencias significativas en los índices de omisiones, adiciones y sustituciones de sílaba, y el índice general de errores de sílaba va disminuyendo significativamente del $2^{\circ}$ al $6^{\circ}$ grado escolar. Sin embargo, en el índice de inversiones de sílaba los datos no fueron significativos, ya que los sujetos cometieron un número muy bajo de inversiones.

Respecto a los errores de acento, los resultados mostraron que los índices de omisiones y adiciones fueron significativamente diferentes entre los cinco grados escolares. Sin embargo, mientras que el número de omisiones y el número de errores de acento fue menor en los niños más grandes, el índice de adiciones mostró una tendencia irregular, encontrando que los niños de $4^{\circ}$ y $8^{\circ}$ grado tuvieron más errores de adición de acento que los niños de $2^{\circ}$ y $6^{\circ}$ grado. La explicación proporcionada a este resultado es que en $2^{\circ}$ grado los niños no han aprendido todavía a utilizar el acento, mientras que en $8^{\circ}$ grado posiblemente presten demasiada atención a signo de acentuación por lo que escriben más acentos de los necesarios.

Los errores de punto morfológico fueron menores en los grupos escolares más avanzados. Por lo que se concluyó que la evaluación es adecuada para la escritura 
hasta $8^{\circ}$ grado y en grados posteriores podría utilizarse con fines de valoración clínica. Los errores de diéresis mostraron una ocurrencia azarosa, no mostrando diferencias estadísticamente significativas entre los grupos escolares.

En los análisis de errores de palabra, se encontró que en todos los grupos aparece la misma proporción de uniones y separaciones de palabra. Respecto a la proporción de errores de deletreo en comparación a la proporción de errores de signos, se encontró una evolución irregular en estos. La proporción de errores de deletreo es mayor en $2^{\circ}$ grado y disminuye hasta $6^{\circ}$ pero aumenta en $8^{\circ}$ grado. Mientras que en la proporción de errores de signo ocurre lo contrario. Estos resultados se explicaron porque en los primeros grados escolares el aprendizaje del deletreo es más importante que los signos morfológicos, por lo que disminuyen los errores de deletreo hasta $6^{\circ}$ grado. Sin embargo, entre $6^{\circ}$ y $8^{\circ}$ grado vuelve a aumentar la proporción de errores de deletreo, posiblemente porque los niños empiezan a escribir más rápido y descuidan el deletreo de las palabras.

\section{Corrección de los errores en escritura}

Identificar los errores que cometen los alumnos permite establecer las estrategias que se requiere aplicar para corregirlos. Esta corrección puede ser realizada tanto por el maestro como por los compañeros del estudiante. Ortega (1994) señaló que la corrección entre los alumnos tiene dos ventajas principales: el alumno se responsabiliza de su aprendizaje y aprende mucho corrigiendo. Aunque también mencionó inconvenientes como que probablemente los alumnos no cuenten con conocimientos suficientes para corregir todos los aspectos del texto, además que no les gusta ser corregidos por un compañero y pueden sentirse desconfiados. No obstante, señaló que, dado que el maestro no siempre estará presente para corregir el trabajo de los alumnos, éstos deben aprender a corregir su trabajo por ellos mismos.

Rosino (2009) enumeró algunas ventajas que tiene el hecho de que los alumnos actúen como revisores del trabajo de sus compañeros. El primer punto es que los alumnos deben contar con esquemas adecuados para llevar a cabo la revisión; propiciar 
el diálogo entre el grupo de estudiantes puede mejorar las estrategias de revisión; enseñar estrategias de revisión puede producir un efecto positivo en la calidad de la escritura; que el alumno lea a alguien lo que ha escrito, permite a éste darse cuenta de lo que está mal.

Rosino (2009, p. 16) proporcionó algunas recomendaciones básicas para la enseñanza de la escritura:

- Evitar una práctica inicial sin supervisión

- Proporcionar corrección inmediata de los errores

- Implicar al alumno en el análisis de sus errores

- Proporcionar modelos detallados de los patrones motores de cada letra

- Evitar actividades poco valiosas como son la copia reiterada de una palabra

- Fomentar una actitud positiva respecto a la correcta formación de las letras

\section{Intervención en los problemas de escritura}

La atención a los problemas de escritura requiere de una evaluación previa para identificar el tipo de problema y aplicar estrategias de intervención adecuadas. Sin embargo, Mohamed (2011) recomiendan que de manera general se debe hacer consciente al estudiante de sus dificultades planteándoles como un reto que debe vencer, se deben diseñar actividades que no representen aburridas y tediosas, las actividades deben complementarse con actividades de lectura.

En la literatura se pueden ubicar básicamente dos tipos de intervenciones. Por un lado, centrados en la práctica de corrección de errores específicos de la grafía y programas integrales que no sólo se centran en corregir los errores, sino que incluyen otros elementos coadyuvantes en el proceso de la escritura.

\section{Intervenciones basadas en prácticas y ejercicios}

Disortografía. De acuerdo con López (2016), se debe tener en cuenta el origen de la disortografía para poder establecer pautas de apoyo. Si se trata de un problema de percepción, discriminación o memoria auditiva, la autora recomienda (p. 22): 
- Discriminación ruido-silencio

- Reconocimiento de sonidos de diversos instrumentos

- Memorización de secuencias de ruidos de objetos (vaso-campana-ladrido de perro)

- Imitación de esquemas rítmicos con palmas

- Imitación de ritmos con sílabas (pi-pi, pi-pi-pi, pi-pi)

Por otra parte, si se trata de un problema de percepción, discriminación y memoria visual, la autora recomienda realizar ejercicios para el reconocimiento de formas gráficas, o ejercicios de percepción figura-fondo. Ahora bien, si el problema es de organización y estructuración espacial, los ejercicios que se pueden realizar son, por ejemplo, tachar flechas que miran hacia la misma dirección en un dibujo o copiar modelos.

Lores-Leyva y Calzadilla-González (2013) recomiendan una serie de ejercicios mecánicos para la atención a los problemas de ortografía:

1. Ejercicios prácticos para trabajar la escritura

- Completar frases

- Ordenar letras y palabras

- Llenar espacios en palabras

- Transcribir, hacer copias utilizando pautado

2. Para la confusión de grafemas semejantes

- Trazar en el aire la grafía que resulta confusa

- Analizar el fonema y grafema

- Dividir en sílabas, descomponer palabras

- Utilizar crucigramas pictográficos

- Intercambiar el lugar de las consonantes para generar nuevas palabras

- Identificar las palabras donde aparece el fonema afectado para realizar un análisis fónico 
Disgrafía. Para este tipo de trastorno, Lores-Leyva y Calzadilla-González (2013) recomiendan:

- Ejercitar el control muscular: colorear, rasgar, recortar, etc.

- Modelar con plastilina

- Copiar textos sencillos

- Realizar dictados sencillos

- Realizar trazados en el aire

- Repasar letras calcadas

No obstante, de acuerdo con Mohamed (2011), existen tres tipos de digrafías que requieren intervenciones distintas: motoras, gráficas y caligráficas. En las disgrafías motoras asociadas a la maduración, las actividades de apoyo deben tener una secuencia lógica en nivel de dificultad. Además, las actividades no deben ser duraderas ni abarcar más de dos o tres líneas. Por lo tanto, la práctica debe distribuirse a lo largo de sesiones cortas. Mohamed (2011, pp. 15-16), señala diferentes secuencias de actividades relacionadas con la disgrafía.

1. Respecto a las habilidades motoras:

- Actividades dirigidas a mejorar la tensión- relajación de dedos, manos y brazos

- Actividades dirigidas a mejorar la prensión

- Actividades para mejorar la prensión gruesa

- Actividades de prensión con los dedos en forma de pinzas

- Actividades dirigidas a mejorar la prensión útil de la escritura (útiles de escritura)

- Actividades para mejorar la direccionalidad y el sentido de la escritura

2. Respecto a las habilidades gráficas:

- Actividades sobre líneas rectas (verticales, horizontales, inclinadas, con arena)

- Actividades sobre líneas curvas

- Actividades sobre líneas mixtas

- Actividades sobre dibujos 
- Actividades sobre figuras complejas

- Actividades sobre letras y palabras

- Juegos favorecedores de las anteriores habilidades

Respecto a las disgrafías caligráficas, Mohamed (2011) señala que es recomendable no detenerse demasiado en actividades madurativas; por lo que las actividades deben centrarse básicamente en la legibilidad, independientemente del nivel de escritura que presente el estudiante.

\section{Programas integrales}

El proceso de aprendizaje de la escritura requiere de una serie de habilidades previas, que le permitan al niño adquirir cada una de las pautas implicadas en el dominio de la escritura (Portalleno, 2003). Por ello, es importante tener en cuenta que corregir los problemas de escritura va más allá de sólo trabajar los aspectos de la grafía, sino que requiere estimular otros aprendizajes. Al respecto, distintos autores han propuesto intervenciones más integrales que consideran otros aspectos y que, por lo tanto, implican una serie de actividades y ejercicios más allá de la corrección de errores.

Santos (2006) desarrolló un programa de intervención que incluye ejercicios para la percepción analítica, la orientación temporo espacial, el desarrollo del lenguaje oral, y el desarrollo del lenguaje escrito; así como actividades dedicadas a la ejercitación y diferenciación de las grafías con parecido óptico o acústico; orientación metodológica al docente para que trabaje los rasgos a través del uso de historietas o rimas que motivan el aprendizaje; y, finalmente, un cuaderno llamado "Aprende conmigo" que contiene actividades para la etapa preparatoria de la enseñanza de la escritura manuscrita y la de ejercitación y consolidación. Un programa similar fue desarrollado por Del Rivero (2013), quien integró seis componentes secuenciados: (1) Lateralidad, enfocado en que el niño comprenda y maneje el concepto de lateralidad; (2) Visomotricidad, enfocado en estimular la motricidad fina; (3) Observar y escuchar, centrado en fortalecer la percepción del niño; (4) Grafomotricidad, centrado en la motricidad fina a través del uso del lápiz; 
(5) Grafoescritura, en la que estimula la reproducción escrita del niño, principalmente a través de la copia; y, finalmente, (6) Perfeccionamiento escritor, enfocado en perfeccionar la caligrafía del niño.

Sin embargo, Egido (2014) señaló que la intervención debe basarse en la etiología, es decir, en la causa o causas que producen la dificultad; por lo que su programa se basa en la reeducación de la maduración como prerrequisito para el inicio de la escritura sistemática. Su programa incluye los siguientes elementos:

1. Reeducación global y segmentaria. Enfocada en la atención a los casos de hipertonía, trastornos del esquema corporal y desequilibrio afectivo. Se basa en la relajación global y segmentaria.

2. Reeducación motora de base. Dado que muchos trastornos de la escritura tienen su origen en una alteración de la coordinación del esquema corporal, este paso se centra en mejorar los aspectos motores mediante actividades centradas en el esquema corporal, de conductas motrices base y percepto-motrices.

3. Reeducación gestual digito-manual. Este apartado se centra en mejorar la precisión de la mano; por lo que se realizan ejercicios manuales y digitales.

4. Reeducación visomotora. Teniendo en cuenta que para escribir se requiere de una coordinación de los movimientos de la mano y el espacio visual; en este paso se trabajan actividades para estimular esta coordinación, a través de perforado y picado, recortado y rasgado, modelado y ensartado.

5. Reeducación grafomotora. Es hasta este paso que se usa el lápiz o bolígrafo, y en éste se pretende ejercitar el grafismo previo a la escritura; es decir, lograr mayor control de los trazos, sin poner atención, aún, en los trastornos de la letra. Los aspectos que se atienden son: control de líneas rectas, control de líneas onduladas y curvas y ejercicios de calcado de dibujos.

6. Reeducación de la letra. Se trabaja en corregir la distorsión de la letra hasta conseguir que el alumno tenga una imagen mnémica del grafema. Esto implica la metodología VAKT, es decir, la percepción visual, kinestésica y táctil. Se enseñan primero las letras en gran tamaño en el pizarrón hasta poder llegar a la hoja pautada. 
7. Sistematización escritora. Cuando el estudiante ha logrado interiorizar cada grafema se puede pasar al acto escritor.

8. Ejercicios de perfeccionamiento de la escritura. En este último paso se trabaja con aspectos como inclinación, proporción, ligadura de letras, espacio, presión, así como los movimientos que acompañan al grafismo.

\section{Conclusiones}

De manera general, la revisión aporta una síntesis de diversas investigaciones realizadas en torno al tema del proceso de enseñanza-aprendizaje de la escritura, y los principales problemas que se presentan durante el mismo. En cuanto al aprendizaje, los estudios se han enfocado principalmente en la relevancia del conocimiento de los códigos de lenguaje, una adecuada motricidad fina, la capacidad para identificar las letras y sus diferencias, y la identificación de sus correspondencias sonoras. En otras palabras, se subraya que las habilidades cognitivas y lingüísticas son las más importantes en la adquisición de la lectoescritura, misma que se reconoce como un proceso lingüísticocognoscitivo, el cual en su desarrollo involucra el conjunto de experiencias lingüísticas, metalingüísticas, y el conocimiento del mundo que cada individuo posee.

También se destaca la habilidad para relacionar los sonidos con imágenes o representaciones gráficas. Es decir, por un lado, el desarrollar la habilidad para separar cada palabra en fonemas y buscar la conexión de cada fonema con su grafema. En este sentido, se recalca que lo anterior, tiene una alta influencia en la pronunciación, lo que a su vez permite asegurar que los errores de lenguaje oral serán directamente transferidos a la escritura, y sólo desaparecerán del lenguaje escrito, cuando sean eliminados del lenguaje oral. Por otro lado, se habrá de fortalecer la habilidad de retomar las palabras que han sido procesadas con anterioridad, aprender y recordar las reglas ortográficas para cada una de ellas, de manera que, este proceso culmina con la composición de textos, acción que representa el dominio de la forma más compleja de aprendizaje de la escritura. 
En relación con el idioma como factor en la importancia de la lengua escrita, se identificó una diferencia significativa, en cuanto al idioma inglés y el español, a la hora de aprender a escribir. Por ejemplo, en el idioma inglés predomina la ruta ortográfica para el aprendizaje de la escritura, lo cual obedece a la abundancia de relaciones no unívocas entre fonemas y grafemas, es decir, la frecuencia del uso de palabras que no se escriben como resultado de las reglas de los grafemas, en otras palabras, como resultado de relacionar los sonidos con imágenes o representaciones gráficas. En cuanto al aprendizaje de la escritura en español, se concluye que la calidad de las representaciones ortográficas no es una condición necesaria para la lectura, como resultado de la débil relación fonema-grafema. En otras palabras, en español es más fácil al aprendizaje de la lectura, sin que esto garantice el correcto desarrollo de la escritura.

En lo referente a los problemas que se presentan cuando se inicia cualquier proceso para el aprendizaje de la escritura, la mayoría de los estudios concuerdan en cuanto a la existencia de diversos trastornos, los cuales a su vez presentan características específicas, así como factores que se asocian con su desarrollo. Asimismo, coinciden en que la disgrafia es el trastorno más común. Además, vale la pena mencionar que, aunque dicho trastorno es reconocido como el más común, este se produce en personas cuya inteligencia se ubica dentro de los límites distinguidos como normales. Al mismo tiempo, se identificaron otros problemas en la escritura, mismos que son ocasionados por daños en distintas zonas cerebrales, los cuales se hacen evidentes cuando se observan en los aprendices dificultades para escribir sílabas con estructura acústica compleja, se presenta la escritura de letras aisladas, alteraciones en la fluidez de la escritura, por ejemplo, es posible escribir letras al dictado en forma aislada, pero no es posible hacerlo con sílabas complejas o palabras. Se observan alteraciones visoespaciales, en otras palabras, se enfrentan problemas para escribir las letras necesarias. Complementando lo anterior, también se identificaron otros trastornos, los cuales se clasificaron en agrafias afásicas, no afásicas y otras alteraciones de la escritura, las cuales incluyen desde escritura escasa, el olvido de los movimientos necesarios para conseguir escribir, errores ortográficos, diferencias notorias en la caligrafía, entre otras. 
Se encontró que una de las principales fuentes de información útil, respecto a la eficiencia del proceso de enseñanza-aprendizaje de la escritura, es la evaluación de los errores que se pueden identificar en las diferentes actividades que realizan los estudiantes, tales como: transcripción o creación de textos y toma de dictado. De acuerdo con los trabajos analizados, se concluye que la valoración de los errores de escritura que cometen los estudiantes permite, por un lado, determinar las actividades que generan mayor conflicto a los estudiantes, así como identificar los problemas, trastornos o alteraciones que pudieran enfrentar los estudiantes; además, proponer estrategias que contribuyan a su corrección.

Finalmente, respecto a la intervención para las problemáticas de escritura, se pueden hacer dos planteamientos centrales. El primero es relacionado a la relevancia que guarda el evaluar el origen del problema, pues esto permitirá diseñar intervenciones más efectivas. El segundo planteamiento es que más que trabajar en la corrección del error en la escritura, se requiere trabajar de forma integral atendiendo las habilidades y conocimientos previos que se requieren para que el niño logre el dominio de la escritura. 


\section{Referencias}

Akhutina, T.V. (2002). Diagnóstico y corrección de la escritura. Revista Española de Neuropsicología, 4(2-3), 236-261.

Arnaiz, P., \& Ruiz, M.S. (2001). La lecto-escritura en la educación infantil: unidades didácticas y aprendizaje significativo. Málaga: Aljibe.

Bornas, X., Servera, M., Llabrés, J., \& Matas, I. (2000). La mejora de los hábitos de escritura a través del modelado por ordenador: Un estudio experimental en preescolares. Anales de Psicología, 16(1), 41-48.

Berruezo, P. (2004). Entendiendo la disgrafía. El ajuste visomotor en la escritura manual. Revista Iberoamericana de Psicomotricidad y Técnicas Corporales, 14, 39-70.

Borzone de Manrique, A.M., \& Signorini, A. (1994). Phonological awareness and reading and spelling abilities in Spanish-speaking children. British Journal of Educational Psychology, 64, 429-439.

Borzone de Manrique, A.M., \& Signorini, A. (1998). Emergent writing forms in Spain. Reading and writing: An Interdisciplinary Journal, 10, 499-517.

Correig, M. (2000). ¿Qué es leer? ¿qué es escribir? En M. Bigas, \& M. Correig (eds.), Didáctica de la lengua en la educación infantil (pp. 125-155). Madrid: Síntesis.

Cuetos, F. (1989). Lectura y escritura de palabras a través de la ruta fonológica. Infancia y Aprendizaje, 45, 71-84.

Del Rivero, G.E. (2013). Estrategias de escritura para disminuir la disgrafía en los niños de primer grado de educación primaria. Tesis de maestría, Universidad Pedagógica Nacional. Recuperado de http://200.23.113.51/pdf/30554.pdf

Egido, B. (2014). Las dificultades de la lectoescritura: Dislexia y disgrafía. Pautas de intervención y estudio de un caso en educación primaria. Tesis de maestría. Universidad de Valladolid, España. Recuperado de https://uvadoc.uva.es/ bitstream/10324/6013/1/TFG-O\%20186.pdf

García-Orza, J., Madrazo, M., \& Viñas, F. (2002). Alteraciones del procesamiento de la escritura: la disgrafía superficial. Revista Española de Neuropsicología, 4(4), 283300. Recuperado de https://dialnet.unirioja.es/descarga/articulo/1007109.pdf 
Hidalgo, M.P. (2009). Orientaciones metodológicas en el proceso de enseñanzaaprendizaje de la escritura. Revista Digital Investigación y Educación, 49, 1-99. Recuperado de https://www.csif.es/contenido/sevilla/general/105637

Jiménez, J., \& Artiles, C. (1990). Factores predictivos del éxito en el aprendizaje de la lectoescritura. Infancia y Aprendizaje, 13(49), 21-36.

Leal, F., Matute, E., \& Zarabozo, D. (2005). La transparencia del sistema ortográfico del español de México y su efecto en el aprendizaje de la escritura. Estudios de Lingüística Aplicada, 23, 127-145.

López, M. (2016). Disgrafía y disortografía: Diagnóstico y tratamiento en alumnos de $2^{\circ}$ de E.P. Tesis de maestría. Universidad de Cantabria, España. Recuperado de https:// repositorio.unican.es/xmlui/handle/10902/8728

Lores-Leyva, I., \& Calzadilla-González, O. (2013). Los trastornos de la lectura y la escritura en escolares de la Educación Primaria. EduSol, 13(42), 13-23. Recuperado de www. redalyc.org/pdf/4757/475748681002.pdf

Mohamed, I. (2011). Tipos de dificultades en la escritura de palabras y en la composición escrita: Evaluación y tratamiento de la disgrafia. Curso $1^{\circ}$ de Psicopedagogía. Recuperado de https://docplayer.es/15094882-Tema5-tipos-de-dificultades-enla-escritura-de-palabras-y-en-la-composicion-escrita-evaluacion-y-tratamientodisgrafia.html

Ortega, A. (1994). Corregir la escritura en el aula de español: algo más que "correcto" e "incorrecto". En ASELE, Actas V (pp. 253-259). España: Centro Virtual Cervantes. Recuperado de https://cvc.cervantes.es/ensenanza/biblioteca_ele/asele/ pdf/05/05_0251.pdf

Portellano, J.A. (2003). La disgrafía: concepto, diagnóstico y tratamiento de los trastornos de la escritura. Madrid: CEPE.

Rosino, M. (2009). La escritura del proceso educativo. Revista para la Difusión del Conocimiento Educativo, 2, 1-20.

Sánchez, N. (2006). Estudio de la agrafia. Clasificación de las alteraciones de la escritura y su rehabilitación. Anales de Otorrinolaringología, 51, 38-43. 
Santana, B. (1985). Estudio del desarrollo de los aspectos morfológicos de la escritura. Estudios de Psicología, 19, 115-132.

Santos, M.C. (2006). Prevención de las disgrafías escolares: necesidad de la escuela actual para la atención a la diversidad: una mirada desde Cuba. Nóesis. Revista de Ciencias Sociales y Humanidades, 15(29), 117-133. Recuperado de https://www. redalyc.org/articulo.oa?id=85902906

Signorini, A., \& Borzone de Manrique, A.M. (2003). Aprendizaje de la lectura y escritura en español. El predominio de las estrategias fonológicas. Interdisciplinaria, 20, 5-30.

Valle, F. (1989). Errores en lectura y escritura: Un modelo dual. Cognitiva, 2, 35-63.

Viñals, F., Vega, O., \& Álvarez-Duque, M.A. (2003). Aproximación neurocognitiva de las alteraciones de la lecto-escritura como base de los programas de recuperación en pacientes con daño cerebral. Revista Española de Neuropsicología, 5, 227-249. 


\title{
Capítulo 2
}

\section{Aprendizaje de las matemáticas}

\author{
Alicia Alelí Chaparro Caso-López y César Gómez-Monarrez
}

En las investigaciones actuales sobre el aprendizaje de las matemáticas, de acuerdo con González-Pienda, Núñez, Álvarez, González-Pumariega y Roces (1999), se distinguen dos líneas específicas de actuación: una centrada en el desarrollo del cálculo y otra cuyo objetivo es la mejora de la capacidad de resolución de problemas. En relación con el primero, un aspecto implicado en el aprendizaje de las matemáticas es la lectura. El niño debe ser capaz de identificar que un símbolo representa una cantidad y un concepto verbal. Trallero y Galve (2009) afirmaron que existen paralelismos entre las dificultades del aprendizaje de la lectura y de la aritmética, porque en ambos casos se produce una transición que va del uso de estrategias de procedimiento muy costosas (análisis fonético y procedimientos de conteo, respectivamente) a la utilización de unidades básicas de información que se recuerdan directamente.

El aprendizaje matemático exige, en primer lugar, el dominio de códigos simbólicos especializados (por ejemplo, operadores, términos numéricos y reglas sintácticas de la aritmética o el código algebraico) y, en segundo lugar, la capacidad de traducir desde otros códigos (imágenes, lenguaje, etc.) a los códigos matemáticos y viceversa (Rivière, 1990). Se requiere, por lo tanto, el aprendizaje del concepto de número para iniciar al aprendizaje del cálculo matemático (Lochy, Pillon, Zesiger y Seron, 2002; Noël y Turconi, 
1999). Power y Dal Martello (1990) propusieron que la escritura de números es dirigida por una representación semántica abstracta, ligada al código verbal y generada por la comprensión del numeral verbal.

En español se utiliza el sistema de notación base diez (SNBD), el cual permite representar los números en varios formatos. En el formato arábigo por medio de dígitos, o cadenas de dígitos, conocidos como numerales arábigos (ejemplo: "3" o "457") y en el verbal, por medio de palabras o secuencias de palabras-número habladas (ejemplo: "tres"o"cuatrocientos cincuenta y siete") y palabras o series de palabras-número escritas (ejemplo: "tres" o "cuatrocientos cincuenta y siete"). Se denomina transcodificación numérica el proceso cognoscitivo que permite traducir códigos numéricos de un formato a otro (Orozco-Hormaza, Guerrero-López y Otálara, 2007).

En el proceso de transcodificación numérica se pueden diferenciar dos subsistemas: el de comprensión y el de producción (McCloskey, Caramazza y Basili, 1985). El subsistema de comprensión descompone el numeral verbal dictado en partículas léxicas o marcas de cantidades básicas y partículas sintácticas o marcas de potencia, que en la expresión verbal están explícitas. El subsistema de producción identifica la potencia máxima que define el número de espacios a llenar ("slots"), y codifica las marcas de cantidad con los correspondientes dígitos, ubicándolos en la posición determinada por la potencia de diez que en el numeral arábigo no está explícita (McCloskey et al., 1985).

Respecto a la segunda línea de investigación enunciada por González-Pienda et al. (1999), relativa a la resolución de operaciones aritméticas, autores como CoronadoHijón (2008) han señalado que cuando un estudiante resuelve un algoritmo debe tener en cuenta una serie de factores sintácticos y semánticos para llegar al resultado correcto. Los componentes sintácticos se refieren a las reglas y procedimientos (contenidos de enseñanza procedimentales) que guían el aprendizaje del alumno, por ejemplo, iniciar la suma por la primera columna de la derecha, proceder columna por columna, etc. En cambio, los aspectos semánticos hacen referencia a conceptos básicos (contenidos de enseñanza conceptuales) implicados en la ejecución del algoritmo y referentes a la comprensión del significado de las operaciones. 


\section{Problemas en matemáticas}

Rivière (1990) mencionó que existe un amplio debate sobre el origen de los problemas de aprendizaje en matemáticas. Mientras que se reconoce que puede existir un aspecto neurológico asociado a las dificultades de cálculo, también se ha encontrado que sujetos con funciones neurológicas normales pueden llegar a mostrar dificultades en el aprendizaje de las matemáticas.

Una de las razones por las que las matemáticas pueden ser tan difíciles para tantos niños es que implican un alto grado de integración de destrezas cognitivas que no son específicas de las matemáticas, pero intervienen en su aprendizaje. Por ejemplo, existe una estrecha relación entre los problemas de lecto-escritura y las dificultades de aprendizaje de matemáticas, al respecto Siegel y Heaven (1986, como se citó en Serrano, 1995) afirmaron que "es casi imposible encontrar niños, excepto de las edades inferiores [...] que tengan dificultades de lectura y obtengan buenas puntuaciones en pruebas escritas de aritmética" (p. 47).

Rivière (1990) afirmó que el enfoque cognoscitivo ha sido más eficaz que el neurológico para explicar las dificultades asociadas al aprendizaje de las matemáticas. Este enfoque propone que los procesos de atención selectiva, memoria de trabajo, memoria a largo plazo, distribución de recursos cognoscitivos, conocimientos previos, entre otros, son los responsables del aprendizaje de las matemáticas. Al respecto, Russell y Ginsburg (1984) encontraron que la diferencia principal entre los niños "normales" y los niños con dificultades de aprendizaje de las matemáticas era el conocimiento de hechos numéricos. Además, en el aprendizaje de las matemáticas la atención selectiva juega un papel determinante. Las operaciones matemáticas requieren de recursos de memoria y procesamiento mental, así como una secuencia de estrategias que hacen posible el desarrollo de los procedimientos. Por esta razón, los niños que muestran problemas de atención presentan dificultades para organizar estructuras jerárquicas de actividades o procesos mentales, situación que afecta particularmente en actividades vinculadas a las matemáticas.

Socas (2007) enumeró algunas de las dificultades que pueden enfrentar los niños en el aprendizaje de las matemáticas: 
- Las dificultades asociadas a la complejidad de los objetos básicos de las matemáticas que se presentan bajo estatus diferentes: el estatus operacional, de carácter dinámico, donde los objetos son vistos como un proceso; y el estatus conceptual, de carácter estático, donde los objetos son vistos como conceptos. Ambos estatus constituyen los dos aspectos complementarios de las matemáticas

- Dificultades asociadas a las rupturas que se dan en relación con los modos de pensamiento matemático. La transición de lo natural a lo entero, de lo natural a lo decimal, de lo racional a lo irracional, o la transición del pensamiento numérico al pensamiento algebraico, etc.

- Las dificultades asociadas a los procesos de enseñanza desarrollados para el aprendizaje de las Matemáticas. Estas dificultades tienen procedencias distintas: la institución escolar, el currículo de matemáticas y los métodos de enseñanza

- Las dificultades asociadas a los procesos de desarrollo cognitivo de los alumnos, sin referirse en ningún caso a alumnos con dificultades de aprendizaje y/o trastorno del desarrollo

- Las dificultades a respuestas afectivas y emocionales hacia las matemáticas, por ejemplo, de tensión o miedo al intentar resolver un problema matemático

Particularmente, en el caso de la aritmética, Geary (1993) distinguió tres tipos de dificultades que los alumnos enfrentan:

- Dificultades en la representación y recuperación de los hechos numéricos de la memoria

- Dificultades con los procedimientos aritméticos, que suelen ser evolutivamente inmaduros, de escasa precisión en su ejecución. Son dificultades bastante generales en la adquisición de las nociones numéricas básicas

- Déficit en la representación espacial y en la interpretación de la información numérica, que se hace patente en la lectura de signos aritméticos, en el alineamiento de números y en la adquisición del concepto de valor posicional 
Trallero y Galve (2009) señalaron que cuando se muestran problemas en el aprendizaje de las matemáticas, que no aparecen en el resto de las áreas, se habla de discalculia, categoría diagnóstica mucho menos usada, conocida e investigada que la dislexia, probablemente porque sus indicadores son menos evidentes en los primeros años escolares. Existen dos tipos de discalculia definidas, las evolutivas y las adquiridas.

Las discalculias evolutivas se relacionan con un desorden genético o congénito de aquellas partes del cerebro implicados en el desarrollo de habilidades matemáticas. Este tipo de desorden puede afectar actividades de tipo lingüístico (comprensión y empleo de los símbolos matemáticos), perceptivo (reconocimiento de símbolos numéricos o aritméticos), atencional (recordar "llevar" en las operaciones) y matemáticas (respetar la secuencia de los pasos en las operaciones).

Las discalculias adquiridas se producen como consecuencia de una lesión cerebral y algunas de sus características son alteraciones en la producción pero no en la comprensión; es decir, los alumnos saben dar un resultado correcto ante una operación, pero no pueden decirlo o escribirlo; muestran un déficit en el procesamiento sintáctico, por ejemplo, trescientos setenta y cinco, lo escriben como 30075; presentan dificultades en la comprensión del signo de una operación; y son incapaces de recuperar hechos numéricos.

\section{Evaluación de los errores en matemáticas}

Los errores forman parte de los productos de la mayoría de los alumnos y constituyen un elemento común en los procesos de enseñanza-aprendizaje de las matemáticas en todos los niveles del sistema educativo. Como señaló Matz (1980, como se citó en Socas, 2007), "los errores son intentos razonables, pero no exitosos de adaptar un conocimiento adquirido a una nueva situación" (p. 33). Los errores son datos objetivos que forman parte de las producciones de los alumnos, en realidad, son la expresión del carácter incompleto de su conocimiento y constituyen un elemento estable a considerar (Azcárate y Cardeñoso, 1994). 
Los errores en matemáticas no son accidentales, sino que surgen por las estrategias y reglas personales empleadas en la resolución de problemas y se desarrollan a partir de las experiencias particulares y con base en los conocimientos matemáticos iníciales (Pochulu, 2009). Además, incluso los alumnos que tienen aparentemente una adecuada ejecución ante los problemas matemáticos pueden ocultar serios errores operacionales, estructurales o de procedimiento que afectarán el aprendizaje subsiguiente. Muchos alumnos pueden tener respuestas acertadas a problemas matemáticos producto del azar (Socas, 2007).

Varios de los errores que los estudiantes cometen en tareas de matemáticas no se deben específicamente a la operación que están resolviendo sino a carencias de conocimientos previos que trasladan a los nuevos conocimientos (Brousseau, Davis y Werner, 1986; del Puerto, Minnaard y Seminara, 2006; Pochulu, 2009). Por lo tanto, el error puede ser considerado como la aplicación de un esquema cognoscitivo inadecuado y no sólo como la evidencia de una falta de conocimiento o distracción (Socas, 1997).

Brousseau (1997) planteó que el error no sólo es un efecto de factores como la ignorancia, la inseguridad y el azar, sino que también puede ocurrir como consecuencia de un conocimiento previo, que antes funcionó pero que al aplicarlo a una nueva tarea resulta incorrecto. Sin embargo, es precisamente debido a que en una situación anterior resultó funcional, que muestra resistencia para ser modificado o rechazado y continúa aplicándose, bloqueando la posibilidad de un nuevo aprendizaje. En este sentido, Mulhern (1989) estableció que las características de los errores que los alumnos cometen en operaciones matemáticas: surgen, por lo general, de manera espontánea; requieren que el alumno realice una reorganización de conocimientos para que pueda vencerlos. Este tipo de errores pueden ser de dos tipos: sistemáticos y al azar, siendo los primeros los que ocurren con más frecuencia y denotan la falta de comprensión de la tarea. Por otra parte, los errores al azar son equivocaciones ocasionales, de las cuales muchas veces el alumno no se da cuenta.

Los primeros errores que los niños pueden cometer son los relacionados con la escritura de las operaciones matemáticas. Ya sea en copia o en dictado, los niños deben 
escribir correctamente los números como un prerrequisito para obtener una respuesta correcta en el desarrollo de cualquier operación matemática. Por lo tanto, los errores que los niños cometen al escribir números es uno de los primeros puntos a evaluar en matemáticas. Orozco-Hormaza et al. (2007), en su estudio sobre los errores cometidos por los niños en la escritura de números, señalaron que el análisis en tiempo real de las producciones erradas de los niños indicó que las equivocaciones al escribir numerales dictados son producto de funcionamiento no canónico en los subsistemas de comprensión y producción. Al interpretar el numeral dictado, el subsistema de comprensión no descompone la expresión verbal, sino que la fragmentan, aplicando reglas correspondientes a expresiones conocidas. En los resultados de su estudio, estos autores describieron las siguientes relaciones entre los numerales escritos por los niños para explicar la escritura incorrecta de números:

- Yuxtaposición. Los niños yuxtaponen cuando escriben, uno a continuación del otro, numerales que codifican fragmentos de la expresión numérica verbal. En algunos casos los numerales corresponden con los fragmentos de la expresión verbal, en otros, no corresponden. Por ejemplo, al dictar el numeral "trescientos sesenta y siete", los niños escriben 30067 o 30057 . El numeral arábigo 300 codifica la expresión de orden superior "trescientos" y corresponde con una unidad en un periodo dado o numeral nudo

- Compactación. Los niños compactan cuando escriben el numeral correspondiente al fragmento de orden inferior en el lugar del/de los último/s cero/s del numeral que codifica el fragmento de orden inmediatamente superior. Por ejemplo, escriben 3067 por "trescientos sesenta y siete". En este tipo de error, el numeral de orden superior igualmente corresponde con una unidad en un período dado o numeral nudo y el numeral correspondiente al fragmento restante, a un numeral compuesto. En algunos casos, los niños escribieron 1005024 por "mil quinientos veinticuatro", o sea, efectuaron una doble compactación. Finalmente, en muy pocos casos, utilizaron literalmente el numeral que codifica la potencia y escribieron el otro componente sobre el último cero; por ejemplo, 410030 por "cuatro mil treinta" 
- Concatenación. Los niños concatenan cuando sólo codifican los dígitos correspondientes a las marcas de cantidad presentes en la expresión verbal. Por ejemplo, por "doscientos seis" escribieron 26; en este caso, los niños no escribieron los ceros intermedios que el numeral dictado exige para mantener el valor de posición. En algunos casos, concatenaron los dígitos que codifican las marcas de cantidad básica presentes en la expresión verbal e incluyeron un "cero"; por "dos mil ocho" escribieron 208. En otros casos, escribieron 2.98 por "dos mil noventa y ocho"; igualmente, concatenaron los dígitos que codifican marcas de cantidad básica y utilizaron "punto que indica mil"

- Composición. Los niños componen los numerales dictados cuando cada dígito codifica marcas de cantidad básica, presentes en la expresión verbal y conserva la posición definida por la marca de potencia. Por ejemplo, escribieron 367 por "trescientos sesenta y siete" o 2198 por "dos mil ciento noventa y ocho". En el caso de los numerales cuyas expresiones verbales no contienen marcas de cantidad, los niños conservaron la posición del digito utilizando ceros (2098 por "dos mil noventa y ocho"). La utilización de este tipo de relación puede generar una producción acertada o un error léxico, conservando el número de dígitos (por "dos mil ciento noventa y ocho", escribe 2178)

- Nudos impropios. Los niños no establecen relación alguna, simplemente escriben un numeral nudo de orden diferente a la expresión verbal dictada, por aumento o disminución del número de ceros. Por ejemplo, por "cuatrocientos" escribieron 40 o 4000

Existen varias categorizaciones sobre los errores en matemáticas y en cada una se establecen diferentes características de los procesos y/o procedimientos involucrados en la resolución de problemas en matemáticas. Por ejemplo, Bermejo, Lago, Rodríguez y Pérez (2000) agruparon los errores en tres categorías: conceptuales, de procedimiento y de ejecución, que como su propio nombre indica denotan niveles de competencia diferentes. Los errores conceptuales hacen referencia a la incapacidad del sujeto para 
construir una representación interna adecuada de la tarea propuesta, incluyen las siguientes estrategias incorrectas: repetir una de las cantidades, inventar la respuesta, transformar el problema, no saberlo hacer, palabra clave, no entender la secuencia del algoritmo, no conocer el signo de sumar o restar y sumar las unidades con las decenas en las expresiones numéricas. Los errores de procedimiento se relacionan con la incapacidad para traducir la representación interna en la elección de un procedimiento de resolución adecuado como: control inadecuado del algoritmo, no saber hacerlo con cantidades grandes y sumar las unidades con las decenas. Finalmente, los errores de ejecución se producen al aplicar el procedimiento adecuado y se situaron dentro de esta categoría los errores de conteo y los errores de cálculo mental.

De acuerdo con Socas (1997), los factores asociados a la comisión de errores en tareas de matemáticas pueden agruparse en cinco: (1) la complejidad de los objetos matemáticos, (2) los procesos del pensamiento matemático, (3) los procesos de enseñanza de las matemáticas, (4) los procesos de desarrollo cognitivo de los alumnos, así como, (5) problemas afectivos o emocionales hacia las matemáticas. Estos factores se ven reflejados en las diversas clasificaciones que existen sobre las causas asociadas a los errores que se cometen en matemáticas (tabla 1).

Distintos autores establecen diversos aspectos y puntos de partida en la explicación del origen del error. No obstante, como se puede observar en el contenido de la tabla 1, las distintas clasificaciones tienen puntos de convergencia. De manera general, en esta clasificación se encuentra que los errores pueden deberse a errores de tipo cognitivo, de percepción, de aprendizajes previos, de aspectos psicológicos y/o emocionales hacia las matemáticas, así como de dificultad de la tarea. Por lo tanto, es posible afirmar que los errores que los alumnos cometen en tareas de matemáticas tienen un origen multicausal, siendo de distinta naturaleza los factores que pueden estar presentes.

Ahora bien, los errores presentados en la tabla 1 corresponden a aspectos generales en la resolución de problemas matemáticos. Sin embargo, en aritmética cada operación tiene errores particulares que los alumnos cometen, Macotela, Bermúdez y Castañeda (1991) en matemáticas identifica los errores que los niños cometen en cada tipo de operación aritmética (tabla 2). 
Tabla 1

Comparación de categorías de error asociados a la resolución de problemas matemáticos

\section{Radatz (1979)}

1. Errores debidos a la dificultad del lenguaje. Para muchos alumnos el aprendizaje de conceptos matemáticos, los símbolos, y el vocabulario es una "lengua extranjera".

2. Errores debidos a dificultades para obtener información espacial. Muchos errores matemáticos surgen de las diferencias entre las imágenes espaciales y el pensamiento espacial de los alumnos.

3. Errores debidos a un aprendizaje deficiente de hechos, destrezas y conceptos previos. Incluyen las deficiencias en el contenido y los problemas específicos de conocimiento, necesarios para desenvolverse satisfactoriamente en la tarea matemática.

4. Errores debidos a la rigidez de pensamiento. Surgen por la falta de flexibilidad en el pensamiento, es decir, el alumno no puede adaptar lo que ya sabe a situaciones nuevas.

5. Errores debidos a la aplicación de reglas o estrategias irrelevantes. Son aquellos producidos por el desarrollo incorrecto de algoritmos, la falta de estrategias en la solución de tareas matemáticas, aplicación de reglas o estrategias similares en contenidos diferentes, etc.

Movshovitz-Hadar, Zaslavsky, \& Inbar (1987)

1. Errores debido a datos mal utilizados. Incluye los errores que pueden ser relacionados con alguna discrepancia entre los datos dados en el problema y cómo el alumno los trató.

2. Errores debidos a una interpretación incorrecta del lenguaje. Incluye los errores que surgen por una traducción incorrecta de hechos matemáticos a un lenguaje coloquial y viceversa.

3. Errores debido al uso de teoremas o definiciones deformadas. Incluye los errores que aparecen por una distorsión de un principio, una regla, teorema o definición.

4. Errores debidos a la falta de verificación de la solución. Incluye los errores cometidos en el resultado final pero no en el proceso.

5. Errores técnicos. Incluye los errores de cálculo, los errores en la extracción de datos de las tablas, los errores en la manipulación de símbolos algebraicos elementales, etc.

Socas (1997)

1. Errores que tienen su origen en un obstáculo. Se considera al obstáculo como un conocimiento adquirido, no como una falta de conocimiento, que fue efectivo en algún contexto especifico, pero que cuando el alumno utiliza dicho conocimiento en otro contexto, da lugar a respuestas inadecuadas.

2. Errores que tienen su origen en la ausencia de sentido. Estos pueden dividirse en tres clases: aritmética, procedimiento o fórmulas. 
3. Errores que tienen su origen en actitudes afectivas y emocionales. Estos errores derivan de la falta de concentración, bloqueos, olvidos, etc.

Astolfi (1999)

1. Errores debidos a la redacción y comprensión de las instrucciones de trabajo.

2. Errores como resultado de hábitos escolares o de una mala interpretación de las interpretaciones.

3. Errores como resultado de las concepciones alternativas de los estudiantes. Un conocimiento o un procedimiento que lo condujo a una respuesta exitosa en el pasado, pero que ya no funciona.

4. Errores ligados a las operaciones intelectuales implicadas.

5. Errores en los procesos adoptados. Surgen cuando el alumno decide apartarse del método dado en clase y utiliza otro procedimiento.

6. Errores debidos a una sobrecarga cognitiva de la actividad a realizar.

7. Errores que tienen su origen en otra disciplina. Surgen por el desconocimiento de contenidos correspondientes a otras disciplinas necesarios para dar respuesta a la tarea propuesta.

8. Errores causados por la complejidad propia del contenido.

Brousseau (2001)

1. Error a un nivel práctico. El profesor considera que son errores de cálculo.

2. Error en la tarea. El profesor los atribuye al descuido.

3. Error de técnica. El profesor critica la ejecución de un modo operativo conocido.

4. Error de tecnología. El profesor critica la elección de la técnica.

5. Error de nivel teórico. Cuando el profesor considera que los conocimientos teóricos del alumno son los responsables del producto generado por éste.

Pochulu (2009)

1. Errores debidos a inferencias o asociaciones incorrectas. Generados por la aplicación de reglas y propiedades justificadas en esquemas similares, o por inferirse que son válidas en contextos parecidos o relacionados.

2. Errores debidos a dificultades para obtener información espacial. Atribuidos a deficiencias en la capacidad para pensar mediante imágenes espaciales o visuales, que llevan a interpretaciones incorrectas de información o hechos matemáticos.

3. Errores debidos a la ausencia de conocimientos previos. Causados por la carencia de aprendizajes relativos a hechos, destrezas y conceptos, que inhiben totalmente el procesamiento de la información e impiden dar una respuesta a la situación. (p. 9)

Fuente: Elaboración propia a partir de la revisión realizada por Bocca y Canter (2010, pp. 4-6); Brousseau (2001) y Pochulu (2009). 
Tabla 2

Tipos de error que cometen los alumnos según el tipo de operación aritmética

\section{Suma}

1. No conserva el lugar de la columna. La respuesta es producto de haber ubicado de manera incorrecta la posición de los dígitos en la columna correspondiente.

2. Olvida llevar. La respuesta incorrecta se debe a que el niño olvidó sumar el número de unidades llevadas en la columna de las decenas.

3. Olvida sumar números en la columna. La respuesta incorrecta se debe a que no se consideraron los números de la cifra intermedia.

4. Suma en forma independiente una o más columnas. La respuesta incorrecta es producto de haber sumado por separado la columna de las unidades.

Resta

1. Suma en lugar de restar. El error se debe a que el niño confundió el signo de la operación o desconoce el procedimiento de resta.

2. Olvida llevar. La respuesta incorrecta es producto de haber olvidado quitar la decena prestada en la columna respectiva.

3. Desconoce el valor del cero en el minuendo. La respuesta incorrecta se debe al desconocimiento del procedimiento para darle valor al cero pidiendo prestado a la columna que le queda a la izquierda.

4. Resta indistintamente el dígito menor del mayor. La respuesta incorrecta ocurre por haber restado el dígito menor del mayor, sin considerar su posición.

\section{Multiplicación}

1. Errores debidos a problemas de suma. En operaciones de dos dígitos por dos dígitos, la parte del procedimiento que requiere sumar, se realiza de manera incorrecta.

2. Errores debidos a un deficiente manejo de las tablas de multiplicar. Aquí, el niño conoce el procedimiento para multiplicar, pero no domina las tablas, por lo que su respuesta resulta incorrecta.

3. Errores en la colocación de los resultados parciales de la multiplicación. Estos errores se deben a la colocación incorrecta de los resultados parciales de la multiplicación.

\section{División}

1. Errores debidos a problemas de resta. En operaciones con residuo, se realiza incorrectamente la parte del procedimiento que corresponde a la resta.

2. Errores debidos a problemas de multiplicación. Se considera aquí el manejo deficiente de las tablas de multiplicar. 
3. Errores debidos a desconocimiento del valor del cero en el dividendo. El error se debe a desconocer el valor del cero. Por tal motivo, el niño lo omite al realizar la operación.

4. Errores en divisiones inexactas. El error se debe a que no se considera el residuo de la primera división y se divide como si cada número de la cifra fuera independiente.

5. Errores debidos a la colocación incorrecta de los resultados parciales de la división. Este tipo de error se debe a colocar en lugar incorrecto el resultado parcial de la división de alguno de los dígitos.

Fuente: Elaboración propia a partir de la categorización de Macotela et al. (1991).

En otra propuesta, Coronado-Hijón (2008) retomando los hallazgos de los estudios de otros autores (Brown y Burton, 1978, Maza, 1995, y Miranda, 1987) enumeró las manifestaciones que pueden observarse en los estudiantes con dificultades de aprendizaje en matemáticas en cada una de las operaciones aritméticas básicas:

- Suma: es preciso observar si el alumno comprende la noción y el mecanismo pero no la automatización de la operación. Presenta dificultad para sumar mentalmente, necesitando de alguna ayuda para realizarla, como contar con los dedos, dibujar palitos, etc. Colocar erróneamente las cantidades y no comprender el concepto de "llevar". A menudo se observa en este tipo de dificultades que en cada columna pongan el resultado completo y que empiece con las operaciones por la izquierda

- Resta: proceso más complejo que la suma ya que exige además del concepto de conservación de la suma, el de reversibilidad. Si se presenta dificultad en cuanto a la posición espacial de las cantidades ocurre que se resta simplemente la cifra mayor de la menor sin tener en cuenta su posición (arriba o abajo). Las "llevadas" no saben dónde añadirlas, si al minuendo o al sustraendo. También en la resta colocan mal las cantidades y empiezan por la izquierda. La confusión de los signos es asimismo frecuente y por ende la operación, e incluso pueden llegar a confundir y alternar suma y resta en una sola operación. Pueden darse asimismo errores al operar con el cero 
- Multiplicación: no entraña tantas dificultades como la resta, ya que es una operación directa como la suma. Incluso hay niños que a pesar de tener importantes fallos en la resta multiplican sin errores. Las principales dificultades que podemos encontrar son:

- La memorización de las tablas

- Errores de cálculo mental de la multiplicación

- Errores con las llevadas

- Errores con la cifra cero

- Confusión con múltiplos de uno de los factores [...]

- Confusión con otra operación [...]

- Error de interferencia: si poco antes se ha planteado $6 \times 8$, al preguntar $6 \times 9$ se responde 48 lo que indica que el resultado anterior interfiere el recuerdo de la multiplicación solicitada a continuación

- División: para resolverla correctamente se deben dominar las tres operaciones anteriores, ya que la división es una combinación de todas ellas. Las principales dificultades están en la disposición espacial. Algunos niños no comprenden por qué tienen que trabajar en el dividendo, sólo con unas cifras dejando otras para más adelante y no saben por dónde empezar, si apartando unas hacia la izquierda o hacia la derecha. Se producen errores con la cifra cero. En el divisor les es muy difícil trabajar con más de una cifra y es frecuente que sólo lo realicen con una (la primera de la derecha o la primera de la izquierda o incluso alternándolas) (pp. 247-248)

Particularmente, en los errores cometidos en operaciones de sustracción, Rivière (1990) señaló que, desde una perspectiva cognoscitiva, los errores que los niños cometen pueden explicarse con base en dos factores:

1. los requisitos de la resta podrían ser excesivos en cuanto a la carga de memoria de trabajo implicada. Muchas estrategias inductoras de errores 
serían intentos de emplear algoritmos gravosos (como son los de -menor de mayor $y$ " $0-x=x$. 2. los algoritmos correctos de resta presuponen una base de conocimientos: no se montan en el vacío. Quizá los algoritmos incorrectos son una indicación de que el alumno no posee tales conocimientos, por lo que en realidad no -comprende - la resta. (p. 7)

Otra explicación de los errores en la substracción es:

una comprensión deficiente de principios básicos que definen la operación de restar. Por ejemplo, cuando el niño recurre a la estrategia de -menor de mayor - demuestra que no ha asimilado ciertos principios fundamentales de la resta, como el de no-conmutatividad de sus términos y carácter global de la substracción. En suma, no comprende realmente lo que es restar. Su problema sería en un sentido profundo, un problema de conocimiento. (Nesher, 1986; Resnick y Omanson, 1987, como se citó en Rivière, 1990, p. 7)

Por lo tanto, se puede afirmar que, además de considerar las diferentes causas presentes en los errores que los niños cometen en matemáticas, también se debe considerar el tipo de operación aritmética que se está resolviendo, pues como puede identificarse en cada operación se cometen distintos tipos de error, aunque algunos son compartidos u originados por problemas en otras operaciones.

\section{Errores en la escritura de los números}

La escritura de los números es un primer requisito para la adecuada resolución de operaciones matemáticas. En los errores cometidos al escribir numerales, Orozco-Hormaza et al. (2007) encontraron que al escribir numerales dictados, en todos los grados los niños tienden a cometer más errores sintácticos que léxicos, cuando se equivocan; es decir, su escritura afecta la estructura del numeral más que a sus elementos. Los autores señalaron que el análisis del tipo de relación que lleva al error y que los niños tienden a 
utilizar en cada grado aporta base empírica para describir el carácter evolutivo del proceso de transcodificación.

En $1^{\circ}$ grado predomina el uso de la relación de yuxtaposición y éste decrece a medida que el grado escolar aumenta; en cambio, la utilización de la relación de concatenación predomina en $3^{\circ}$ grado y su incremento es directamente proporcional al de los grados escolares. Estas tendencias y el incremento del acierto en $3^{\circ}$ grado constituyen los indicadores que permiten proponer una evolución del proceso de escritura, pues los niños han incorporado la regla que implica codificar marcas de cantidad, pero en numerales con ceros intermedios todavía no dominan el valor de la posición. Por otro lado, en $2^{\circ}$ grados los niños presentan la media de acierto más baja y el mayor porcentaje de errores sintácticos. El porcentaje de la relación de composición es menor que en $1^{\circ}$ y $3^{\circ}$, el porcentaje de uso de la yuxtaposición es ligeramente menor que los niños de $1^{\circ}$ y se incrementa la utilización de las relaciones de compactación y concatenación. El desempeño de los niños al escribir numerales varía en función del tipo de numeral dictado.

En todos los grados, los niños tienden a escribir correctamente los numerales nudo, en $1^{\circ}$, los numerales con cero en la decena y en $3^{\circ}$, los numerales con cero en la unidad de mil, con cero en la decena y en la unidad sin cero. Los numerales que mayor dificultad representan para los niños son: en $1^{\circ}$, los numerales sin cero (524) y con cero en las unidades (520); en $2^{\circ}$ y $3^{\circ}$, los numerales con ceros en las centenas $(5046,35046)$.

\section{Estrategias de intervención para corregir los errores en matemáticas}

Los niños con dificultades en el aprendizaje de las matemáticas necesitan una mayor cantidad de ejercicios de práctica que les permitan establecer el aprendizaje de los procesos implicados, así como la generalización de estos (Rivière, 1990). Como punto inicial, de acuerdo con Azcárate y Cardeñoso (1994), es importante que los profesores conozcan los modelos erróneos de los alumnos con el fin de poder crear las condiciones necesarias para provocar el progreso y la reorganización de las ideas. Bermejo et al. (2000) señalaron que la mayoría de los estudiantes comúnmente comente errores conceptuales. Es decir, los niños resuelven incorrectamente las operaciones porque tie- 
nen conocimientos errados acerca de los procedimientos, o han realizado una interpretación incorrecta de la información que se les presenta. Por lo tanto, el conocimiento de los tipos de error puede ayudar al profesor a plantear estrategias de enseñanza que puedan ser adecuadas a cada tipo de error que manifiestan sus alumnos.

Además de conocer los errores de sus alumnos, los docentes deben crear un clima propicio para el aprendizaje. De acuerdo con Bermejo et al. (2000), el profesor debe establecer un ambiente donde el alumno tenga la oportunidad de discutir, integrar la nueva información en relación con otra, explicar y justificar sus propios métodos de solución. Brousseau (1997) desarrolló la Teoría de las Situaciones Didácticas, en la cual uno de los planteamientos centrales es que el aprendizaje se logra a través de un proceso didáctico en donde se resuelven problemas en un contexto social. Es a partir de la interacción de este contexto social que se valida la solución del problema y se desarrolla el conocimiento del alumno. En esta interacción se presentan varias situaciones (de decisión, de validación, de formulación, de comunicación, etc.).

Asimismo, se debe dar oportunidad para que los alumnos elaboren sus propias explicaciones de la resolución de distintos problemas matemáticos. Sin embargo, no se debe perder de vista la importancia de generar interés en los estudiantes, al respecto, Vinner (1997) cuestionó el hecho de proponer estrategias de enseñanza de las matemáticas basadas en el planteamiento de situaciones de solución de problemas. Este autor afirmó que estas situaciones pueden resultar de poco interés para los alumnos. A este respecto, Azcárate y Cardeñoso (1994) afirmaron que es importante desarrollar situaciones de trabajo que hagan evidente el significado que los alumnos dan a los conceptos matemáticos. Es necesario crear un ambiente donde el error desempeñe un papel importante, que sea el motor de la acción y la reflexión de los alumnos de la clase. Se debe conseguir que el rol del alumno en clase sea el de protagonista de su aprendizaje; es decir que, si fracasa en la resolución de un problema, pueda analizar sus errores, volver a considerar su estrategia, rectificar su acción y adaptarse a la situación, consciente de la importancia de controlar este proceso. 
Trallero y Galve (2009) señalaron que existen dos líneas de intervención generales que se utilizan en matemáticas. La primera se centra en el entrenamiento de los sujetos en el desarrollo de automatismos de cálculo al considerar que el dominio de los cálculos numéricos es básico para acceder a otras nociones matemáticas, al respecto se ha evidenciado que los alumnos con dificultades en el aprendizaje de las matemáticas muestran deficiencias en la evolución del uso de estrategias básicas a más complejas, por lo que es necesario acelerar este tránsito.

La segunda línea de intervención tiene como objetivo la mejora en la capacidad de resolución de problemas, lo que implica tanto procesos metacognitivos, como cognitivos. Para ello, se trabaja sobre cada una de las fases del proceso de resolución de problemas, enseñando a autorregular comportamientos estratégicos mediante explicaciones metacognitivas, modelado de estrategias, etc.

Biggs (1985) propuso algunas acciones que deben tomarse en cuenta como parte esencial para el aprendizaje de las matemáticas: estimular la interacción y reflexión conjunta entre los niños con dificultades y los "buenos matemáticos"; estimular la comprensión por parte de los niños de por qué aprenden matemáticas (haciéndoselas usar en vez de pedir continuamente cálculos sin comprender lo que hacen); evitar en lo posible comentarios negativos, sustituyéndolos por ocasiones en que los propios niños puedan descubrir por sí mismos sus errores y las soluciones posibles; emplear materiales atractivos y fomentar un aprendizaje basado más en la resolución de problemas que en cálculos escritos.

La mayoría de las intervenciones educativas que analizan los tipos de errores que cometen los alumnos son de corte cognoscitivo, pues es precisamente este enfoque el que ha dado relevancia al estudio de los errores. Sin embargo, los errores son también productos observables cuya clasificación puede ayudar a describir el tipo de respuesta que los alumnos tienen en distintas tareas y no necesariamente el tipo de procesos internos que se desarrollan en el pensamiento de los alumnos. Vinner (1997) señaló que en ocasiones el enfoque cognoscitivo, en su afán de respetar el pensamiento de los niños, ha ido demasiado lejos al grado de rechazar el término concepto o conocimiento 
erróneo y reemplazándolo por concepto o conocimiento alternativo. Además, se ha invertido un gran esfuerzo didáctico en las correcciones cognoscitivas cuando quizás sea más efectivo utilizar otro tipo de corrección.

No puede negarse la importancia de la investigación cognoscitiva. Sin embargo, no todos los eventos involucrados en el aprendizaje de las matemáticas pueden ser explicados en términos cognoscitivos, y es una falacia asumir que la aproximación cognoscitiva es adecuada para cualquier situación de aprendizaje en matemáticas. Se habla mucho de que las situaciones que plantean a los estudiantes solucionar un problema son situaciones de aprendizaje, pero en realidad esto no se puede garantizar pues nadie tiene control sobre el pensamiento de los alumnos. En realidad, los alumnos tratarán de complacer el sistema educativo con ciertas conductas aceptables, precisamente buscarán dar la respuesta correcta al profesor. Entonces, en lugar de generar el aprendizaje del proceso de solución de problemas, ellos intentarán otros procesos que puedan producir la respuesta correcta (por ejemplo, hacer trampa o adivinar la respuesta).

Por lo tanto, las intervenciones que se generen para atender los problemas en matemáticas que presentan los alumnos no sólo deben considerar los aspectos mecánicos, sino que debe desarrollarse un acompañamiento multifactorial que atienda a las diferentes esferas y áreas que inciden en el aprendizaje y dominio de las matemáticas.

\section{Conclusión}

Con base en la información presentada, queda clara la importancia que tiene el conocimiento tanto de los tipos de error que los estudiantes cometen en matemáticas, así como de los posibles orígenes de estos, a fin de generar estrategias de prevención e intervención que disminuyan estos errores y fortalezcan el proceso de aprendizaje de las matemáticas. Los aspectos expuestos han mostrado las principales problemáticas, que han sido objeto de debate por la constante presencia de errores durante el proceso mismo de aprendizaje, los errores son intentos, no accidentales, y no exitosos de adaptar y ejecutar un conocimiento. Al mismo tiempo, estas problemáticas han sido clasificadas en aspectos neurológicos, como la discalculia evolutiva o adquirida, y no neurológicos, 
como la alta exigencia de destrezas cognitivas, la percepción negativa del área de conocimiento, el proceso de enseñanza del docente o la ausencia de conocimiento previo.

A partir de lo anterior, se reconoce que las dificultades en el aprendizaje de las matemáticas tienen diversas procedencias, y son una oportunidad para que el docente diseñe soluciones e intervenciones estratégicas que aproximen al estudiante al conocimiento, con el fin de que el alumno cristalice o reestructure esquemas mentales.

A su vez, es importante tener en cuenta todos y cada uno de los elementos implicados en el aprendizaje de las matemáticas, pues como se vio, aspectos como el lenguaje y la lectura y escritura apropiada de los números juega igualmente un papel importante, y debe ser atendida. Por lo que sería conveniente que el planteamiento curricular, normalmente estructurado por organismos del gobierno central, organice los aprendizajes considerando aquello que los estudiantes deben desarrollar previo al abordaje de esta área de conocimiento.

También, se abre paso a nuevas interrogantes respecto al aprendizaje de las matemáticas. Dado que éste se ha concebido como un proceso con diversas dificultades, es necesario que se formulen nuevos estudios donde, por un lado, se elaboren soluciones a las dificultades ya mencionadas, y por otro, se integren diversas áreas de conocimiento que busquen dar respuestas alternativas a las que conciben el aprendizaje de la matemática como un área de conocimiento aislada.

Cabe mencionar que el esfuerzo conjunto de investigadores y docentes no serán lo suficientemente eficaces sin involucrar al alumno en su propio proceso. Por lo tanto, es significativo que para que el alumno adquiera protagonismo, se le informe la relevancia de la adquisición de conocimientos pertenecientes al área de las matemáticas y se interese por conocer y desarrollar sus procesos cognitivos.

A través de las líneas que anteceden se ha expuesto el interés que han tenido diversos autores por el estudio del aprendizaje de las matemáticas, tales aportaciones han perfilado diversas vertientes dentro de un mismo campo de conocimiento. No obstante, lo expuesto en este capítulo debe adquirir un sentido pragmático, es decir, debe existir una transferencia del conocimiento expuesto a la labor del docente dentro del aula. 
A manera de cierre, rescatamos los principales hallazgos derivados de la revisión plasmada en el presente capítulo:

- Las dificultades del aprendizaje se presentan en sujetos con y sin problemas neurológicos

- La lectura y la escritura son un prerrequisito para el aprendizaje de la matemática

- Las matemáticas suelen ser complicadas por su alto grado de exigencia de destrezas cognitivas que no son pertenecientes a las matemáticas

- Los responsables del aprendizaje de las matemáticas son: la atención selectiva, memoria de trabajo, memoria a largo plazo, distribución de recursos cognitivos, conocimientos previos

- Los errores son intentos razonables, no accidentales y no exitosos de adaptar un conocimiento adquirido a una nueva situación

- A pesar de que algunos alumnos aparentan tener una adecuada ejecución de conocimientos matemáticos, pueden ocultar serios errores en sus estructuras mentales, lo cual podría afectar a futuro en la adquisición de nuevos conocimientos

- Existe la posibilidad de que el alumno cuente con un vasto conocimiento matemático, pero no sabe seleccionarlo y trasladarlo a una situación distinta

- Entre las operaciones aritméticas, la resta es la más compleja

- Las matemáticas requieren de un estilo de pensamiento, flexible y capaz de adaptar el mundo natural a elementos matemáticos

- Que el alumno no cuestione y reorganice su conocimiento puede convertirse en una barrera para un aprendizaje posterior

- Existen varias categorizaciones sobre los errores en matemáticas y en cada una se establecen diferentes características de los procesos y/o procedimientos involucrados en la resolución de problemas

- Que el docente conozca los modelos erróneos de sus estudiantes favorece el diseño de estrategias pertinentes

- Definir un hecho como erróneo no ofende la integridad del pensamiento del niño y hace consciente al estudiante del área en la que debe mejorar 
- La práctica constante y el dominio es uno de los principales medios para acceder a nociones matemáticas

- Un mayor protagonismo del estudiante, la reflexión conjunta y la utilización de procesos metacognitivos diluyen las barreras del aprendizaje de las matemáticas.

- No se puede asegurar que la planeación de una situación o el diseño de una solución asegure el aprendizaje

- Los alumnos pueden mostrar conductas deseables o dar respuestas correctas sin haber desarrollado realmente un aprendizaje 


\section{Referencias}

Azcárate, M., \& Cardeñoso, J. (1994). La naturaleza de la matemática escolar: problema fundamental de la didáctica de la matemática. Investigación en la escuela, (24), 74-88. Recuperado de http://www.investigacionenlaescuela.es/articulos/24/ R24_7.pdf

Astolfi, J.P. (1999). El error, un medio para enseñar. Sevilla: Diada.

Bocca, M., \& Canter, C. (2010). Errores en geometría: clasificación e incidencia en un curso preuniversitario. Revista Iberoamericana de Educación, 53(2). Recuperado de https://rieoei.org/historico/deloslectores/3241Bocco.pdf

Bermejo, V., Lago, M.O., Rodríguez, P., \& Pérez, M. (2000). Fracaso escolar en matemáticas: Cómo intervenir para mejorar los rendimientos infantiles. Revista de Psicología General y Aplicada, 53, 43-62.

Biggs, J.B. (1985). The role of metalearning in study processes. British Journal of Educational Psychology, 55, 185-212.

Brousseau, G. (1997). Theory of didactical situations in mathematics. En N. Balacheff, M. Cooper, R. Sutherland, \& V. Warfield (Eds.), Mathematics Education Library (pp. 456-467). London: Kluwer Academic Publishers.

Brousseau, G. (2001). Les erreurs des élèves en mathématiques: Etude dans le cadre de la théorie des situations didactiques. Petit, 10(57).

Brousseau, G., Davis, R., \&Werner, T. (1986). Observing Students atWork. En B. Christiansen, G. Howson, \& M. Otte (Coords.), Perspetives on Mathematics Education. Dordrecht: Reidel.

Coronado-Hijón, A. (2008). Dificultades de aprendizaje de las matemáticas: Conceptos básicos y diagnóstico. Revista de Humanidades, 15, 237-252. Recuperado de https://documat.unirioja.es/descarga/articulo/2766543.pdf

del Puerto, S.M., Minnaard, C.L., \& Seminara, S.A. (2006). Análisis de los errores: una valiosa fuente de información acerca del aprendizaje de las Matemáticas. Revista Iberoamericana de Educación, 38(4), 1-13. Recuperado de https://rieoei.org/RIE/ article/view/2646 
Geary, D.C. (1993). Mathematical disabilities: Cognitive, neuropsychological, and genetic components. PsychologicalBulletin, 114(2),345-362.http://doi.org/10.1037//00332909.114.2.345

González-Pienda, J.A., Núñez, J.C., Álvarez, L., González-Pumariega, S., \& Roces, C. (1999). Comprensión de problemas aritméticos en alumnos con y sin éxito. Psicothema, 11(3), 505-515. Recuperado de http://www.psicothema.com/pdf/304.pdf

Lochy, A., Pillon, A., Zesiger, P., \& Seron, X. (2002). Verbal Structure of Numerals and Digits Handwriting: New Evidence from Kinematics. The Quarterly Journal of Experimental Psychology, 55A(1), 263-288. http://doi.org/10.1080/02724980143000271

Macotela, S., Bermúdez, P., \& Castañeda, I. (1991). Inventario de Ejecución Académica: un Modelo Diagnóstico-prescriptivo para el manejo de problemas asociados a la lectura, la escritura y las matemáticas. México: Facultad de Psicología, UNAM.

McCloskey, M., Caramazza, A., \& Basili, A. (1985). Cognitive Mechanism in Number Processing and Calculation: Evidence from dyscalculia. Brain and Cognition, 4, 171-196. http://doi.org/10.1016/0278-2626(85)90069-7

Movshovitz-Hadar, N., Zaslavsky, O., \& Inbar S. (1987). An empirical classification model for errors in high school mathematics. Journal for Research in Mathematics Education, 18(1), 3-14. http://doi.org/10.2307/749532

Mulhern, G. (1989). Between the ears: Making inferences about internal processes. En B. Grecer, \& G. Mulhern. (Coords.), New Directions in Mathematics Education. Londres: Routledge.

Noël, M., \&Turconi, E. (1999). Assessing number transcoding in children. European Review of applied psychology, 49(4), 295-302.

Orozco-Hormaza, M., Guerrero-López, D. F., \& Otálora, Y. (2007). Los errores sintácticos al escribir numerales en rango superior. Infancia y Aprendizaje, 30, 1-16.

Pochulu, M.D. (2009). Análisis y categorización de errores en el aprendizaje de la matemática en alumnos que ingresan a la universidad. Revista lberoamericana de Educación, 1-15. 
Power, R.J.D., \& Dal Martello, M.F. (1990). The dictation of Italian Numerals. Language and Cognitive Processes, 5, 237-254. http://doi.org/10.1080/01690969008402106

Radatz, H. (1979). Error analysis in mathematics education. Journal for Research in Mathematics Education, 10(3), 163-172.

Rivière, A. (1990). Problemas y dificultades en el aprendizaje de las matemáticas: una perspectiva cognitiva. En M. Alvarado, C. Coll, \& J. Palacios (Coords.), Desarrollo psicológico y educación (pp. 155-182). Madrid: Alianza.

Russell, R., \& Ginsburg, H. (1984). Cognitive analysis of children's mathematics difficulties. Cognition and Instruction, 1, 217-244.

Serrano, P. (1995). Proceso de resolución de problemas aritméticos en el alumnado sordo: aspectos diferenciales respecto al oyente. Tesis doctoral, Universidad Autónoma de Barcelona. Recuperado de http://www.tesisenred.net/bitstream/ handle/10803/4764/csp1de2.pdf?sequence $=1$

Socas, M. (1997). Dificultades, obstáculos y errores en el aprendizaje de las Matemáticas en la Educación Secundaria. En L. Rico (Coord.), La educación matemática en la enseñanza secundaria (pp. 125-154). Barcelona: Horsori.

Socas, M.M. (2007). Dificultades y errores en el aprendizaje de las Matemáticas. Análisis desde el Enfoque Lógico Semiótico. Investigación en Educación Matemática, XI, 19-52. Recuperado de https://core.ac.uk/download/pdf/12341704.pdf

Trallero, M., \& Galve, J.L. (2009). La importancia de los problemas aritmético-verbales en la educación primaria. Análisis de la situación actual y propuestas de mejora. Madrid: Editorial EOS.

Vinner, S. (1997). The pseudo-conceptual and the pseudo-analytical thought processes in mathematics learning. Educational Studies in Mathematics, 34, 97-129. 


\title{
Capítulo 3
}

\section{Relevancia de la interacción en el aula desde la perspectiva psicológica}

\author{
Amy Nayeli Vargas Ceseña, Alicia Alelí Chaparro Caso-López \\ y Juan Carlos Rodríguez Macías
}

Las interacciones en el aula son un elemento fundamental en el contexto escolar, ya que influyen en gran medida en los procesos de enseñanza y aprendizaje, sin dejar de mencionar que existen otrosfactores quetambién seven involucrados en dichos procesos (Bertoglia, 2005). De acuerdo con Blanco (2009), uno de los aspectos de importancia para estudiar las interacciones entre los sujetos que forman parte del contexto escolar es que la educación se fundamenta principalmente en las interacciones que ahí ocurren, en el significado que sus miembros le otorgan a las mismas, su repercusión en el modo de comportarse y cómo lo anterior afecta los resultados de los aprendizajes de los estudiantes.

Antes de profundizar en las características de las interacciones, se tomará en cuenta la definición que Bertoglia (2005) hace sobre ellas, conceptualizándolas como:

un proceso bidireccional que considera una participación conjunta y una implicación activa de ambos participantes, lo que genera un estado de influencia mutua simultánea basada no sólo en "una respuesta a" sino también en "una anticipación de". Las dos partes, por lo tanto, intervienen al mismo tiempo exteriorizando sus propios puntos de vista e interiorizando 
la postura del otro lo que permite que cada persona construya nuevas realidades como consecuencia de la interacción. (p. 58)

A partir de esa definición, se puede entender que el significado que da cada individuo a la conducta de los demás sujetos será lo que motivará su comportamiento en respuesta. A su vez, existen representaciones mentales o expectativas que se tienen de las personas por ser parte de un grupo social, entonces la relación que tendrán dos sujetos será con base en los patrones de comportamiento que se les atribuye a tales grupos sociales. Por ejemplo, un docente posee su concepción sobre lo que es un estudiante, por lo tanto, interactuará con él en congruencia al esquema mental que aprendió sobre lo que un estudiante representa.

De acuerdo con Razo y Cabrero (2016), las interacciones en el contexto escolar implican vínculos interpersonales emocionales en los que se demuestran interacciones respetuosas, de confianza y que motivan a los estudiantes para aprender unos de otros, permitiendo el desarrollo de habilidades sociales y cognitivas. Asimismo, las autoras resaltan que el proceso de interacción conlleva un intercambio de conocimientos que abonan al desarrollo integral de los estudiantes y al desarrollo laboral de los docentes.

La preocupación por el estudio de las interacciones en el aula se ha desarrollado con distintos propósitos: identificar el perfil ideal de los docentes, describir estilos de enseñanza, analizar el clima socioemocional del aula, describir comportamientos del profesor eficaz, entre otros. Sin embargo, el factor en común en las distintas investigaciones ha sido identificar y definir la enseñanza eficaz, principalmente con la finalidad de incluir las características encontradas sobre el perfil docente, los métodos de enseñanza y las competencias profesionales eficaces en los programas de formación del profesorado (Coll y Sánchez, 2008).

Ahora bien, la interacción en el aula no se resume solo a la interacción entre docente y estudiantes, también implica la interacción entre pares, dependiendo de la intención educativa que se pretenda (Zavala, 2002). Por lo cual, es importante describir las características de cada uno de los tipos de interacción que ocurren en el aula y cuáles son las implicaciones educativas que conllevan. 


\section{Tipos de interacción en el aula}

La interacción en el contexto educativo integra distintas experiencias en el aula, como lo son vínculos socioemocionales, la forma en que se organiza el trabajo en clase y las estrategias pedagógicas para profundizar en el conocimiento (Razo y Cabrero, 2016). Dichas experiencias en el aula son creadas por el docente y los estudiantes que la conforman, por lo que se pueden presentar dos tipos de interacción: la interacción entre el docente y sus estudiantes (Escobar, 2015) y la interacción entre los mismos estudiantes (Coll, 1984). A continuación, se presentan las características de cada una de ellas.

\section{Interacción docente-estudiante}

Escobar (2015) define este tipo de interacción como"la relación mutua que se establece entre personas de diferente nivel de razonamiento y edades desiguales" (p. 3). La autora menciona algunas posturas que describen este tipo de interacción, como las de Mares, Guevara, Rueda, Rivas y Rocha (2004) y Correa (2006), que señalan algunos niveles de interacción entre el estudiante y el docente en el aula de clases y cómo estas facilitan la adquisición y desarrollo de habilidades y capacidades que son indispensables para que los estudiantes continúen con su formación académica.

García-Rangel, García y Reyes (2014) mencionaron que, desde una perspectiva humanista, las interacciones entre docente y estudiantes deben estar permeadas de atención, respeto, cordialidad, responsabilidad, reconocimiento, intención, disposición, compromiso y agrado de recibir educación y dar enseñanza. Mientras que, Galvis (2015) señaló que el docente es un motivador del aprendizaje de los estudiantes al proporcionarles apoyo pedagógico que incluya una relación de confianza y tome en cuenta las necesidades educativas de sus estudiantes.

Mares et al. (2004), describieron cinco niveles de interacción docente-estudiante, mismos que según lo indican son necesarios en el proceso de enseñanza-aprendizaje. Los niveles son: contextual, suplementario, selector, sustitutivo referencial y sustitutivo no referencial. Dichos niveles se describen de la siguiente manera: 
- Contextual. El aula es un medio lleno de estímulos, por lo tanto, los alumnos deben de adaptarse a ellos para poder participar de las actividades propuestas en clase

- Suplementario. Este nivel representa la oportunidad que los estudiantes tienen de modificar su ambiente de trabajo, es decir, actuar de manera que generen cambios en su contexto

- Selector. Ante una misma situación, cada niño puede decidir una entre múltiples maneras en la que responderá

- Sustitutivo referencial. Los estudiantes tienen este tipo de interacciones cuando hacen referencia a escenarios pasados y futuros, se da un desprendimiento del presente

- Sustitutivo no referencial. Permite a los estudiantes elaborar juicios argumentados o explicaciones sobre las relaciones que han logrado

Los niveles descritos por Mares et al. (2004) involucran un proceso de la interacción, el cual comienza conociendo y comprendiendo el contexto en el que uno se encuentra, para poder llegar al nivel más alto, que implica procesos del pensamiento más complejos, en los cuales tienen que ver juicios y explicaciones con referencia a las interacciones que están llevando a cabo. Los autores relacionan el proceso de interacción con la adquisición de conocimientos académicos, es decir, cuando se fomentan interacciones que llegan hasta el nivel sustitutivo no referencial, se logrará una comprensión más amplia de los contenidos.

Por su parte, Correa (2006) expone tres modelos de intercambio o interacción docente-estudiante:

- Maestro-alumno: en el cual el docente establece muy pocas relaciones con los estudiantes. Él es el principal actor en el aula y no da pie a que los estudiantes participen o se involucren de manera activa en las actividades de la clase

- Alumno-maestro-alumno: este tipo de interacción ocurre de manera más bidireccional que el primer tipo. El docente promueve oportunidades para que los estudiantes participen y se creen conversaciones a partir de las opiniones de estos 
- Alumno-maestro-alumno-alumno-maestro: en este modelo ocurre una interacción, principalmente, entre pares. Aunque el docente es partícipe de la interacción, lo hace desde un papel más externo

Correa (2006) agregó un último modelo en el que las interacciones entre docenteestudiante y estudiante-estudiante son más equitativas. Se da principalmente cuando se trabaja en equipos y, mientras los estudiantes se relacionan entre sí, el docente interactúa de manera aleatoria con los grupos de estudiantes conformados. Los modelos que señala el autor toman en cuenta a las interacciones como las oportunidades de comunicación que existen en el aula. Esta perspectiva de interacción no se basa en las consecuencias que estas podrían generar en el estudiante o en el docente, sino más bien en el tipo de comunicación que existe en el aula.

Escobar (2015) realizó un análisis de las posturas entre Mares et al. (2004) y Correa (2006) en el que señaló que existe relación entre las ideas de los dos autores, mencionando que ambos resaltan que la interacción docente-estudiante no acontece de manera uno a uno, sino que se presenta entre el docente y todos los estudiantes que forman parte de su grupo. Sin embargo, también señaló que existen algunas diferencias entre las perspectivas de los autores, mientras que Mares et al. (2004) se enfocan en la formación académica a través de la interacción, el punto central de Correa (2006) es el lenguaje como medio para interactuar en el aula.

Aunque la manera en que el docente puede interactuar con sus estudiantes puede llevarse a cabo de distintas formas, Pianta, Hamre y Allen (2012) señalaron que es indiscutible que cuando estas interacciones son positivas tendrán resultados positivos en la educación de los estudiantes. Entre las consecuencias positivas que mencionan los autores se encuentran: obtener mejor logro educativo, adquirir mayor compromiso escolar y actitudes positivas ante las actividades educativas.

\section{Interacción estudiante-estudiante}

La interacción entre pares es también un factor importante en el desempeño escolar de los estudiantes. Si bien la interacción entre el docente y los estudiantes ha tenido 
bastante relevancia para explicar el logro académico, se puede afirmar que también la relación entre pares juega un papel importante en el rendimiento escolar. Sin embargo, para lograr el cometido anterior, no basta la convivencia coloquial entre compañeros, sino que se deben llevar a cabo actividades y estrategias didácticas que promuevan las relaciones que conseguirán los objetivos educativos esperados (Coll, 1984).

Las interacciones entre pares tienden a tomarse con cautela en las instituciones educativas, ya que se tiene la idea tradicionalista de que este tipo de interacciones desviará la atención de los estudiantes de lo que realmente importa. Asimismo, ven al docente como el transmisor del conocimiento y al estudiante como receptor pasivo (García, 1993). Sin embargo, como mencionaron Molina y Pérez (2006), en la escuela los estudiantes crean lazos de amistad significativos que, si docentes y directivos saben utilizarlos a favor de la educación, pueden tener repercusiones positivas en el aprendizaje de los estudiantes.

Los docentes, como guías en el aula, pueden organizar la dinámica de sus actividades de tres maneras: cooperativa, competitiva e individualista (Coll, 1984). A continuación, se describen:

- La forma cooperativa hace referencia al trabajo grupal en actividades, en las cuales todos los miembros deben participar y apoyarse para obtener recompensas de manera equitativa

- La forma competitiva se presenta cuando un solo compañero recibe recompensa por obtener los resultados esperados en determinada tarea

- La forma individualista tiene que ver con recompensar a los estudiantes con base en su desempeño individual

Ante estos tres tipos de organización de las actividades escolares, la forma cooperativa es la que promueve realmente una influencia positiva en las relaciones entre los estudiantes, ya que el trabajo en equipo permite el apoyo entre compañeros, el aprendizaje de valores como el respeto mutuo y una convivencia que permite el logro de aprendizajes y metas escolares. 
Llevar a cabo actividades grupales en las que se interactúa entre pares no necesariamente garantiza aprendizajes o interacciones de calidad, por lo que BarbosaHerrera, Valdivia, López-Pismante y López (2017), mencionaron que los factores clave para determinar dicha calidad son las habilidades comunicativas, cohesión y cooperación del grupo, aspectos que el docente debe promover como guía. Coll (1984) identificó tres tipos de relaciones entre los estudiantes que pueden tener influencia positiva en su rendimiento académico:

- Cuando existen puntos de vista distintos sobre una tarea a realizar, por lo que se inicia un proceso de diálogo entre ellos

- Cuando uno de los alumnos apoya a otro, le enseña, instruye o explica una tarea

- Cuando hay un control entre los roles de los miembros del grupo, es decir, se reparten las responsabilidades de la tarea

Todos los tipos de interacción entre estudiantes pueden ocurrir de manera positiva o negativa, pero Coll (1984) señaló que una de las maneras en que se pueden enfocar las interacciones de manera positiva es otorgando roles y responsabilidades a cada uno de los estudiantes, lo cual resultará más favorecedor en el desempeño académico.

Como pudo apreciarse, la interacción en el aula es un proceso complejo que puede ocurrir de distintas maneras, ya sea entre docente y estudiantes o entre los mismos estudiantes. Además de estas particularidades de la interacción, existen distintos paradigmas psicológicos, particularmente, correspondientes a la psicología educativa, que incluyen entre sus postulados la relevancia de la interacción entre los actores del aula. A continuación, se describen algunos de los paradigmas que aportan al tema.

\section{Interacción en el aula desde paradigmas psicológicos}

Mares et al. (2004) señalaron que uno de los aspectos con gran influencia en los procesos de enseñanza y aprendizaje es la interacción que se da dentro del aula. Mencionan que desde la teoría de la psicología educativa se pueden explicar las condiciones para orientar la práctica educativa y mejorar la calidad de las interacciones y, por ende, el 
desempeño escolar de los estudiantes. Algunos de los enfoques psicológicos que tratan sobre el proceso de interacción y que han sido llevados a las aulas son: el interaccionismo simbólico, el paradigma sociocultural, la perspectiva ecológica del desarrollo humano y el paradigma psicogenético. Se señalan algunas de las características principales de cada paradigma en cuanto a su postura sobre las interacciones.

\section{Interaccionismo simbólico}

El interaccionismo simbólico tiene sus orígenes en el año de 1938 y a Herbert Blumer como principal representante. La comunicación es el aspecto central de esta corriente, ya que en sus postulados se plantea que la cultura y la personalidad se desarrollan a partir del proceso de socialización, el cual surge de la comunicación entre los individuos (Rizo, 2006). Asimismo, esta corriente perteneciente de manera más específica a la psicología social da importancia al ser humano como miembro activo en una sociedad que busca la interpretación de distintos símbolos (Pons, 2010).

De acuerdo con Rizo (2006), la corriente interaccionista resalta tres aspectos importantes sobre las interacciones en el aula. Primero, se señala la empatía como un factor relevante en el proceso de comunicación, es decir, comprender la situación del sujeto con el que se interactúa. En segundo lugar, se explica que la realidad de la sociedad se crea a través de las interacciones entre individuos y grupos sociales. Finalmente, se busca interpretar los procesos de comunicación y los símbolos y significados que las personas le otorgan a la situación inmediata en la cual se encuentran.

Desde la perspectiva del interaccionismo simbólico, el aula es vista como un microcosmos social. El docente y los estudiantes definen las directrices con las que se trabaja y se interactúa en el aula. Los principales intercambios que ocurren en el aula hacen referencia a las reglas de conducta, la manera en que el docente calificará trabajos o las modalidades en que se abordará algún tema (Lennon, 2006).

El lenguaje es la principal práctica social que moldea la experiencia del aula. Permite la adaptación a los significados a los que son expuestos los estudiantes en el contexto escolar y, posteriormente, se llega a un proceso de reflexión sobre dichos 
significados. En ese sentido, el aprendizaje es visto como un proceso de formación y adaptación a una cultura mientras se participa de la misma y, a su vez, la enseñanza es la manera en que se organiza el proceso de interacción y reflexión entre los estudiantes y docente en el que se llega a construcciones de significados mediante la discusión y negociación (Godino y Llinares, 2000).

Ante la realidad cambiante de la sociedad y, por lo tanto, de la educación, los actores deben crear constantemente nuevos roles y significados para definir la situación en la que se encuentran inmersos (Olguín-Meza, 2019). Los principios del interaccionismo simbólico fueron analizados por Godino y Llinares (2000) en una clase de matemáticas, en la cual el docente planteaba problemas a los estudiantes, quienes activamente externaban sus opiniones sobre las posibles respuestas al problema. El objetivo perseguido es que los estudiantes lleguen a la respuesta correcta de manera grupal.

Es importante resaltar que, al aplicar técnicas acordes con este paradigma, los estudiantes deben estar previamente familiarizados con la "cultura de clase" para lograr los objetivos propuestos. El interaccionismo simbólico hace entonces de la educación una representación de la cultura en la que se encuentran inmersos sus estudiantes. Con base en el lenguaje, expresado en formas de comunicación y como un proceso de socialización, se llega al desarrollo del conocimiento mediante la interpretación de los signos y símbolos que se van presentando en el aula.

\section{Paradigma sociocultural}

Lev Vygotsky propuso el paradigma sociocultural, el cual es un enfoque que aportó tanto al campo de la psicología como el de la educación, entrelazando ambos campos para obtener como concepto principal de su teoría a la pedagogía humana. Asimismo, Vygotsky da importancia a la relación del desarrollo evolutivo de cada individuo y el aprendizaje, resaltando que cada persona posee una historia sociocultural que le permitió ir adquiriendo conocimientos desde antes de entrar al contexto educativo (Carrera y Mazzarella, 2001). 
De acuerdo con Lucci (2006), este paradigma surgió a partir de las carencias que Vygotsky encontraba en las teorías psicológicas que prevalecían en su época: Psicoanálisis, Conductismo y Gestalt, para explicar de manera contundente el desarrollo de los procesos psicológicos. Por lo tanto, creó un nuevo paradigma que explicaba el desarrollo de tales procesos a través de una determinación histórica y cultural. El autor mencionó los principales planteamientos de la teoría sociocultural, entre los que se encuentran los siguientes:

- La cultura en la que se desenvuelve el hombre será la misma que lo moldee

- La cultura moldeará al hombre mediante la interacción social que existe entre los miembros de esta, por lo que un individuo es determinado por los demás individuos de su cultura, así como él también será determinante de los demás sujetos

- La cultura, interacción social y aprendizaje social determinarán la actividad mental de cada individuo

- El desarrollo ocurre en un proceso complejo que va desde el origen de la especie, el origen de la sociedad, el origen del hombre y, por último, el origen del individuo

- El desarrollo mental es un proceso sociogenético

- El lenguaje, comprendido en todas sus formas de expresión, es el principal mediador para el desarrollo de los procesos psicológicos

Ahora bien, el paradigma sociocultural presenta aportaciones que pueden ser aplicadas al contexto educativo, en esta teoría se señalan dos niveles evolutivos relacionados con ello (Carrera y Mazzarella, 2001):

- Nivel evolutivo real. Son los procedimientos o actividades que un individuo (por lo regular en el contexto educativo el niño o adolescente) puede realizar por sí solo

- Nivel de desarrollo potencial. Son aquellas actividades que el individuo puede realizar con apoyo de alguien más

La perspectiva que se tiene del estudiante es la de un "ser social, producto y protagonista de las múltiples interacciones sociales en que se involucra a lo largo de su vida 
escolar y extraescolar" (Hernández, 2012, p. 232). Por lo tanto, los procesos de enseñanza y aprendizaje estarán dados con base en el grupo cultural en el que se encuentre el estudiante y las interacciones entre los miembros de dicho grupo, lo que dará lugar al inicio del desarrollo de procesos psicológicos que serán interiorizados y convertidos en aprendizajes (Lucci, 2006).

La interacción social de los estudiantes con sus pares o adultos (docente, padres, etc.) es sumamente importante en su desarrollo, tanto cognitivo como afectivo (Carrera y Mazzarella, 2001). Por una parte, Hernández (2012) resaltó que estudios sobre las interacciones entre pares han demostrado que es una actividad enriquecedora en la medida en que permite construir y ampliar el conocimiento, y que se da principalmente mediante la comunicación entre los actores de este tipo de interacción. Por otra parte, concibe a la interacción entre el docente y sus estudiantes como una interacción asimétrica, en la cual el docente funge como guía, tiene una estructura planeada previamente sobre cómo interactuará con sus estudiantes en clase para llevar a cabo los procesos de enseñanza y aprendizaje.

Gaspar y Castro (2005) realizaron una investigación en una clase de ciencias, en la cual el docente se basó en técnicas del paradigma sociocultural, guiando la realización de un experimento. A los estudiantes se les pidió crear hipótesis sobre los posibles resultados del experimento, mientras tanto el docente unificaba las ideas del grupo para finalizar la actividad. En primera instancia, se resalta que la consideración de las opiniones de los estudiantes, y en segunda instancia, se les permite acercarse directamente a los objetos de aprendizaje.

Otro ejemplo de este paradigma aplicado al contexto educativo es el estudio de Sansó, Navarro y Huguet (2016), quienes analizaron la interacción en aulas con diversidad sociocultural. Encontraron que las prácticas del docente con resultados efectivos fueron el trabajo en grupo, promover la interactividad entre el alumnado, comunicación de significados en las tareas y actividades de discusión. De manera general, el docente ofrecía apoyo a sus estudiantes para que, posteriormente, lograran trabajar por sí mismos. 
El paradigma sociocultural tiene como base los antecedentes histórico-culturales de sus miembros, los cuales son moldeados por las interacciones sociales que establecen entre sí, tomado en cuenta el lenguaje como medio principal de las interacciones. Los antecedentes de cada individuo, o conocimientos previos, serán llevados al aula y determinarán los aspectos que cada uno puede realizar por sí mismos o cuando necesitan apoyo de otros para concretar conocimientos, siendo ese momento donde poseen su máximo protagonismo las interacciones en el aula.

\section{Perspectiva ecológica del desarrollo humano}

Esta perspectiva estudia cómo los seres humanos en desarrollo se adaptan a su entorno en constante cambio y cómo dicho proceso de adaptación se ve influenciado por las interacciones que se mantienen entre las personas y por el macroentorno en el que se encuentra (Monreal y Guitart, 2012). El desarrollo humano es concebido entonces, desde esta teoría, como los cambios continuos que ocurren mientras el individuo se relaciona con su entorno (Bronfenbrenner, 2002).

El ambiente o entorno ecológico es la clave de este paradigma y se explica como un conjunto de estructuras seriadas que consta de distintos niveles (Bronfenbrenner, 2002). El primer nivel hace referencia al ambiente más cercano en el que el individuo se desarrolla, por ejemplo, su hogar o la escuela. El segundo nivel consiste en las relaciones o interconexiones que existen entre cada uno de los ambientes cercanos en los que se desenvuelve el individuo. En este caso, se trataría de las relaciones que puede encontrar el individuo entre lo que aprende en casa y lo que aprende en la escuela. Posteriormente, en un tercer nivel se asegura que aquellos ambientes en los que no participa el individuo también son determinantes para su desarrollo, por ejemplo, las condiciones de empleo de sus padres. En este último ejemplo, el ambiente sería el lugar de trabajo de sus padres que, si bien es inmediato a ellos, no lo es para sus hijos y aun así posee influencia para su desarrollo.

Alzate, Ocampo y Martínez (2016) mencionaron que la teoría ecológica de Bronfenbrenner es de utilidad en el contexto educativo, ya que se abordan conceptos cultu- 
rales y sociales de los distintos ambientes a los que pertenecen los estudiantes. Además, esto repercute a nivel psicológico, puesto que se busca el desarrollo integral de las personas -en este caso los estudiantes-, tomando en cuenta la interculturalidad de cada uno de ellos.

Cadima, Leal y Burchinal (2010), realizaron un estudio en preescolar, tomando como base la teoría ecológica al considerar factores como las condiciones familiares y las habilidades previas con las que contaban los estudiantes, y concluyeron que los mejores resultados se obtenían en aulas cuyos docentes mantenían interacciones cálidas, conversaciones instruccionales y de retroalimentación, permitiendo extender el razonamiento y el lenguaje de sus estudiantes. Por su parte, Poulou (2014) señaló que el docente es el mediador para que el estudiante se adapte al ambiente escolar, por lo tanto, este debe proveerles: confianza, apoyo y comprensión, lo cual se lleva a cabo mediante la identificación de las necesidades e intereses del grupo, así como facilitando actividades motivantes.

El paradigma ecológico refiere, entonces, al proceso de adaptación al que se someten los individuos en el contexto escolar, el cual ocurre mediante las interacciones tanto con sus pares como con los docentes. En el aula, los estudiantes se exponen a conceptos culturales y sociales que forman parte de los antecedentes de desarrollo de sus compañeros, pero que posteriormente serán interiorizados por ellos, adquiriendo nuevos conocimientos que les permitirán desarrollarse intelectualmente.

\section{Paradigma psicogenético}

El principal representante de este paradigma es Jean Piaget, cuyos trabajos sobre lógica y el pensamiento verbal de los niños marcaron sus orígenes. El interés de Piaget era conocer el desarrollo de las funciones psicológicas y cómo estas permitían la creación de conocimiento. Al no encontrar teorías que le proporcionaran información relevante que explicaran sus inquietudes, decidió comenzar a realizar investigaciones empíricas sobre su tema de interés (Hernández, 2012). 
Este paradigma concibe el desarrollo intelectual como un proceso de reestructuración, el cual acontece debido a cambios externos que colocan en desequilibrio a las personas, llevándolas a realizar un cambio estructural que le permite crear nuevas ideas o esquemas. A su vez, describe que las capacidades sensoriomotrices y la interacción con el medio sociocultural también influyen en el desarrollo de la inteligencia (Saldarriaga, Bravo y Loor, 2016).

El estudiante es concebido como un constructor activo del conocimiento que se encuentra en determinado nivel de desarrollo cognitivo, el cual debe ser conocido por el docente, ya que dicho nivel condicionará las acciones y actitudes que tendrá el estudiante en el aula. Se mencionó también que el desarrollo cognitivo del niño se manifestará cuando este participe en interacciones sociales que permitan el diálogo y conflicto de respuestas que llevará a la reestructuración de ideas y, por ende, al conocimiento. Por lo tanto, el docente debe proporcionar estrategias de enseñanza que permitan la realización del trabajo cooperativo, de discusión y reflexión que promueva reconstrucciones de contenido (Hernández, 2012).

Algunas de las prácticas docentes relacionadas con este paradigma son tomar en cuenta las necesidades individuales de los estudiantes, así como llevar a cabo debates y actividades investigativas (Durán, 2009). Asimismo, el papel de autoridad del docente debe disminuir para que los estudiantes de manera autónoma construyan su conocimiento, trabajando de manera colaborativa y respetando cuando se comenten errores (Hernández, 2012).

De acuerdo con Cortez y Tunal (2018), es importante que el docente conozca el nivel de desarrollo en que se encuentran sus estudiantes. Conviene utilizar actividades en las que se manipulen objetos de estudio para aquellos en la etapa sensoriomotriz, lo que consigue estimular su creatividad. Para los estudiantes en el nivel preoperacional funcionan las actividades en equipo en las que puedan intercambiar ideas con sus compañeros, utilizando el pensamiento lógico para generar hipótesis de ciertas problemáticas.

Al concretizar la etapa preoperacional, se comienzan a realizar operaciones concretas en las que de manera autónoma pueden comenzar a explicar símbolos y sig- 
nos comunicativos, por lo que el lenguaje se refuerza. Por último, cuando el estudiante domina los criterios antes mencionados, el docente debe posibilitar que comience a realizar experimentos en los cuales compruebe hipótesis previamente planteadas, de manera que utilice el pensamiento lógico adquirido (Cortez y Tunal, 2018).

La principal aportación de este paradigma al campo de la educación es que el estudiante es el constructor de su propio conocimiento, pero lo hace mediante las interacciones que mantiene principalmente con sus compañeros, mientras que el docente guía dichas interacciones. Se da importancia a la reestructuración que realizan los individuos para crear nuevas ideas a partir de reflexiones y diálogos que se suscitan en el aula.

\section{Conclusión}

Se puede percibir que, a partir de la postura de distintos autores, se concuerda en la influencia y relevancia que poseen las interacciones en el aula, en los procesos de enseñanza y aprendizaje y en el desarrollo integral de los estudiantes. A su vez, los diferentes paradigmas psicológicos que explican los procesos de interacción aportan fundamentos y bases epistemológicas que tienen la oportunidad de enriquecer las investigaciones que se realizan en referencia a este tema.

Si bien, la adquisición de conocimientos de los estudiantes es una de las principales consecuencias que parten de las interacciones en el aula, se resalta la importancia que posee el docente como guía de sus estudiantes. Por lo que es prioritario que los docentes realicen una reflexión respecto a su práctica, en la cual tomen en cuenta el tipo de interacciones que deben mantener con sus estudiantes, fomentando una profunda cooperación y comunicación entre los mismos. Si el docente descuida este aspecto sólo podría aspirar a tener con sus estudiantes una relación trivial que no repercutiría en aprendizajes significativos.

Ahora bien, los procesos de enseñanza y aprendizaje, vistos desde los distintos paradigmas, conllevan a que el docente aprecie las distintas características y antecedentes culturales que poseen sus estudiantes, puesto que será el punto de partida para conocer cuáles serán las mejores estrategias de enseñanza que pudiera implementar. 
A partir de ubicar el nivel de desarrollo en el que se encuentran, podrá generar situaciones de confrontación o reflexión que permita a los estudiantes comenzar a reestructurar sus ideas y generar nuevos esquemas de conocimiento.

Finalmente, la interacción en el aula no deja de ser un proceso complejo que implica una gran cantidad de factores, como las estrategias de enseñanza utilizadas por el docente, el nivel de desarrollo o antecedentes histórico-culturales de los estudiantes, así como también del entorno del que provienen. Sin embargo, conocer los distintos paradigmas psicológicos que aportan al tema de las interacciones en el aula, permite a los docentes conocer la importancia de generar espacios de interacción que concluirán en la adquisición de conocimientos de sus estudiantes. 


\section{Referencias}

Alzate, L., Ocampo, M.C., \& Martínez, J. (2016). Aportes de la teoría ecológica a la construcción de la neuropsicopedagogía infantil. Revista Fundación Universitaria Luis Amigó, 3(2), 222-230.

Barbosa-Herrera, J.C., Valdivia, A., López-Pismante, P., \& López, M. (2017). El papel del profesor en la interacción entre pares en una actividad extracurricular. Estudio en una experiencia de canal de TV escolar en línea. Estudios Pedagógicos, 43(3), 2746. Recuperado de https://bit.ly/2OU20IB

Bertoglia, L. (2005). La interacción profesor-alumno. Una visión desde los procesos atribucionales. Psicoperspectivas, 4(1), 57-73. Recuperado de http://www.psicoperspectivas.cl/index.php/psicoperspectivas/article/ viewFile/26/26\%3Forigin\%3DpublicationDetail

Blanco, E. (2009). Eficacia escolar y clima organizacional: apuntes para una investigación de procesos escolares. Estudios sociológicos, 27(80), 671-694. Recuperado de http://www.redalyc.org/pdf/598/59820676011.pdf

Bronfenbrenner, U. (2002). La ecología del desarrollo humano. Barcelona: Paidós. Recuperado de https://bit.ly/2NDrD3M

Cadima, J., Leal, T., \& Burchinal, M. (2010). The quality of teacher-student interactions: Associations with first graders' academic and behavioral outcomes. Journal of School Psychology, 48, 457-482.

Carrera, B., \& Mazzarella, C. (2001). Vygotsky: enfoque sociocultural. Educere, 5(13), 4144. Recuperado de http://www.redalyc.org/pdf/356/35601309.pdf

Coll, C. (1984). Estructura grupal, interacción entre alumnos y aprendizaje escolar. Infancia y aprendizaje, 17(28), 119-138. Recuperado de http://aula.infd.edu.ar/ aula/archivos/repositorio/500/703/Coll_Estructura_grupal.pdf

Coll, C., \& Sánchez, E. (2008). Presentación. El análisis de la interacción alumno-profesor: líneas de investigación. Revista de educación, 346, 15-32. Recuperado de http:// www.revistaeducacion.mepsyd.es/re346/re346_01.pdf 
Correa, M. (2006). Contexto, interacción y conocimiento en el aula. Pensamiento Psicológico, 2(7), 133-148.

Cortez, N.A., \& Tunal, G. (2018). Técnicas de enseñanza basadas en el modelo de desarrollo cognitivo. Educación y humanismo, 20(35), 74-95. http://doi.org/10.17081/ eduhum.20.35.3018

Durán, R. (2009). Aportes de Piaget a la educación: hacia una didáctica socioconstructivista. Dimensión empresarial, 7(2), 8-11. Recuperado de https://dialnet. unirioja.es/servlet/articulo?codigo $=3990224$

Escobar, M. (2015). Influencia de la interacción alumno-docente en el proceso enseñanzaaprendizaje. Paakat: Revista de Tecnología y Sociedad, 5(8), Recuperado de https:// bit.ly/2aABXqb

Galvis, S. (2015). La interacción docente-estudiante en el aula: una visión humanizada de la educación. Revista de Investigaciones UCM, 15(26), 70-78. http://doi. org/10.22383/ri.v15i2.45

García, J.A. (1993). Interacción entre iguales en entornos de integración escolar. Un ensayo de desarrollo profesional con profesores de Educación Infantil y de ESG.B. Tesis de doctorado. España: Universidad Complutense de Madrid.

García-Rangel, E., García, A., \& Reyes, J. (2014). Relación maestro-alumno y sus implicaciones en el aprendizaje. Ra Ximhai, 10(5), 279-290. Recuperado de http:// www.redalyc.org/pdf/461/46132134019.pdf

Gaspar, A., \& Castro, I.C. (2005). Atividades experimentais de demonstrações em sala de aula: uma análise segundo o referencial da teoria de Vygotsky. Investigações em Ensino de Ciências, 10(2), 227-254. Recuperado de https://www.if.ufrgs.br/cref/ ojs/index.php/ienci/article/view/518/315

Godino, J., \& Llinares, S. (2000). El interaccionismo simbólico en educación matemática. Educación matemática, 12(1), 70-92. Recuperado de https://bit.ly/2IfRrwB Hernández, G. (2012). Paradigmas en psicología de la educación. México: Paidós. Lennon, O. (2006). Interaccionismo simbólico y educación. Revista electrónica diálogos educativos, 6(12), 29-46. 
Lucci, M.A. (2006). La propuesta de Vygotsky: la psicología sociohistórica. Profesorado. Revista de currículum y formación del profesorado, 10(2), 1-11. Recuperado de https://bit.ly/2Dx6nrB

Mares, G., Guevara, Y., Rueda, E., Rivas, O., \& Rocha, H. (2004). Análisis de las interacciones maestra-alumnos durante la enseñanza de las ciencias naturales en primaria. Revista Mexicana de Investigación Educativa, 9(22), 721-745.

Molina, N., \& Pérez, I. (2006). El clima de las relaciones interpersonales en el aula un caso de estudio. Paradigma, 27(2). Recuperado de https://bit.ly/2fegEwV

Monreal, M.G., \& Guitart, M.E. (2012). Consideraciones educativas de la perspectiva ecológica de Urie Bronfenbrenner. Contextos Educativos, 15, 79-92. Recuperado de https://bit.ly/2pSxYZG

Olguín-Meza, M.J. (2019). Teorías clásicas en la sociología de educación. Publicación semestral, (11), 1-8. Recuperado de https://bit.ly/2DTvYZR

Pianta, R.C., Hamre, B.K., \& Allen, J.P. (2012). Teacher-Student Relationships and Engagement: Conceptualizing, Measuring, and Improving the Capacity of Classroom Interactions. En S.L. Christenson et al. (eds.), Handbook of Research on Student Engagement (pp. 365-386). Virginia, USA: Springer.

Pons, J. (2010). La aportación a la psicología social del interaccionismo simbólico. Una revisión histórica. EduPsykhé: Revista de psicología y psicopedagogía, 9(1), 23-42. Recuperado de https://bit.ly/2Q94sLt

Poulou, M. (2014). The effects on students' emotional and behavioural difficulties of teacher-student interactions, students' social skills and classroom context. British Educational Research Journal, 40(6), 986-1004.Recuperado de https://libcon.rec. uabc.mx:4440/10.1002/berj.3131

Razo, A., \& Cabrero, I. (2016). El poder de las interacciones educativas en el aprendizaje de los jóvenes. Análisis a partir de la videograbación de la práctica docente en Educación Media Superior en México. México: CIDE, PIPE y SEP. Recuperado de https://bit. ly/2MVOxhv 
Rizo, M. (2006). La interacción y la comunicación desde los enfoques de la psicología social y la sociología fenomenológica. Breve exploración teórica. Anàlisi, 33, 4562. Recuperado de https://bit.ly/2sk3owm

Saldarriaga, P., Bravo, G., \& Loor, M. (2016). La teoría constructivista de Jean Piaget y su significación para la pedagogía contemporánea. Dominio de las ciencias, 2, 127137.

Sansó, C., Navarro, J.L., \& Huguet, Á. (2016). Análisis de la interacción en un aula con alta diversidad sociocultural. Revista Electrónica Interuniversitaria de Formación del Profesorado, 19(1), 159-174. Recuperado de https://revistas.um.es/reifop/article/ view/224711

Zavala, A. (2002). La práctica educativa. Cómo enseñar. España: Graó. Recuperado de https://bit.ly/2Q8XrKD 


\section{Capítulo 4}

\section{Efectividad de prácticas directivas en contextos escolares vulnerables}

Genoveva Gutiérrez Ruiz, Noé Mora Osuna

y Alicia Alelí Chaparro Caso-López

La educación en México, constantemente, se ve envuelta en polémica por diversas razones, algunas arraigadas en el inconsciente colectivo y otras que, así como han surgido, han desaparecido. Asimismo, las instituciones educativas se enfrentan a diversos factores contextuales, como la economía del país o las características del sistema educativo en el que se desenvuelven, que influyen en los resultados de aprendizaje de los alumnos.

Por lo tanto, es necesario considerar la relación entre factores contextuales y prácticas escolares en los resultados del aprendizaje, pues las condiciones sociales que rodean a una escuela pueden determinar las prácticas al interior; sobre todo, en un país en el cual, de acuerdo con el Consejo Nacional de Evaluación de la Política de desarrollo Social (CONEVAL, 2016), prácticamente la mitad de su población se encuentra inmersa en la pobreza. Por ello, resulta imperioso no solo desarrollar sino implementar los mecanismos que coadyuven a mitigar los efectos negativos que de dicha condición se generan.

Aunado a lo anterior, existen otras condiciones que impactan en la calidad de la educación y el desempeño, tanto de los estudiantes como del personal escolar. Según datos reportados por la Organización para la Cooperación y el Desarrollo Económicos, en su informe Panorama de la Educación 2017 (OCDE, 2017), en nivel primaria las 
aulas están saturadas; en promedio, cada aula en este nivel está conformada por 25 estudiantes, cuando la recomendación es de 14 estudiantes por maestro. Respecto al nivel secundaria, México ocupa el cuarto lugar en el porcentaje de personas de entre 25 y 34 años que no han estudiado este nivel. Así, el país se ubica como la nación con mayor proporción de adultos jóvenes sin estudios, comparado con los demás países de la OCDE.

En cuanto a recursos, la OCDE registró que, durante el 2015 el gasto en educación correspondió al $17 \%$ del presupuesto, ello posicionó a México como uno de los países con mayor porcentaje destinado a este rubro. Sin embargo, el gasto destinado por estudiante en educación obligatoria fue el más bajo de toda la OCDE. El promedio de gasto de los países integrantes de la OCDE fue de $\$ 10,522$ dólares por estudiante durante toda su trayectoria académica (de primaria hasta preparatoria), mientras que el gasto en los estudiantes mexicanos no superó los $\$ 4,000$ dólares.

Respecto a los programas en donde menos se invirtió, resaltaron aquellos en los cuales el gasto fue menor del 50\% presupuestado: el "Programa de Inclusión y alfabetización digital" con un gasto solo del $6.8 \%$ de lo que se tenía calculado; el "Programa Nacional de Convivencia Escolar" con un 21.5\%; "Políticas de igualdad de género en el sector educativo" con el 23\%; "Protección de los derechos tutelados por la Ley Federal del Derecho de Autor" con un 29.1\% y; "Programa para el Desarrollo Profesional Docente" con un gasto del $36.3 \%$. Resulta paradójico, que sea precisamente en las áreas de mayor necesidad donde existe el mayor descuido en cuanto a la administración de los recursos disponibles.

Otra situación presentada por la OCDE (2017) es que la cantidad de alumnos por docente en instituciones públicas representa el doble en comparación a la matrícula de las instituciones privadas, lo cual actúa en detrimento de la calidad de la educación que se ofrece. También resulta notorio que los estudiantes mexicanos pasan poco tiempo en clase, en comparación con la media de la OCDE (532 y 1,029 horas, respectivamente). Además, al contrario de la tendencia en el resto de los países de la OCDE, que registran una disminución del promedio de estudiantes por clase, en México, el número de 
alumnos por clase ha aumentado. Lo anterior provoca bajo desempeño académico, reprobación y deserción escolar, entre otros, lo que finalmente redunda en un perjuicio individual, social y económico (Castaño, Gallón, Gómez y Vázquez, 2006; Nava, Rodríguez y Zambrano, 2007).

Como es de esperarse, dicho escenario no permite que las condiciones para la enseñanza sean óptimas. De igual manera, habrá que tomar en cuenta el carácter laboral de los entornos educativos y el impacto que este tiene, tanto en el desempeño académico de los estudiantes como en el desempeño laboral del director, el docente, el personal administrativo y el personal de apoyo. Las escuelas, al igual que las empresas, son consideradas organizaciones, dado que cuentan con un funcionamiento similar; sin embargo, ambas persiguen fines distintos. Si bien, en educación el fin último no es el de obtener ganancias económicas, existe la figura de empleado y de empleador, se labora en un ambiente determinado, con recursos asignados, bajo ciertas circunstancias y en horarios establecidos. La escuela se caracteriza por ser una organización con objetivos específicos, utilizar recursos, poseer una estructura definida y encontrarse inmersa en un entorno mediado por la cultura (Antúnez, 2004).

Desde principios de 1990, la formación del director, así como sus prácticas, han sido objeto de investigación a nivel internacional. La región Iberoamericana no ha sido ajena a esta tendencia; cuenta de ello son los diversos estudios respecto a la profesionalización de los directores escolares; misma que debe entenderse como independiente de la profesionalización docente (Valiente, Del Toro y González, 2017). La sociedad demanda que los puestos directivos sean ocupados por personas capacitadas; esta demanda se traduce en la necesidad de actualizar los perfiles de los puestos de director, con el propósito de responder a los cambios sociales y reformas educativas.

Para el adecuado funcionamiento de las escuelas debe existir un organigrama y una estructura determinada. En esta, el personal directivo ejerce funciones preestablecidas, mismas que permean a toda la comunidad escolar.

Derivado de la firma del Acuerdo Nacional para la Modernización de la Educación Básica (ANMEB) (Presidencia de la República, 1992), aparece en la escena educativa el 
término de gestión y la concepción del director evoluciona. Las funciones directivas pasan de estar centradas en los procesos administrativos a enfocarse en los procesos pedagógicos.

Cabe aclarar que, la gestión es entendida como todas aquellas acciones orientadas al logro de objetivos planteados en determinado plazo, para lo cual se coordinan esfuerzos en los que participa todo el personal, a través de la cooperación. Dichas acciones deberán ser evaluadas para ayudar en la toma de decisiones (Prue y Morgan, 2016). Es decir, aunque esta descripción resulta genérica, cada director aplicará las acciones pertinentes dependiendo de su situación.

Las funciones de la dirección en la escuela resultan un factor clave para la eficacia escolar. De acuerdo con Murillo (2008), las características del director que contribuyen al desarrollo integral de los alumnos son las siguientes:

- Una persona comprometida con la escuela, con los docentes y los alumnos

- Un buen profesional, con una alta capacidad técnica, que asume un fuerte liderazgo en la comunidad escolar

- Promueve una dirección colegiada: comparte información, decisiones y responsabilidades

- Se preocupa por temas pedagógicos, por el desarrollo profesional de los profesores, atiende a todos y cada uno de los docentes

- Posee un estilo directivo colaborativo, se preocupa por fomentar la participación de los docentes, las familias y los estudiantes, no solo en las actividades escolares, también los involucra en la toma de decisiones de la escuela

Acorde a lo anterior, la persona que se encuentre al frente de la escuela debe poseer características únicas, así como la experiencia suficiente para llevar a cabo una labor de tal envergadura. Por lo que, ocupar un puesto directivo representa un reto en cualquier profesión, y en el ámbito educativo no es la excepción.

Las escuelas se encuentran en contextos diferentes, sus características varían en muchos aspectos: administración, recursos, clima organizacional, características del 
personal o el nivel de autonomía de la escuela. Dichas características condicionan la actividad institucional y, por ende, el impacto en los resultados académicos de sus estudiantes; por lo tanto, los directivos deben reconocer las características contextuales y, a partir de ellas, orientar la toma de decisiones, con el fin de modificar aquellas características que actúan en detrimento del desempeño escolar.

En ocasiones, las escuelas se encuentran en contextos vulnerables, por lo tanto, para actuar es necesario centrar la atención en ciertas características que son exclusivas de estos entornos. El operar bajo circunstancias de vulnerabilidad, implica que los procesos de educación y aprendizaje se tornen aún más complejos, dado que su comunidad se encuentra en constante riesgo.

Sin embargo, existen escuelas que son verdaderamente eficaces y que, independientemente de los recursos con los que cuenten, ofrecen a sus estudiantes la posibilidad de desarrollarse de manera integral, en un ambiente académico de confianza y respeto; incluyendo a toda la comunidad escolar y a la sociedad en general. Así, el personal a su cargo está consciente de los factores de riesgo y de la condición de vulnerabilidad a la que la comunidad educativa se enfrenta, así como de los aspectos negativos, lo cual potencializa su noción de los aspectos positivos, y también de las debilidades y fortalezas. Las escuelas que cuentan con estas características mejoran a pesar de las condiciones contextuales (Cervini, 2006; Mata y Ballesteros, 2011; Murillo, 2005).

Algunas escuelas implementan acciones que responden a su contexto; sus procesos se orientan a disminuir el impacto de los factores de riesgo utilizando factores protectores. Para mitigar los efectos negativos del entorno, las escuelas pueden apoyarse en la comunidad, instituciones de gobierno, organizaciones civiles, así como en los padres de familia. Para ello, es necesario que las relaciones entre los agentes educativos se generen desde el interior de la escuela; en el caso de los directores, deberán buscar alianzas que resulten en beneficio de toda la comunidad escolar.

Por lo general, las escuelas con prácticas eficaces en situaciones de vulnerabilidad poseen un ambiente escolar y laboral positivo, y las expectativas que se tienen, tanto de los estudiantes como del personal, son altas. Además, los docentes se involucran en 
actividades extraescolares, aunque esto implique trabajar fuera de su jornada laboral. Asimismo, los objetivos que se plantean son claros y el personal cumple con el perfil para el puesto que se le contrata (Bellei, Muñoz, Pérez y Raczynski, 2003).

Específicamente en contextos vulnerables relacionados a la pobreza, existen estudios que ponen en evidencia el poder de transformación que poseen las escuelas situadas en contextos de vulnerabilidad. Es digno de mencionar la investigación realizada por el Fondo de las Naciones Unidas para la Infancia (UNICEF), titulada Escuelas efectivas en sectores de pobreza, ¿Quién dijo que no se puede? (como se citó en Bellei et al., 2003). En esta, se analizaron 14 escuelas, caracterizadas por tener en su matrícula a estudiantes de bajo nivel socioeconómico y resultados académicos altos. Las características de los centros estudiados fueron las siguientes:

1. Poseen una cultura escolar positiva, constituida por un fuerte capital simbólico, sentido de identidad y ética del trabajo.

2. Tiene objetivos claros y concretos, enfocados en formar a sus alumnos de manera integral.

3. Los líderes institucionales y pedagógicos a cargo de la escuela tienen la experiencia necesaria.

4. Nada es dejado al azar, sin embargo, los docentes cuentan con autonomía. Se organizan los recursos priorizando los objetivos y trabajan en equipo.

5. Han aprendido a manejar la heterogeneidad de sus alumnos; son integrados de igual manera a las demás actividades de la escuela.

6. Presentan reglas claras y un manejo explícito de la disciplina. Cuentan con normas de conducta, además de derechos y responsabilidades explícitos.

7. Buscan y aprovechan los recursos humanos disponibles.

8. Aprovechan y gestionan el apoyo externo y los recursos materiales con los que cuenta.

9. Existe una relación de apoyo y colaboración entre recurso privado, municipal (recurso público) y propio de la escuela.

10. Se preocupan por construir un puente de comunicación con los padres o tutores. 
Las escuelas presentaron un estilo de gestión que integraba de manera articulada cuestiones institucionales, administrativas y pedagógicas, lo cual resultaba en beneficio para toda la comunidad educativa e impactaba de manera positiva en los resultados académicos. Ello da cuenta de la importancia del equilibrio de las actividades de gestión ante las situaciones tan diversas que pueden llegar a presentarse en los entornos educativos.

Aquellas organizaciones que se plantean un panorama realista de su funcionamiento y de su entorno son capaces de identificar y gestionar sus puntos de vulnerabilidad y de adaptarse a situaciones inesperadas utilizando sus propios recursos (McManus, Seville, Vargo y Brunsdon, 2008). En el caso de las organizaciones educativas, las escuelas que participan en los diversos programas de apoyo gubernamentales y de organizaciones no gubernamentales, y de proyectos internos, obtienen mejores resultados académicos y un mejor funcionamiento en otras áreas. Hasta que se utilizan los recursos financieros e implementan estrategias que respondan al contexto particular, la condición de vulnerabilidad deja de serlo y se abren áreas de oportunidad y crecimiento.

Las escuelas que obtiene mejores resultados académicos, a pesar de encontrarse en situación de vulnerabilidad, llevan a cabo acciones orientadas primordialmente a reforzar las habilidades y capacidades de sus estudiantes. Esto se logra al ofrecer acompañamiento en forma de tutorías y asesorías, ya sea por parte del personal docente o mediante los mismos compañeros de clase. Por lo general, cuentan con un ambiente ordenado, puesto que el aprendizaje ocurre más fácilmente si el orden prevalece, es decir, si los estudiantes y profesores asisten a clases regularmente y con un tiempo establecido; si las instalaciones están limpias y en buen estado; y si los materiales necesarios se proporcionan de forma rutinaria (Aragón, 2013).

Al analizar los elementos que componen la práctica educativa, así como las características de los contextos en que éstas ocurren, se obtiene un panorama que permite actuar en consecuencia. Sin embargo, dado que la cultura de la evaluación es relativamente nueva, los procesos para llevarla a cabo no siempre son bien recibidos por los actores involucrados, aunque la finalidad principal sea la de comparar los resultados de 
escuelas y alumnos (Moreno, 2011). Es indispensable tomar en cuenta el contexto si se busca mejorar la calidad de la educación que se ofrece.

El director, como figura al frente de la organización educativa, deberá poseer la sensibilidad necesaria para reflexionar sobre su entorno y, así, orientar su práctica diaria. Desde este entendimiento, deberá guiar las acciones que mitiguen los efectos de los factores de riesgo, al mismo tiempo que dirige el actuar del personal docente, administrativo y de apoyo. Si la sociedad y la comunidad escolar unen fuerzas y orientan sus objetivos a la promoción de factores protectores, los estudiantes se encontrarán protegidos de los riesgos inherentes a los entornos vulnerables. Para ello, se precisa que el director lleve a cabo los procesos de gestión acordes a su contexto.

Con base en los argumentos expuestos, es evidente que las funciones del director, así como su liderazgo pedagógico, son pieza central de los centros escolares. Las funciones de gestión que se implementen desde la dirección representan un impacto para toda la comunidad escolar, repercuten directamente en el clima escolar y laboral y, por ende, en el logro académico de los estudiantes. Más aún, cuando la escuela se encuentre inmersa en un contexto social y escolar vulnerable, las acciones que se lleven a cabo por los directivos marcarán la diferencia en el futuro de los estudiantes.

Los factores de riesgo identificados en una comunidad escolar inmersa en un contexto vulnerable son múltiples. Entre los principales podemos identificar: violencia, criminalidad, drogadicción y pandillerismo. También existe insuficiencia de infraestructura y equipamiento, lo que no posibilita ampliar la matrícula aun cuando hay demanda en la comunidad. El entorno social inmediato, es decir, el contexto familiar, se encuentra caracterizado por precariedad, escaso interés de los padres por participar activamente en la educación de sus hijos, y casos aislados de violencia intrafamiliar. Ante estas situaciones, la falta de preparación de los docentes para enfrentar la diversidad de la problemática estudiantil queda, como es de esperarse, en evidencia.

En escenarios educativos con características de vulnerabilidad que, dicho sea de paso, no son pocos en el país, destacan tres elementos principales sobre los cuales se basa la dinámica escolar: liderazgo, organización y redes de apoyo. Estos elementos 
constituyen un cimiento para la comunidad escolar; si su gestión se realiza de la mejor manera, considerando las particularidades del contexto inmediato, el pronóstico vislumbra un futuro alentador.

\section{Liderazgo}

En el contexto educativo, el liderazgo hace referencia al manejo de recursos y procesos al interior de la escuela, de forma efectiva y eficaz, focalizados en la innovación para la mejora (Canlan, Minsong, Burns y Vuilleumier, 2016). Utilizar diferentes tipos de liderazgo moldea de manera particular la cultura escolar y el estilo que ejerza el director impacta en la dinámica escolar. Asimismo, estudios confirman que el liderazgo de tipo pedagógico prevalece en los equipos directivos de las escuelas con estudiantes que presentan mejor rendimiento académico (Horn y Marfán, 2010; Lizasoain y Angulo, 2014).

Algunas de las prácticas de liderazgo pedagógico son:

- La inclusión de los docentes, miembros del consejo técnico, alumnos y padres de familia para tomar decisiones, solicitando críticas y recomendaciones,

- el trabajo multidisciplinario en proyectos escolares,

- la actualización profesional docente mediante cursos y capacitaciones,

- la promoción de actividades para motivar a los estudiantes,

- el establecimiento de metas con relación a los resultados académicos y la evaluación a los docentes,

- el fomento al trabajo colectivo entre directivos y personal docente y

- el establecimiento de metas.

\section{Organización}

El término organización, en el contexto educativo, abarca el conjunto de actividades que el personal escolar realiza para estructurar la acción educativa durante la jornada escolar. Un ambiente escolar es organizado cuando, entre otras condiciones, docentes y estudiantes asisten a clases de manera regular y dentro de los horarios establecidos, y los espacios destinados para la acción educativa y el aprendizaje son adecuados; esto 
último hace referencia no solo a que se cuente con instalaciones y materiales de enseñanza, también es importante que se encuentren disponibles para todos y en buenas condiciones (Aragón, 2013).

Es necesaria una adecuada administración de los recursos disponibles (espacios, infraestructura, material didáctico y personal de la escuela), incluido el tiempo; este último factor es un aspecto de suma importancia para que tanto docentes como directivos construyan las condiciones adecuadas para beneficiar a los estudiantes y así fomentar un ambiente de aprendizaje. El concepto de tiempo efectivo hace alusión a todas las actividades que se programan en un periodo de tiempo asignado a cuestiones meramente pedagógicas, ya sea que se desarrollen dentro o fuera del aula (Martinic, Vergara y Huepe, 2013). Lo anterior debe acontecer en un ambiente propicio para el aprendizaje, que posea elementos de orden y disciplina, tanto al interior del aula (Cotton, 1995; Murillo, 2008; Román, 2008) como de la escuela y sus alrededores (Aguerrondo, 2008; Aragón, 2013; Cotton, 1995; Murillo, 2008; Robinson, Hohepa y Lloyd, 2009).

Las acciones de organización que se llevan a cabo difieren de un plantel a otro, ya que cada escuela posee autonomía en cuanto a la toma de este tipo de decisiones (Murillo y Román, 2013). Sin embargo, en lo que la mayoría de las escuelas eficaces coinciden es que administran de manera correcta todos los recursos de los que disponen, incluyendo al personal, los espacios y el tiempo de la jornada escolar (Intxausti, Juaristi y Lizasoain, 2016; Murillo y Krishensky, 2012).

El director figura como el responsable formal, por lo tanto, tiene un papel preponderante dentro de la organización institucional y en administrar el tiempo de la jornada escolar (Intxausti et al., 2016), así como en el establecimiento de las metas y expectativas que la escuela tenga, mismas que deberán estar enfocadas completamente en el aprendizaje de los estudiantes (Bolívar, López y Murillo, 2013). Sin embargo, la participación y organización del personal desempeña un papel importante, tanto en gestionar los tiempos, como en el cumplimiento de los horarios y las actividades establecidas (Aragón, 2013). El horario escolar representa la vía de comunicación formal de la planeación a toda la comunidad escolar, por medio de esta herramienta se informan 
las pautas de la jornada laboral del personal de la escuela y el horario de clases de los alumnos (Cabrera y Herrera, 2016). Por lo tanto, es deber de toda la comunidad escolar que la realización de las actividades se lleve a cabo en tiempo y forma.

Al equipo directivo (director, subdirector o colaboradores) le corresponde elaborar un plan eficiente, que concilie aspectos tales como los horarios para estudiantes y profesores, la distribución de los espacios educativos, los recursos, los proyectos pedagógicos, los compromisos institucionales y las necesidades personales de la comunidad escolar (Husti, 1992). Sin embargo, es necesario equilibrar la participación del personal docente, administrativo y del equipo directivo (Aragón, 2013; Azpillaga, Intxausti y Joaristi, 2014; Cabrera y Herrera, 2016; Murillo y Román, 2013), es decir, para obtener mejores resultados, la responsabilidad debe de ser compartida entre todos los miembros de la comunidad escolar.

\section{Redes de apoyo}

El considerarse parte activa de la sociedad y del entorno inmediato resulta benéfico para toda la comunidad escolar. Y el involucramiento de los padres de familia es, sin duda, uno de los aspectos con mayor impacto en los resultados académicos de los estudiantes. Otro factor importante es el apoyo que la sociedad ofrece al plantel educativo (Díaz-Gibson, Civís y Longás, 2013).

La comunidad y las instituciones pueden ofrecer su apoyo mediante diversos mecanismos; la escuela, a través de distintos procesos de gestión, conforma redes de apoyo, que ayudan a que la comunidad escolar comparta la responsabilidad educativa con diversos actores (Epstein y Dauber, 1991; López, García, Oliva, Moreta y Bellerín, 2014). De esta manera, los centros escolares fortalecen sus procesos educativos por medio de la gestión.

Las escuelas fomentan la participación de los padres de familia al mantener una comunicación bidireccional constante, involucrándolos en la mayoría de las actividades que la escuela realiza, tanto académicas como culturales, deportivas e incluso religiosas. Los procesos de organización y gestión al interior de las escuelas en México se formulan, 
en un principio, bajo un esquema de trabajo similar (sugerido por el sistema educativo). Sin embrago, las prácticas de gestión que se realizan al interior de las escuelas difieren tanto en cantidad como en calidad. Aquellas escuelas que realizan más y mejores acciones encaminadas a fomentar la generación de redes de apoyo obtiene un beneficio social que de otra manera sería imposible conseguir.

\section{Conclusión}

La identificación de los escenarios, en los cuales se lleva a cabo la labor educativa, otorga elementos de protección para toda la comunidad escolar, siempre y cuando esta información se utilice de manera adecuada, se haga un seguimiento y una evaluación que concluyan en planes e intervenciones plausibles.

Las prácticas encaminadas a mitigar los efectos adversos de los entornos vulnerables constituyen la columna vertebral para el buen funcionamiento de estas escuelas. Cuando el liderazgo directivo se ejerce con un fin pedagógico, las escuelas desarrollan una cultura escolar positiva, mediante la cual se propicia un ambiente de confianza, mediante el establecimiento de objetivos claros y la oportunidad de ofrecer una educación integral para los estudiantes.

Es preciso señalar que, la formación del director debe de ser la apropiada para el perfil requerido. Quien ocupe este puesto deberá ostentar una mezcla de preparación académica, experiencia profesional y vocación. Cada factor, a pesar de tener gran peso, por sí solo no garantiza un buen desempeño.

Por otro lado, desarrollar el sentido de comunidad, tanto al interior de la escuela como fuera de esta, genera una red de apoyo que funciona como escudo ante la adversidad contextual. Así, el entorno vulnerable se transforma en diversas áreas de oportunidad, en las cuales toda la comunidad escolar se puede involucrar. Aunque el liderazgo del director, en conjunto con su equipo, es quién debe conducir el funcionamiento de la escuela, el involucramiento de todos los actores es lo que configura la dinámica y cultura escolar. 
Si bien, existe un organigrama y horario establecidos, por lo general, estos no se respetan como debería de ser. El saber delegar responsabilidades y mantener un rol activo, sin usurpar funciones ni extender el horario escolar y laboral asignado, son prácticas que resultan benéficas para toda la comunidad escolar. Lo anterior, se refiere por igual a directivos, docentes, autoridades, padres de familia, inclusive a los estudiantes. Asimismo, las prácticas encaminadas a la gestión de recursos son pieza fundamental para el buen funcionamiento de las escuelas ubicadas en contextos vulnerables, donde los recursos son escasos -desde los materiales hasta los humanos-. Por ello, solventar las carencias específicas a las que se enfrenta la comunidad escolar previene las consecuencias negativas propias de este tipo de contextos.

En un sentido más amplio, el involucramiento de la sociedad es una vía de dos sentidos, es decir, tanto se beneficia la comunidad escolar como la sociedad en general. Independientemente de los programas predestinados a apoyar directamente a la comunidad (campañas de limpieza, recuperación de espacios públicos, colectas, etc.), si una escuela otorga educación de calidad a sus estudiantes, los egresados se desempeñarán de forma satisfactoria en sus trayectorias académicas y, posteriormente, en sus entornos laborales, por ende, retribuirán a la sociedad. Podrá decirse, entonces, que la escuela ha cumplido con su papel formativo de manera cabal. 


\section{Referencias}

Aguerrondo, I. (2008). La influencia del contexto en la efectividad de la escuela. Consideraciones para el desarrollo profesional docente. En J. Murillo (Coord.), Eficacia escolar y factores asociados en América Latina y el Caribe. Santiago, Chile: Oficina Regional de Educación de la UNESCO para América Latina y el Caribe (OREALC/UNESCO Santiago) / Laboratorio Latinoamericano de Evaluación de la Calidad de la Educación (LLECE).

Antúnez, S. (2004). Organización escolar y acción directiva. México: Secretaría de Educación Pública.

Aragón, F. (2013). Factores de gestión asociados a resultados educativos en escuelas primarias del estado de Sonora. En M. Navarro, \& A. Barraza (Coords.), Dirección, liderazgo, modelos y procesos de gestión: claves hacia la transformación (pp. 381416). México: Red Durango de Investigadores Educativos A. C.

Azpillaga, V., Intxausti, N., \& Joaristi, L. (2014). Implicación de las familias en los centros escolares de alta eficacia en la Comunidad Autónoma del País Vasco. Bordón. Revista de Pedagogía, 66(3), 27-37. https://doi.org/10.13042/Bordon.2014.66302

Bellei, C., Muñoz, G., Pérez, L.M., \& Raczynski, D. (2003). Escuelas efectivas en sectores de pobreza. ¿Quién dijo que no se puede? En R. Hevia, La educación en Chile Hoy (pp. 347-372). Santiago de Chile: Universidad Diego Portales.

Bolívar, A., López, J., \& Murillo, F.J. (2013). Liderazgo en las instituciones educativas. Una revisión de líneas de investigación. Revista Fuentes, 14, 15-60. Recuperado de http://institucional.us.es/revistas/fuente/14/Firma\%20invitada.pdf

Cabrera, V., \& Herrera, P. (2016). Una escuela con nuevos ritmos: Percepciones sobre el uso del tiempo escolar. Perspectiva Educacional, 55(1), 20-37. Recuperado de http:// www.perspectivaeducacional.cl/index.php/peducacional/article/view/371

Canlan, M., Minsong, K., Burns, M., \& Vuilleumier, C. (2016). Poco a poco: Leadership practices supporting productive communities of practice in schools serving the new mainstream. Educational administration quarterly, 52(1), 3-44. Recuperado de https://journals.sagepub.com/doi/10.1177/0013161X15615390 
Castaño, E., Gallón, S., Gómez, K., \& Vásquez, J. (2006). Análisis de los factores asociados a la deserción y graduación estudiantil universitaria. Lecturas de Economía, (65), 9-35. Recuperado de https://www.redalyc.org/articulo.oa?id=155213357001

Cervini, R. (2006). Los efectos de la escuela y del aula sobre el logro en matemáticas y en lengua en la educación secundaria. Un modelo multinivel. Perfiles Educativos, 28(112), 68-97. Recuperado de http://scielo.unam.mx/pdf/peredu/v28n112/ n112a4.pdf

Consejo Nacional de Evaluación de la Política de desarrollo Social (CONEVAL). (2018). Medición de la pobreza. Resultados de pobreza en México 2016 a nivel nacional y por entidades federativas. Recuperado de https://www.coneval.org.mx/Medicion/ MP/Paginas/Pobreza_2016.aspx

Cotton, K. (1995). Effective schooling practices: A research synthesis, 1995 update. Portland, OR: Northwest Regional Educational Laboratory. Recuperado de http://www. kean.edu/ lelovitz/docs/EDD6005/Effective\%20School\%20Prac.pdf

Díaz-Gibson, J., Civís, M., \& Longás, J. (2013). La gobernanza de redes socioeducativas: claves para una gestión exitosa. Teoría de la Educación, 25(2), 213-230. Recuperado de https://dialnet.unirioja.es/servlet/articulo?codigo $=4517220$

Epstein, J.L., \& Dauber, S.L. (1991). School programs and teacher practices of parent involvement in inner-city elementary and middle schools. The elementary school journal, 91(3), 289-305. Recuperado de https://www.journals.uchicago.edu/doi/ abs/10.1086/461656

Horn, A., \& Marfán, J. (2010). Relación entre liderazgo educativo y desempeño escolar: Revisión de la investigación en Chile. Psicoperspectivas, 9(2), 82-104. Recuperado de http://www.psicoperspectivas.cl/index.php/psicoperspectivas/article/ view/116

Husti, A. (1992). Del tiempo escolar uniforme a la planificación móvil del tiempo. Revista de Educación, 298, 271-305. Recuperado de http://www.mecd. gob.es/dctm/revista-de-educacion/articulosre298/re2981200486. pdf?documentld=0901e72b8135769a 
Intxausti, N., Juaristi, L., \& Lizasoain, L. (2016). Educational leadership as best practice in highly effective schools in the Autonomous Region of the Basque County (Spain). Educational Management Administration \& Leadership, 44(3) 397-419. https://doi. org/10.1177/1741143214558570

Lizasoain L., \& Angulo A. (2014). Buenas prácticas de escuelas eficaces del País Vasco. Metodología y primeros resultados. Participación Educativa, 3(4), 17-27. Recuperado de http://ntic.educación.es/cee/revista/pdfs/n4art_lizasoain_angulo.pdf López, J., García, E., Oliva, N., Moreta, B., \& Bellerín, A. (2014). El liderazgo escolar a través del análisis de la actividad diaria de los directores. REICE. Revista Iberoamericana sobre Calidad, Eficacia y Cambio en Educación, 12(5), 61-7. Recuperado de https:// www.redalyc.org/html/551/55132460003/

Martinic, S., Vergara, C., \& Huepe, D. (2013). Uso del tiempo e interacciones en la sala de clases. Un estudio de casos en Chile. Pro-Posiçõe. 24(1), 123-135. Recuperado de http://www.scielo.br/pdf/pp/v24n1/v24n1a09.pdf

Mata, P., \& Ballesteros, B. (2011). Diversidad cultural, eficacia escolar y mejora de la escuela: encuentros y desencuentros. Revista de Educación, 358(2), 17-37. Recuperado de http://www2.uned.es/grupointer/re358_02_patri_belen.pdf

McManus, S., Seville, E., Vargo, J., \& Brunsdon, D. (2008). Facilitated process for improving organizational resilience. Natural Hazards Review, 9(2), 81-90. Recuperado de http://ascelibrary.org/doi/abs/10.1061/(ASCE)1527-6988(2008)9:2(81)

Moreno, T. (2011). La cultura de la evaluación y la mejora de la escuela. Perfiles educativos, 33(131), 116-130. Recuperado de http://www.scielo.org.mx/scielo. php?script=sci_arttext\&pid=S0185-26982011000100008\&lng=es\&tlng=es

Murillo, F.J. (2005). ¿Importa la escuela? Una estimación de los efectos escolares en España. Tendencias pedagógicas, 10, 29-45. Recuperado de https://dialnet. unirioja.es/descarga/articulo/1407962.pdf

Murillo, F.J. (2008). Enfoque situación y desafíos de la investigación sobre eficacia escolar en américa Latina y el Caribe. En UNESCO, Eficacia escolar y factores asociados en América Latina y el Caribe (pp. 17-48). Santiago de Chile: UNESCO. 
Murillo, F.J., \& Krichesky, G.J. (2012). El proceso de cambio escolar: Una guía para impulsar y sostener la mejora de las escuelas. REICE: Revista Electrónica Iberoamericana sobre Calidad, Eficacia y Cambio en Educación. 10(1), 26-43. Recuperado de http:// www.rinace.net/reice/numeros/arts/vol10num1/art2.pdf

Murillo, J., \& Román, M. (2013). La distribución del tiempo de los directores de escuelas de Educación Primaria en América Latina y su incidencia en el desempeño de los estudiantes. Revista de Educación, 361. http://www.revistaeducacion.mec.es/ doi/361_138.pdf

Nava, G., Rodríguez, P., \& Zambrano, R. (2007). Factores de reprobación en los alumnos del Centro Universitario de Ciencias de la Salud de la Universidad de Guadalajara. Revista de educación y desarrollo, (7), 17-26. Recuperado de http://www.cucs.udg. $\mathrm{mx} /$ revistas/edu_desarrollo/anteriores/7/007_RED_completa.pdf?\#page $=18$

Organización para la Cooperación y el Desarrollo Económicos (OCDE). (2017). Panorama de la educación 2017. Indicadores de la OCDE. Recuperado de http://www. fundacionsantillana.com/PDFs/PANORAMA\%20EDUCACION\%202017.pdf

Presidencia de la República (1992). DECRETO para la celebración de convenios en el marco del Acuerdo Nacional para la Modernización de la Educación Básica. Diario Oficial de la Federación (DOF), 14-05-1992. Recuperado de http://www.dof.gob. $\mathrm{mx} /$ nota_detalle.php?codigo $=4666809 \& \mathrm{fecha}=19 / 05 / 1992$

Prue, A., \& Morgan, G. (2016). Evaluaciones nacionales del rendimiento académico. Volumen 2: Desarrollo de pruebas y cuestionarios para una evaluación nacional del rendimiento académico. Washington, DC: Banco Mundial. https://doi. org/10.1596/978-1-4648-0745-9

Robinson, Hohepa, \& Lloyd, 2009. School Leadership and Student Outcomes: Identifying what works and why. Best Evidence Synthesis Iteration. New Zeland: Ministry of Education. Recuperado de https://www.educationcounts.govt.nz/publications/ series $/ 2515 / 60169 / 60170$ 
Román, M. (2008). Investigación Latinoamericana sobre enseñanza eficaz, 209-225. En J. Murillo (Coord.), Eficacia escolar y factores asociados en América Latina y el Caribe. Santiago, Chile: Oficina Regional de Educación de la UNESCO para América Latina y el Caribe (OREALC/UNESCO Santiago) / Laboratorio Latinoamericano de Evaluación de la Calidad de la Educación (LLECE).

Valiente, P., Del Toro, J., \& González, J. (2017). Tendencias actuales en la formación especializada de los directores escolares: hallazgos desde la sistematización. Revista Dilemas Contemporáneos: Educación, Política y Valores, 4(3). Recuperado de https:/www.dilemascontemporaneoseducacionpoliticayvalores.com/ edici\%E2\%99\%80n-2013/ano-iv-publicacion-no-3-mayo-2017/ 


\section{Capítulo 5}

\section{Evaluación del diseño de la prueba de matemáticas de primaria (06) del PLANEA ELCE 2015}

Juan Carlos Pérez-Morán, Juan Carlos Rodríguez Macías, Ramsés Vázquez Lira y Alina Alejandra Ramos Vargas

Encontrar formas para mejorar el diseño de las pruebas educativas de gran escala es una necesidad recurrente para los sistemas de evaluación, organizaciones y equipos encargados de su desarrollo y validación a nivel nacional e internacional (Ravela et al., 2008). En México, con los cambios recientes en la legislación federal, se puso mayor énfasis en la rendición de cuentas y la evaluación del avance del Sistema Educativo Nacional (SEN) a través de pruebas de logro educativo a gran escala. Actualmente, con la presencia del Instituto Nacional para la Evaluación de la Educación (INEE, 2018) se espera que las evaluaciones de logro educativo contempladas en el Plan Nacional para las Evaluaciones de los Aprendizajes (PLANEA) cuenten con una serie de características sobre la calidad técnica, atendiendo los criterios para el desarrollo de pruebas del INEE (2017) y los estándares para pruebas psicológicas y educativas de la American Educational Research Association, American Psychological Association y National Council on Measurement in Education (AERA, APA y NCME, 2014).

Con la implementación del PLANEA, se espera recabar información que sea útil para la mejora de los aprendizajes de todos los estudiantes de educación básica obligatoria, incluyendo a aquellos estudiantes con discapacidades y con una lengua materna diferente al castellano. Con el alto nivel de participación de los estudiantes 
de todo el país en el PLANEA y de su obligatoriedad de implementación, se crea una gran responsabilidad social y política a los responsables de los Sistemas Estatales de Educación (SEE), dado que los resultados se informan públicamente para la rendición de cuentas. Con ello, hay una necesidad crítica del INEE por asegurar la calidad del diseño de las pruebas nacionales.

Actualmente, en los estándares de la AERA, APA y NCME (2014), así como investigadores y desarrolladores de pruebas reconocidos a nivel internacional (Gierl y Lai, 2018; Johnstone, 2003; Pérez-Morán, Rojas y Vázquez-Lira, 2018; You, Li, Zhang y Liu, 2018; Dolan, Hall, Banerjee, Chun y Strangman, 2005; Ketterlin-Geller, 2005; entre otros), recomiendan la aplicación del Modelo para la Evaluación del Diseño Universal (MEDU) desarrollado por Thompson, Johnstone y Thurlow (2002) para el diseño de las pruebas, garantizando que sean accesibles a cualquier persona, sin necesidad de una adaptación posterior a su desarrollo. Aunque el MEDU es un concepto que comenzó en el campo de la arquitectura, se expandió rápidamente hacia iniciativas ambientales, recreación, arte, salud y, por supuesto, educación (Mace, 1985). Por tal motivo, las pruebas diseñadas con un enfoque universal ofrecen un panorama prometedor para proporcionar condiciones de evaluación adecuadas para todos los estudiantes evaluados, brindándoles una oportunidad comparable para decantar su logro a través de instrumentos de evaluación estandarizados (Anderson, Lai, Alonzo y Tindal, 2011). Es por ello, que el MEDU presenta un replanteamiento metodológico para el análisis del sesgo en las evaluaciones educativas de gran escala, que ayuda a garantizar que la información sea de calidad en términos de justicia de las pruebas.

\section{Normatividad de la evaluación en México}

El INEE, como organismo constitucional autónomo, tiene por objeto coordinar el Sistema Nacional de Evaluación Educativa (SNEE), así como evaluar la calidad, el desempeño y los resultados del SEN, en lo que se refiere a la educación básica y obligatoria, tanto pública como privada, en todas sus modalidades y servicios (Gobierno Federal, 2013). Aunado a ello, y de forma especial, el INEE tiene la responsabilidad de diseñar y realizar 
mediciones y evaluaciones que correspondan a componentes, procesos o resultados del SEN respecto a los atributos de alumnos, docentes y autoridades escolares, así como de las características de las instituciones, las políticas y los programas educativos.

Como respuesta a los compromisos establecidos, en especial aquellos relacionados con la evaluación de la calidad, el desempeño y los resultados del SEN, el INEE diseñó y aplicó por primera vez en el año 2015 el Plan Nacional para las Evaluaciones de los Aprendizajes (PLANEA). Como antecedente, en el año 2013, el Instituto solicitó a un comité de expertos un estudio de validez y confiabilidad de las pruebas ENLACE (Evaluación Nacionales del Logro Académico en Centros Escolares) y las pruebas EXCALE (Exámenes para la Calidad y el Logro Educativo), administrados por la Secretaría de Educación Pública (SEP) y el INEE respectivamente (Martínez-Rizo, 2015). Entre las recomendaciones que señalaron los expertos del estudio de validez destacan cinco grandes compromisos que el INEE debía de asumir para cuidar que el nuevo plan de evaluaciones nacionales cuente con las características de calidad técnica esperados: (1) rigor metodológico del diseño, construcción y aplicación de las pruebas; (2) correspondencia de los resultados con los propósitos que se plantearon durante su diseño; (3) justicia de la prueba con la reducción del sesgo de las evaluaciones que pudiera resultar de la diversidad lingüística, de género, étnica y cultural del país; (4) control en los mecanismos de aplicación, indicando los casos en que los resultados pudieran no ser confiables; y (5) precisión y comparabilidad de las medidas, para que sus resultados pudieran ser confiables a lo largo del tiempo.

A partir de dicho estudio, el Instituto diseñó -en coordinación con la SEPel PLANEA con tres modalidades de evaluación para conocer el aprendizaje de los estudiantes con la intención de mantener las principales fortalezas de ENLACE y EXCALE y superar sus debilidades: Evaluación del Logro referida al Sistema Educativo Nacional (ELSEN), y la Evaluación del Logro referida a los Centros Escolares (ELCE). Con dichas modalidades del PLANEA, tanto el INEE como la SEP, esperan obtener distintos niveles de desagregación de la información de los aprendizajes logrados por los estudiantes en el país, integrar las evaluaciones nacionales para un desarrollo lógico y articulado, 
mejorar la coordinación entre SEP e INEE en temas de evaluación, e incorporar a las autoridades estatales y las escuelas al sistema de monitoreo de los avances del SEN (INEE, 2018). En especial, con el PLANEA ELCE se espera cumplir con el propósito de ofrecer información contextualizada para el monitoreo, planeación, programación y operación del sistema educativo y de forma específica información para la mejora de los procesos de enseñanza a nivel de los centros escolares (unidades de análisis).

Con base en la revisión de las experiencias de evaluación anteriores, particularmente ENLACE y EXCALE (Martínez-Rizo, 2015), así como de la búsqueda de diseños que cumplieran con los propósitos mencionados, el INEE definió elementos esenciales de lo que ahora conocemos como el PLANEA, dentro del cual para lo que compete al presente capítulo se resalta "[Incorporar] procedimientos para identificar el sesgo de las evaluaciones que pudiera resultar de la diversidad de género, étnica, cultural y lingüística, y para evitar comparaciones injustas" (INEE, 2015, p. 12). Esto con el fin de que las evaluaciones con las que cuenta el INEE, posean las características técnicas que le permitan tener certeza de que se está atendiendo el principio de imparcialidad y equidad. Por lo tanto, es viable y muy recomendable, adoptar un enfoque más integral para abordar estas limitaciones de las pruebas, por lo que el objetivo de aplicar los principios de diseño universal a las evaluaciones a cargo del INEE, es poder diseñar y desarrollar evaluaciones que permitan la participación de la gama más amplia de estudiantes y que den como resultado conclusiones con un grado más alto de validez sobre su desempeño.

\section{Modelo para la Evaluación del Diseño Universal}

En el Modelo para la Evaluación del Diseño Universal (MEDU) se parte de un enfoque basado en los principios de accesibilidad para una amplia variedad de usuarios finales. Thompson et al. (2002), describieron los elementos que debían contener las evaluaciones diseñadas universalmente. En su informe, esta metodología se alineó a evaluaciones a gran escala, resaltando la necesidad imperante sobre atender la necesidad de que "a todos los examinados se les brinde una oportunidad equitativa y comparable para demostrar su dominio en el(los) constructo(s) de la prueba a aplicar" (p. 5). 
Para ello, los Estándares para Pruebas Educativas y Psicológicas (AERA, APA y $N C M E, 2014)$ también abordan esta necesidad, el tratamiento equitativo también incluye factores tales como las condiciones de prueba apropiadas y la igualdad de oportunidades para familiarizarse con el formato de la prueba, los materiales de práctica, etc., con base en las categorías de análisis propuestos por Thompson et al. (2002): (1) inclusión poblacional, (2) definición precisa del constructo, (3) accesibilidad e imparcialidad (4) acomodación flexible de los contenidos, (5) procedimientos e instrucciones simples, claras e intuitivas, (6) máxima legibilidad, y (7) máxima comprensibilidad (p. 6).

Por ejemplo, Johnstone (2003) generó un diseño experimental en donde 231 estudiantes de bajo desempeño resolvieron dos pruebas, el orden de presentación se contrabalanceó entre los participantes. Utilizó una prueba (diseñada tradicionalmente) integrada por los reactivos liberados de una evaluación a gran escala, la cual se presentó en formato estándar, por su parte, una segunda prueba se creó utilizando los constructos de la prueba tradicional, pero incluyó características del MEDU; esta segunda prueba aseguró la correspondencia del contenido (uno a uno) entre los constructos de los reactivos de ambas pruebas. Los resultados de los 231 participantes en ambas pruebas se contrastaron y demostraron que los estudiantes obtuvieron puntuaciones significativamente más altas en la prueba diseñada bajo el MEDU. Estos hallazgos tienen implicaciones entorno al grado de validez cuando se evalúan a estudiantes con condiciones desafiantes o desprivilegiadas, en donde pese a que tuvieran condiciones que pudieran ser consideradas una barrera (p. ej. origen étnico, grado de marginación de su localidad, género, entre otras); por ello, las evaluaciones al ser generadas a través del MEDU, permiten eliminar o matizar ciertas barreras alrededor de los métodos de evaluación, extrayendo la parte sustantiva de los aprendizajes evaluados y generando una mayor inclusión social y, por ende, una disminución de la inequidad por parte de las evaluaciones, y en un país como México, donde existe tanta riqueza cultural y sociodemográfica, el poder apoyarse del MEDU para brindar un sistema educativo de calidad y equidad acerca mucho más hacia el Derecho Humano a una Educación Obligatoria de Calidad del país. 
Cabe resaltar que el MEDU debe tenerse presente a lo largo de todas las fases del proceso de medición (desde el diseño y desarrollo de la prueba hasta la administración, puntuación, interpretación y uso de resultados), ya que una característica fundamental, es que las evaluaciones elaboradas bajo este esquema, se refinan continuamente, permitiendo la participación activa de una gran variedad de estudiantes lo que da como resultado inferencias más robustas sobre su desempeño, debido al alto grado de validez que guardan. Se basan en la premisa de que cada estudiante en la escuela es parte de la población a la que se va a realizar la prueba, y que los resultados de esta no deben verse influenciados por variables tales como discapacidad, género, grupo étnico o idioma. Por lo tanto, las evaluaciones diseñadas universalmente pueden reducir la necesidad de adaptaciones al eliminar las barreras de acceso asociadas con las pruebas en sí mismas. Así, el MEDU es una vía para aumentar la participación en las evaluaciones enfocadas al SNE, ya que se basan en la misma ética de equidad e inclusión que se espera para las personas con discapacidades, grupo étnico o género, debido a que el desempeño en la prueba no se debe ver afectado por dichas variables. Por otro lado, es importante recordar que el MEDU no aborda las deficiencias en la instrucción, ya que los estudiantes que no hayan tenido la oportunidad de aprender los conceptos o temas evaluados estarán en desventaja durante la prueba, sin importar cuán universal sea el diseño de la evaluación.

\section{Propósito del estudio}

"Evaluar el diseño de los ítems liberados de la prueba de Matemáticas de primaria (06) del PLANEA ELCE 2015 bajo el MEDU". Cabe destacar que existe una ventaja respecto a la prueba seleccionada, ya que pertenece a un campo ampliamente estudiado con métodos similares (Brown y Burton, 1978; Chen y Macdonald, 2011; Gierl et al., 2009; Ma, Çetin y Green, 2009; Pérez-Morán, 2014; Pérez-Morán et al., 2018; Pérez-Morán, Larrazolo, Backhoff y Guaner, 2015; Revuelta y Ponsoda, 1998; Romero, Ponsoda y Ximénez, 2008). Con ello, se espera recabar información que ayude a los desarrolladores de las evaluaciones a mejorar sus procesos de diseño y a los tomadores de decisiones 
a interpretar de forma más justa los resultados de las evaluaciones, además de aportar a la discusión y debate en el ámbito disciplinar. Asimismo, se pretende mostrar los beneficios de la aplicación de métodos cognitivos para identificar posibles sesgos en los ítems de las pruebas mediante el análisis de los procesos de respuestas de un grupo de expertos y estudiantes aportando evidencias, validez de constructo y de equidad de la prueba (Messick, 1989; Snow y Lohman, (1989).

\section{Método}

\section{Tipo de estudio}

Psicométrico y de validación, en donde se complementaron los métodos cognitivos de panel de expertos y protocolos verbales con estudiantes, así como aspectos principales del MEDU propuestos porThompson et al. (2002). En investigaciones basadas en el MEDU se ha encontrado que los diseñadores de pruebas pueden desarrollar evaluaciones más accesibles para los examinados mediante su aplicación (Johnstone, 2003). También, se ha encontrado que con la aplicación del MEDU, el apego a estrategias de diseño eficaz y el uso de métodos cognitivos se puede minimizar la varianza irrelevante del constructo originada por problemas en el diseño, formato y sesgos culturales presentes en los ítems de las pruebas (Haladyna, Downing y Rodríguez, 2002; Ercikan et al., 2010; Smith-Castro y Molina, 2011).

En especial, los métodos del panel de expertos y los protocolos verbales con estudiantes son de gran ayuda para lograr una evaluación más granulada del diseño de los ítems y aumentar la validez de las evidencias convergentes recabadas en ambos métodos, al contrastar las hipótesis de los expertos respecto al diseño de los ítems y los reportes verbales con las evocaciones del proceso de respuesta de los estudiantes ante los ítems en análisis. Por ejemplo, contar con hipótesis de expertos referentes a los requerimientos para contestar un ítem puede ayudar a prever de explicaciones en los casos en donde, durante las técnicas de pensamiento en voz alta, se les dificulta a los estudiantes de corta edad verbalizar lo que piensan, o en casos en donde se suscitan procesos en tan sólo algunos segundos y que, por lo tanto, no es posible su 
introspección (Sternberg, 1977). Asimismo, contar con información granulada de los procesos de respuesta de examinados ante los ítems de una prueba puede ayudar a verificar o corregir las hipótesis de los expertos con información muy pobre o escasa referente a los requerimientos para responder los ítems (Ericsson y Simon, 1984, 1993; Leighton, 2004, 2017; Leighton y Gierl, 2007; Messick, 1989; Snow y Lohman, 1989).

\section{Participantes}

Se trabajó con dos tipos de participantes en el estudio, correspondientes a las dos técnicas cognitivas aplicadas. Para el panel de expertos se determinó trabajar con cinco especialistas con experiencia en la enseñanza de las Matemáticas: tres psicólogos con experiencia en atención a estudiantes de primaria y secundaria con problemas de aprendizaje en matemáticas, un especialista en análisis y modelamiento de procesos cognitivos en el campo del pensamiento lógico-matemático, y un docente con amplia experiencia en la enseñanza de las Matemáticas en educación básica. Para la selección de los expertos se siguieron las recomendaciones de Rupp, Templin y Henson (2010), con respecto a la elección de profesionales con un conocimiento profundo de los procesos de solución de problemas que utilizan los individuos en el dominio de interés, de las diferentes vertientes para el desarrollo y aprendizaje de los componentes o atributos de la prueba y de los contextos en los que los examinados adquieren y utilizan dichos atributos.

Por su parte, para los protocolos de pensamiento en voz alta aplicando técnicas concurrentes y retrospectivas se contó con la participación de ocho estudiantes voluntarios de sexto de primaria (cuatro mujeres y cuatro hombres), tanto de rendimiento alto y bajo. En cuanto a la estimación de la cantidad de participantes requeridos para el análisis de protocolos, Nielsen (1994) menciona que puede ser variada según sea el propósito del estudio. Para el análisis de protocolos llevado a cabo en esta investigación sólo se requirió de un grupo pequeño de participantes que aportara suficiente información de sus procesos de respuesta ante los ítems estudiados con el fin de verificar si estos están representados en el modelo cognitivo elaborado previamente por los expertos. 
Para el establecimiento de los criterios de selección de los participantes de los protocolos verbales se tomaron en cuenta las recomendaciones de Ericsson y Simon (1984; 1993). Dichos autores proponen incorporar al análisis del proceso de respuesta tanto a novatos como a expertos en el dominio de interés. Por lo tanto, se establecieron como criterios para la selección de los participantes las variables de rendimiento escolar, grado educativo y la recomendación del profesor. Además, se estableció que, del total de participantes, $50 \%$ fueran hombres y $50 \%$ fueran mujeres.

Como criterio de selección de estudiantes novatos y expertos se estableció un promedio de rendimiento escolar mayor a 8.5 y que, además, fueran referidos por los profesores como estudiantes sobresalientes en el dominio de las Matemáticas. Dichos estudiantes conformaron el grupo de estudiantes expertos para el piloteo. De igual forma, se estableció la selección de estudiantes de sexto grado de primaria que presentaran un promedio mayor a 6.0 pero menor a 8.0 y que fueran referidos por los profesores como estudiantes con bajo desempeño o no sobresalientes en el dominio de las Matemáticas. Dichos estudiantes conformaron el grupo de estudiantes novatos. De la misma forma, se determinó que del total de participantes, 50\% fueran estudiantes expertos y $50 \%$ fueran estudiantes novatos.

\section{Instrumentos}

Los instrumentos para el análisis del diseño de los ítems mediante métodos cognitivos fueron: el sistema de categorías para la evaluación del diseño universal adaptado especialmente para los ítems liberados de la prueba de Matemáticas primaria (06) del PLANEA ELCE 2015 (ver Apéndice A) y el formato del protocolo verbal concurrente y retrospectivo elaborado por Pérez-Morán (2014). Es importante mencionar que se adaptaron y desarrollaron categorías y códigos de análisis para la evaluación del diseño de los ítems en estudio tomando en cuenta los aspectos básicos y categorías del MEDU propuestos por Thompson et al. (2002). Asimismo, es necesario resaltar que expertos en el campo de la medición (Ericsson y Simon, 1984; 1993; Leighton y Gierl, 2007; Messick, 1989; Nichols, Kobrin, Lai y Koepfler, 2016) recomiendan ampliamente el uso de métodos 
cognitivos y, de forma muy particular, de paneles de expertos y reportes verbales dados sus beneficios y aportaciones al tema de validez y equidad de las pruebas.

\section{Procedimiento del estudio}

El procedimiento del estudio se estructuró en tres fases. En la primera fase, se seleccionaron los métodos cognitivos, se habilitó un laboratorio cognitivo y se diseñaron los formatos de la guía para los protocolos verbales con estudiantes, así como el sistema de categorías para el análisis de los ítems tomando en cuenta los elementos del MEDU. En la segunda fase, el panel de expertos realizó el análisis cognitivo-reticular de los ítems, mapearon los modelos teóricos de respuesta y elaboraron hipótesis de posibles problemas de diseño de cada uno de los ítems de la prueba. Posteriormente, durante la misma fase, se aplicaron los protocolos verbales con técnicas de pensamiento en voz alta (concurrentes) y entrevistas cognitivas (retrospectivas) a estudiantes. Para la tercera y última fase, los expertos verificaron sus hipótesis planteadas de los procesos de respuesta de los estudiantes, así como de los posibles problemas de varianza irrelevante o algún tipo de sesgo presentes en los ítems.

\section{Resultados}

En los resultados de la evaluación del diseño universal obtenidos por el panel de expertos y los protocolos verbales con estudiantes se encontró que, de los 50 ítems liberados de la prueba de Matemáticas 06 del PLANEA ELCE 2015, 46 ítems (92\%) presentaron al menos un problema de diseño universal. En total, se detectaron 101 problemas, donde la moda corresponde a 2 problemas por ítem y el ítem con más problemas es el PMB14 con 6 de ellos relacionados con los elementos del MEDU de inclusión poblacional, definición precisa del constructo y máxima comprensibilidad (ver Apéndice A). Respecto a los resultados de la evaluación del diseño universal de los ítems en cada uno de los seis elementos del MEDU, se encontró que: 9 ítems (18\%) presentaron al menos un problema relacionado con el elemento I. Inclusión poblacional; 34 ítems (68\%) con el elemento II. Definición precisa del constructo; 3 ítems (6\%) con el elemento III. Accesibilidad e imparcialidad; 
en el elemento IV. Acomodación flexible de los contenidos no se encontraron ítems con problemas; 8 ítems (16\%) presentaron problemas relacionados con el elemento $V$. Procedimientos e instrucciones claras, simples e intuitivas; y, por último, 10 ítems (20\%) presentaron problemas relacionados con el elemento VI. Máxima comprensibilidad. Por su parte, en los resultados de la evaluación de los ítems clasificando los problemas en los rubros de: (I) alineación curricular, (II) sesgo y (III) diseño, se encontró que, en el primer rubro 34 ítems (68\%) presentaron problemas, 12 ítems (24\%) en el segundo y 31 ítems (62\%) en el tercer rubro.

\section{Problemas de alineación curricular}

Del $68 \%$ de los ítems que presentaron problemas de alineación curricular, el ítem PMA18 y PMA01 son dos ejemplos que pueden ilustrar de forma clara el problema señalado. El ítem PMA18 fue diseñado para evaluar el contenido: Resolver problemas aditivos con números decimales. La incógnita es el resultado, que corresponde al bloque I del libro de texto: Desafíos matemáticos de sexto grado de primaria. Sin embargo, los resultados de los métodos cognitivos aplicados señalan que los modelos de enseñanza del libro de texto no coinciden con los procesos de respuesta requeridos para contestar el ítem. Tras los análisis realizados, se encontró que el ítem PMA18 se encuentra claramente relacionado con el contenido 4.4.3. Resolución de sumas o restas con números decimales en diferentes contextos del bloque IV del libro de texto: Desafíos matemáticos de cuarto grado de primaria; mismo de donde se desprende la intención didáctica: Que los alumnos interpreten la parte decimal de un número en el contexto de la medición, para resolver problemas aditivos (figura 1). 


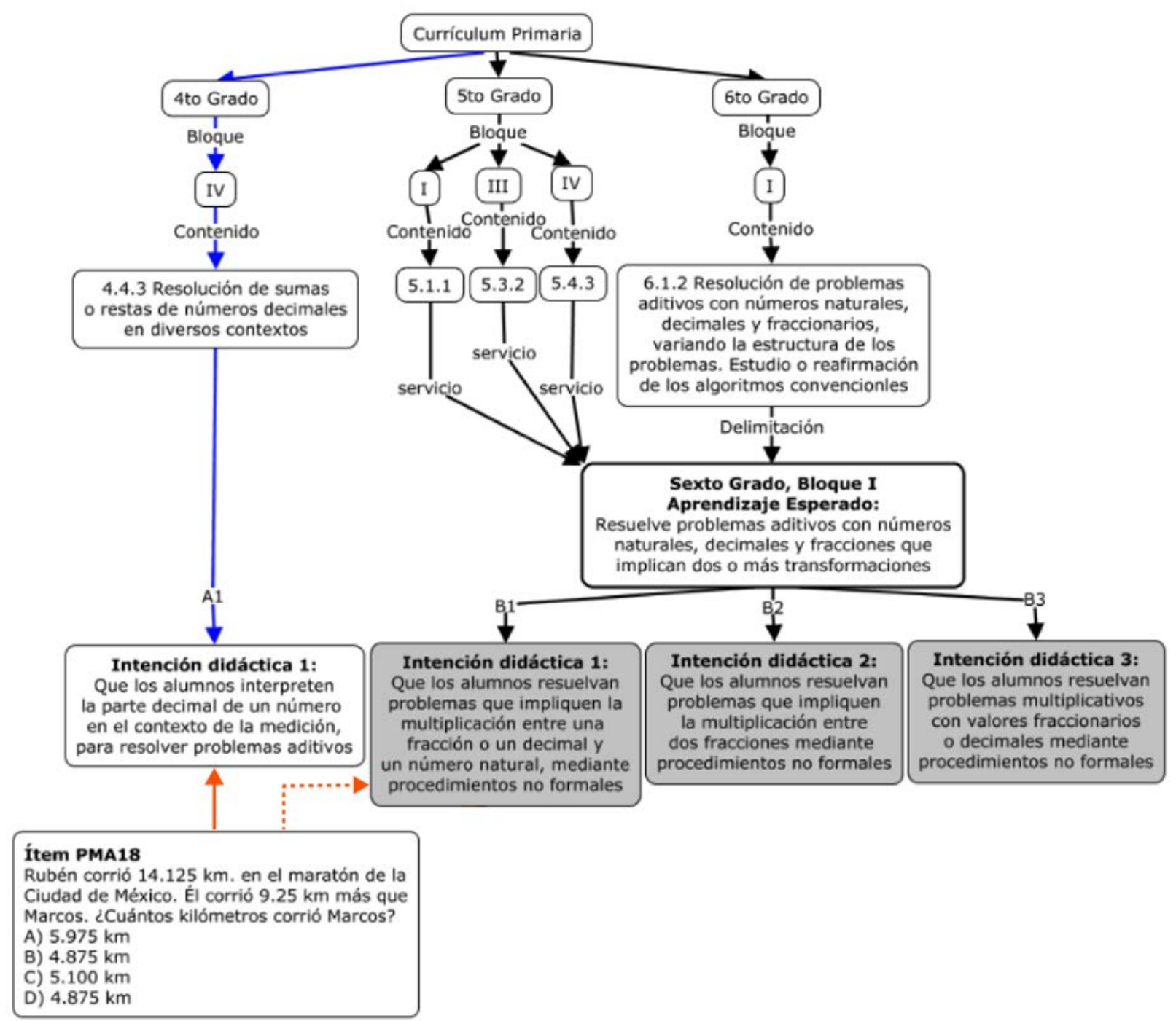

Figura 1. Diagrama de la genealogía reticular y problema de Alineación curricular del ítem PMA18.

Otro ejemplo emblemático relacionado con el problema de alineación curricular es el caso del ítem PMA01 (figura 2). Los expertos encontraron un problema de sobresimplificado en la demanda de dicho ítem. En la especificación del ítem PMA01 se define como contenido a evaluar el cálculo Del área de triángulos que corresponde al Aprendizaje esperado: Calcula el perímetro y el área de triángulos y cuadriláteros, perteneciente al eje: 
Forma, espacio y medida de $5^{\circ}$ grado de primaria. Sin embargo, se puede ver, revisando los procesos de respuesta evocados por los estudiantes, que se requiere para contestar correctamente dicho ítem otras habilidades más complejas como la comprensión de problemas matemáticos contextualizados, la deducción de los elementos del contexto requeridos para aplicar un modelo aritmético y el cálculo del área de un triángulo con rotación de la base.

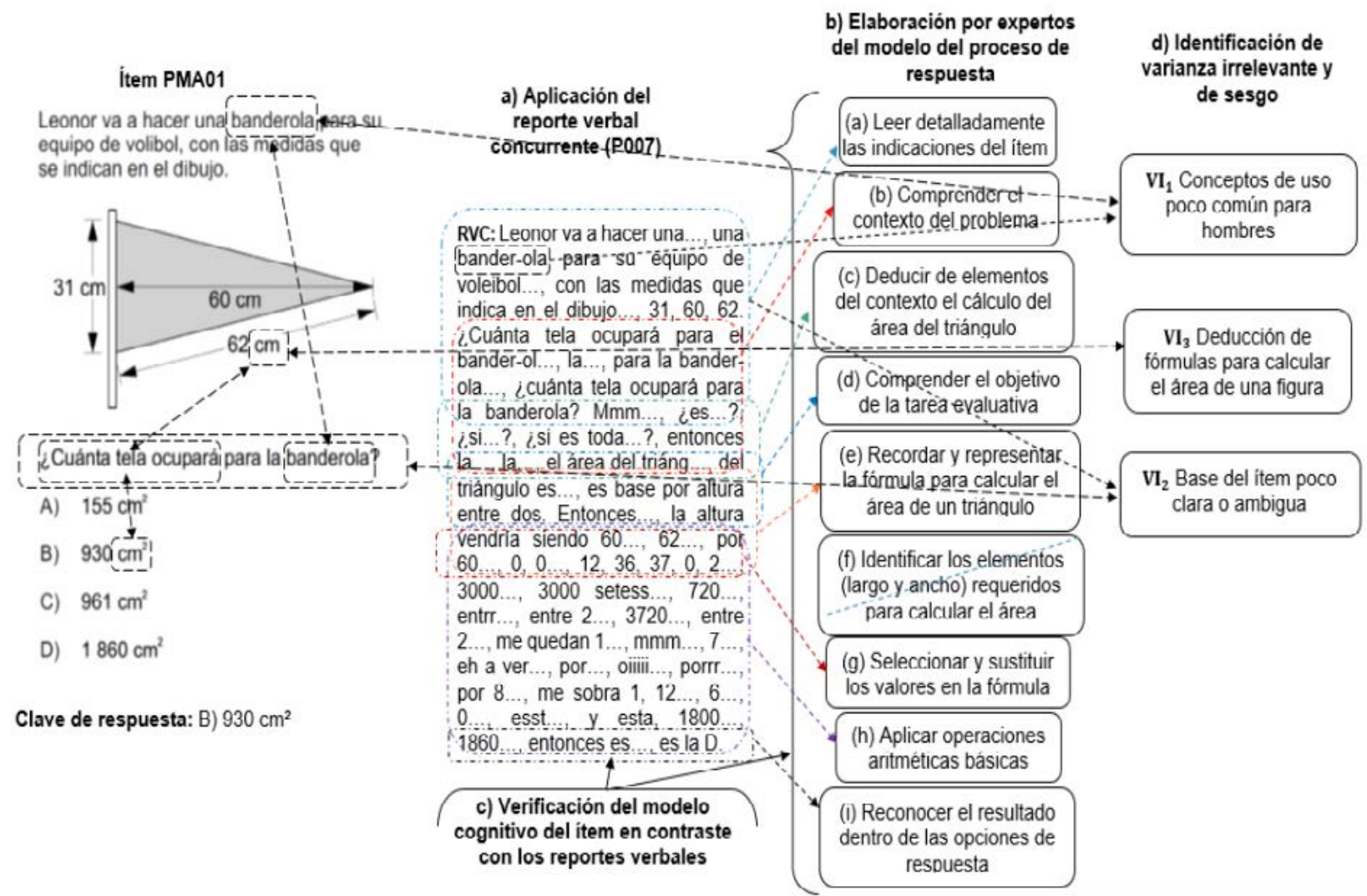

Figura 2. Diagrama del modelo de un proceso de respuesta erróneo subyacente al ítem PMA01.

También, durante el análisis de los documentos curriculares oficiales, asociados con el caso del ítem PMA01, los expertos encontraron que el estándar curricular en la Guía del maestro del Plan de estudio 2011 no coincidía con el Aprendizaje esperado establecido en la especificación (figura 3). Nótese que el estándar curricular presenta 
una descripción diferente a la especificación, señalando como estándar curricular el uso de fórmulas para calcular perímetros y áreas. Sin embargo, no se establece nada referente al aprendizaje de la comprensión de problemas matemáticos contextualizados o a la deducción de elementos de un contexto particular para el cálculo del área del triángulo, ni nada relacionado con el aprendizaje del cálculo del área de un triángulo con base rotada.

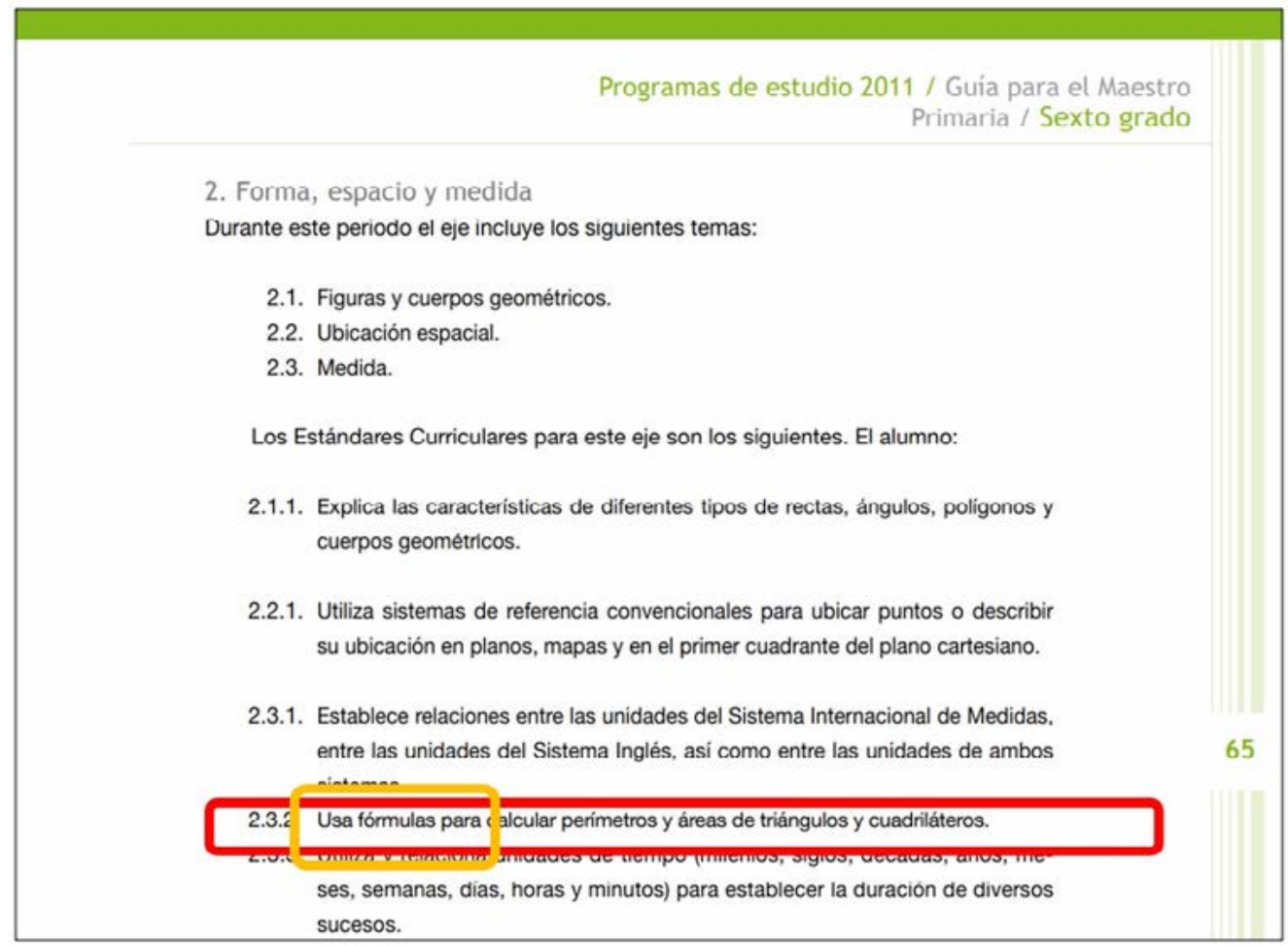

Figura 3. Estándar curricular al que se alinea la especificación del ítem PMA01 de la prueba de Matemáticas de primaria del PLANEA ELCE 2015.

De igual forma, los expertos analizaron los libros de texto del maestro como los del alumno para poder diseñar la genealogía curricular de cada uno de los ítems de la prueba en estudio. Se encontró que el ítem PMA01 se encuentra asociado especialmente con las intenciones didácticas 1 y 2 del contenido 5.3.6. del libro de texto del alumno de $5^{\circ}$ de primaria. En la figura 4, puede observarse de forma resumida los modelos de enseñanza de las intenciones didácticas en las que se encontró mayor alineación con el ítem PMA01 y su especificación. 

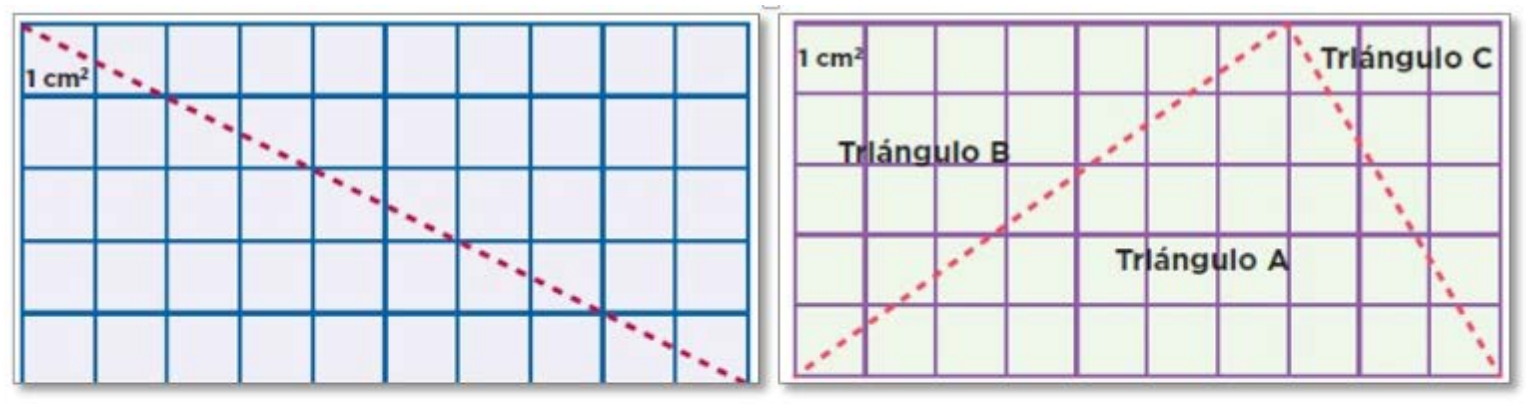

Modelo del proceso de enseñanza de la intención didáctica 1: a) En parejas leer las actividades a realizar, b) utilizar material de apoyo (pág. 209 del libro de texto), c) leer el primer problema, d) trazar una línea diagonal en el rectángulo (figura 1), e) leer la primera pregunta, f) obtener el área del rectángulo, g) responder el cuestionamiento, h) leer la segunda pregunta, i) superponer los triángulos obtenidos y responder cómo son, j) leer la tercer pregunta, $\mathrm{k}$ ) obtener el área de cada triangulo, l) responder la pregunta, $\mathrm{m}$ ) leer la cuarta pregunta, $\mathrm{n}$ ) describir como se obtiene el área de un triángulo, o) leer segundo problema, p) trazar dos rectas como lo indica la figura y recortar, q) superponer los triángulos y determinar el área de cada uno, y r) responder cuál fue el área de cada triangulo.
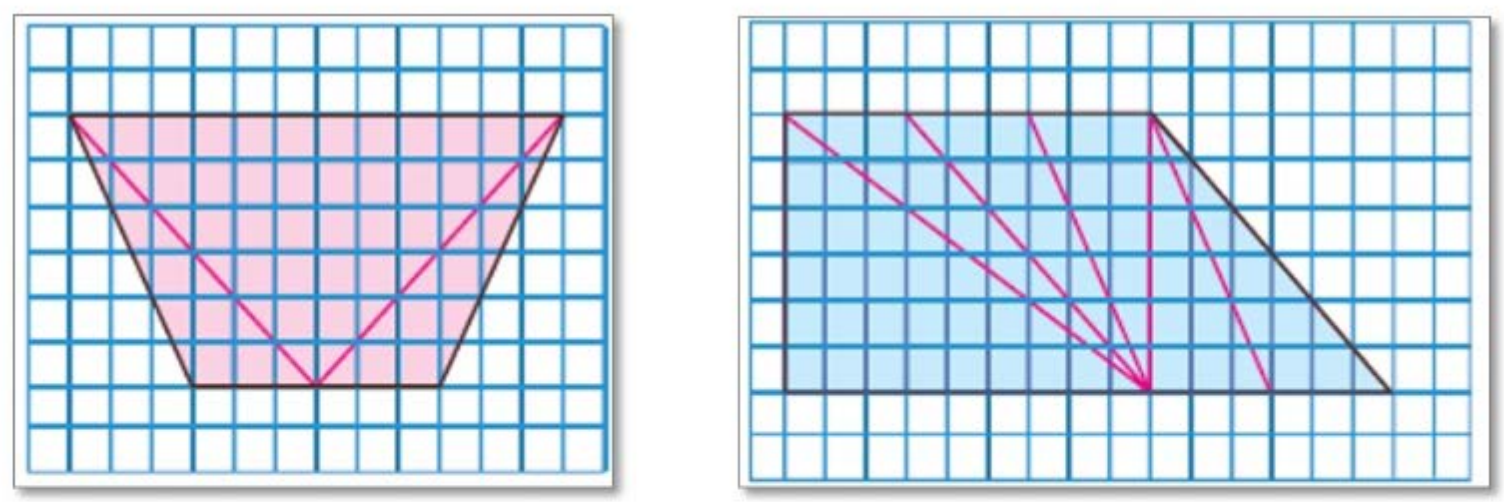

Modelo del proceso de enseñanza de la intención didáctica 2: a) Leer en parejas las actividades a realizar, b) observar imagen que contienen las figuras, c) calcular el área de cada triangulo y de la figura que los contiene, d) leer la primera pregunta, e) responder cómo son la base y la altura de cada uno de los triángulos que forman el romboide, f) responder cómo son las áreas de tales triángulos, g) responder cómo son la base y la altura de cada uno de los triángulos que forman el trapecio, h) responder cómo son las áreas de tales triángulos, i) escribir conclusiones, j) formar equipos para realizar la segunda actividad, y k) calcular las áreas de cada triángulo y las áreas de las figuras completas que se muestran en las ilustraciones.

Figura 4. Modelos de enseñanza de las Intenciones didácticas 1 y 2 del contenido 5.3 .6 de $5^{\circ}$ de primaria. 


\section{Problemas de sesgo}

En cuanto a los resultados de la evaluación de los ítems en lo referente a los problemas de sesgo identificados, se puede decir que, el haber complementado el análisis con el panel de expertos y protocolos verbales con estudiantes ayudó a obtener videncias convergentes que permitieron tener mayor certeza de las hipótesis planteadas. En la figura 2, correspondiente al ítem PMA01, se observa la convergencia de los resultados de los dos métodos utilizados. En especial nótese el contraste entre las hipótesis de varianza irrelevante y sesgo con las verbalizaciones de uno de los participantes. En síntesis, fueron tres los principales problemas de diseño y sesgo que presenta el ítem PMA01: a) problemas de inclusión poblacional, b) definición imprecisa del constructo (referente a la alineación de este), y c) problemas de comprensibilidad de la base del ítem.

En resumen, durante el análisis cognitivo, los expertos detectaron que 12 ítems presentaron problemas de sesgo, correspondiente al $24 \%$ del total de ítems de la prueba. Los problemas detectados están relacionados con (1) tamaño inadecuado de los elementos del ítem, (2) baja calidad visual de los elementos del ítem, (3) uso de conceptos con nivel bajo de inclusión de nivel socioeconómico y (4) uso de conceptos asociados con grupos, culturas o lugares particulares. Los problemas de sesgo mencionados pueden ocasionar que un grupo minoritario o en condiciones de vulnerabilidad (por ejemplo, alumnos con debilidad visual) tengan problemas para contestar adecuadamente los ítems.

Otro buen ejemplo de los ítems de la prueba identificado con problemas de sesgo fue el PMA14 (figura 5). El problema particular de dicho ítem tiene que ver especialmente con el uso de letras pequeñas y borrosas, dificultando la tarea de contestar el ítem a las personas con debilidad visual. Durante el laboratorio cognitivo los sustentantes tuvieron que acercarse a la prueba para leer las letras de la gráfica; por unanimidad, los 8 estudiantes participantes en los protocolos verbales manifestaron que las letras eran muy pequeñas. Especialmente, perdieron tiempo descifrando las palabras e inclinaron la cabeza a la izquierda para leer la señalización "Cantidad de alumnos". 
La maestra de segundo grado preguntó a sus alumnos, cuáles eran sus juguetes favoritos y con los datos obtenidos elaboró la siguiente gráfica.

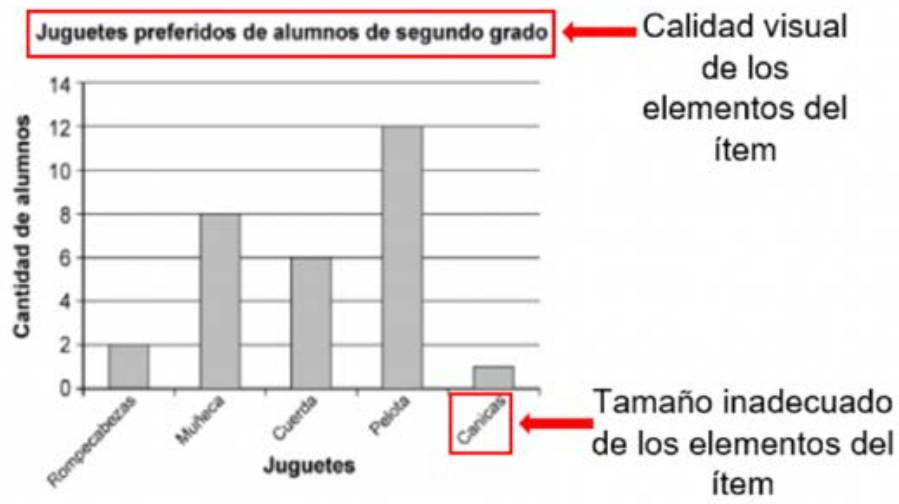

¿Cuántos alumnos tiene el grupo de segundo grado?
A) 5
B) 12
C) 28
D) 29

Figura 5. Problemas de sego presentes en el ítem PMA14.

\section{Problemas de diseño}

Por su parte, 31 ítems (62) de la prueba fueron detectados por el panel de expertos con problemas de diseño. Los ítems que clasificados en dicho rubro presentaron problemas relacionados con (1) falta de comprensibilidad total o parcial de las instrucciones, (2) base del ítem poco clara o ambigua, (3) uso ambiguo de términos y conceptos en la base del reactivo, (4) desorganización lógica de las ideas de la base del ítem y (5) elementos complementarios del ítem que ocasionan procesos de distracción en los sustentantes.

En particular, un claro ejemplo del rubro relacionado con los problemas de diseño es el presentado por el ítem PMB08 (figura 6), ya que dicho ítem cuenta con un polígono irregular donde se incluyen elementos de sombreado y punteado que hacen énfasis en su relleno (área). Durante el laboratorio cognitivo los sustentantes manifestaron que el sombreado de la figura y los puntos (que señalaron como abolladuras, puntos, marcas) los hacían pensar que se les solicitaba obtener el área; por lo que tuvieron que regresar a las indicaciones, hasta por más de una ocasión, para asegurar la comprensión de la tarea solicitada. Algunos sustentantes invirtieron tiempo en encontrarle forma a la figura (pájaro, nave, entre otras), perdiendo tiempo valioso para la realización de la prueba. 
Se requiere pintar el contorno de la siguiente figura geométrica. ¿Cuántos metros habrá que pintar?

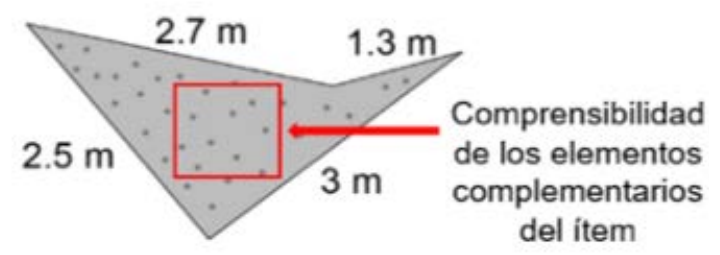
A) 9.5 metros
B) 8.2 metros
C) 5.7 metros
D) 3.75 metros

Figura 6. Problemas de diseño presentes en el ítem PMB08.

\section{Conclusiones}

A modo de conclusión, se puede decir que se logró con éxito la evaluación del diseño universal de los ítems de la prueba de Matemáticas de primaria (06) del PLANEA ELCE 2015, al identificar, con base en evidencias convergentes resultantes del panel de expertos y de los protocolos verbales con estudiantes, que el $98 \%$ de los ítems de la prueba presentan problemas asociados a los elementos que componen el MEDU, propuesto por Thompson et al. (2002). También, se puede decir que fue un acierto el seguir las sugerencias de especialistas en el campo de la medición (Haladyna et al., 2002; Ercikan et al., 2010; Johnstone, 2003) en cuanto a complementar la implementación del MEDU con el uso de métodos cognitivos para identificar evidencias convergentes y causales de varianza irrelevante del constructo originada por problemas de diseño, alineación al constructo y sesgos culturales de los ítems de las pruebas en análisis.

Realizar estudios que aporten evidencias de validez y equidad para mejorar de la calidad técnica de las pruebas es una actividad obligada para los desarrolladores y los tomadores de decisiones, en especial, para que las pruebas cuenten con las evidencias 
teóricas y empíricas que fundamenten las interpretaciones, consecuencias y usos de resultados de forma justa y ética en los distintos contextos y procesos de aplicación (AERA, APA y NCME, 2014; Messick, 1989). En conclusión, se puede decir que se logró recabar información para que los desarrolladores de las evaluaciones nacionales mejoren sus procesos de diseño y los tomadores de decisiones del Sistema Educativo Nacional (SEN) puedan interpretar de forma más justa y correcta los resultados del PLANEA ELCE. 


\section{Referencias}

American Educational Research Association (AERA), American Psychological Association (APA), \& National Council on Measurement in Education (NCME). (2014). Standards for Educational and Psychological Testing. Washington, D. C.: American Educational Research Association.

Anderson, D., Lai, C., Alonzo, J., \& Tindal, G. (2011). Examining a Grade-Level Math CBM Designed for Persistently Low-Performing Students. Educational Assessment, 16(1),15-34.

Brown, J., \& Burton, R. (1978). Diagnostic models for procedural bugs in basic mathematical skills. Cognitive Science, 2, 155-192.

Chen, Y., \& Macdonald, G. (2011). Validating Cognitive Sources of Mathematics Item Difficulty: Application of the LLTM to Fraction Conceptual Items. Psychological Assessment, 7, 74-93.

Dolan, R.P., Hall, T.E., Banerjee, M., Chun, E., \& Strangman, N. (2005). Applying principles of universal design to test delivery: The effect of computer-based read-aloud on test performance of high school students with learning disabilities. Journal of Technology, Learning, and Assessment, 3(7).

Ercikan, K., Arim, R., Law, D., Domene, J., Gagnon, F., \& Lacroix, S. (2010). Application of think aloud protocols for examining and confirming sources of differential item functioning identified by expert reviews. Educational Measurement: Issues and Practice, 29(2), 24-35.

Ericsson, K.A., \& Simon, H.A. (1984). Protocol analysis: verbal reports as data. Cambridge: MIT Press.

Ericsson, K.A., \& Simon, H.A. (1993). Protocol Analysis: Verbal Reports as Data. Cambridge, MA: MIT Press.

Gierl, M. J., \& Lai, H. (2018). Using Automatic Item Generation to Create Solutions and Rationales for Computerized Formative Testing. Applied Psychological Measurement, 42(1), 42-57. 
Gierl, M., Leighton, J., Changjiang, W., Jiawen, Z., Rebecca, G., \& Tan, A. (2009). Validating Cognitive Models of Task Performance in Algebra on the SAT. Research Report 2009-3. New York: College Board.

Gobierno Federal (2013). Decreto por el que se expide la Ley del Instituto Nacional para la Evaluación de la Educación. Diario Oficial de la Federación, DOF 11-09-13. Recuperado de http://www.dof.gob.mx/nota_detalle. php?codigo $=5313842 \&$ fecha $=11 / 09 / 2013$

Haladyna, T., Downing, S.M., \& Rodríguez, M.C. (2002). A review of multiple-choice item writing guidelines for classroom assessment. Applied Measurement in Education, 15(3), 309-334.

Instituto Nacional para la Evaluación de la Educación (INEE). (2015). Plan Nacional para la Evaluación de los Aprendizajes (PLANEA). México: INEE. Recuperado de http:// planea.sep.gob.mx/content/general/docs/2015/PlaneaDocumentoRector.pdf

Instituto Nacional para la Evaluación de la Educación (INEE). (2017). Criterios técnicos para el desarrollo, uso y mantenimiento de instrumentos de evaluación. México: INEE.

Instituto Nacional para la Evaluación de la Educación (INEE). (2018). Plan Nacional para la Evaluación de los Aprendizajes (PLANEA). México: INEE.

Johnstone, C. (2003). Improving validity of large-scale tests: Universal design and student performance (Technical Report 37). Minneapolis: National Center on Educational Outcomes.

Ketterlin-Geller, L.R. (2005). Knowing what all students know: Procedures for developing universally designed assessments. Journal of Technology, Learning, and Assessment. 4(1).

Leighton, J.P. (2004). Avoiding Misconception, Misuse, and Missed Opportunities: The Collection of Verbal Reports in Educational Achievement Testing. Educational Measurement: Issues and Practice, 23(4), 6-15.

Leighton, J.P. (2017). Using think-aloud interviews and cognitive labs in educational research. New York: Oxford University Press. 
Leighton, J., \& Gierl,M. (2007).Verbal Reports as Data for Cognitive Diagnostic Assessment. En J. Leighton, \& M. Gierl (Eds.), Cognitive Diagnostic Assessment for Education (pp. 146-172). USA: Cambridge University Press.

Mace, R. (1985). Universal Design, Barrier Free Environments for Everyone. Designers West, 33(1), 147-152.

Ma, L. Çetin, E., \& Green, K. (2009). Cognitive assessment in Mathematics with the Least Squares Distance Method. Congreso anual de la AERA 2009, San Diego.

Martínez-Rizo, F. (Coord.). (2015). Las pruebas ENLACE y EXCALE. Un estudio de validación. México: INEE.

Messick, S. (1989). Validity. En R.L. Linn (Ed.), Educational measurement (pp. 13-103). New York: Macmillan.

Nichols, P. D., Kobrin, J.L., Lai, M., \& Koepfler, J. (2016). The role of theories of learning and cognition in assessment design and development. En A.A. Rupp, \& J.P. Leighton (Eds.), The handbook of cognition and assessment: Frameworks, methodologies, and applications (pp. 297-327). Chichester, England:Wiley-Blackwell.

Nielsen, J. (1994). Estimating the number of subjects needed for a thinking aloud test. International Journal of Human-Computer Studies, 41, 385-397.

Pérez-Morán, J.C. (2014). Análisis del aspecto sustantivo de la validez de constructo de una prueba de habilidades cuantitativas. Tesis doctoral. Universidad Autónoma de Baja California, Baja California, México.

Pérez-Morán, J.C., Larrazolo, N., Backhoff, E., \& Guaner, R. (2015). Análisis de la estructura cognitiva del área de habilidades cuantitativas del EXHCOBA mediante el modelo LLTM de Fisher. Revista Internacional de Educación y Aprendizaje, 3(1), 25-38.

Pérez-Morán, J.C., Rojas, G., \& Vázquez-Lira, R. (Coords.). (2018). Análisis de validez y del diagnóstico cognitivo de las pruebas de Matemáticas de primaria (06) y secundaria (09) de PLANEA ELCE 2015. Reporte técnico. México: INEE.

Ravela, P., Arregui, P., Valverde, G., Wolfe, R., Ferrer G., Martínez Rizo, F., Aylwin, M., \&Wolff, L. (Eds.). (2008). Las evaluaciones educativas que América Latina necesita. Santiago: PREAL. 
Revuelta, J., \& Ponsoda, V. (1998). Un test adaptativo informatizado de análisis lógico basado en la generación automática de ítems. Psicothema, 10, 753-760.

Romero, S., Ponsoda, V., \& Ximénez, C. (2008). Análisis de un test de aritmética mediante el modelo logístico lineal de rasgo latente 1. Revista Latinoamericana de Psicología, 40, 85-95.

Rupp, A., Templin, J., \& Henson, R. A. (2010). Diagnostic assessment: Theory, methods, and applications. New York: Guilford.

Smith-Castro, V., \& Molina, M. (2011). La entrevista cognitiva: Guía para su aplicación en la evaluación y mejoramiento de instrumentos de papel y lápiz. Cuaderno metodológico, 5. Recuperado de https://www.academia.edu/2175997/Entrevista_ Cognitiva_2011_

Snow, R., \& Lohman, D. (1989). Implications of cognitive psychology for educational measurement. In R.L. Linn (Ed.), Educational measurement (pp. 263-331). New York: Macmillan.

Sternberg, R. (1977). Intelligence, information processing, and analogical reasoning: The componential analysis of human abilities. Oxford: Lawrence Erlbaum.

Thompson, S., Johnstone, C., \& Thurlow, M. (2002). Universal design applied to large scale assessments (Synthesis Report 44). Minneapolis, MN: National Center on Educational Outcomes.

You, X., Li, M., Zhang, D., \& Liu, H. (2018). Application of a Learning Diagnosis System in Chinese Classrooms. Applied Psychological Measurement, 42(1), 89-94. 
Segunda parte:

Educación superior 


\section{Capítulo 6}

\section{Relación Universidad-desarrollo tecnológico en el marco de la sociedad y la economía del conocimiento ${ }^{1}$}

Rodolfo García-Galván y Juan Carlos Rodríguez Macías

En la búsqueda de una comprensión más profunda de los roles de la Universidad dentro de la complejidad de la sociedad y economía del conocimiento, es indispensable una discusión teórica y conceptual de las categorías y variables que están implícitas en el fenómeno. Para no andar deambulando, es preciso buscar la simplicidad dentro de la complejidad; esto es, en las páginas que integran este documento haremos el intento por rescatar los principales conceptos y sus relaciones que aparecen cuando acudimos a los textos que abordan las cuestiones del conocimiento. En efecto, para entender, explicar y tratar de vislumbrar escenarios a futuro, se requiere una plataforma teóricoconceptual consistente y fiable.

La estructura sería endeble si no se considera una crítica a la disolución clásica de la dicotomía ciencia-tecnología, si se sigue pensando que el conocimiento realmente es un bien público puro, que las universidades son instituciones básicamente para la formación de recursos humanos, y que todavía entre sus objetivos están el investigar y diseminar el conocimiento (derivado de los proyectos de investigación) de forma desinteresada, que

1 Una versión corta y preliminar de este documento, fue presentada como ponencia, en el 3er Congreso Internacional de Investigación en Ciencias Económico Administrativas "Estrategias innovadoras: afrontando los retos de la economía global", realizado en Pachuca, Hidalgo los días 14-16 de octubre de 2015, en la Universidad Autónoma del Estado de Hidalgo. 
el crecimiento exponencial del conocimiento universitario en automático resolverá los grandes y complejos problemas de las sociedades y economías de nuestro tiempo. Las consecuencias de no entender bien las relaciones entre las variables pueden conducir a cometer errores serios en el diseño de políticas tecnocientíficas, de investigación y de la administración-gestión de las organizaciones del conocimiento como las universidades.

Aunque varios modelos o esquemas explicativos asumen que las universidades son un actor esencial (y quizá de liderazgo) en la dinámica de la economía basada en el conocimiento, éstas no siempre cuentan con los recursos humanos, materiales y financieros para que eso realmente suceda. Por lo tanto, en el trabajo también se llama la atención sobre los requerimientos que deben cubrirse para que la Universidad sea un actor verdadero y relevante.

Así, se establece como objetivo emprender un análisis crítico y reconstructivo de las categorías (y las relaciones entre éstas) que forman la base de la discusión de los asuntos de la economía-sociedad del conocimiento, en la cual sobresale el vínculo Universidad-desarrollo tecnológico y socioeconómico. De esta manera, se propone un reacomodo de conceptos y relaciones teóricas: tecnociencia como proceso integrado, en lugar de la dicotomía clásica ciencia y tecnología; conocimiento como bien semipúblico, en vez de considerarse como completamente libre o bien público puro; papel de las Tecnologías de la Información y la Comunicación (TIC) en el crecimiento exponencial de la producción y reproducción del conocimiento que no necesariamente equivale a una mayor calidad; y Universidad como actor, potencialmente, más relevante en la economía y sociedad del conocimiento.

En términos metodológicos, dado que se trata de una investigación pura de consecuencias teórico-conceptuales, la racionalidad procede de manera deductiva (se abordan categorías generales que son los fundamentos para un entendimiento más adecuado de lo que ha dado en llamarse sociedad-economía del conocimiento). Este proceso se apoya en la epistemología institucionalista que se deslinda de la racionalidad absoluta, del individualismo metodológico, en la cual caben los análisis comparativos y los problemas se estudian en relación al ambiente que los rodea. El institucionalismo 
también acredita como fuente de información fiable, los hallazgos y resultados de otros académicos de la misma disciplina, así como los resultados y las conclusiones a las que se llega en otras disciplinas del conocimiento.

El documento se estructura en dos apartados. El primero se dedica a considerar a la Universidad como generadora y diseminadora del conocimiento tecnocientífico, donde se aclara la relevancia de las categorías de tecnociencia y del conocimiento como bien económico y semipúblico; además, se reflexiona en cuanto a la producción e intercambio de conocimiento. En la segunda sección, se discute el desarrollo tecnológico y socioeconómico como función emergente de la Universidad; aquí también se resalta el papel de esta institución como actor central en la sociedad-economía del conocimiento. Por último, se encuentran las reflexiones finales.

\section{La Universidad como generadora y diseminadora del conocimiento tecnocientífico}

En este apartado se parte de dos cuestiones implícitas en el tratamiento de los asuntos relacionados con el conocimiento para, posteriormente, posicionar a la Universidad como una de las instituciones que más explota las potencialidades de las TIC para acelerar la producción-reproducción y accesibilidad al conocimiento, así como para ampliar o complementar los procesos de la enseñanza y el aprendizaje.

Primero, quizá sea tiempo de superar el estudio de la ciencia y la tecnología como procesos o actividades separadas (en las universidades, los centros de investigación y en las empresas intensivas en conocimiento), y dar paso a una situación simbiótica en la que no se pueda abordar de forma apropiada la una sin la otra; en tal caso, se retoma el concepto integradory unificado de"tecnociencia". Segundo, un análisis del conocimiento como bien económico no se entendería sin tomar en consideración sus características específicas que lo distinguen del resto de las mercancías. Esas propiedades influyen para que el conocimiento se llegue a entender como un bien semipúblico y que, por lo tanto, las fallas del mercado requieran de mecanismos alternativos para financiar o procurar las actividades de investigación tecnocientífica. En las siguientes páginas se profundiza en estos aspectos. 
¿Por qué hablar de tecnociencia o conocimiento tecnocientífico?

La dualidad ciencia-tecnología podría entenderse, en principio, cuando se justifica que un fenómeno tiene explicaciones lógicas y, debido a ello, se recurre a la ciencia (investigación básica) para buscar y encontrar las causas de ese fenómeno; una vez identificadas estas últimas se proponen modelos (de simulación) para refinar la relación de variables, en seguida, las variables pueden ser manipuladas para reproduciry controlar los fenómenos, en esta fase final ya nos encontramos en el terreno de lo aplicado (o de la tecnología). Sin embargo, la presente explicación aún no remarca el proceso continuo implícito al pasar de lo científico a lo tecnológico.

Se propone una categoría envolvente "tecnociencia" porque:

1. Permite seguir una innovación, basada en el conocimiento, desde su génesis hasta su aplicación en el ámbito productivo y su comercialización;

2. Es más general y evita sesgos hacia lo únicamente científico o tecnológico;

3. Las inversiones en el conocimiento para el desarrollo económico y social requieren hacerse en función del continuo, el fomento o impulso de la tecnociencia es más importante que la simple adopción y adaptación de tecnologías, hasta cierto punto ya estandarizadas;

4. Se asume que lo más básico de la ciencia puede tener múltiples aplicaciones, pero que sólo existen diferentes momentos en su desarrollo.

Del Río (1994) sostiene que la convergencia entre lo que, comúnmente, se ha denominado ciencia y lo que se ha dado en llamar tecnología se viene dando desde finales del siglo XVIII con la fundación de la Ecole Polytechnique y la reforma universitaria alemana, eventos que tuvieron como propósito que los científicos prepararan a los futuros ingenieros en conocimientos matemáticos, físicos y químicos que posteriormente aplicarían.

Debido a que la ciencia básica genera conocimientos que pueden usarse y convertirse en desarrollos tecnológicos que luego se traducen en bienes y servicios, y que satisfacen necesidades de la población; la ciencia y la tecnología moderna están 
entrelazadas y no puede desarrollarse una sin la otra. En este sentido, algo que resulta esencial, es que si bien ciencia y tecnología deben estar indisolublemente relacionadas, es necesario entender que difícilmente puede desarrollarse tecnología de punta sin la ciencia, es decir, sin la generación de nuevos conocimientos (Drucker, 2015).

Así, más que pensar en ciencia y tecnología como una dualidad, se trata de un mismo proceso que a lo mucho podría descomponerse en diferentes momentos; en sí, la "tecnociencia" podría entenderse como un proceso continuo que puede ir desde el conocimiento más abstracto hasta la industrialización y comercialización de las ideas (García-Galván, 2014) concretadas en productos, procesos, nuevos nichos de mercado, nuevos arreglos organizacionales o prácticas novedosas al interior de las mismas organizaciones. Aunque la dinámica también podría darse al revés. Asimismo, en el recorrido es importante considerar el rol que juegan los diferentes actores en cada fase.

El análisis económico de la organización de la investigación, en las esferas de la ciencia y la tecnología, pone énfasis en el hecho de que estamos tratando con un sistema interrelacionado compuesto por distintas actividades que pueden reforzarse y enriquecerse mutuamente, además, implica un sistema que se sostiene de una intrincada y delicada pieza de la maquinaria social e institucional (Dasgupta y David, 1994, pp. 489-490).

De forma más clara, cuatro elementos relevantes dan soporte a esta definición:

1. Muchas empresas de industrias basadas en el conocimiento sustentan su producción e intercambio en el conocimiento avanzado (Pavitt, 1984; Arora, Andrea y Gambardella, 2001; Gittelman, 2006). En la actualidad, este proceso ha ido más lejos que la mayor parte de las actividades económicas y sociales que se relacionan, directa o indirectamente, con el conocimiento. La propia dinámica del capitalismo actual se caracteriza por ciclos muy cortos de los productos, por lo que la producción de las empresas competitivas necesita acompañarse de una actividad innovativa intensa. Esta tendencia, conduce a las empresas a reconsiderar o redimensionar la importancia del conocimiento, asumiendo actividades de investigación internamente o vinculándose con las organizaciones especializadas como las universidades y los centros de investigación. 
2. De acuerdo con David y Foray (2002), cuando se trata de actividades relacionadas con el conocimiento nos encontramos ante escenarios tecnocientíficos en los que un potente entramado de artefactos de compleja elaboración permiten a los científicos ir cada vez más lejos, trascendiendo el estado actual del conocimiento. Simultáneamente, los avances que, tradicionalmente, podrían ubicarse en lo más básico o abstracto -pero acumulativos para la ciencia normal en la perspectiva kuniana- han provocado una gran ola de nuevos desarrollos tecnológicos.2 Ejemplos de este proceso son los avances registrados y sintetizados en la biotecnología, las TIC, la nanotecnología, la industria aeroespacial, las neurociencias, la robótica, entre otras áreas. Tales avances se han ido concretizando en poderosos instrumentos tecnocientíficos de observación y medición como el Gran Telescopio Milimétrico, el Gran Colisionador de Hadrones, el Gran Telescopio Canarias, el Observatorio de Rayos Gamma, las estaciones espaciales y, los diversos y potentes laboratorios multidisciplinarios con capacidad para diseñar y rediseñar nuevos organismos vivos.

3. El concepto de tecnociencia permite involucrar a otros actores de manera directa que a veces no se ven o no se quieren mirar, en términos de Latour (1992):

La tecnociencia tiene un interior porque tiene un exterior. Hay un rizo de retroalimentación positiva en esta inofensiva definición: cuanto más grande, más sólida, más pura sea la ciencia en el interior, más lejos tienen que ir los otros científicos al exterior. Es debido a esta retroalimentación

2 Las relaciones entre la ciencia y la tecnología también se caracterizan por fuertes complementariedades: por una parte, mejorando la base de información para las decisiones de la I\&D aplicada, una teoría científica mejora la efectividad con la cual los recursos dedicados al desarrollo tecnológico pueden ser mejor asignados entre las alternativas en competencia; por la otra, los avances tecnológicos (instrumentaciones) reducen el costo de la investigación básica y aplicada. Finalmente, se pueden identificar los vínculos que facilitan las transferencias y transposiciones del conocimiento entre los diversos campos (Foray, 2004, p. 57). 
que, si entramos en un laboratorio, no veremos ni relaciones públicas, ni políticas, ni problemas éticos, ni lucha de clases, ni abogados; veremos a la ciencia aislada de la sociedad. Pero este aislamiento existe sólo en la medida en que otros científicos se ocupen constantemente de reclutar inversores, de interesar y convencer a la gente. Los científicos puros son como polluelos desvalidos, mientras los adultos se afanan en construir el nido y alimentarles. (pp. 151-152) ${ }^{3}$

4. La expresión "la tecnociencia nos ayuda a resolver muchos problemas" queda mejor que si solo nos referimos a la ciencia o la tecnología por separado, ya que se trata de la fusión de dos poderosas herramientas que, si bien no representan per se las soluciones directas a todos los problemas, la mayoría de las respuestas a las encrucijadas que enfrenta la humanidad sí se apoyan en la ciencia para encontrar explicaciones y soluciones adecuadas. ${ }^{4} \mathrm{Al}$ respecto, un texto llamativo

3 Cuando los científicos y los ingenieros son exitosos al crear y recrear un ancho mundo interior, quiere decir que otros colegas están trabajando, en otros frentes, para lograr los mismos objetivos; cuando no tienen éxito significa que científicos e ingenieros se quedan solos en su camino. De este modo, cuando los científicos parecen totalmente independientes, rodeados de colegas que piensan en su ciencia de forma obsesiva, significa que son completamente dependientes, alineados con los intereses de muchas otras personas; $y$, por el contrario, si logran ser realmente independientes, no consiguen los recursos necesarios para equipar un laboratorio, ganarse la vida o reclutar a otro colega que pueda entender lo que están haciendo (Latour, 1992, p. 153).

4 Por ejemplo, cuando el ser humano se enfrenta a problemas complejos que pueden causar pérdida de cientos o miles de vidas de manera instantánea, es común que las sociedades recurran a la ciencia para, primero, explicarlos y luego tratar de pronosticarlos o controlarlos (por ejemplo, los maremotos o la intensidad inesperada de huracanes). Incluso, ante periodos prolongados de estancamiento económico o de crisis, se piensa que el conocimiento avanzado puede contribuir a la solución, al respecto esta nota es ilustrativa: “Una nación que dependa de otras para la obtención de sus nuevos conocimientos científicos básicos tendrá un lento progreso industrial y será débil en su posición competitiva en el comercio mundial, independiente de su destreza mecánica" (Bush, 1999, p. 112). 
e ilustrativo, sobre las bondades del conocimiento avanzado para la solución de diversos problemas en tiempos de paz y en la guerra, es el de Bush (1999) en el que se persuade al Presidente Roosevelt para que apoye con financiamiento público el desarrollo del conocimiento en todas sus etapas, argumentando que estas acciones conducirían a darle solución a muchos problemas conocidos (enfermedades, desempleo, desnutrición, pobreza, inseguridad nacional, subdesarrollo agrícola e industrial, etc.) y aún problemas por aparecer.

En suma, si se busca que el conocimiento avanzado generado, principalmente, en las organizaciones del conocimiento tenga un impacto más claro en el desarrollo económico y social, se tiene que pensar en fomentar la "tecnociencia" en toda su extensión, como un proceso simultáneo y equilibrado en todas sus etapas que evite los sesgos hacia uno de los extremos, de lo contrario, los objetivos y las metas buscadas podrían frustrarse. Así, cuando se piensa que el fomento a la investigación aplicada es una forma más adecuada para resolver los problemas más apremiantes, en realidad, se podrían estar minando las posibilidades futuras para resolver otros problemas.

\section{Peculiaridades del conocimiento como bien económico y semipúblico}

Los resultados de la investigación tecnocientífica conllevan ciertas propiedades que los distinguen de las demás mercancías, y éstas influyen en las decisiones de los empresarios de invertir o no en los proyectos de investigación. Las propiedades más sobresalientes del conocimiento como bien económico ${ }^{5}$ son: incertidumbre, inapropiabilidad absoluta, indivisibilidad, acumulatividad, no especificidad, retrasos frecuentes y costos elevados.

5 El término "información" es muy común en economía, pero, en la práctica, "información" significa conocimiento reducido y convertido en mensajes que fácilmente pueden ser comunicados a través de las decisiones de los agentes. La transformación del conocimiento en "información" es una condición necesaria para el intercambio del conocimiento como una mercancía. Además, la codificación del conocimiento es una etapa en el proceso de la reducción y la conversión, el cual posibilita la transmisión, la verificación, el almacenamiento y la reproducción de la "información" a los menores costos (Dasgupta y David, 1994, p. 493). 
Nelson (1959) establece que en el desarrollo científico y en la invención, existe incertidumbre y conforme nos acercamos al extremo de la ciencia básica hay mayor incertidumbre respecto a los resultados esperados y, por el contrario, a medida que nos aproximamos a las cuestiones aplicadas, la incertidumbre es menor; por lo tanto, en esta fase existe una probabilidad más alta de que un proyecto refleje los resultados o ganancias esperadas. Asimismo, Arrow (1962) supone que la incertidumbre sólo ocurre en las relaciones de producción. Los productores toman una decisión sobre los insumos en este momento, pero los productos no pueden pronosticarse por completo a partir de los insumos. Así, la producción de un bien bajo incertidumbre puede describirse entonces como la producción de un vector de opciones de bienes (p. 155).

En cuanto a la inapropiabilidad, Arrow (1962) también sostiene que ninguna cantidad de protección puede convertir algo tan intangible como la información (conocimiento tecnocientífico) en un bien completamente apropiable; el mismo uso en cualquier forma productiva, necesariamente lo revela, por lo menos en parte.

Para Pavitt (1984) y Teece (1988), el cambio técnico es en principio un proceso específico y acumulativo para las empresas y las organizaciones. Lo que éstas pueden hacer técnicamente en el futuro está condicionado por lo que han hecho. De forma paralela, distintas actividades centrales generan trayectorias tecnológicas divergentes que pueden explicarse por las especificidades sectoriales.

Sin embargo, Kay $(1988$, p. 283) señala que la no especificidad es relevante ya que gran parte de la actividad de Investigación y Desarrollo (I\&D) no es específica a un producto, puesto que una pieza particular de trabajo se puede traducir en una variedad de productos finales; además, la I\&D genera sinergias tecnológicas o economías de alcance. También, gran parte de la actividad de I\&D no es específica de una empresa debido a que genera externalidades y problemas en los derechos de propiedad. En cuanto a los retrasos, Kay menciona que, normalmente, un proyecto importante toma muchos años antes de que sea encuadrado en mercancías comerciales; dichos retrasos pueden retroalimentar a otros problemas como el peligro de perder la propiedad del conocimiento, el aumento de costos y la incertidumbre. 
Las propiedades hasta aquí señaladas, de alguna manera, influyen en las decisiones que toman las empresas a la hora de invertir en proyectos de investigación tecnocientífica; por lo tanto, una firma convencional sólo lleva a cabo una inversión cuando puede internalizar todos o la mayor parte de los beneficios probables de sus desembolsos, y dado que la investigación avanzada, normalmente otorga beneficios marginales sociales mayores a los beneficios privados, entonces, las empresas siempre se resistirán a producir este tipo de bienes. En este sentido, el mercado no resuelve la subinversión que existe para la producción de mercancías que generan grandes externalidades positivas como lo es el conocimiento.

Sin embargo, en la vida cotidiana, los individuos, las empresas y los gobiernos, adicional al consumo de los bienes privados, también disfrutan el consumo de los bienes públicos. Cuando Samuelson (1954, p. 387) reflexionó sobre los últimos, mencionó que estos bienes $\left(x_{n+1}, \ldots, x_{n+m}\right)$ son aquellos de los cuales todos disfrutan en común, en el sentido de que el consumo de cada individuo del bien no conduce a la sustracción del consumo de algún otro individuo de ese mismo bien. Así, el hecho de que se agreguen individuos al consumo del bien " $x$ " no implica una merma del bien. Además, como lo establecieron Dasgupta y David (1994) y Lundvall (2004), resulta muy costoso para los productores de estos bienes excluir de su consumo a los free riders.

Los bienes públicos puros (por ejemplo, un parque público) contienen dos características adicionales: la no exclusividad y la no rivalidad. En este tipo de bienes es muy difícil fijar o definir los derechos de propiedad, sus costos marginales de producción tienden a cero y no es posible excluir a nadie de su consumo. El mercado falla en proporcionar estos bienes y no puede dejarse al mecanismo de los precios que los asigne (Ayala, 1999).

Si el conocimiento es un bien público que puede accederse por cualquiera, no hay incentivos para que los agentes privados racionales inviertan en su producción. Si es menos costoso imitar que producir nuevo conocimiento, la tasa de retorno social sería mayor que la tasa de retorno privada, y los agentes privados invertirían muy poco (Lundvall, 2004, p. 23). 
En los trabajos de Dasgupta y David (1994), Stiglitz (1999), Lundvall (2004) y Foray (2004) se reconoció, con ciertos matices, que la producción y el consumo del conocimiento como bien económico cumple con las características que lo definen como bien público. Por ejemplo, Stiglitz (1999) menciona que el conocimiento de un teorema matemático satisface los atributos de la no rivalidad y la no exclusividad (si yo enseño a otro el teorema, yo continúo disfrutando de éste, al mismo tiempo que el otro lo hace, y por la misma demostración, una vez que yo publique el teorema, cualquiera puede disfrutarlo). De este modo, para Stiglitz (1999) y Foray (2004), la no rivalidad implica que hay un $\mathrm{CMg}=0$ de un disfrute adicional de los beneficios del conocimiento. No obstante, al precio de cero únicamente el conocimiento que pueda ser producido al costo de cero será producido.

Adicional a las dos propiedades (no rivalidad y no exclusividad) señaladas en la literatura de manera recurrente, Foray (2004) estableció que la acumulatividad es otra característica que le da el carácter de público al conocimiento. Al respecto, se puede decir que el conocimiento es acumulativo porque los nuevos hallazgos o los resultados de investigaciones que ahora se están desarrollando, o que se desarrollarán, dependen en gran medida del conocimiento que ya está disponible (la publicación y el acceso [libre] a los artículos académicos e industriales, a los capítulos de libros, a las obras completas y a los documentos técnicos de las patentes son un insumo indispensable para llevar a cabo actividades de investigación tecnocientífica). De tal forma que, entre mayor acceso se tenga a los resultados de investigaciones previas de frontera, mayor posibilidad habrá de producir conocimiento verdaderamente valioso.

Considerar al conocimiento como un bien público es una primera aproximación porque, de acuerdo con Lundvall (2004, pp. 24-25), la realidad es compleja y la mayor parte del conocimiento no es completamente público ni completamente privado. La base del conocimiento está fragmentada, y puede ilustrarse mejor si se considera que está constituida por un número de "piscinas" semipúblicas de las cuales su acceso es compartido regionalmente, profesionalmente y mediante la creación de redes. A medida que se incrementa la complejidad de los cimientos del conocimiento y la colaboración 
entre las organizaciones tiende a desarrollarse, es necesaria una mayor interacción para comprender y aprovechar mejor el conocimiento tácito.

Open \& public access es un nombre equivocado, por el hecho de que éste implica enormes inversiones en aprender antes de que la información tenga algún significado. Así, existen mucho menos "spillovers" (externalidades positivas) completamente disponibles de las que se asumen en la economía estándar, y por eso se requiere la formación o construcción de capacidades de absorción. De hecho, el know how es el tipo de conocimiento con el menor acceso público y, normalmente, se accede sólo por medio de la contratación de expertos, o por medio de la fusión de las organizaciones interesadas (Lundvall, 2004, pp. 26-27).

Aunque con mayor caución y cierta ambivalencia, Stiglitz (1999, pp. 309-310) también reconoce que, para adquirir y usar el conocimiento, los individuos tienen que haber gastado recursos, justo como los que ellos podrían haber gastado para obtener agua de un lago público. Sin embargo, que quizá haya costos significativos asociados con la transmisión del conocimiento de ningún modo afecta la naturaleza del bien público: los proveedores privados pueden proporcionar la transmisión por un cargo que refleje el CMg de la transmisión, mientras que el bien en sí se mantiene libre. Pero, debido a que los retornos de algunas formas del conocimiento en cierta medida puedan ser apropiados (existe algún grado de no exclusividad), el conocimiento es frecuentemente pensado como bien público impuro.

Es preciso reconocer que alcanzar un acceso exitoso a la mayor parte del conocimiento avanzado, de cualquier campo, disciplina o área, requiere la formación y el entrenamiento de ciertas habilidades y capacidades de lenguaje, de razonamiento abstracto y de pensamiento creativo; y la carencia de tales destrezas implicaría una ignorancia casi completa respecto al tópico en cuestión ${ }^{6}$.

6 Por ejemplo, la comprensión y la explicación de las leyes fundamentales de la biología molecular no es para legos o incluso aficionados. El verdadero uso, provechoso, de esa forma de conocimiento demanda recursos humanos altamente especializados que quizá hayan invertido una década en su formación profesional e investigativa como biólogos moleculares, antes de entender y explicar bien los procesos de este conocimiento tecnocientífico. 
Así, de acuerdo con Lundvall (2004, p. 27), muy poco conocimiento es "perfectamente público". Aún la información del know what puede ser imposible de acceder por aquellos que no están conectados a las telecomunicaciones adecuadas o a las redes sociales. El científico y otros tipos de conocimiento complejo puede ser perfectamente accesible en principio, pero para su acceso efectivo los usuarios tienen que invertir en la construcción de capacidades de absorción. El know how nunca es completamente transferible dado que la forma en la que una persona hace las cosas refleja la personalidad del individuo. Asimismo, poco conocimiento económicamente útil puede ser completamente privado en el largo plazo; los trucos del negocio son compartidos dentro de la profesión; el know how puede ser enseñado y aprendido en las interacciones entre el maestro y el aprendiz; el nuevo conocimiento tecnológico puede ser costoso para imitarse pero, cuando éste es más eficiente que el viejo, existen varias formas de obtenerlo7.

En suma, el conocimiento puede considerarse como bien económico cuasi-público; primero por sus características inherentes que lo hacen escurridizo para sus poseedores (incertidumbre, inapropiabilidad, indivisibilidad y acumulatividad); y luego, por las propiedades de no exclusividad y de no rivalidad. Pero, aunque en principio pueda accederse libremente, en realidad, su verdadero aprovechamiento (comprensión, recombinación, expansión) requiere la formación o construcción de habilidades y capacidades previas (casi siempre entrenamiento profesional institucionalizado). En este sentido, es más apropiado entender al conocimiento como un bien cuasi o semipúblico.

Otros elementos que abonan a esta consideración es que, actualmente, existen muchas empresas interesadas en la producción de conocimiento tecnocientífico del que obtienen o puede obtener cuantiosas ganancias, las denominadas industrias basadas en la ciencia; no obstante, en este terreno, el afán de lucro es lo que mueve a las firmas

$7 \quad$ La ingeniería de reversa, la biopiratería, la piratería del software y las extendidas actividades de los hackers informáticos son ejemplos de que la parte más privada del conocimiento tecnocientífico no se puede mantener por mucho tiempo. El espionaje inteligente conlleva un contraespionaje tanto o más inteligente. 
para producir y reproducir el conocimiento, por lo que vastos sectores quedan fuera del interés de las firmas más osadas en ese objetivo. Esta condición, conduce a considerar tres mecanismos esenciales para la inversión en el desarrollo de proyectos tecnocientíficos, de acuerdo con Dasgupta y David (1994), Foray (2004)ㄹ, y Stiglitz (1999), tenemos:

- Que el estado-gobierno se haga cargo de la producción del conocimiento con una dimensión más pública, dado que éste es necesario para la comprensión y la solución de muchos problemas de interés de las mayorías. Sin embargo, las agencias gubernamentales han demostrado ser ineficientes por problemas de asignación relacionados con la burocracia

- Mediante la formación de mercados tecnocientíficos y la asignación de derechos de propiedad intelectual (patentes), dejar al mercado exclusivamente la asignación de recursos para la tecnociencia. Pero, como se ha demostrado, el mercado falla y se lograría muy poca inversión en estas actividades de suma importancia. Sólo las industrias basadas en la ciencia lograrían inversiones suficientes

- Procuración o patrocinio por parte de empresas y del gobierno para que otras instituciones-organizaciones se encarguen del desarrollo de la tecnociencia, estas organizaciones están representadas por las universidades y los centros públicos de investigación. Para autores como Dasgupta y David (1994) y Antonelli (2008), este mecanismo logra resolver el problema de la falta de incentivos de la burocracia gubernamental y las restricciones buscadas por las empresas para no revelar o difundir oportunamente el conocimiento

La tendencia mundial actual indica que las políticas públicas diseñadas para la promoción de la tecnociencia, tienden a fomentar la consolidación de los derechos de propiedad intelectual, y la comercialización del conocimiento producido en las universidades y en los centros públicos de investigación. Se piensa que, únicamente de esa

8 Los trabajos de Dasgupta y David (1994) y Foray (2004), retomando las aportaciones de Pigou, se refieren a este sistema de financiamiento como las 3P (procuramiento, propiedad y patrocinio), de acuerdo con el proveedor o productor (generador) preponderante. 
manera, se puede alcanzar una mayor interacción academia-industria, y que entonces las aportaciones de las instituciones-organizaciones del conocimiento al desarrollo económico y social, será mayor.

\section{Aceleración de la producción y reproducción del conocimiento por las TIC}

En la perspectiva de Foray (2004, p. 35), asistimos a la era del rápido crecimiento del conocimiento y de los flujos de éste. Ello se ve reflejado en el aumento en el número de agentes capaces de producir, difundir y absorber el conocimiento, y una caída sustancial en los costos marginales del procesamiento de la información y el conocimiento. Se acelera la velocidad a la cual el conocimiento es creado y acumulado ${ }^{9}$, reflejando la intensificación de una fase de progreso científico y tecnológico.

Para la producción de conocimiento, en general, se puede hablar de dos maneras de realizarla, por un lado, en los quehaceres cotidianos conforme la división y la especialización del trabajo se hacen más acentuadas, se vuelve probable la posibilidad de que surjan innovaciones por el learning by doing o incluso por el learning by using. Sin embargo, este tipo de conocimiento es más informal y con mayor nivel de tacidad. Por el otro lado, se encuentra el conocimiento que se genera o se produce en los espacios específicos para tal fin (fuera de las fábricas o de las actividades económicas convencionales), se trata de las actividades de investigación que se llevan a cabo en las universidades, en los centros de investigación, y también en las firmas basadas en la tecnociencia. Digamos que, en esta segunda forma, se formaliza y fomenta institucionalmente la producción de conocimiento avanzado.

9 Mientras que la humanidad tardó1750 años para que la cantidad de conocimiento se duplicara por primera vez; en los inicios del siglo XXI existe la posibilidad de que el conocimiento se duplique cada 5 años, y se estima que hacia el 2020 la cantidad de conocimiento se duplicará cada 73 días (Brunner, 2003 como se citó en Rodríguez Ponce, 2009, p. 823). Mención aparte, merece la discusión sobre la calidad y fiabilidad del nuevo conocimiento. 
Una diferencia notable entre la producción de conocimiento informal y de conocimiento sistematizado o formalizado, es la posibilidad de codificación que se puede alcanzar. Así, el conocimiento informal o tácito conlleva un mayor grado de dificultad y el costo para lograr su codificación (ponerlo en un manual, en un artículo o en una patente) podría ser muy alto; en comparación, la producción sistematizada, desde un principio, se plantea la codificación que, desde la perspectiva de Foray (2004), capacita a los agentes para desarrollar un número de operaciones a un muy bajo costo marginal. Por ejemplo, debido a que la codificación del conocimiento es fácil de reproducir, la cantidad de copias puede ser multiplicada.

Aunque el costo de producción de la primera copia o del primer borrador (básicamente el costo de la codificación) pueda ser muy alto, el costo de las copias subsecuentes decrecerá rápidamente, por lo tanto, el conocimiento codificado puede ser reproducido y diseminado al infinito. En este sentido, es claro que la codificación que cambia las condiciones de circulación del conocimiento constituye la conditio sine qua non los avances de la tecnología de la información pueden servir para mejorar la circulación hasta que ésta sea casi perfecta; en efecto, la codificación es una condición necesaria para la rápida producción, reproducción y acumulación del conocimiento (Foray, 2004).

Otra de las grandes aportaciones de las TIC es que provocaron que los costos de la codificación disminuyeran drásticamente. Además, estas nuevas TIC han tenido un impacto decisivo para expandir sustancialmente los campos susceptibles de codificar, y simultáneamente, han incrementado la rentabilidad de la codificación ${ }^{10}$ (Foray, 2004).

Los avances notables en las telecomunicaciones han ocasionado que los costos de la comunicación hayan descendido dramáticamente, y han hecho posibleel desarrollo de redes de comunicación en regiones del mundo donde esto llevaría décadas con las viejas

10 Por ejemplo, las TIC permiten enormes ganancias de productividad, especialmente en el procesamiento, el almacenaje y el intercambio de información. Entonces, la codificación del conocimiento y las nuevas TIC están en el corazón del advenimiento de la economía basada en el conocimiento (Foray, 2004). 
tecnologías. Dehecho, se está comprobando que la internet puedeser una herramienta de inmenso poder para compartir el conocimiento en todas sus dimensiones (Stiglitz, 1999).

La cada vez mayor codificación del conocimiento ha provocado a la par una mayor circulación de éste por medio de la utilización de las nuevas TIC, ahora mucho más personas pueden tener acceso a enormes repositorios de información y de conocimiento codificado. Desde esta perspectiva es factible pensar en un uso adecuado de las TIC para acelerar el aprendizaje mediante la educación virtual o en línea.

Las nuevas TIC, también, permiten a los usuarios acceder y trabajar sobre sistemas de conocimiento a distancia, tomar cursos de aprendizaje a distancia dentro de una estructura de relaciones interactivas profesor-estudiante, y tener grandes cantidades de información disponible en sus escritorios (es decir, como tener una biblioteca universal a muy bajo costo) (Foray, 2004, p. 28). De esta forma, la utilización de las TIC acelera notablemente la disposición del conocimiento y lo hace más público. ${ }^{11}$

Conforme la dupla, nuevas y poderosas TIC-mayor codificación del conocimiento, se ha venido consolidando, paralelamente, la función de la investigación en las universidades, así como en las instituciones de educación superior se ha extendido y ha logrado cierto nivel de consolidación; esto ha sucedido por dos razones fundamentales: 1. Las universidades con sus institutos de investigación y las actividades relacionadas en las Facultades, así como los centros de investigación (públicos y privados), son de los actores, dentro de la sociedad y economía basada en el conocimiento, que más han adoptado y adaptado las TIC para desempeñar sus actividades de docencia, investigación y, ahora también, de desarrollo económico y social. Por ejemplo, y de acuerdo con la noción de Dasgupta y David (1994) sobre la república de la ciencia, las TIC han permitido un crecimiento exponencial en la producción, la reproducción y la diseminación del conocimiento (actividades esencialmente llevadas a cabo en las universidades y los centros de investigación).

2. La cada vez mayor codificación del conocimiento ha permitido un mayor desarrollo

11 En términos de Stiglitz (1999), en la actualidad, se reconoce cada vez más que el conocimiento no sólo es un bien público sino que es un bien público global o internacional; y también, se reconoce que el conocimiento es central para alcanzar un desarrollo exitoso. 
de lo que es susceptible de comercialización. Por ejemplo, el conocimiento formal explícito en un documento técnico como una patente, ha dado lugar a la expansión de los derechos de propiedad intelectual. En consecuencia, ahora una universidad puede reclamar regalías por el uso de una patente. Esta situación ha provocado una percepción generalizada de que las universidades no sólo son capaces de generar ciencia básica, sino que tienen las capacidades y habilidades suficientes para generar conocimiento tecnológico. De este modo, universidades y centros de investigación son vistos como agentes que pueden transferir tecnología y como consultores, reales y en potencia, para las empresas y los gobiernos.

Adicional a lo anterior, Antonelli (2008) y Dasgupta y David (1994) sostienen que los mecanismos de gobernación de las universidades (libertad de investigación, primacía por la difusión, comunalismo del conocimiento, formas propias de contratación y de promoción) superan lo que se hace en la burocracia del gobierno y en las empresas ${ }^{12}$ (donde suelen presentarse muchos problemas de agencia-principal y de largos retrasos en la difusión del conocimiento). Esto lleva a que la universidad se perciba como el mejor lugar para realizar investigación fundamental y aplicada, y que, adicionalmente, contribuya, en gran medida, al fortalecimiento de lo que Foray (2004) denomina infratecnología (conjuntos de métodos, bases de datos científicos y de ingeniería, modelos, estándares de medidas y de calidad).

Sin embargo, el hecho de que estemos en medio de las $\mathrm{TIC}^{13}$, de la codificación y de las universidades funcionando como fábricas de conocimiento tecnocientífico, no significa que tengamos un acceso directo al conocimiento verdaderamente relevante,

12 Esto no excluye la posibilidad de que las empresas adopten la filosofía de las universidades, y que en algunos grandes centros de investigación, sobre todo de las grandes firmas, se emulen las formas de la universidad, a tal grado que podría hablarse de empresas como protouniversidades (García-Galván, 2009).

13 La plena realización del potencial de las TIC ha sido un proceso que ha tomado mucho tiempo y ha sido objeto de ajustes contingentes por el lado técnico, el organizacional y el institucional (Foray 2004, p. 32). 
ello requiere de entrenamiento, de formación o construcción de capacidades y habilidades intelectuales para el uso adecuado del conocimiento; éstas últimas, en buena medida, se pueden obtener a través de las universidades, por eso la importancia de esta institución en el seno de la economía basada en el conocimiento.

Pese al notable crecimiento de la producción y reproducción del conocimiento, su insuficiencia se refleja en que muchas veces, se tiene la sensación de que muchos problemas fundamentales se mantienen lejos de su resolución, estos problemas pueden ser de distinta índole, importancia y complejidad; por ejemplo, el cambio climático, la escasez generalizada de agua, grandes problemas de salud pública como la obesidad, las enfermedades mentales y las pandemias como el SIDA y la diabetes, tasas elevadas de desempleo de los jóvenes, bajo crecimiento económico, baja cobertura y calidad educativa, delincuencia organizada, corrupción, etc.

No obstante, Stiglitz (1999) indicó que mucho del conocimiento requerido para lograr un desarrollo exitoso no se encuentra patentado o no está protegido por derechos de propiedad, no es el tipo de conocimiento del que se desprendan productos o procesos. Más bien, es de otro tipo que es igual de fundamental y que contribuye a responder estos ejemplos de preguntas: cómo organizar a las empresas, cómo organizar a las sociedades y cómo vivir de manera más saludable sin comprometer al medio ambiente. Parte de este conocimiento, aporta elementos para el mejor diseño de políticas públicas y gubernamentales que promuevan el crecimiento.

La vasta lista de problemas sin resolver nos lleva a pensar que es necesario aumentar la producción y reproducción de conocimiento aplicado sin descuidar los fundamentos teóricos y básicos, como ya lo reconocían académicos como Nelson (1959) y Bush (1999). Al final, los distintos actores sociales y económicos fincan en la ciencia (tecnociencia) sus esperanzas de que los principales problemas que los aquejan pronto se resolverán. Particularmente, en los países en desarrollo, un conocimiento más fiable y de mayor cuantía es urgente e indispensable para superar problemáticas que en las sociedades avanzadas ya han sido resueltas. 
A la condición de una mayor cantidad y calidad del conocimiento tecnocientífico, es necesario un acceso más amplio a los activos del conocimiento. Para llevar adelante estos dos propósitos, el papel de las organizaciones del conocimiento es relevante, porque son las plataformas naturales para la formación y construcción de habilidades tecnocientíficas requeridas para desenvolverse en el contexto de la economía y sociedad del conocimiento.

\section{Desarrollo tecnológico y socioeconómico como función emergente de la Universidad}

Desde el surgimiento de la Universidad, como institución de la modernidad, su función primordial fue la enseñanza o la transmisión de conocimientos de personas expertas a los alumnos. Desde ese momento, los aportes principales de esta institución a la sociedad y a la economía, se daban a través de la formación de habilidades y capacidades de conocimiento (transmitido-aprendido) para resolver problemas (más allá de que los principales esfuerzos se dirigieran a los asuntos científicos, artísticos, estéticos, filosóficos); grosso modo, estas actividades podrían encuadrarse en lo que actualmente se conoce como formación de capital humano, ${ }^{14}$ que sigue siendo una función fundamental de la Universidad.

De acuerdo con Etzkowitz (2003) y Azagra (2004), una de las grandes transiciones de la Universidad, fue cuando se le agregó la función de la investigación; es decir, el momento en que se le exige realizar actividades concernientes a la generación o producción de conocimientos avanzados, con el objetivo explícito de resolver diversos problemas del entorno; aunque, sin un afán de lucro y con financiamiento público mayoritario. El hecho de que la investigación se haya consolidado como una función primordial de

14 La concepción original de capital implica la producción de un bien para producir más bienes en el futuro. Extrapolando este concepto al capital humano, implicaría la formación de profesionistas para que éstos formen o preparen a más profesionistas en el futuro, pero también para que formen y preparen a la sociedad en general para producir más y mejores bienes de toda índole; e incluso para ejercer liderazgos sociales y económicos más avanzados. 
las universidades ${ }^{15}$ no estuvo exenta de conflictos de interés entre los propios miembros de las universidades y los actores externos.

Reconociendo a las universidades como los espacios idóneos para realizar la investigación y, de esa manera, producir y diseminar el conocimiento. Cuando el debate se centraba en cómo debería hacerse la búsqueda del conocimiento, había un sistema de reglas que regían a la ciencia abierta, las más importantes son: la regla de la prioridad, de la diseminación abierta y la regla de la autonomía. Se supone que con estos lineamientos se resolvió el denominado trade-off del conocimiento (entre la necesidad de crear incentivos para la producción del conocimiento científico y la necesidad de potencializar su diseminación con el fin de fomentar la producción futura) (Dasgupta y David, 1994; Rossi, 2008).

La generación de conocimiento, en el marco de las tres reglas, sólo podía realizarse cuando la sociedad, a través del gobierno (subsidios cruzados), garantizaba recursos para que las mentes más prominentes se dedicaran a producir y diseminar al máximo el conocimiento, que estas mentes pensaban era el más importante y adecuado para empujar hacia afuera las fronteras de la ciencia y para resolver multitud de problemas.

Sin embargo, desde las décadas de 1970 y 1980 se ha venido consolidando una tendencia mundial en la que se observa una mayor presión para que la Universidad aporte más, directamente, al desarrollo económico y social. Estas exigencias se dan en un contexto en el que se crítica la asignación en automático de recursos públicos a las universidades. Gradualmente, se le ha venido exigiendo a la Universidad un involucramiento mayor con lo que, en strictu sensu, serían actividades empresariales como los mecanismos de competencia para asignación de incentivos laborales y de investigación, búsquedas alternas de financiamiento (generación de recursos propios por venta de servicios [cuotas, consultorías, subcontratación] y comercialización de tecnología), prestación de servicios con base en estándares de calidad (tal y como si

15 Aún con el discurso seductor de la Universidad emprendedora y empresarial, todavía existen muchas universidades que no han transitado plenamente de la función docente a la función investigadora; y esto es más común en los países en desarrollo. 
fueran empresas). Estos mecanismos son simultáneos con un discurso que pretende justificar la insuficiencia de recursos públicos para financiar a las universidades.

En nuestros días, existe una vasta literatura sobre los procesos y la evolución de la interacción de las organizaciones del conocimiento con su entorno (sociedad, empresas y gobierno). Los entramados normativos, operativos, organizacionales y de la cultura dentro de las universidades y de las empresas pueden considerarse como un cambio institucional (Acosta, 2000; García-Galván, 2018); en el cual, la intensificación de la colaboración de las universidades con su entorno también puede reconocerse como una nueva institución para el desarrollo económico y social (García-Galván, 2018).

Por otro lado, cuando las universidades llegan a tener comportamientos semejantes a las empresas, éstas no dejan sus funciones anteriores de enseñar e investigar desinteresadamente (en temas y problemas que no son del interés directo de los actores empresariales). En efecto, las principales universidades, reconocidas como empresas exitosas que crean empresas derivadas, también se encuentran entre los competidores más fuertes para los fondos de investigación (Cortés, 2006, p. 99).

Asimismo, y a pesar de que, en muchos pasajes, la Universidad se comporta como una empresa -protouniversidad en la perspectiva de García-Galván (2009), o grupos de investigación gestionados como en las gerencias de los negocios en la perspectiva de Etzkowitz (2003)-, y de que muchas firmas de los sectores intensivos en tecnociencia asuman funciones muy propias de la Universidad, Antonelli (2008) indicó que no se ha encontrado una mejor forma de gobernación para fomentar la producción y la diseminación del conocimiento, que logre resolver el problema de agencia-principal derivado de la naturaleza de las actividades científicas y de investigación.

En este sentido, la existencia y la consolidación de un buen entramado de universidades y de instituciones de educación superior (de calidad) es una condición necesaria para la aspiración a una sociedad y economía basadas en el conocimiento. Pero, para que la Universidad potencialice y expanda su papel en los nuevos desafíos requiere de fuertes cimientos. 
En términos más específicos, Henao-García, López y Garcés (2014, p. 256) señalaron que al menos existen cuatro formas en que las universidades se fortalecen y a la vez contribuyen con el uso del conocimiento en el ámbito económico y social:

1. la construcción de las bases del conocimiento mediante la investigación;

2. la creación de capacidades a través de la enseñanza y el entrenamiento en investigación;

3. la difusión del conocimiento por medio de la interacción con los usuarios del conocimiento;

4. el mantenimiento del conocimiento (almacenamiento y transmisión intergeneracional a través de la codificación).

Para que el rol de las universidades se concretice en el desarrollo tecnocientífico y socioeconómico, éstas deben contar con una plataforma básica en cuanto a recursos humanos especializados y de alto nivel, infraestructura para la investigación avanzada y, capacidades-habilidades para relacionarse con el entorno. Esto, en la tripleta resumida de Henao-García et al. (2014), se considera como capital humano (estudiantes de posgrados y jóvenes investigadores, grupos de investigación avanzada, profesores-investigadores con la mayor formación); capital estructural (laboratorios y centros de investigación, bibliotecas y bases de datos especializadas, infraestructura que garantice un aprovechamiento adecuado de las TIC, unidades de emprendimiento e incubación de empresas, áreas de gestión especializada de recursos financieros para los proyectos); y capital relacional (normatividad pertinente para la transferencia de conocimiento, oficinas de extensión-vinculación y de transferencia de tecnología, esquemas de incentivos para la gestión de la propiedad intelectual y la comercialización del conocimiento, docentes e investigadores participando en intercambios o en proyectos conjuntos).

Para lograr tal cometido, se utilizan instrumentos como la consultoría en general, los contratos y los convenios específicos de investigación que aportan información y propuestas de solución para problemas precisos, el patentamiento, la comercialización del conocimiento (patentes dadas en licencia) o desarrollo de proyectos conjuntos, in- 
cubación de empresas (de base tecnocientífica), clusters de investigación tecnocientífica -industrial, formación y operación de parques tecnocientíficos. Además, la formación y preparación de personal altamente capacitado y especializado capaz de insertarse en los sectores económicos tecnocientíficos, así como la intención explícita en los planes y programas de estudio de formar emprendedores.

En el marco de la discusión del modelo de la tripe hélice y de la convergencia entre las tres esferas (Universidad-gobierno-industria) se busca que los investigadores académicos se conviertan en empresarios de sus propias tecnologías, los empresarios trabajen en un laboratorio de la universidad o en una oficina de transferencia tecnológica, los investigadores públicos dediquen tiempo a trabajar en una empresa o los investigadores académicos e industriales dirijan agencias regionales responsables de la transferencia de tecnología (Cortés, 2006, p. 96).

Las funciones empresariales y de desarrollo económico de las universidades son simultáneas a las actitudes privadas (no equivalentes a la privatización de activos), impulsadas desde el exterior y que se observan en su interior, estos gestos se reflejan en el reclamo de derechos de propiedad intelectual para ciertos activos del conocimiento como las patentes universitarias que a posteriori se busca comercializar (por medio de licencias), la participación de las empresas en el financiamiento conjunto de proyectos de investigación (colaboración en investigación) de los que luego también pueden buscarse derechos de propiedad intelectual. De este modo, para autores como Moser (2013) y Boldrin y Levine (2013), la búsqueda indiscriminada de patentes por las universidades estadounidenses está inhibiendo la diseminación, por lo que reduce las posibilidades de producir más conocimiento en el futuro, bloquea una mayor producción de innovaciones y provoca redundancia en actividades de investigación.

Por lo anterior, es conveniente que se busquen mecanismos alternativos para mitigar los efectos perversos del patentamiento y del reconocimiento de los derechos de propiedad intelectual. En consecuencia, si se busca que la Universidad potencialice su papel como plataforma de una mayor actividad innovativa, que pueda contribuir a un mejor desempeño competitivo y que, por lo tanto, su aportación al desarrollo eco- 
nómico y social sea mayor, entonces, se requiere diseñar instrumentos o mecanismos que mejoren el aprovechamiento del conocimiento producido en las universidades. Las estrategias indiscriminadas para promover la comercialización del conocimiento y el patentamiento, no garantizan per se un mejor desempeño innovativo, competitivo y socioeconómico.

En suma, las dimensiones emprendedoras y empresariales de la Universidad actual, son una expresión de la sociedad y economía basadas en el conocimiento, en las que se exige a estas instituciones ser actores más activos y directos para consolidar estas grandes tendencias de nuestro tiempo. En este sentido, y en sintonía con Cortés (2006, p.100), en la evolución de la Universidad, se puede resaltar su carácter dinámico que puede observarse por las continuas transformaciones sufridas a lo largo de la historia, tanto en sus misiones como en su propia finalidad como institución social.

\section{Universidad como actor central en la sociedad-economía del conocimiento}

Las universidades tienen un rol fundamental en la economía y la sociedad basadas en el conocimiento, pues en éstas la creación o generación de ideas e intangibles, tales como innovaciones, marcas, patentes, sistemas de organización, rutinas organizativas y know how, constituyen los principales determinantes del éxito en las organizaciones (Rodríguez-Ponce, 2009, p. 823).

En este contexto, las universidades asumen los siguientes roles: formación de capital humano, generación de conocimiento avanzado, contribución a la equidad y al desarrollo del entorno. De hecho, en nuestro tiempo, la fuente de la ventaja competitiva reside en la capacidad para adquirir, transmitir y aplicar el conocimiento. Así, las TIC se convierten en medios para que el saber humano se pueda generar, se intercambie o se comparta, se conozca y se aplique por las personas y las organizaciones. En consecuencia, la generación de conocimiento (actividad primordial de las universidades) se lleva a cabo con la finalidad de crear valor estratégico; por tanto, las instituciones universitarias se constituyen como un elemento básico para generar mayores niveles de competitividad en sus respectivos países (Rodríguez-Ponce, 2009). 
En otros trabajos (García-Galván, 2009; 2014; 2018) se reconoce claramente a las universidades y a los centros de investigación (a partir de sus actividades de colaboración e interacción tecnocientífica con las empresas) como una forma híbrida de coordinación de las actividades económicas. Pero, en sentido estricto, este mecanismo intermedio no sustituye los roles tradicionales de las universidades y las empresas por separado, más bien se ha concebido para complementar y potenciar las habilidades y las capacidades innovativas de las organizaciones, que mediante la gestión de los activos del conocimiento (por ejemplo, patentes) se puede arribar a un mejor desempeño competitivo, de tal forma que se puedan alcanzar mayores niveles de bienestar económico y social.

La creación de conocimiento avanzado es un imperativo estratégico inherente a las instituciones universitarias en la sociedad basada en el conocimiento. Así, para ser competitivos, los países deben invertir en investigación, desarrollo e innovación. Asimismo, si los países disponen de una oferta de calidad y en cantidad suficiente de cuadros científicos e investigadores, entonces, es posible que las empresas mejoren su potencial de innovación y, por ende, su capacidad para competir en mercados globales. Empresas más competitivas consolidan un país más competitivo y capaz de tender hacia la generación de procesos productivos que superen la simple extracción de materias primas (Rodríguez-Ponce, 2009, p. 827).

Una de las consecuencias positivas esperadas de un buen sistema universitario es que, con sus egresados incorporándose a las actividades del entorno, se eleve la probabilidad de producir bienes y servicios de mayor valor agregado, así como de empresas más relacionadas con el conocimiento tecnocientífico de gran valor económico. Por ejemplo, no es lo mismo producir tortillas que software (la diferencia en valor por unidad puede ser abismal). Por lo tanto, es igualmente probable que en los territorios o las regiones donde abundan los campus universitarios se observe, en general, una mayor cantidad de negocios de tecnologías intermedias y avanzadas.

Adicional a lo anterior, de acuerdo con Brunner (2008, como se citó en RodríguezPonce, 2009, p. 827), entre los grandes beneficios socioeconómicos de la educación superior, impartida principalmente en las universidades, se identifican: 
- Posibilidad de mayores ingresos tributarios

- Productividad más elevada

- Mano de obra más flexible y con posibilidades de mayor movilidad

- Menor necesidad de subsidios gubernamentales

- Mejores salarios y mayores prestaciones no salariales

- Mayor propensión al ahorro

- Menores tasas de criminalidad

- Mayor propensión al altruismo y a la solidaridad con la comunidad

- Cohesión social y mayor aprecio por la diversidad

- Mayores capacidades de adaptación y de uso de las nuevas tecnologías

- Mejores condiciones de salud, calidad de vida familiar y de expectativas de vida

Ahora bien, a sabiendas de los grandes beneficios socioeconómicos que pueden derivarse de un buen entramado universitario y de educación superior, el desafío es cómo mejorar la calidad de todas las actividades que ya se realizan y, a la vez, cómo ampliar la cobertura para garantizar más espacios a los jóvenes que se encuentran en edad de formarse en una carrera universitaria. Al respecto, la tendencia es que la infraestructura física para expandir la universidad presencial no crece o lo hace muy poco, ${ }^{16}$ por lo que las universidades han optado por ofrecer formación alternativa mediante mecanismos híbridos (presencial-virtual), o se fomenta el aprendizaje completamente virtual; no obstante, siempre ha estado presente la preocupación de hasta dónde se puede llegar y si las alternativas garantizan una calidad al menos similar a la modalidad presencial tradicional.

16 Es bien sabido que, en el país, desde hace más de tres décadas, no se ha creado una sola universidad pública estatal de tamaño similar a las ya existentes. Lo que ha venido sucediendo es que, a veces, estas universidades abren nuevos campus, algunos bastante precarios en cuanto a infraestructura y planta docente e investigadora. 


\section{Reflexiones finales}

Una mirada crítica a la discusión sobre la relación que tiene la Universidad con el desarrollo tecnológico y socioeconómico, lleva a pensar en una categoría general y más ilustrativa para referirnos al conocimiento más fundamental y a la tecnología plasmada en productos y procesos de manera simultánea; esta es la "tecnociencia" que toma en consideración la vinculación indisoluble entre la ciencia y la tecnología (tanto en el análisis teórico-metodológico como en los actores que participan en su promoción) que en las discusiones convencionales siguen apareciendo separadas o como una dualidad.

El análisis crítico también aclara que el conocimiento o la información tecnocientífica debe considerarse, antes que nada, como un bien semipúblico cuyo acceso pleno demanda habilidades mínimas previas y entrenamiento especializado; el disfrute y uso libre y sin costo, que normalmente se sugiere, podría verse como una ingenuidad. Asimismo, las propiedades de no rivalidad y no exclusividad de su dimensión más pública se alteran cuando se reconocen los derechos de propiedad intelectual y se busca la comercialización del conocimiento. La condición semipública conduce a que se busquen diferentes mecanismos de financiamiento para la producción, la diseminación y la utilización (mercado, Estado-gobierno, y patrocinios públicos y privados).

El aumento en la cantidad de actores involucrados en la generación, difusión y uso del conocimiento, así como las cada vez mayores posibilidades de codificación han posibilitado un crecimiento exponencial de la producción y la reproducción del conocimiento, ambas actividades ancladas en las poderosas TIC que han reducido drásticamente los costos de la codificación. Adicionalmente, una mayor codificación otorga más facilidades para la comercialización de este activo intangible.

Las universidades en su papel de organizaciones mejor preparadas para acelerar la producción y reproducción del conocimiento, a la vez se observan como los actores clave que pueden aportar más y mejores elementos para resolver los problemas complejos. Al respecto, en las misiones de la Universidad se ha hecho explícito el objetivo de contribuir a la resolución de múltiples problemas del entorno más inmediato. De este modo, anteponiendo los subsidios cruzados otorgados y la introducción de mecanismos 
competitivos para el acceso al financiamiento público, a la Universidad se le exige una mayor contribución al desarrollo tecnocientífico y socioeconómico.

Bajo las condiciones actuales, la existencia y consolidación de un adecuado entramado de universidades y de instituciones de educación superior (IES) es una condición necesaria para aspirar a una verdadera sociedad y economía basadas en el conocimiento. No obstante, para que la Universidad potencialice su papel como plataforma de arranque para la innovación y la competitividad, y para que sus aportaciones al desarrollo económico y social sean mayores, se requiere diseñar instrumentos o mecanismos que mejoren el aprovechamiento del conocimiento producido en sus instalaciones.

Si las sociedades y las economías, en general, aumentan sus capacidades para adquirir, transmitir y aplicar el conocimiento tecnocientífico, entonces, las ventajas competitivas serán mayores. Además, una mayor colaboración o vinculación universidadempresa y con otros actores empujan hacia fuera los niveles de competitividad.

En el camino hacia una sociedad-economía basada en el conocimiento es preciso disponer de dos insumos básicos, a saber: a) un buen entramado universitario y de instituciones de educación superior; b) ampliar y mejorar los niveles de calidad de la investigación y de la enseñanza-aprendizaje.

Por último, dado que en el proceso de la investigación nunca puede llegarse a conclusiones definitivas y absolutas, en las siguientes líneas se enlistan algunos temas relevantes para la agenda de investigación futura:

- En las discusiones universitarias, sobre producción, difusión y diseminación del conocimiento tecnocientífico se requiere asumir que éste no es un bien completamente público y que, por lo tanto, se requieren grandes esfuerzos de formación y entrenamiento para asimilar plenamente este tipo de conocimiento

- Profundizar en el análisis de las condiciones bajo las cuales las universidades buscan una mayor vinculación e interacción con el sector productivo. El discurso de la pertinencia de los estudios podría esconder una intención de sumisión completa o al menos desigual 
- Reflexionar sobre la necesidad de aumentar la cobertura de la educación superior a través del sistema universitario, pero simultáneamente mejorar y enriquecer los planes y programas de estudio que se ofrecen

- Una verdadera contribución de la Universidad al desarrollo tecnológico y socioeconómico necesita de acciones más decididas y de mayores recursos, para pasar de los discursos y de la simulación a la conformación de firmas tecnocientíficas, de clusters tecnocientíficos y de parques tecnocientíficos

- Reflexionar sobre las ventajas y desventajas de la gestión de los derechos de propiedad intelectual. La comercialización miope del conocimiento universitario podría agrandar los problemas de innovación tecnológica más que propiciarla

- La adopción y adaptación de las TIC a los procesos de enseñanza-aprendizaje no es automática; por lo tanto, es necesario seguir indagando en las formas en que se podrían utilizar las TIC, tanto para aumentar la cobertura en educación superior como para elevar sus niveles de calidad 


\section{Referencias}

Acosta, A. (2000). Estado, políticas y universidades en un periodo de transición. México: Universidad de Guadalajara y FCE.

Antonelli, C. (2008). The new economics of the university: a knowledge governance approach. Journal of Technology Transfer, (33), 1-22.

Arora, A., Andrea F., \& Gambardella, A. (2001). Markets for Technology. The Economics of Innovation and Corporate Strategy. Cambridge, MA: The MIT Press.

Arrow, K. (1962). El bienestar económico y la asignación de recursos para la invención. En N. Rosenberg (Ed.), Economía del cambio tecnológico. México: Fondo de Cultura Económica.

Ayala, J. (1999). Instituciones y Economía, una Introducción al Neoinstitucionalismo Económico. México: FCE.

Azagra, J.M. (2004). La Contribución de las Universidades a la Innovación: efectos del fomento de la interacción universidad-empresa y las patentes universitarias. Tesis Doctoral. Universidad de Valencia, España.

Boldrin, M., \& Levine, D. (2013). The Case Againts Patents. Journal of Economic Perspective, $27(1), 3-22$.

Bush, V. (1999). Ciencia, la frontera sin fin. Un informe al presidente, julio de 1945. REDES, VI(14), 89-156.

Cortés, F. (2006). La relación universidad-entorno socioeconómico y la innovación. Revista Ingeniería e Investigación, 26(2), 94-101.

Dasgupta, P., \& David, P. (1994). Toward a new economics of science. Research Policy, (23), 487-521.

David, P., \& Foray, D. (2002). Una introducción a la economía y a la sociedad del saber. Revista Internacional de Ciencias Sociales, (171).

Del Río, F. (1994). Vidas paralelas en la ciencia y la tecnología. En R. Varela, \& L. Mayer (Comp.), Los Grandes Problemas de la Ciencia y la Tecnología. México: UAM y UNAM.

Drucker, R. (2015). Una reflexión sobre la ciencia en México. La Jornada. Recuperado de http://www.jornada.unam.mx/2015/06/01/opinion/020a1pol 
Etzkowitz,H.(2003). Research groups as"quasi-firms": the invention of the entrepreneurial university. Research Policy, 32, 109-121.

Foray, D. (2004). Economics of Knowledge. Cambridge, MA: The MIT Press.

García-Galván, R. (2009). Análisis teórico de la transferencia de conocimientos universidad-empresa mediante la colaboración. Economía: teoría y práctica, (29), 51-86.

García-Galván, R. (2014). Desempeño económico y factores económicos detrás del rezago tecnocientífico en México. Revista Cofactor, V(9).

García-Galván, R. (2018). El papel de las instituciones y de la colaboración universidadempresa en el desarrollo: evidencias de la UAEMÉX y la UABC. Paradigma económico, 10(1), 81-118.

Gittelman, M. (2006). National institutions, public-private knowledge flows, and innovation performance: A comparative study of the biotechnology industry in the US and France. Research Policy, (35), 1052-1068.

Henao-García, E., López, M., \& Garcés, R. (2014). Medición de capacidades en investigación e innovación en instituciones de educación superior: una mirada desde el enfoque de las capacidades dinámicas. Entramado, 10(1), 252-271.

Kay, N. (1988). The R+D function: corporate strategy and structure. En G. Dosi, C. Freeman, R. Nelson, G. Silverberg, \& L. Soete (Ed.), Technical Change and Economic Theory. London and New York: Pinter Publishers.

Latour, B. (1992). Ciencia en acción. Cómo seguir a los científicos e ingenieros a través de la sociedad. Barcelona, España: Labor.

Lundvall, B. (2004). The Economics of Knowledge and Learning. Research on Technological Innovation and Management Policy, (8), 21-42.

Moser, P. (2013). Patents and Innovation: Evidence from Economic History. Journal of Economic Perspectives, 27(1), 23-44.

Nelson, R. (1959). La economía sencilla de la investigación científica básica. En N. Rosenberg, (Ed.), Economía del cambio tecnológico. México: Fondo de Cultura Económica. 
Pavitt, K. (1984). Sectoral patterns of technical change:Towards a taxonomy and a theory. Research Policy, (13), 343-373.

Rodríguez-Ponce, E. (2009). El Rol de las Universidades en la Sociedad del Conocimiento y en la Era de la Globalización: Evidencia desde Chile. Interciencia, 34(11), 822-829.

Rossi, F. (2008). The economics of knowledge and the governance of universities' third stream activities [Working paper No. 87]. DIME Working Papers on Intellectual Property Rights. Recuperado de http://www.ausicom.com/filelib/ PDF/ResearchLibrary/Third\%20stream\%20funding\%20of\%20knowledge\%20 interactions.pdf

Samuelson, P. (1954). The Pure Theory of Public Expenditure. Review of Economics and Statistics, (36), 387-389.

Stiglitz, J. (1999). Knowledge as a Public Good. En I. Kaul, I. Grunberg, \& M. Stern (Eds.), Global Public Goods, International Cooperation in the 21st Century (pp. 308-325). New York: The United Nations Development Programme.

Teece, D. (1988). Technological change and the nature of the firm. En G. Dosi, C. Freeman, R. Nelson, G. Silverberg, \& L. Soete (Ed.), Technical Change and Economic Theory. London and New York: Pinter Publishers. 


\section{Capítulo 7}

\section{Cumplir con los otros: una revisión documental sobre la colaboración UABC-Tercer sector}

Ricardo Lindquist Sánchez, Rodolfo García-Galván

y Alicia Alelí Chaparro Caso-López

La primera universidad de la historia moderna fue fundada por un grupo de estudiantes y surgió a partir de una necesidad social: la búsqueda de conocimiento. Este grupo de jóvenes, originarios de distintas municipalidades de Italia, viajó a Bolonia en 1088 con la intención de solicitar a eruditos de la zona que los instruyeran en la glosa del Código Justiniano. Así, en el marco de un continente fragmentado por los conflictos bélicos entre árabes y españoles, bizantinos y turcos, y la amenaza latente de la expansión de los normandos, fue posible el surgimiento de una Universitas Scholarium: la de Bolonia (Rashdal, 1987).

Aun cuando existe una acepción ampliamente difundida en la que se asocia el origen de la universitas con el carácter universal de la formación universitaria, lo cierto es que, en el medievo, "universitas" era el término latino más cercano a comunidad o universo. De esta manera, la primera universidad surgió bajo el esquema de Universitas Scholarium (comunidad de estudiantes) y tuvo como Rector a un elemento estudiantil que poseía la facultad de contratar profesores (Kerr, 1983; Rashdal, 1987).

Pero no fue hasta 1155 que el entonces emperador del Sacro Imperio RomanoGermánico, Francisco I Barbarroja, reconoció oficialmente a la Universidad de Bolonia, a cambio de que sus líderes estudiantiles aceptaran el Authentica Habita. Este último, era un reglamento que, entre otros preceptos, dotaba a los estudiantes de privilegios 
clericales ${ }^{1}$, siempre y cuando accedieran a portar vestimenta eclesiástica y, en caso de ser necesario, ser juzgados por otros miembros de la Universidad.

Como señalan Dmitrishin (2013) y Rashdal (1987), el éxito progresivo de la Universitas Scholarium provocó que un colectivo de profesores se asentaran en Francia para fundar una institución en donde ofrecer sus servicios: la Universidad de París, una Universitas Magistrorum (comunidad de profesores). Las áreas de mayor arraigo en esta universidad fueron el Derecho -ya consolidado en Bolonia -, la Medicina y la Teología.

Como su par boloñesa, la Universidad de Paris concedió a uno de sus miembros la responsabilidad de ostentar la Rectoría.

Bajo este esquema surgirían, un siglo más tarde, las Universitas Scholarium et Magistrorum, conformadas por estudiantes y profesores que, en términos regularmente armónicos, compartían el poder. Una de las primeras universidades instauradas bajo este modelo mixto fue la de Salamanca, en España, cuya fundación se consolidó en 1218. No obstante, tanto esta universidad como la de Alcalá de Henares (erigida dos siglos después) tendieron a relegar la responsabilidad directiva a los miembros del profesorado. En la Universidad de Salamanca, por ejemplo, existía la figura del maestrescuela, un elemento responsable de autorizar planes de estudio, otorgar grados académicos y supervisar las labores de docencia (Tünnermann, 1999).

El de Salamanca fue el modelo que dio forma a las universidades reales y pontificias (en tanto que eran aprobadas por el Rey y el Papa) fundadas en la Nueva España: a la de México y la de Lima (s. XVI), a la de Bolivia, Mérida (s. XVII) y a la de Oaxaca (s. XVIII). En el caso de México, entonces territorio novohispano, la universidad sepultó al Calmécac y el Telpochcalli, escuelas aztecas enfocadas en la formación de sacerdotes y militares, respectivamente. Como se podrá observar, los objetivos del imperio español se concentraban en garantizar la formación superior de sus cortesanos, al tiempo que la formación inicial era relegada a la alfabetización (secular y religiosa) en el caso de los indígenas, y al adiestramiento caballeresco, en el caso de los hispanos. Es necesario re-

1 Consistentes, sobre todo, en un subsidio estatal que les permitía vivir sin la necesidad de trabajar. 
saltar que, a pesar de la diferencia de estratos, el papel de la mujer en la educación fue prácticamente nulo durante casi trescientos años (Tünnermann, 1999).

De acuerdo con este autor, a partir del siglo XIX, apenas un par de décadas después del proceso de independización, las universidades novohispanas abandonaron el modelo colonial para convertirse en universidades republicanas. Entonces, el antecedente formativo de mayor eco era el francés, en el que Napoleón instauraba un modelo universitario de riguroso control imperial, concentrado en la legitimación discursiva del régimen militar y la formación de los profesionales que "la nación" demandaba². De ahí que las universidades republicanas no fueran sino universidades coloniales sometidas a un nuevo ente regulador.

Simultáneamente en Alemania, y con el apoyo de intelectuales como Hegel y Schiller, Wilhelm von Humboldt ideaba otra forma de entender la universidad. Para este pensador, la universidad debía estar regida no por el poder, sino por un tópico de mayor trascendencia ontológica: el espíritu científico. Para ello, resaltó la necesidad de que la universidad se enfocara, además de la docencia, en la producción de conocimiento y declaró que, como medio institucional, el espacio universitario debe ser el árbol de la ciencia (Perkin, 2007).

En 1810, tras persuadir a Federico Guillermo III, rey de Prusia, von Humboldt fundó la Universidad de Berlín. A través de ésta, puso en práctica sus principales convicciones pedagógicas, haciendo de la universidad no solo una institución orientada a transmitir el conocimiento, sino a exponer el proceso de concepción de este. Con el éxito de la universidad berlinesa, se consolidó la tendencia reformadora en el resto de las universidades alemanas y, a partir de entonces, docencia e investigación se convirtieron en una bina indiscernible en el quehacer universitario (Moncada, 2008).

En este sentido, ya es posible observar, a grandes rasgos, la evolución de las funciones sustantivas tradicionales. Primero, la universidad se consolidó como una instancia enfocada principalmente en la docencia; después, influido por el humanismo

2 Principalmente soldados para La Gran Armeè, médicos (para que curaran a los soldados) y profesores (para que formaran a más médicos y soldados). 
y la corriente postkantiana, von Humboldt develó la agenda científica tras la producción de conocimiento (investigación). No obstante, es válido preguntarnos: ¿cómo y en qué momento surgió la tercera función sustantiva, concerniente a la colaboración o vinculación con el entorno? De la misma manera, se tiene como objetivo en este capítulo explicitar el proceso de colaboración de la Universidad Autónoma de Baja California (UABC) con el Tercer Sector.

\section{La tercera función y sus cambios}

Además de ser actividades basadas en el conocimiento, hay otro rasgo que une a la investigación y a la docencia: ocurren al interior de la universidad. Si bien, ambas tienen un vínculo con el exterior a largo plazo -la docencia al formar a futuros profesionistas y la investigación al producir conocimiento que tentativamente será útil para la sociedad - a ninguna de estas funciones se les exigía, en su momento, producir una mejora tangible en su entorno. Este aparente inmovilismo generó el surgimiento de diversos movimientos estudiantiles.

Uno de los movimientos más destacados, sobre todo por poner en la agenda política de Latinoamérica el tópico de la extensión universitaria, fue el de Córdoba, en Argentina. Este movimiento, surgido en 1918, nació en la Universidad Nacional de Córdoba y tuvo como principal bandera el democratizar dicha institución evitando la llegada de un Rector que representaba el statu quo. El momento cúspide de la manifestación se logró el 15 de junio del mismo año, cuando los estudiantes instauraron la Federación Universitaria de Córdoba y presionaron al entonces presidente de la república para que reformara los estatutos universitarios.

Los estudiantes de Córdoba señalaban que la universidad latinoamericana padecía un alejamiento olímpico con relación al pueblo. Como precedente de éxito, recurrían a las experiencias de las universidades técnicas europeas: un conjunto de instituciones instauradas por el Estado que lograban promover la formación técnica gratuita de los estratos más vulnerables. A cambio de subsidiar su formación, el gobierno hacía que los futuros egresados se comprometieran a laborar en el sector público y desempeñaran alguna tarea en su rubro que retribuyera a la sociedad. 
Tres décadas más tarde, tomando como antecedente los logros del movimiento de Córdoba, se consolida la Unión de Universidades de América Latina (UDUAL). Así, en 1949, teniendo a la Universidad Nacional Autónoma de México (UNAM) como sede, se desarrolla el Primer Congreso de Universidades Latinoamericanas. De este último emanó, dos años después, la Carta de las Universidades Latinoamericanas, en la que se enuncia que la universidad debe: 1) contribuir a la elevación del nivel espiritual de los habitantes a través de la cultura; 2) ser la expresión real de su momento histórico y 3) aspirar a convertirse en un sistema activo de funciones que beneficien a la colectividad que la sostiene (Carta de las Universidades Latinoamericanas, 1951).

Con relación a la acepción inicial de la extensión, Tünnermann (1999) señala:

Es obvio que predominó un criterio de "entrega" y hasta podría decirse de "dádiva cultural" o, en todo caso, un marcado acento "paternalista" o "asistencial" en las labores que se realizaban. La universidad, consciente de su condición de institución superior del saber, trataba de remediar un poco su situación privilegiada y procuraba que algo de su quehacer se proyectara a los sectores menos favorecidos. Pero es ella la que decide sobre el contenido y el alcance de su proyección. Además, en esa proyección, es la universidad la que da y la colectividad la que recibe. La extensión se realiza así mediante un canal de una sola vía, que va de la universidad, depositaria del saber y la cultura, al pueblo, simple destinatario de esa proyección y al cual se supone incapaz de aportar nada valioso [...] los programas de extensión y difusión generalmente consistieron en el auspicio de conferencias, charlas, un teatro experimental, un coro, quizá una orquesta, un conjunto de danza o una radio universitaria, en el mejor de los casos. (p. 125)

Uno de los pensadores más críticos frente a la idea de extender la cultura al pueblo fue Paulo Freire. En su libro, La educación como práctica de la libertad (Freire, 1978) declara que: 
el término extensión se encuentra en relación significativa con transmisión, entrega, donación, mesianismo, mecanismo, invasión cultural, manipulación, etc. $Y$ todos estos términos envuelven acciones que, transformando al hombre en una casi "cosa" lo niegan como un ser de transformación del mundo. (p. 88)

Así mismo, añade que la única manera de evitar que la extensión conlleve una forma de dominación es basándola en el diálogo.

Justo cuando la extensión parecía enfrentarse a una inminente reforma filosófica, el discurso de la vinculación comenzó a figurar en la agenda universitaria. La década de los ochenta estuvo marcada por la crisis económica en diversos países de América Latina, y generó la reducción radical del presupuesto asignado a la educación superior. En consecuencia, las universidades latinoamericanas se vieron en la necesidad de identificar rutas que permitieran obtener mayores beneficios pecuniarios. Una de ellas, retomada principalmente de la dinámica norteamericana, fue la vinculación.

A diferencia de la extensión, en donde, no sin ciertos errores, se buscaba contribuir con el entorno a través de la cultura y el conocimiento, la vinculación nació con el propósito de establecer enlaces comerciales con figuras altamente rentables. En este sentido, Luna (1997) identifica que la vinculación ha pasado por dos etapas: en la primera, se iniciaron los mecanismos de financiación e incentivos gubernamentales, y en la segunda, se conformó un modelo neoestructural ligado a las políticas de integración al mercado.

Lo anterior explica que la vinculación universitaria se concentre en la interacción con dos actores: el gobierno y las empresas. Con el primero, se establecen relaciones, raramente mediadas por el conocimiento, para incrementar el capital reputacional $y$, eventualmente, engrosar el subsidio estatal. Mientras que con el segundo se busca subsanar la débil partida presupuestal otorgada por el primero. Provocando, en síntesis, que la vinculación se convierta en una actividad de carácter técnico, con débiles raíces conceptuales (Campos y Sánchez, 2006). 
Pero ¿qué ocurre entonces con aquellos actores con los que la vinculación no se traduce en un beneficio económico a corto plazo?, ¿es legítimo que la universidad sacrifique su vocación ontológica en aras de tener un presupuesto más holgado?, ¿quiénes y cómo son los actores sociales que no forman parte del sector empresarial o del gobierno? Veamos en las siguientes líneas algunas respuestas tentativas.

\section{La noción de tercer sector}

Además de las motivaciones económicas que pueden enmarcarse en el capitalismo académico ${ }^{3}$, la débil colaboración con el sector social podría obedecer a una identidad difusa de lo social. Para Paiva (2004), el conflicto medular es que el sector social no posee un rostro definido. Cuando las universidades piensan en la colaboración con el gobierno, por ejemplo, tienen clara la relación con Secretarías y organismos descentralizados; si de colaborar con el sector privado se trata, prevén el contacto con pequeñas y grandes empresas. Sin embargo, cuando se habla de colaboración con la sociedad, las universidades reducen la práctica al discurso extensionista de la responsabilidad social.

Una de las posibles raíces de la laxitud identificada por Paiva (2004) es la confusión entre dos términos esenciales: sociedad civil y tercer sector. Como señala Aguilar (2006), la concepción de sociedad civil que permea hasta nuestros días se sustenta en la idea gramsciana de que todo aquello que no pertenece al gobierno forma parte de la sociedad civil. Esto explica que, a pesar de la vasta literatura producida en el marco de la economía del conocimiento, el estudio de la colaboración universidad-sociedad esté centrado en el acercamiento con las empresas.

Con la intención de diferenciar este microsector (el de la sociedad civil y los movimientos sociales) del término sociedad en el que, no sin cierta razón, se incorpora a las empresas y el gobierno (en tanto que también son parte de la sociedad), surge el término "tercer sector", propuesto por Salamon y Anheier (1995). Para ellos, en la

3 Entendido como un fenómeno que implica que las universidades se encuentren subsumidas al mercado y pierdan con ello su autonomía y que, en consecuencia, tomen decisiones "académicas" a partir de motivaciones económicas. 
sociedad existen tres sectores: 1) el Estado; 2) la empresa privada, y 3) el tercer sector de las organizaciones ciudadanas. Desde este enfoque, según Aguilar (2006), "las organizaciones de la sociedad civil serían sólo las que pertenecen al tercer sector"(p. 88).

Otra forma de facilitar la comprensión sobre qué es y qué caracteriza a las organizaciones del tercer sector, es la estrella de Yoshimoto (2006). En su propuesta, que se muestra en la figura 1, Yoshimoto expone algunos criterios para ubicar en cuadrantes quiénes pueden considerarse parte de este sector.

La estrella de Yoshimoto (2006) permite delimitar las raíces ontológicas del tercer sector. Pero, si bien es útil para establecer un primer acercamiento a sus fines, la propuesta puede resultar escueta al ser analizada desde una perspectiva taxonómica: si se habla de buscar el bien público a través de actividades no lucrativas (al menos no en el discurso), ¿no se traslaparía su concepción con las labores del gobierno?

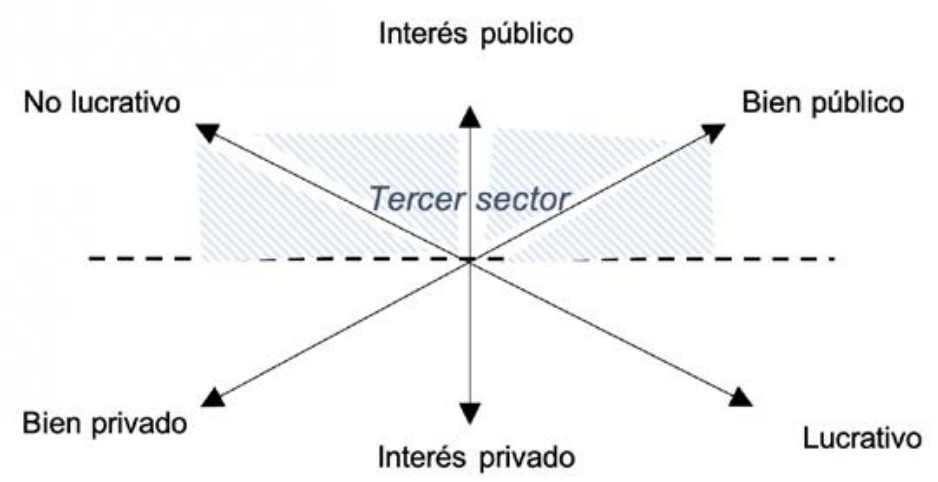

Figura 1. Principales atributos del tercer sector. Adaptado de Yoshimoto (2006).

En efecto, y con la intención de evitar más dispersiones conceptuales, se presenta el siguiente constructo de tercer sector:

El tercer sector es un espacio de acción autónomo distinto del gobierno y de las empresas privadas, conformado por organizaciones o asociaciones no lucrativas, en el que se atienden demandas sociales y comunitarias no satisfechas por los otros actores. 
Hasta ahora, es posible observar que la convergencia de dichos fenómenos -búsqueda de actores económicamente rentables y confusión sobre la identidad del sector social -, ha propiciado que en las interacciones con el tercer sector predomine el carácter asistencialista y el interés de fortalecer la imagen de la universidad. En este sentido, se ha dejado de lado la resolución de las problemáticas sociales, así como el reconocimiento de las Organizaciones No Gubernamentales (ONG), como instancias poseedoras de conocimiento empírico que podría ser un insumo para el desarrollo de las funciones sustantivas universitarias.

\section{Un acercamiento a lo nuestro (la cuestión metodológica)}

Los apartados previos nos ayudan a comprender, en primera instancia, que la universidad no nació como una institución alejada del pueblo, sino como un mecanismo creado por la propia sociedad para sistematizar la adquisición de conocimiento. Además, han sido útiles para dimensionar, a grandes rasgos, la evolución de las funciones sustantivas, en general, y de la tercera función, en particular. Así mismo, de forma concreta, permiten inferir: a) que la idea de extensión surgió como una vía para aminorar el alejamiento universidad-sociedad (aunque se convirtiera después en una suerte de asistencialismo universitario); b) que la vinculación nace en el contexto de la crisis económica de los ochenta como una alternativa para obtener ingresos propios; c) que ambas agendas, la de la extensión y la de la vinculación, se han olvidado del tercer sector.

El objeto de este capítulo es caracterizar el estado de la colaboración entre la UABC y el tercer sector. Para ello, se llevó a cabo una revisión documental concerniente en el análisis de los documentos normativos de la UABC; la revisión del repositorio de convenios de colaboración de la Universidad; la exploración de los datos del Sistema Integral de Servicio Social (SISS); y el cotejo de los comentarios emitidos por un grupo de académicos de la Universidad en torno a la interacción institucional con el tercer sector.

En cuanto a la revisión de la normatividad, se contemplaron los documentos de mayor peso jurídico en la UABC: la Ley Orgánica (1957), el Estatuto General (1983) y el Modelo Educativo (2013). Para complementar la revisión normativa, se analizaron 
también los convenios vigentes sostenidos por la $\mathrm{UABC}$, teniendo como fecha de corte el mes de diciembre de 2017. Los datos que se recuperaron son: fecha de vigencia del convenio, ámbito, objeto e instancias que lo operan. El mismo rango temporal se estableció como criterio para la exploración del SISS, misma que tuvo como propósito la identificación de los espacios en los cuales los estudiantes se encuentran realizando su Servicio Social de la Primera Etapa o el Profesional.

Por último, se incluye el apartado cualitativo de un cuestionario de percepción enviado, vía correo electrónico, a académicos de la UABC pertenecientes al Sistema Nacional de Investigadores (SNI) ${ }^{4}$, en donde los participantes tuvieron la oportunidad de emitir comentarios concretos sobre el fenómeno de la interacción con el tercer sector.

\section{Resultados}

\section{Revisión normativa}

En el principal eje normativo universitario, Ley Orgánica de la UABC (1957), se plantea que uno de los fines primordiales es:

Fomentar y llevar a cabo investigaciones científicas, dando preferencia a aquellas que tienden a resolver los problemas estatales y nacionales; $y$ extender los beneficios de la cultura. (Art. 1)

Así como la Ley Orgánica establece el propósito de resolver problemas estatales y nacionales, el Estatuto General de la UABC (1983) contempla:

Que la Universidad debe orientar sus actividades a satisfacer las demandas y necesidades de una región, por medio de la vinculación armónica entre las funciones sustantivas de docencia, investigación y extensión. (Art. 150B, F.II)

4 Dicho criterio fue establecido en aras de garantizar que los académicos produzcan conocimiento y que, como resultado, la colaboración que establezcan con los actores del entorno se encuentre mediada por el mismo. 
Como se observa, a diferencia de la Ley Orgánica, el Estatuto -quizá por su cercanía temporal con la aparición de las tendencias en vinculación- habla de resolver problemas regionales, contemplando como vehículo la articulación entre las tres funciones sustantivas, y no solo a la extensión, como se ha propuesto en otros trabajos. Sin embargo, ambas normas coinciden en la vocación ontológica de la universidad de contribuir al desarrollo de su entorno.

En el Modelo Educativo de la UABC (2013), se expone un constructo de vinculación, entendida como:

\begin{abstract}
el conjunto de acciones que se llevan a cabo bajo la forma de contratación de servicios, prácticas profesionales, servicio social, investigación aplicada, desarrollo e innovación tecnológicos, educación continua, formación de emprendedores, consultoría y asistencia técnica que propician el desarrollo social, cultural, económico y productivo de la región. (p. 84)
\end{abstract}

De esta manera, puede observarse que la acepción de vinculación que prima al interior de la universidad es, sobre todo, de carácter operativo.

En este mismo documento, la Universidad esboza un Esquema de Vinculación Universitaria, en donde se afirma que las modalidades antes mencionadas surgen de las demandas sociales, y que su correcta aplicación se traduce en un impacto social, productivo y cultural. Lo que no queda claro, es la ruta que la Universidad emplea para realizar este diagnóstico de las necesidades del sector social -cuyas características tampoco se definen-, ni los indicadores que permiten medir el impacto de las modalidades de vinculación universitaria.

\title{
Revisión del SISS
}

\section{Servicio social comunitario}

De acuerdo con el Reglamento de Servicio Social de la UABC (2007), el servicio social comunitario es una experiencia de aprendizaje a la que el estudiante debe dedicar 300 
horas y cuyos objetivos generales son: (1) apoyar la formación de una conciencia de responsabilidad social en la comunidad universitaria, y (2) prestar servicios que apoyen la resolución de problemas de las comunidades y grupos con los que se trabaje (Art. 5).

A través del servicio social, se busca que el estudiante apoye la resolución de problemáticas presentes en las comunidades y grupos de su entorno. Por ello, resulta grave que el $74 \%$ se encuentren asignados a programas que se ofertan al interior de la propia Universidad (figura 2). Con lo anterior, se ejemplifica uno de los problemas que aquejan al servicio social como mecanismo de vinculación: el que las propias universidades lo utilicen como moneda de cambio para que sus estudiantes realicen actividades administrativas sin remuneración económica ni formativa.

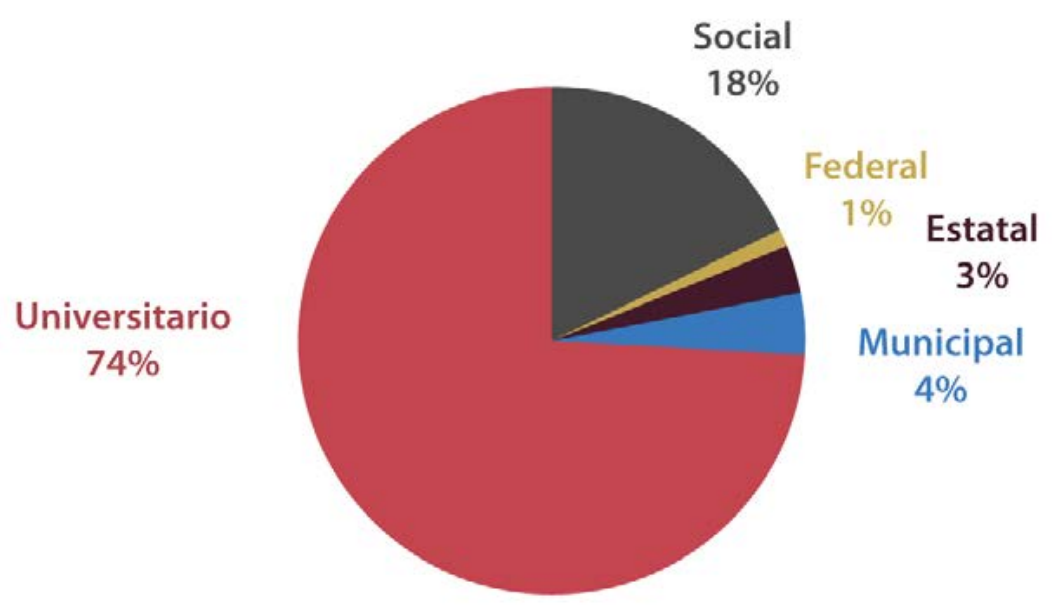

Figura 2. Porcentaje de estudiantes asignados a programas de servicio social comunitario según el sector de acción. Elaboración propia con datos del Sistema Integral de Servicio Social, UABC.

Asimismo, se observa que el tercer sector (sector social), aquel en donde mayor eco tienen las problemáticas comunitarias, cuenta apenas con un $18 \%$ de los estudiantes asignados a algún programa de servicio social comunitario. 
Servicio social profesional

A diferencia del servicio social comunitario (o primera etapa), en donde el estudiante no precisa poner en práctica los conocimientos adquiridos en el programa educativo que cursa, en el servicio social profesional, el estudiante debe extender a los actores de su comunidad aquello que ha podido aprender.

Como en la etapa anterior, el servicio social profesional no parece cumplir su propósito normativo, tomando como referencia los programas en los que los estudiantes se encuentran asignados. Ya que, como se muestra en la figura 3, la mayoría de los estudiantes se encuentran asignados a programas de servicio social internos de la UABC, y solo el $1 \%$ presta su servicio social en el tercer sector (sociedad) o en el sector productivo (empresas).

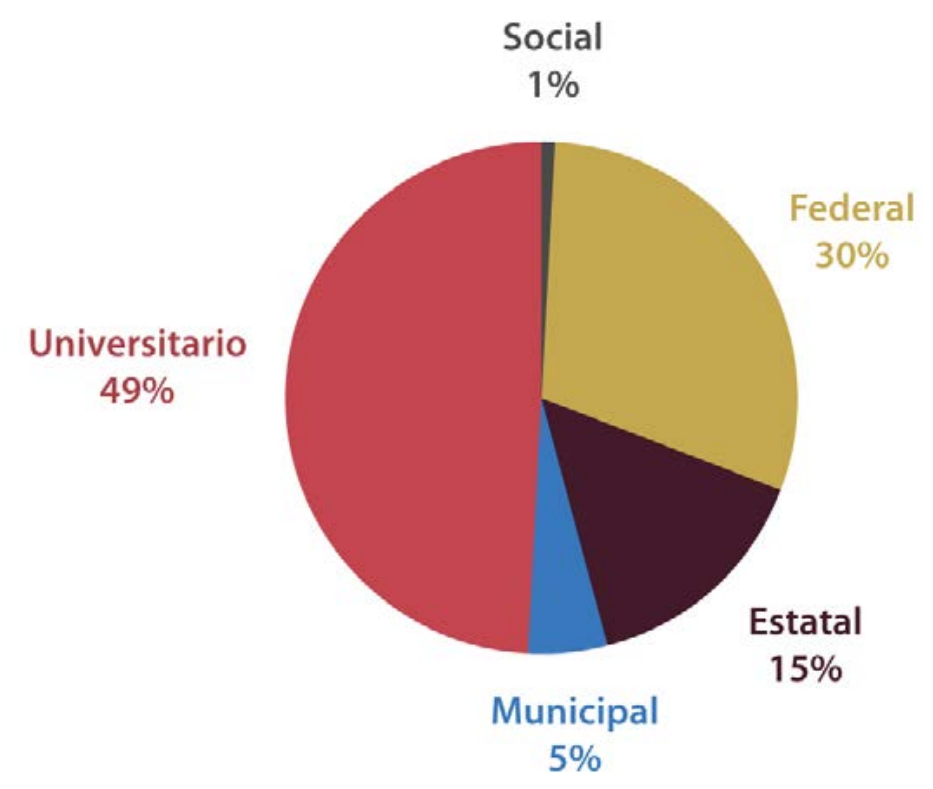

Figura 3. Porcentaje de estudiantes asignados a programas de servicio social profesional según el sector de acción. Elaboración propia con datos del Sistema Integral de Servicio Social, UABC. 


\section{Revisión del repositorio de convenios}

Hacia finales de 2017, la UABC contaba con un total de 531 convenios vigentes, establecidos con los siguientes actores: gobierno, empresas, sector educativo, sector no gubernamental y entidades intrainstitucionales. En la figura 4 se detalla la distribución de dichos convenios, con el objetivo de identificar cuáles son las instancias con las que la UABC sostiene un mayor nivel de interacción, de acuerdo con la información recuperada del repositorio de convenios del portal de transparencia universitaria de la UABC (2017).

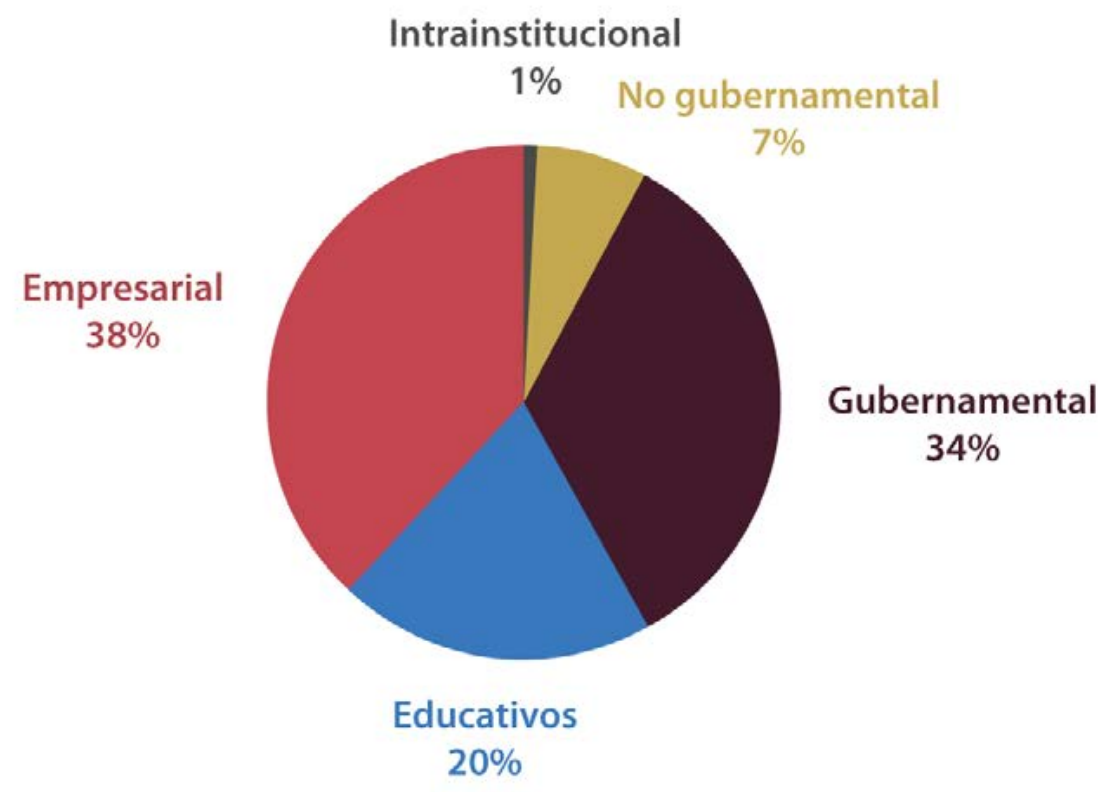

Figura 4. Distribución de los convenios vigentes según los actores. Por actores educativos se entienden escuelas primarias, secundarias o de educación media superior, públicas o privadas. Elaboración propia a partir de la información recuperada del repositorio de convenios del portal de transparencia universitaria de la UABC (2017).

En general, los resultados de la revisión del repositorio de convenios de la UABC son congruentes con los aportes de Ibarra (2003) y Paiva (2004) quienes sostienen que, debido a la inercia del capitalismo académico, las universidades -sobre todo aquellas en vías de consolidación- prefieren colaborar con la industria y las autoridades gubernamentales. En tanto que las primeras pueden ayudar a obtener capital económico y las segundas capital reputacional. 
Destaca también que no todas las áreas del conocimiento presentan el mismo nivel de colaboración. Como se aprecia en la figura 5, en la UABC las áreas de las Ciencias Naturales y las Ingenierías tienen una colaboración más intensa con los actores externos que las Ciencias Sociales o las Humanidades. Esto, en cierto sentido, podría explicarse debido a la afinidad del perfil de egreso de programas educativos de corte tecnocientífico con las necesidades de la industria.

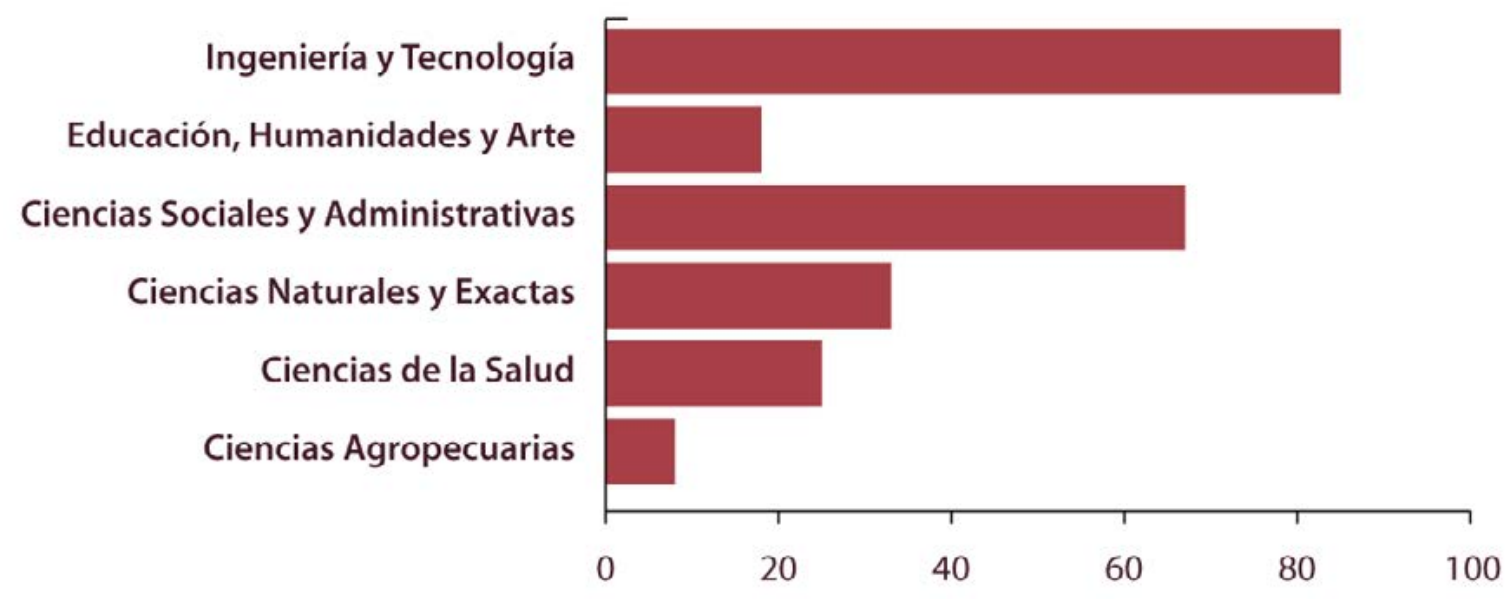

Figura 5. Convenios de colaboración según el área de conocimiento. Elaboración propia a partir de la información recuperada del repositorio de convenios del portal de transparencia universitaria de la UABC (2016).

\section{Percepción de los investigadores}

Con el propósito de identificar la percepción de los académicos de la UABC respecto a la colaboración con el tercer sector, les fue enviada una encuesta, vía correo electrónico. En total, de acuerdo con datos del Portal Electrónico de la Coordinación de Posgrado e Investigación de la UABC, la universidad en sus tres campus (Ensenada, Mexicali y Tijuana) cuenta con 375 académicos que forman parte del SNI. De éstos, 75 respondieron la encuesta, lo que representa el $20 \%$ de la población.

En la encuesta se consideró el siguiente reactivo: “¿Cuál es su opinión general sobre la colaboración que la UABC sostiene con su entorno?", el cual fue de respuesta 
construida y no contaba con un límite de caracteres. De los 75 participantes, 45 emitieron un comentario. No obstante, de estos 45 , más de 20 hicieron comentarios que no ofrecen una perspectiva completa. En este sentido, se recuperaron un total de 18 comentarios, agrupados en siete dimensiones analíticas, que pueden ser revisados de forma íntegra en la tabla 1.

Tabla 1

Opiniones de los investigadores sobre la colaboración de la UABC con su entorno regional

\section{Dimensión} analítica

\section{Comentarios de los académicos}

\begin{tabular}{|c|c|}
\hline \multirow[b]{3}{*}{ Compromiso } & Que requiere compromiso y acercamiento de ambas partes. \\
\hline & $\begin{array}{l}\text { Es de suma importancia sumar esfuerzos entre ambas partes para así obtener todos } \\
\text { los beneficios. }\end{array}$ \\
\hline & $\begin{array}{l}\text { Considero que es de vital importancia la colaboración con el tercer sector, en muchos } \\
\text { aspectos y creo que es una línea de trabajo que se encuentra "invisibilizada" y poco } \\
\text { aprovechada. La universidad pública tiene un compromiso con la sociedad y me } \\
\text { parece que una buena manera de atender a este compromiso sería a través de } \\
\text { actividades de vinculación con el tercer sector. }\end{array}$ \\
\hline $\begin{array}{c}\text { Divulgación } \\
\text { de capacidades }\end{array}$ & $\begin{array}{l}\text { Colaboración adecuada, y se requiere un mayor proceso de intensificación de } \\
\text { la misma. Además, que el tercer sector conozca que la UABC puede ser útil en los } \\
\text { procesos de resolución de problemas específicos del entorno. }\end{array}$ \\
\hline \multirow{3}{*}{$\begin{array}{l}\text { Procesos } \\
\text { Administrativos }\end{array}$} & Necesita tener mayores facilidades por parte de la administración de UABC. \\
\hline & $\begin{array}{l}\text { Al establecer normativa institucional se está lejos de facilitarla. Mis colaboraciones } \\
\text { son evidentes en mis artículos, sin embargo, si quisiera que se reconociera por } \\
\text { esquemas de UABC (tal como PREDEPA [Programa de Reconocimiento alDesempeño } \\
\text { del Personal Académico]) debo registrarla ante alguno de sus departamentos (no } \\
\text { recuerdo cuál), lo cual da flojera y lo veo innecesario, porque lo que produzco lo } \\
\text { puedo hacer sin un convenio o registro. }\end{array}$ \\
\hline & $\begin{array}{l}\text { Disminuir la carga administrativa de los profesores-investigadores o eficientizar los } \\
\text { procesos ayudaría enormemente en las gestiones de enlace de la UABC. }\end{array}$ \\
\hline
\end{tabular}




\begin{tabular}{|c|c|}
\hline $\begin{array}{c}\text { Dimensión } \\
\text { analítica }\end{array}$ & Comentarios de los académicos \\
\hline \multirow{4}{*}{$\begin{array}{c}\text { Procesos } \\
\text { Administrativos }\end{array}$} & $\begin{array}{l}\text { Creo que debe prestarse mayor atención a la transferencia de conocimiento por } \\
\text { medio de agentes de transferencia (knowledge brokers) que deben establecer un } \\
\text { enlace entre los creadores y los sectores de interés (por ejemplo, del sector productivo } \\
\text { u otros), con los cuales requerimos vincularnos. }\end{array}$ \\
\hline & $\begin{array}{l}\text { Considero que hace falta más actividad en los encargados de hacer vinculación, } \\
\text { ya que uno como persona moral puede acercarse, pero hay toda una línea de } \\
\text { procedimientos que desconocemos, o bien, que no nos compete conocer. Así que } \\
\text { estosgrupos deberían estar alineados en este sentido, en promover la vinculación con } \\
\text { el entorno social para transmitir información, o en el mejor de los casos, tecnologías } \\
\text { (cualquiera que fuese el contexto). }\end{array}$ \\
\hline & $\begin{array}{l}\text { Es una actividad que merece ser apoyada institucionalmente de manera decidida y } \\
\text { mediante mecanismos claros y sencillos que faciliten la realización de proyectos de } \\
\text { investigación que aporten mayores elementos de información para la solución de } \\
\text { problemas regionales y locales. }\end{array}$ \\
\hline & $\begin{array}{l}\text { Se encuentra limitada, no hay agilidad administrativa ni esquema de incentivos } \\
\text { para promover esta vertiente. La actividad docente tradicional es la estrategia } \\
\text { preponderante y no se ha aceptado el paradigma de la mejora de la docencia a } \\
\text { través de la investigación y la vinculación. }\end{array}$ \\
\hline \multirow{2}{*}{$\begin{array}{l}\text { Conflicto } \\
\text { de interés }\end{array}$} & $\begin{array}{l}\text { A la UABC sólo le interesan los proyectos de vinculación que dejen dinero. El tercer } \\
\text { sector casi no es tomado en cuenta, a menos que se dé de modo asistencialista, pero } \\
\text { entonces el apoyo es mínimo. }\end{array}$ \\
\hline & $\begin{array}{l}\text { La institución ha perdido posicionamiento por los grupos de la administración } \\
\text { central desde hace } 16 \text { años, que solo tienen interés en unas cuantas familias que se } \\
\text { benefician. }\end{array}$ \\
\hline $\begin{array}{l}\text { Implicaciones } \\
\text { formativas }\end{array}$ & $\begin{array}{l}\text { La colaboración es muy importante ya que fortalece la docencia. Solo si de ésta } \\
\text { salen proyectos de investigación, no como venta de servicios. Debe haber siempre } \\
\text { algo a cambio que favorezca al entorno o a la Universidad (estudiantes). También } \\
\text { esta colaboración favorece enormemente a los estudiantes en formación para que } \\
\text { puedan integrarse al sector productivo. }\end{array}$ \\
\hline
\end{tabular}




\begin{tabular}{cl}
$\begin{array}{c}\text { Dimensión } \\
\text { analítica }\end{array}$ & \multicolumn{1}{c}{ Comentarios de los académicos } \\
\hline \multirow{2}{*}{$\begin{array}{c}\text { Implicaciones } \\
\text { formativas }\end{array}$} & \begin{tabular}{l} 
El estudiante atiende problemas reales que tienen las empresas. \\
\cline { 2 - 2 } de ella.
\end{tabular} \\
\hline Prestigio/ & $\begin{array}{l}\text { Ésta es muy importante porque es lo que nos ayuda a crecer en nuestro entorno } \\
\text { posicionamiento la posibilidad de enfrentarse a la realidad, sensibilizarsey aprender }\end{array}$ \\
\hline \multirow{2}{*}{$\begin{array}{c}\text { Desarrollo nivel local y regional, como nacional e internacional. } \\
\text { social }\end{array}$} & $\begin{array}{l}\text { Considero que la vinculación con Organizaciones de la Sociedad Civil es una forma } \\
\text { de fortalecer el capital social de nuestra localidad, precisamente en una coyuntura } \\
\text { en que pocos actores sociales y políticos están interesados en apoyar. }\end{array}$ \\
\hline
\end{tabular}

En general, lo que se encuentra en estas opiniones es una perspectiva crítica acerca de cómo se lleva a cabo la gestión de las actividades de colaboración tecnocientífica y sobre el rumbo que debería seguir esta función universitaria. Resalta el hecho de que la UABC cuenta con muchas potencialidades para ampliar y profundizar la colaboración con los actores del entorno, particularmente, con las organizaciones del tercer sector.

\section{Conclusiones}

Desde la perspectiva sociológica, la importancia de que la Universidad colabore con el tercer sector puede entenderse en el contexto de la crisis que México padece. Sin embargo, también se trata de un argumento histórico: la universidad debe volver a su cauce, el de resolver una necesidad social. Pero esta respuesta no puede remitirse solo a la formación de recursos humanos, sino que debe adherirse a las funciones de investigación, con una producción de conocimiento más sensible a los requerimientos de la sociedad, y a la de colaboración, estrechando lazos con los actores sociales más necesitados.

A través del presente capítulo, ha quedado claro que el olvido del tercer sector no es una excepción en la UABC. Se habla de olvido, en la medida en que la resolución de las problemáticas sociales sí fue contemplada en la normatividad universitaria, pero se ha diluido en el vaivén de las reformas políticas y económicas. Además del olvido, 
es importante hablar de las áreas de mejora. La UABC aún contempla en su modelo educativo (referente pedagógico de sus funciones) diversos mecanismos para atender las necesidades sociales. El problema sobreviene al observar que estos mecanismos, aunque estructurados, presentan numerosas distorsiones.

El primero de estos vicios, se encuentra en el rubro del servicio social, una herramienta que, por su naturaleza filosófica y su carácter constitucional, podría ser el canal idóneo para colaborar con el tercer sector. En su lugar, es posible observar que esta modalidad de aprendizaje, en sus dos facetas (comunitaria y profesional), se encuentra sitiada por la propia Universidad. Así, como ya fue mencionado, la UABC podría estar contemplando en este mecanismo una vía para sobrellevar los recortes presupuestales utilizando, a cambio, prestadores de servicio social como empleados no remunerados (Vallaeys, 2003).

Para afianzar las áreas de oportunidad detectadas en materia de colaboración con el tercer sector, es útil retomar los comentarios de los académicos. En particular, los participantes señalaron dos grandes obstáculos en el proceso de colaboración con el tercer sector. El primero de ellos, es de carácter político y se traduce en un débil compromiso social; pero el interés de la Universidad en realizar solo aquellas actividades que conlleven un beneficio económico también podría leerse en el marco de la escasez presupuestal. Mientras, el segundo obstáculo señalado por los académicos es de carácter operativo: la imprecisión normativa y la lentitud administrativa. Aunque estas últimas no son, de alguna manera, sino expresiones del débil compromiso institucional.

En síntesis, el reto que la UABC enfrenta es el de estar a la altura de las necesidades de la sociedad que la sostiene; y, más que nada, el de formar a una generación responsable y crítica, interesada en colaborar con actores económicamente redituables, pero también en contribuir a la construcción de un entorno más equitativo. Entendiendo que, de no hacerlo, se desaprovecharía el potencial de organizaciones que tienen conocimiento de vanguardia sobre la problemática social y se pondría en tela de juicio la congruencia discursiva de la Universidad, en tanto que el humanismo, como postura filosófica, no puede olvidarse nunca de los necesitados. 


\section{Referencias}

Aguilar, R. (2006). Las organizaciones de la sociedad civil en México: su evolución y principales retos. México: Universidad Iberoamericana.

Campos, G., \& Sánchez, G. (2006). La vinculación universitaria y sus interpretaciones. Ingenierías, 9(30), 18-25.

Carta de Universidades Latinoamericanas (1951). Documento emanado del Primer Congreso de Universidades Latinoamericanas. México: Universidad Nacional Autónoma de México.

Dmitrishin, A. (2013). Deconstructing Distinctions. The European University in Comparative Historial Perspective. Entremons, UPF Journal of World History, (5), $1-18$.

Freire, P. (1978). La educación como práctica de la libertad. España: Siglo XXI Editores.

Ibarra, E. (2003). Capitalismo académico y globalización: la universidad reinventada. Educação \& Sociedade, 24(84).

Kerr, C. (1983). The Uses of the University. Boston: Harvard University Press.

Luna, M. (1997). Panorama de la vinculación en la Universidad Autónoma Metropolitana. En Gobierno, academia y empresas en México: Hacia una nueva configuración de relaciones. México: Plaza y Valdés.

Moncada, J. (2008). La universidad: un acercamiento histórico-filosófico. Ideas y Valores, $17,131-138$.

Paiva, V. (2004). ¿Qué es el tercer sector? Revista Científica de UCES, 8(1), 99-116.

Perkin, H. (2007). History of Universities. In J. Forest \& P. Altbach (Eds.), International Handbook of Higher Education (pp. 159-205). USA: Springer.

Rashdal, H. (1987). The Univerities OfEurope in the Middle Ages. Londres: Oxford University Press.

Salamon, L., \& Anheier, H. (1995). En busca del sector no lucrativo: la cuestión de las definiciones. Umbral XXI, 14-15.

Tünnermann, C. (1999). Historia de las universidades de América Latina. Costa Rica: Editorial Universitaria Centroamericana. 
Universidad Autónoma de Baja California. (1957). Ley Orgánica de la Universidad Autónoma del Estado de Baja California. Baja California, México: UABC.

Universidad Autónoma de Baja California. (1983). Estatuto General de la Universidad Autónoma de Baja California. Baja California, México: UABC.

Universidad Autónoma de Baja California. (2007). Reglamento de Servicio Social de la Universidad Autónoma de Baja California. Baja California, México: UABC.

Universidad Autónoma de Baja California. (2013). Modelo Educativo de la UABC. Baja California, México: UABC.

Vallaeys, F. (2003). Orientaciones para la enseñanza de la ética, el capital social y el desarrollo en las universidades latinoamericanas. Revista Venezolana de Gerencia, $8(21)$.

Yoshimoto, T. (2006). Why the Third Sector in Japan Dit Not Succeed: A Critical View on Third Sectors as Service Providers. Public Performance \& Managament Review, 30(2), 139-154. 


\title{
Capítulo 8
}

\section{Contexto institucional de la cooperación IES-sector productivo: marco general para México y Baja California}

\author{
Marcela Morales Páez, Rodolfo García-Galván \\ y Juan Carlos Rodríguez Macías
}

Desde hace algunos años se ha venido consolidando una rica discusión de lo que representan los arreglos institucionales para el desarrollo económico y social regional. De hecho, buenos entramados institucionales (normas jurídicas avanzadas, reglas y convenciones sociales que abonen a una mayor civilización; así como instrumentos de planeación bien sustentados, y que impliquen una correspondencia inteligente entre los niveles aspiracionales y la realidad de la que se parte), pueden detonar el desarrollo regional.

Ahora bien, si se percibe que las instituciones vigentes no están coadyuvando lo suficiente para promover el crecimiento y el desarrollo, entonces, pueden implementarse reformas o adecuaciones que propicien el fomento de las actividades relacionadas. De este modo, en las universidades, y en las instituciones de educación superior (IES), en general, se han registrado sendas reformas en las últimas décadas cuyo objetivo primordial ha sido provocar un mayor acercamiento entre las IES y el sector productivo (SP); a estas reformas, Acosta (2000) y García-Galván (2018) las han señalado como cambios institucionales en las organizaciones del conocimiento. Estos cambios en los arreglos institucionales se han registrado, principalmente, en los últimos dos decenios; por consiguiente, en este capítulo nos proponemos responder a la pregunta: ¿Cuáles son los principales rasgos del cambio institucional respecto a la cooperación IES-SP, 
registrados en México y Baja California, y a la vez reflejados en los arreglos normativos y en los instrumentos de planeación?

El objetivo es identificar y describir los elementos normativos jurídicos y de la planeación estratégica, nacional y estatal, que impliquen manifestaciones de fomento e impulso a la cooperación tecnocientífica IES-SP.

En lo referente a la estrategia metodológica, que a la vez se va reflejando en la estructura del capítulo, se parte de una revisión teórico-conceptual de las instituciones, teniendo en cuenta que la cooperación IES-SP puede considerarse como una nueva institución; asimismo, se revisan rápidamente los mecanismos, las estrategias y los modos de la cooperación. Después de esta revisión, se procede a realizar un análisis de contenido de las bases institucionales nacionales y estatales que sustentan la cooperación tecnocientífica. En efecto, se trata de un análisis de contenido deductivo, iniciando con categorías generales que luego se concretizan en las legislaciones y en los documentos de la planeación estratégica.

\section{¿Qué son las instituciones?}

Desde el enfoque de la Nueva Economía Institucional, las instituciones se dividen en dos tipos: (a) instituciones formales, que incluyen las reglas establecidas explícitamente, por ejemplo, leyes, reglamentos y normas oficiales, y (b) las instituciones informales, que son regulaciones implícitas en el comportamiento de un grupo social específico, como convenciones y códigos de conducta; ambos tipos de instituciones regulan la interacción entre individuos y organizaciones, además estructuran incentivos en el intercambio político, social y económico (Caballero, 2011; North, 1993 [2006]).

Por su parte, los seguidores de la perspectiva evolucionista utilizan un concepto muy amplio de instituciones, el cual abarca tanto a las organizaciones (corporaciones, bancos y universidades) como a entidades sociales integradas y sistemáticas como el dinero, el lenguaje, las leyes, hábitos, reglas, costumbres, tradiciones y convenciones sociales (Vertova, 2014).

En la tabla 1 se enlistan algunas de las aportaciones más relevantes a la definición de las de instituciones. 
Tabla 1

Principales aportaciones a la conceptualización de las instituciones

\begin{tabular}{|c|c|}
\hline & Conceptualización \\
\hline North (1993) & $\begin{array}{l}\text { Las instituciones son las reglas del juego en una sociedad, es decir, las limitaciones } \\
\text { creadas por el hombre que conforman el marco en cuyo interior ocurre la interacción } \\
\text { humana: estructuran incentivos en el intercambio humano político, social y } \\
\text { económico. }\end{array}$ \\
\hline $\begin{array}{c}\text { Hodgson } \\
\text { (2007) }\end{array}$ & $\begin{array}{l}\text { Las instituciones son las estructuras sociales de mayor importancia, ya que consti- } \\
\text { tuyen la esencia misma de la vida en sociedad, al permitir, limitar y contribuir a la } \\
\text { construcción de patrones de comportamiento. "Las instituciones son sistemas dura- } \\
\text { deros de reglas sociales, establecidas e incrustadas, que estructuran las interacciones } \\
\text { sociales" (p. 19). }\end{array}$ \\
\hline Aoki (2007) & $\begin{array}{l}\text { Una institución es un patrón sobresaliente y autosustentado de interacciones sociales, } \\
\text { ya que es representado por reglas significativas que cada agente conoce, las cuales } \\
\text { son incorporadas al comportamiento social cuando los agentes comparten creencias } \\
\text { acerca de cómo debe jugarse el juego. }\end{array}$ \\
\hline $\begin{array}{c}\text { Gandlgruber } \\
\text { (2007) }\end{array}$ & $\begin{array}{l}\text { "(...) las instituciones: se perciben como entidades que guían las acciones individuales, } \\
\text { creando patrones estables de comportamiento. Estos patrones son resultado de } \\
\text { diversos procesos vinculados de replicación y de selección de los diferentes tipos } \\
\text { de arreglos institucionales. Se muestra la existencia de una relación directa entre los } \\
\text { procesos de formación de diferentes instituciones, particularmente entre las rutinas } \\
\text { organizacionales y los hábitos individuales" (p. 101). }\end{array}$ \\
\hline $\begin{array}{c}\text { North, Wallis } \\
\text { y Weingast } \\
(2009)\end{array}$ & $\begin{array}{l}\text { Las instituciones son distintas a las organizaciones: son las reglas del juego, los } \\
\text { patrones de interacción que gobiernan y restringen las relaciones entre individuos. } \\
\text { Las instituciones incluyen reglas formales, leyes escritas, convenciones sociales } \\
\text { formales, normas informales de comportamiento; y comparten creencias acerca del } \\
\text { mundo, tanto como los medios de ejecución. }\end{array}$ \\
\hline $\begin{array}{c}\text { Greif y } \\
\text { Christopher } \\
\text { (2011) }\end{array}$ & $\begin{array}{l}\text { El estudio de las instituciones como enfoque de equilibrio se centra en las } \\
\text { manifestaciones del comportamiento de la motivación endógena: de qué manera el } \\
\text { comportamiento genera instituciones que perpetúan este comportamiento. Por lo } \\
\text { tanto, la dinámica institucional trata fundamentalmente acerca de los cambios en la } \\
\text { motivación, y de las regularidades del comportamiento; el foco analítico está en los } \\
\text { cambios en creencias, normas y expectativas. }\end{array}$ \\
\hline
\end{tabular}


De las definiciones presentadas en tabla 1, destacan las aportaciones de North (1993), Hodgson (2007), Aoki (2007) y North et al. (2009), en las que hay un consenso, al considerar que las instituciones estructuran y facilitan las interacciones sociales (entre los individuos y entre las organizaciones). En este sentido, la ampliación e intensificación de la colaboración IES-SP puede apreciarse como un tipo de institución inherente a la economía y sociedad basadas en el conocimiento. Más aún, García-Galván (2018) establece que los movimientos en sentidos diferentes en las políticas universitarias (nuevos arreglos legislativos, planeación estratégica, reestructuración organizacional, nuevos esquemas de incentivos) y en las estrategias empresariales, pueden ser considerados como un cambio institucional en los dos ámbitos (organizaciones del conocimiento y empresas).

Una perspectiva interesante es la de Searle (2005), quien en lugar de definir qué es una institución, propone comenzar con declaraciones que reportan hechos institucionales; de manera que, al analizar la naturaleza de los hechos institucionales y la forma en que difieren de otros tipos de hechos, se podrá responder a la pregunta ¿Qué es una institución? Según este autor, existen tres nociones primarias para explicar la realidad social e institucional:

1. Intencionalidad colectiva (común a humanos y animales). La intencionalidad es el rasgo de la mente por el cual ésta se dirige hacia los asuntos del mundo (las creencias, deseos, temores, percepciones son intencionales). La intencionalidad colectiva es la base de toda sociedad.

2. Asignación de una función (común a humanos y animales). Es la capacidad de imponer funciones a objetos donde el objeto no tiene esa función intrínsecamente. La asignación de funciones es relativa al observador.

3. Funciones de estatus (específica de los seres humanos). Es un tipo especial de asignación de función en el cual el objeto o persona a la cual se ha asignado la función desempeña dicha función no solamente en virtud de su estructura física, sino que puede desempeñarla en virtud del hecho de que existe una asignación y aceptación colectiva de cierto estatus; es decir, $X$ cuenta como $Y$ en $C$, donde 
$X$ es un objeto, persona o estado de asuntos, $Y$ es el estatus especial y $C$ es el contexto.

Sintetizando las aportaciones de los autores antes citados, se puede establecer que las instituciones son conjuntos de normas, reglas y convenciones sociales que regulan la interacción entre los individuos que pertenecen a grupos sociales particulares, las cuales pueden estar, o no, personificadas por organizaciones.

Aunque, como se ha mencionado en otros trabajos (García-Galván, 2011; 2018), la cooperación IES-SP es un modo de coordinación económica que se ubica entre el mercado y la jerarquía; ello no implica un desapego de reglas y convenciones menores, e incluso una nueva cultura organizacional; asimismo, conforme se consolida la interacción surgen nuevas instituciones (reglas y convenciones), y esto es lo que se está observando en el seno de las organizaciones del conocimiento.

En la práctica, un marco institucional particular está conformado por instituciones formales, generadas y organizadas para cumplir con un propósito específico. De este modo, las tendencias actuales sugieren que, las IES y las empresas están cada vez más interesadas en intensificar sus interacciones con la finalidad de obtener beneficios mutuos.

\section{Mecanismos, estrategias y modos de cooperación}

En la literatura revisada sobre la cooperación universidad-empresa, destaca el hecho de que ésta se lleva a cabo en distintos niveles de concreción. A continuación, se exponen algunos de los principales conceptos relacionados con la temática.

De inicio, se precisa que, a diferencia del mecanismo como un proceso natural o como directrices normativas supremas, las estrategias pueden concebirse como un conjunto de lineamientos pensados y diseñados para lograr un objetivo o una meta respecto a algún asunto específico; en este caso, el fomento tecnocientífico en las regiones. En consecuencia, si pensamos en estrategias tenemos que pensar en quién o quiénes trazan las mismas; hasta ahora han sido fundamentalmente los entes gubernamen- 
tales -mediante las políticas públicas o gubernamentales-, pero cada vez se adhieren más actores como las mismas empresas, las universidades y las diversas organizaciones sociales que permanecen al margen de las estructuras del poder oficial. En este sentido, de acuerdo con Gibbons et al. (1997) y Latour (1992), se supone que en las nuevas formas de producción y aprovechamiento del conocimiento tecnocientífico participan múltiples actores interesados' ${ }^{1}$.

En particular, Villasana (2011) menciona que la interacción entre las organizaciones es un "mecanismo" esencial para el intercambio de conocimiento y la colaboración, con el objetivo de promover la innovación, como un elemento común que se comparte. La misma autora, haciendo referencia al modelo de la triple hélice, menciona que éste destaca la importancia de financiar la asignación y creación de "mecanismos" que promuevan las relaciones entre la universidad y la industria.

Por su parte, la Comisión Económica para América Latina y el Caribe (CEPAL, 2010) ha venido promoviendo "estrategias" para acercar las organizaciones del conocimiento (universidades y centros públicos de investigación) con las empresas. El objetivo es avanzar en la comprensión de dicha relación, factor que es determinante de las posibilidades de innovar, de realizar transferencia tecnológica y de generar efectos de difusión del conocimiento en la sociedad. Las estrategias promovidas, por este organismo multilateral regional, están encaminadas a buscar una senda de crecimiento y desarrollo sostenidos para América Latina.

En este contexto, las IES y las agencias reguladoras (gubernamentales), desempeñan un papel primordial en la instauración del cambio tecnológico, el desarrollo científico y la dinámica innovadora de los países. Sin embargo, dichos agentes, generalmente no operan de acuerdo con la lógica del mercado, lo cual genera una serie de retos al diseñar los instrumentos y mecanismos necesarios para impulsar el desarrollo

1 Por ejemplo, para Latour (1992) los actores que participan en los hechos científicos y tecnológicos, no se limitan, ni de lejos, a los investigadores y académicos especializados; en la lista, que incluso puede considerarse corta, se incluyen políticos, funcionarios, empresarios y fundaciones altruistas. 
científico y tecnológico (CEPAL, 2010). La CEPAL también destaca que, en la mayoría de los países de Latinoamérica, las instituciones de educación superior (IES) generalmente no cuentan con una "estrategia" definida orientada a regular las actividades de investigación con el fin de favorecer la innovación y la transferencia de tecnologías. Entonces, las universidades y centros de investigación requieren hacer mayores esfuerzos para delinear más y mejores estrategias para el fomento tecnocientífico, pero estas estrategias necesitan su contraparte en el sector productivo. Sin embargo, si la meta es embarcarse en la trayectoria de la economía y sociedad basada en el conocimiento, tanto empresas como IES tienen que intensificar su colaboración.

En síntesis, en el diseño de políticas y estrategias tecnocientíficas novedosas y de mayor efectividad se requiere garantizar la participación de los principales actores interesados, pero esa participación simultánea tiene que ser guiada y coordinada por algún agente que actúe como el timonel, ese agente normalmente se representa por el Estado-gobierno (concretado en su ministerio de ciencia y tecnología). En efecto, aludiendo a la noción de tecnociencia, la promoción del desarrollo científico y de la innovación tecnológica, es un asunto que compete a tres agentes fundamentales; es decir, las universidades, las organizaciones del conocimiento y las empresas.

Por otra parte, García-Galván (2011) destaca que las alianzas que se realizan entre empresas asumen muchas formas de colaboración, entre las que destacan las empresas conjuntas (joint ventures), las franquicias y la subcontratación. A partir de su descripción, se deduce el sentido de equivalencia que se da a los términos "forma" y "modalidad". Además, este autor propone la siguiente tipología para la cooperación que se lleva a cabo entre los distintos tipos de organizaciones (tabla 2). Por consiguiente, para García-Galván, tipo, forma y modalidad pueden tomarse como sinónimos o equivalentes cuando se analizan los nexos o los vínculos entre las OC y las empresas.

De forma similar, para la CEPAL (2010), los distintos "tipos" de interacción incluyen varios "canales", por ejemplo, para el tipo proyectos conjuntos se presentan los canales: cooperación en investigación y desarrollo, contratos de investigación, intercambio de investigadores, redes formales de trabajo, y parques científicos y tecnológicos; de ma- 
Tabla 2

Los tipos de cooperación de las firmas y sus fines

\begin{tabular}{|c|c|c|}
\hline Tipos & Socios & Fines \\
\hline Vertical & $\begin{array}{c}\text { Proveedores y } \\
\text { clientes }\end{array}$ & $\begin{array}{l}\text { Cuando las firmas no son directamente competidoras, sino } \\
\text { independientesenelmercadoodebienescomplementarios. } \\
\text { Es de suma importancia seguir a los clientes para ayudar a } \\
\text { definir las innovaciones (nuevos productos, novedosos o } \\
\text { complejos). La meta de la cooperación con los proveedores } \\
\text { ha estado más ligada a la reducción de costos y subcontratar } \\
\text { actividades a los proveedores. }\end{array}$ \\
\hline Horizontal & $\begin{array}{c}\text { Competidores, } \\
\text { rivales }\end{array}$ & $\begin{array}{l}\text { Se ha enfocado, principalmente, a las alianzas para alcanzar } \\
\text { economías de escala, y sobre los acuerdos para minimizar los } \\
\text { costos y disminuir los riesgos de los proyectos tecnológicos. }\end{array}$ \\
\hline $\begin{array}{l}\text { Interorganizacional } \\
\text { o transveral }^{1}\end{array}$ & $\begin{array}{l}\text { Universidades, } \\
\text { centros } \\
\text { públicos de } \\
\text { investigación }\end{array}$ & $\begin{array}{l}\text { La cooperación entre las organizaciones del conocimiento } \\
\text { (OC) y la industria se ha intensificado. Las firmas ven a la } \\
\text { ciencia pública como una fuente externa de rápido acceso. } \\
\text { La ciencia es más importante como fuente de información } \\
\text { para la innovación en aquellos campos basados en la ciencia } \\
\text { y la tecnología. Además, la cooperación con la academia } \\
\text { es vista como una fuente no cara del conocimiento } \\
\text { especializado. }\end{array}$ \\
\hline
\end{tabular}

Fuente: Adaptación de García-Galván (2011, p. 194).

1 Si bien, García-Galván (2011) consideró a la colaboración empresa-universidad como cooperación interorganizacional, el mismo autor en un trabajo posterior (García-Galván, 2014), después de realizar nuevas búsquedas y ampliar sus reflexiones, consideró que era mejor considerar a este tipo de colaboración como transversal, pues se refiere a la consecución de objetivos y metas comunes de organizaciones ontológicamente disímbolas. También es justo reconocer que el término apareció primero en González (2003), y de ahí fue retomado, aunque con nuevos matices. 
nera similar, para el tipo licenciamiento, los canales serían: patentes, oficinas de transferencia tecnológica (CEPAL, 2010). Asimismo, la CEPAL (2010) destaca que la interacción que se da entre las IES y las empresas depende de la institucionalidad de cada país y que puede presentar formas, intensidad y canales, diversos y cambiantes.

El recorrido teórico-conceptual previo sienta las bases para pasar a la discusión concreta de lo que establecen los arreglos normativos y legislativos; así como los actos político-administrativos y operativos que representa la planeación estratégica. En ambas dimensiones simbólicas (normas y planeación), se justifica y promueve un mayor acercamiento entre las IES y las empresas, y más específicamente, se estimulan y fomentan ciertas modalidades de cooperación IES-empresas. Veamos de qué se trata en el siguiente apartado.

\section{Normatividad y prospectiva de la cooperación IES-sector productivo}

En esta sección se presenta el posicionamiento de las actividades de vinculación entre las IES y el sector productivo al interior del marco institucional nacional y estatal. Como parte de este marco se considera tanto la normatividad (legislación) como la prospectiva derivada de los instrumentos de planeación. Una aproximación a la relevancia que se le otorga en las legislaciones, a la función de colaboración con el sector productivo, es la cantidad y la centralidad de los artículos referidos al fenómeno; es desde este enfoque que se presenta el siguiente análisis.

\section{La cooperación IES-SP en la legislación nacional y estatal}

Las leyes de carácter nacional que hacen referencia a las actividades de vinculación entre las IES y el sector productivo son: a) Ley General de Educación, b) Ley de Ciencia y Tecnología, y c) Ley General de Responsabilidades Administrativas. Asimismo, en el ámbito estatal destaca la Ley de Educación del Estado de Baja California.

De inicio, en la Ley General de Educación (2018), los artículos de particular relevancia para la temática en cuestión son tres: 12,13 y 25. Por otra parte, once artículos: 1 , 2, 8, 12, 13, 21, 25 BIS, 40, 40 BIS, 51 y 64, de la Ley de Ciencia y Tecnología (2015) hacen 
referencia a cuestiones relacionadas con la cooperación IES-SP. Por sus implicaciones institucionales disruptivas, es de particular interés a nivel nacional, el artículo 37 de la Ley General de Responsabilidades Administrativas (2016) (tabla 3).

\section{Tabla 3}

Legislación nacional

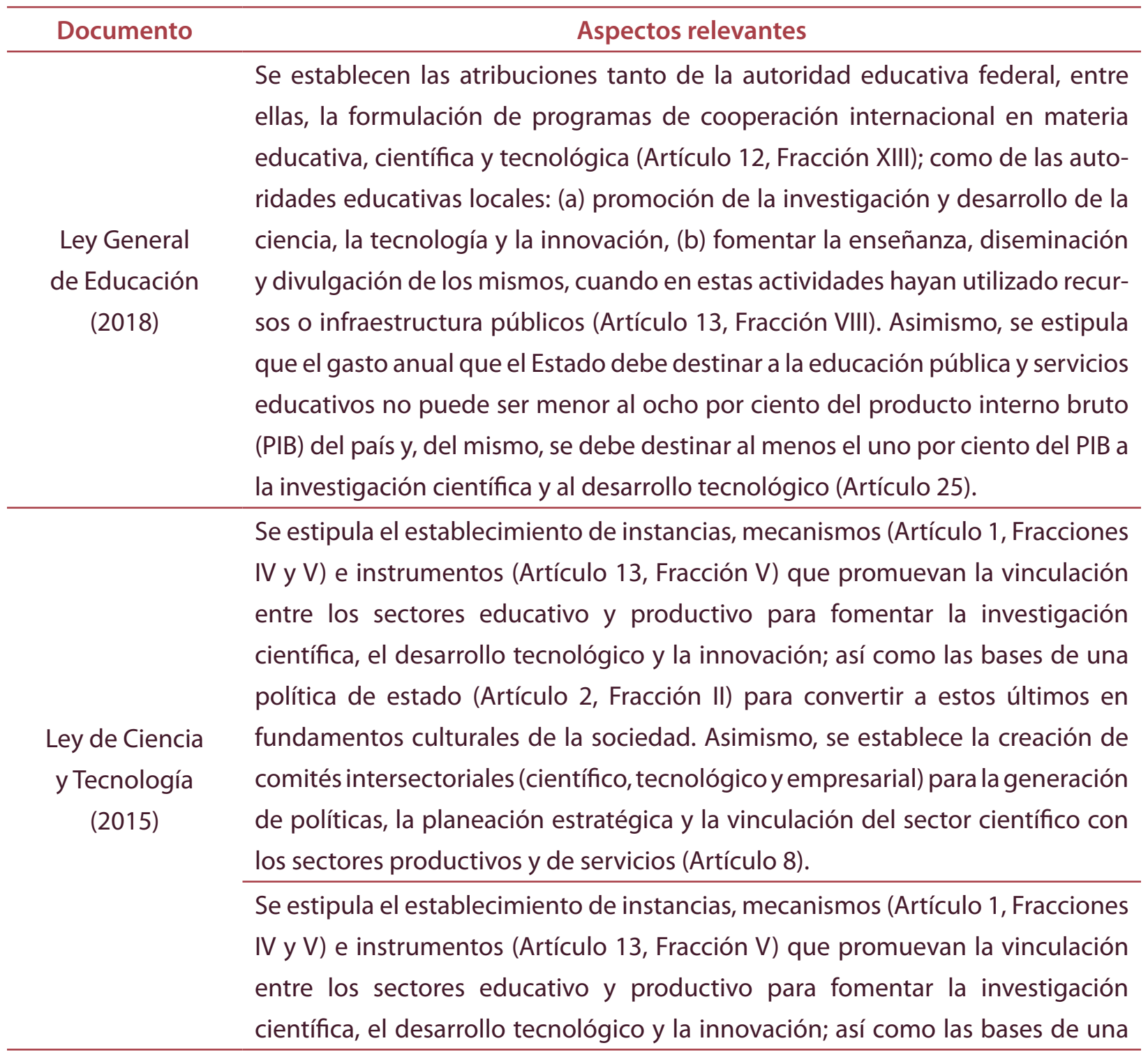




\begin{tabular}{|c|c|}
\hline Documento & Aspectos relevantes \\
\hline \multirow{4}{*}{$\begin{array}{c}\text { Ley de Ciencia } \\
\text { y Tecnología } \\
\text { (2015) }\end{array}$} & $\begin{array}{l}\text { política de estado (Artículo 2, Fracción II) para convertir a estos últimos en fun- } \\
\text { damentos culturales de la sociedad. Asimismo, se establece la creación de comi- } \\
\text { tés intersectoriales (científico, tecnológico y empresarial) para la generación de } \\
\text { políticas, la planeación estratégica y la vinculación del sector científico con los } \\
\text { sectores productivos y de servicios (Artículo 8). }\end{array}$ \\
\hline & $\begin{array}{l}\text { En lo referente a los recursos públicos otorgados para las actividades de inves- } \\
\text { tigación científica, desarrollo tecnológico e innovación, los mismos deberán in- } \\
\text { cidir en la enseñanza-aprendizaje de la ciencia y la tecnología, la calidad de la } \\
\text { educación superior, y la vinculación con el sector productivo y de servicios. Los } \\
\text { recursos antes mencionados pueden provenir de fondos públicos y privados, } \\
\text { nacionales e internacionales, creando para tal fin incentivos fiscales (Artículo 12, } \\
\text { Fracciones V, VI, VII). }\end{array}$ \\
\hline & $\begin{array}{l}\text { Se señala la creación del Programa Especial de Ciencia, Tecnología e Innovación } \\
\text { (PECiTI) como parte de las atribuciones del Consejo Nacional de Ciencia y Tec- } \\
\text { nología (CONACYT) (Artículo 21). También se menciona el establecimiento de } \\
\text { fondos sectoriales de innovación, los cuales tienen como propósito el desarrollo } \\
\text { de redes, unidades de vinculación y trasferencia de conocimiento, empresas y } \\
\text { actividades de base tecnológica, actividades y empresas que vinculen a los sec- } \\
\text { tores científico y productivo; así como la creación y consolidación de parques } \\
\text { científicos y tecnológicos (Artículo } 25 \text { Bis, Fracciones I, II, III, VI, VII). }\end{array}$ \\
\hline & $\begin{array}{l}\text { Con respecto al impulso del desarrollo científico en el sector privado, se conce- } \\
\text { de prioridad a los proyectos vinculados con la pequeña y mediana empresa (Ar- } \\
\text { tículo 40). En lo referente al sector público, las entidades que realicen activida- } \\
\text { des de investigación científica, desarrollo tecnológico e innovación (incluyendo } \\
\text { universidades y centros de investigación) pueden crear unidades de vinculación } \\
\text { y transferencia de conocimiento (Artículo } 40 \text { Bis), y conformar asociaciones es- } \\
\text { tratégicas, alianzas tecnológicas, consorcios, nuevas empresas privadas de base } \\
\text { tecnológica y redes regionales de innovación (Artículo 51), con el propósito de } \\
\text { incorporar los desarrollos tecnológicos e innovaciones realizadas en las mismas. } \\
\text { Por último, para incrementar la disponibilidad del conocimiento científico hacia } \\
\text { los educandos, educadores, académicos, investigadores, científicos, tecnólogos } \\
\text { y población en general; se estipula la creación de repositorios - de publicaciones } \\
\text { en formato digital- por disciplinas científicas y tecnológicas (Artículo 64). }\end{array}$ \\
\hline
\end{tabular}




\begin{tabular}{|c|c|}
\hline Documento & Aspectos relevantes \\
\hline $\begin{array}{l}\text { Ley General de } \\
\text { Responsabilidades } \\
\text { Administrativas } \\
\text { (2016) }\end{array}$ & $\begin{array}{l}\text { Se establece que los investigadores de universidades y centros de investigación } \\
\text { públicos pueden llevara caboactividades de vinculación con los sectores público, } \\
\text { privado y social, y recibir beneficios por las mismas. Entre estas actividades } \\
\text { se citan: "participación de investigación científica y desarrollo tecnológico } \\
\text { con terceros; transferencia de conocimiento; licenciamientos; participación } \\
\text { como socios accionistas de empresas privadas de base tecnológica o como } \\
\text { colaboradores o beneficiarios en actividades con fines de lucro derivadas de } \\
\text { cualquier figura de propiedad intelectual perteneciente a la propia institución, } \\
\text { centro o entidad, según corresponda" (Artículo 37). }\end{array}$ \\
\hline
\end{tabular}

En la contraparte estatal, la Ley de Educación del Estado de Baja California (2015) incluye dos artículos importantes: el 14 y el 16 BIS (tabla 4). Aunque, es preciso advertir que, normalmente, los arreglos institucionales de alcance regional (estatal) sólo hacen eco de las pautas que marcan las normas y legislaciones nacionales; y pocas veces, trascienden las directrices enmarcadas.

Tabla 4

Legislación nacional

Documento Aspectos relevantes

Se establece como fin de la educación pública, "Impulsar actitudes que Ley de Educación estimulen la investigación e innovación científica y tecnológica, procurando la del Estado de Baja vinculación con el sector productivo" (Art. 14, Frac VII). Entre las atribuciones California del ejecutivo del estado y los ayuntamientos, en materia educativa, destaca (2015) "Promover la investigación y el desarrollo de la ciencia y la tecnología, y fomentar su enseñanza y divulgación" (Art. 16BIS, Frac. X).

\section{La cooperación IES-SP en la planeación nacional y estatal}

De forma similar que, para la legislación, a continuación, se presentan las aportaciones relevantes en los distintos instrumentos de planeación. 
Respecto del Plan Nacional de Desarrollo 2013-2018 (Presidencia de la República, 2013) destaca el Objetivo 3.5, con las correspondientes Estrategias 3.5.1, 3.5.4 y 3.5.6 de la Meta Nacional III, México con educación de calidad; a través de los cuales, se pretende vincular los distintos niveles educativos con el quehacer científico, el desarrollo tecnológico y el sector productivo. En el Programa Sectorial de Educación 2013-2018 (Secretaría de Educación Pública [SEP], 2013) se establecieron seis objetivos para articular los esfuerzos en materia educativa; en cada caso, se generaron las estrategias y líneas de acción correspondientes. En particular, el objetivo 6 es el encaminado a fortalecer el desarrollo de la ciencia y la tecnología. Entre los objetivos, estrategias y líneas de acción del Programa Especial de Ciencia, Tecnología e Innovación 2014-2018 (CONACYT, 2014) es de interés primordial el objetivo 4 y las estrategias 4.1 y 4.2. Por último, la Asociación Nacional de Universidades e Instituciones de Educación Superior (ANUIES, 2016) para solventar las necesidades establecidas en el Plan de Desarrollo Institucional, Visión 2030 presenta el objetivo estratégico II, así como el objetivo específico 2.2 (tabla 5).

\section{Tabla 5}

Planeación nacional

\section{Documento Aspectos relevantes}

En la Meta Nacional III (México con educación de calidad) se propone implementar políticas de Estado que vinculen los niveles educativos con el quehacer científico, el desarrollo tecnológico y el sector productivo, lo anterior con el propósito de formar profesionistas que coadyuven al fortalecimiento de la innova-

Plan Nacional de

Desarrollo 2013-2018 ción nacional (p. 59). En el diagnóstico realizado para dicha meta se menciona que: (a) es necesario ajustar la oferta educativa con los requerimientos de los sectores social y productivo (p. 62); (b) la contribución de México a la producción mundial de conocimiento es menor al 1\% (p. 63); (c) para propiciar el desarrollo en ciencia y tecnología es necesario que la inversión en las mismas sea superior o igual al 1\% del PIB; sin embargo, en 2012 esta cifra fue de $0.5 \%$ (p. 65); (d) existe una notable desvinculación entre el sector científico-tecnológico y el sector empresarial, por lo que es necesario realizar acciones de coordinación [...] 


\begin{tabular}{|c|c|}
\hline Documento & Aspectos relevantes \\
\hline \multirow{3}{*}{$\begin{array}{l}\text { Plan Nacional de } \\
\text { Desarrollo } \\
2013-2018\end{array}$} & $\begin{array}{l}\text { para que las empresas puedan aprovechar las capacidades de las instituciones } \\
\text { de educación superior y los centros públicos de investigación (p. 65); (e) se } \\
\text { debe incrementar el capital semilla para la generación de empresas de base } \\
\text { tecnológica (p. 65). }\end{array}$ \\
\hline & $\begin{array}{l}\text { En el Plan de Acción correspondiente se destaca que el progreso económico y } \\
\text { social sostenible-generado a través del desarrollo científico, tecnológico y la in- } \\
\text { novación - se sustenta en una vinculación firme entre los sectores académico y } \\
\text { científico-tecnológico, con el sector privado. Asimismo, es necesario incrementar } \\
\text { la inversión, pública y privada, en actividades de innovación y desarrollo (p. 68). }\end{array}$ \\
\hline & $\begin{array}{l}\text { Con respecto a los Objetivos, Estrategias y Líneas de Acción de la Meta III, se } \\
\text { destacan los elementos siguientes: Objetivo } 3.5 \text { Hacer del desarrollo científico, } \\
\text { tecnológico y la innovación pilares para el progreso económico y social sosteni- } \\
\text { ble. Asimismo, las estrategias relevantes son la 3.5.4, referente a la vinculación } \\
\text { IES-SP, propiamente dicha, y las estrategias 3.5.1 y 3.5.6 en las que se establecen } \\
\text { las líneas de acción con respecto a la inversión e infraestructura necesarias para } \\
\text { fortalecer dicha vinculación. }\end{array}$ \\
\hline $\begin{array}{l}\text { Programa } \\
\text { Sectorial } \\
\text { de Educación } \\
\text { 2013-2018 }\end{array}$ & $\begin{array}{l}\text { El objetivo encaminado al fortalecimiento de la ciencia y la tecnología es el } \\
\text { número seis, el cual cita: "Impulsar la educación científica y tecnológica como } \\
\text { elemento indispensable para la transformación de México en una sociedad del } \\
\text { conocimiento" (p. 12); lo anterior en colaboración con el CONACYT. Según el } \\
\text { diagnóstico: (a) es imprescindible coadyuvar a que las instituciones de educa- } \\
\text { ción superior desarrollen una organización interna que les permita responder } \\
\text { a las demandas de los sectores sociales y productivos; (b) el rezago en la capa- } \\
\text { cidad de generación y aplicación del conocimiento se debe, en parte, a que el } \\
\text { sistema educativo no está suficientemente vinculado con el sector productivo; } \\
\text { (c) el Estado debe invertir una cantidad de recursos que considere el incremen- } \\
\text { to del número de investigadores. Con respecto a las Líneas de Acción Transver- } \\
\text { sales: de la Estrategia 1. Democratizar la Productividad, destacan las líneas de } \\
\text { acción 1, } 2 \text { y } 4 \text {. }\end{array}$ \\
\hline $\begin{array}{l}\text { Programa Especial } \\
\text { de Ciencia, } \\
\text { Tecnología } \\
\text { e Innovación } \\
2014-2018\end{array}$ & $\begin{array}{l}\text { Tiene su fundamento en el Objetivo } 3.5 \text { del Plan Nacional de Desarrollo (p. 12). } \\
\text { Entre los elementos del diagnóstico son destacables: (a) la composición del Sis- } \\
\text { tema Nacional de Ciencia, Tecnología e Innovación (SNCTI), en el cual, los algu- } \\
\text { nos actores están débilmente enlazados entre sí (p. 18); (b) la participación del } \\
\text { sector empresarial en el financiamiento del Gasto en Investigación Científica [...] }\end{array}$ \\
\hline
\end{tabular}




\begin{tabular}{|c|c|}
\hline Documento & Aspectos relevantes \\
\hline $\begin{array}{l}\text { Programa Especial } \\
\text { de Ciencia, } \\
\text { Tecnología } \\
\text { e Innovación } \\
2014-2018\end{array}$ & $\begin{array}{l}\text { y Desarrollo Experimental (GIDE) ha disminuido a partir de } 2008 \text { (p. 20); (c) el } \\
\text { Sistema de Centros de Investigación CONACYT es parte de la infraestructura } \\
\text { científica y tecnológica de la Administración Pública Federal, y está considerado } \\
\text { como el segundo en importancia después del de las IES públicas debido a su } \\
\text { impacto en la producción científica y tecnológica, así como por el número de } \\
\text { miembros del SNI adscritos al mismo (p. 28); (d) la normatividad institucional, } \\
\text { tanto de IES como de Centros Públicos de Investigación (CPI), tiene un efecto } \\
\text { negativo sobre la facilitación, agilización, flexibilidad y promoción necesarios } \\
\text { para estimular el desarrollo de empresas a partir de los propios investigadores } \\
\text { o instituciones (p. 28); (e) se requiere la creación y consolidación de clusters, } \\
\text { tecnopolos, parques científico-tecnológicos (físicos o virtuales) y nuevos cen- } \\
\text { tros de investigación, que fortalezcan el desarrollo regional y que propicien la } \\
\text { colaboración con otros países (p. 29); (f) con respecto al Desarrollo regional; } \\
\text { impulso a las vocaciones y capacidades locales, se establece el Marco estruc- } \\
\text { tural de la ciencia y la tecnología en las entidades federativas y la Conferencia } \\
\text { Nacional de Ciencia Tecnología e Innovación (CNCTI); y (g) el país cuenta con } \\
\text { diversos instrumentos de política para estimular los desarrollos emprendedores } \\
\text { y la inversión en Investigación Científica y Desarrollo Experimental, así como } \\
\text { la vinculación entre los sectores académico y productivo. Entre los objetivos, } \\
\text { estrategias y líneas de acción, es de interés primordial el objetivo 4: “Contribuir } \\
\text { a la generación, transferencia y aprovechamiento del conocimiento vinculando } \\
\text { a las IES y los centros de investigación con empresas" (p. 56), y las estrategias } \\
4.1 \text { Promover la vinculación entre las IES y CPI con los sectores público, privado } \\
\text { y social y } 4.2 \text { Impulsar e incentivar el registro de la propiedad intelectual en las } \\
\text { IES, CPI y empresas. }\end{array}$ \\
\hline $\begin{array}{l}\text { Plan de Desarrollo } \\
\text { Institucional, } \\
\text { Visión } 2030 \\
\text { ANUIES }\end{array}$ & $\begin{array}{l}\text { Como parte de los antecedentes, se establece que la ANUIES ha coadyuvado a } \\
\text { la vinculación entre las instituciones asociadas y los sectores público, privado } \\
\text { y social, con el propósito de fortalecer la pertinencia y competitividad de los } \\
\text { estudios ofertados. En relación con el contexto actual en el cual se generó este } \\
\text { documento, se exponen cinco tendencias de la sociedad contemporánea y de } \\
\text { la educación superior, entre las cuales es preponderante la denominada: socie- } \\
\text { dades del conocimiento. }\end{array}$ \\
\hline
\end{tabular}




\begin{tabular}{|c|c|}
\hline Documento & Aspectos relevantes \\
\hline \multirow{3}{*}{$\begin{array}{l}\text { Plan de Desarrollo } \\
\text { Institucional, } \\
\text { Visión } 2030 \\
\text { ANUIES }\end{array}$} & $\begin{array}{l}\text { Como parte de esta tendencia, se destaca "la coexistencia de universidades } \\
\text { tradicionales y de nuevos centros de investigación asociados a la industria, así } \\
\text { como al establecimiento de proyectos de investigación en los que participan } \\
\text { universidades, gobiernos y empresas" (p. 19). Sin embargo, el progreso dispar } \\
\text { entre países desarrollados y países en vías de desarrollo, así como la apropia- } \\
\text { ción del conocimiento por agentes privados, podrían incrementar las diferen- } \\
\text { cias científico-tecnológicas y educativas, tanto internacionales como al interior } \\
\text { de cada país. }\end{array}$ \\
\hline & $\begin{array}{l}\text { Como parte del contexto, también se incluye la Agenda } 2030 \text { para el Desarrollo } \\
\text { Sostenible (ONU, 2016); entre cuyas metas respecto del empleo, el fomento de } \\
\text { la innovación y el desarrollo tecnológico, destaca: "Aumentar la investigación } \\
\text { científica y mejorar la capacidad tecnológica de los sectores industriales de to- } \\
\text { dos los países, en particular los países en desarrollo, entre otras cosas fomen- } \\
\text { tando la innovación y aumentando sustancialmente el número de personas } \\
\text { que trabajan en el campo de la investigación y el desarrollo por cada millón de } \\
\text { personas, así como aumentando los gastos en investigación y desarrollo de los } \\
\text { sectores público y privado" (p. 26). }\end{array}$ \\
\hline & $\begin{array}{l}\text { Para solventar las necesidades antes planteadas se establece el objetivo estraté- } \\
\text { gico Il: "Fomentar la vinculación y el intercambio académico de las instituciones } \\
\text { asociadas para incidir en el desarrollo regional y nacional". Y en particular el ob- } \\
\text { jetivo específico } 2.2 \text { "Fortalecer la vinculación de las instituciones de educación } \\
\text { superior con los distintos sectores de la sociedad" con su meta correspondiente } \\
\text { "Formular, difundir e implantar el Programa de Vinculación e Innovación social". }\end{array}$ \\
\hline
\end{tabular}

Fuente: Elaboración propia con base en Presidencia de la República (2013), SEP (2013), CONACYT (2014) y ANUIES (2016).

Por último, en el análisis de la planeación estatal se incluyen los siguientes documentos. Primeramente, en el Plan Estatal de Desarrollo 2014-2019 BC (Actualización), el objetivo 3.3 es de importancia fundamental para los procesos de vinculación entre las IES y el sector productivo. Asimismo, del Programa de Educación de Baja California 2015-2019, destaca el objetivo 4.3 correspondiente a la Educación Superior. Por último, la Agenda de innovación de Baja California incluye un diagnóstico, una hoja de ruta, y recomendaciones para guiar las actividades productivas (tabla 6). 
Tabla 6

Planeación estatal

\begin{tabular}{|c|c|}
\hline Documento & Aspectos relevantes \\
\hline \multirow[b]{2}{*}{$\begin{array}{l}\text { Plan Estatal de } \\
\text { Desarrollo 2014- } \\
2019 \text { BC } \\
\text { (Actualización) }\end{array}$} & $\begin{array}{l}\text { Dentro del apartado Diagnóstico estratégico, sección Educación para la vida, } \\
\text { se establece que una de las dimensiones estratégicas hacia las que se orienta } \\
\text { el modelo de gestión y política educativa estatal en materia de educación su- } \\
\text { perior implica "una eficaz articulación de la educación superior e investigación } \\
\text { científica con las prioridades del desarrollo económico y social local y regional" } \\
\text { (pp. 76-77). }\end{array}$ \\
\hline & $\begin{array}{l}\text { Asimismo, en el apartado Soluciones para Baja California, en la sección Desarro- } \\
\text { llo económico sustentable, se plantea el objetivo 3.3, que cita: “Crear las condi- } \\
\text { ciones óptimas para la creación de nuevas empresas y la consolidación de las } \\
\text { ya existentes, a través de procesos de innovación con alto valor agregado” (p. } \\
\text { 162), entre cuyas metas destacan: (a) incrementar la participación de los fondos } \\
\text { federales destinados a I+D, (b) proporcionar a las empresas fondos para la incor- } \\
\text { poración de procesos tecnológicos con el propósito de fomentar la innovación } \\
\text { e impulsar su productividad, y (c) fortalecer el Consejo Estatal de Ciencia, Tec- } \\
\text { nología e Innovación. }\end{array}$ \\
\hline \multirow{2}{*}{$\begin{array}{l}\text { Programa de } \\
\text { Educación de Baja } \\
\text { California 2015- } \\
2019\end{array}$} & $\begin{array}{l}\text { La política sectorial para educación superior relacionada con la cooperación } \\
\text { tecnocientífica incluye el aseguramiento de la vinculación de las IES con los sec- } \\
\text { tores social y productivo, así como el fortalecimiento "de la investigación aplica- } \\
\text { da con enfoque al desarrollo regional del estado a través de un sistema estatal } \\
\text { interinstitucional" (p. 71). }\end{array}$ \\
\hline & $\begin{array}{l}\text { Los temas y subtemas del objetivo } 4.3 \text { del apartado Educación Superiorincluyen: } \\
\text { (a) consolidar mecanismos de vinculación entre las IES y los sectores produc- } \\
\text { tivo y social, (b) fomentar el desarrollo de destrezas y habilidades asociadas a } \\
\text { la ciencia, tecnología e innovación, (c) impulsar la consolidación de programas } \\
\text { de posgrado que atiendan las necesidades de investigación de la entidad, (c) } \\
\text { impulsar la generación de proyectos dirigidos a la innovación e investigación } \\
\text { científica y tecnológica que incidan los diferentes sectores. }\end{array}$ \\
\hline
\end{tabular}




\begin{tabular}{|c|c|}
\hline Documento & Aspectos relevantes \\
\hline & $\begin{array}{l}\text { La elaboración de la Agenda Estatal de Innovación de Baja California (AGEIBC) } \\
\text { se fundamentó en un proceso participativo de actores clave de los sectores } \\
\text { académico, empresarial, social y gubernamental. Es un instrumento de política } \\
\text { pública que incluye una hoja de ruta, así como recomendaciones para: (a) la } \\
\text { instrumentación de los proyectos y (b) la articulación del ecosistema de inno- } \\
\text { vación del estado. En particular, respecto a las estructuras de apoyo al sistema } \\
\text { productivo, se destaca que el impulso al desarrollo económico del estado tiene } \\
\text { su fundamento en la política de clusters; los cuales son un punto de conver- } \\
\text { gencia de actores relacionados con la investigación, el desarrollo tecnológico } \\
\text { y la innovación. Los clusters identificados son: Automotriz, Aeroespacial, Dispo- } \\
\text { sitivos Médicos, Servicios Médicos y Dentales, Tecnologías de la Información, } \\
\text { Electrónica, Logística, Agroindustria y Vitivinícola. }\end{array}$ \\
\hline $\begin{array}{c}\text { Agenda } \\
\text { de innovación } \\
\text { de Baja California }\end{array}$ & $\begin{array}{l}\text { En relación con las capacidades científicas, en el análisis del sistema científi- } \\
\text { co-tecnológico, se encontró que en } 2013 \text { hubo } 611 \text { investigadores inscritos al } \\
\text { Sistema Nacional de Investigadores (SNI) en el estado, cifra equivalente al } 3 \% \\
\text { del total nacional. Como parte del análisis del sistema de ciencia, tecnología e } \\
\text { innovación, en la AGEIBC se menciona que "Baja California dispone de un tejido } \\
\text { empresarial, científico y educativo propicio para realizar actividades de desa- } \\
\text { rrollo tecnológico de alto valor, tanto en lo referente a número de instituciones } \\
\text { como a la calidad de las mismas. Sin embargo, es indispensable promover el } \\
\text { trabajo colaborativo y el incremento presupuestal (...) Baja California es un es- } \\
\text { tado con alto potencial innovador, pero requiere mejorar sus procesos de arti- } \\
\text { culación de los diversos agentes" (p. 41). }\end{array}$ \\
\hline
\end{tabular}

Finalmente, la Hoja de ruta de la AGEIBC tiene como objetivo: promover la vinculación entre los agentes de la triple hélice (academia, gobierno y empresas) en cada una de las áreas de especialización seleccionadas, a saber: Agroindustria Alimentaria, Aeroespacial, Biotecnología, Energías Renovables y Manufactura Avanzada.

Fuente: Elaboración propia con base en Gobierno del Estado de Baja California $(2015 ; 2016)$ y CONACYT (2015).

En suma, con los elementos empíricos desplegados a partir de los arreglos normativos y legislativos nacionales y estatales, así como de los planteamientos de la planeación estratégica nacional y estatal, hemos querido dejar constancia de la doble 
correspondencia entre los planteamientos teórico-conceptuales y los gestos simbólicos en pro de la gobernabilidad de las interacciones entre las IES y las empresas que son la parte medular del sector productivo.

A partir de lo que se ha descrito y discutido en las páginas previas puede decirse que, a un nivel del discurso institucional, se observa un interés genuino por las actividades relacionadas con la producción de conocimiento tecnocientífico y su respectiva difusión-divulgación y aprovechamiento; la riqueza del contenido de la legislación y de los documentos de planeación analizados así lo demuestra. El gran problema, que casi siempre está presente, es la estrechez de los recursos destinados al fomento de estas actividades, y más en lo que se refiere a la cooperación tecnocientífica auténtica.

\section{Reflexiones finales}

Luego de realizar el análisis teórico-conceptual y documental, surgen algunas interrogantes relacionadas con la temática. De inicio, ¿realmente existe la voluntad política de fortalecer la vinculación entre las IES y el sector productivo? Lo anterior se cuestiona debido a que, a pesar de que tanto las legislaciones como las planeaciones, estatales y nacionales, incluyen aspectos relacionados con dicha vinculación; en la práctica, los recursos que se destinan a la misma son irrisorios.

De igual forma, se presentan una serie de políticas, estrategias, mecanismos, programas, objetivos y metas; los cuales, a la fecha ya deberían haberse realizado. Así, sería interesante ampliar lo que se expone en este capítulo a dicho análisis. 


\section{Referencias}

Acosta, A. (2000). Estado, políticas y universidades en un periodo de transición. México: Universidad de Guadalajara / Fondo de Cultura Económica.

Aoki, M. (2007). Endogenizing institutions and institutional changes. Journal of Institutional Economics, 3(1), 1-31.

Asociación Nacional de Universidades e Instituciones de Educación Superior (ANUIES). (2016). Plan de Desarrollo Institucional, Visión 2030. Recuperado de http://www. anuies.mx/media/docs/avisos/pdf/PlanDesarrolloVision2030_v2.pdf

Caballero, G. (2011). Economía de las instituciones: de Coase y North a Williamson y Ostrom. Ekonomiaz, Revista Vasca de Economía, 77(2), 14-51.

Comisión Económica para América Latina y el Caribe (CEPAL). (2010). Espacios iberoamericanos: vínculos entre universidades y empresas para el desarrollo tecnológico. Santiago de Chile: CEPAL. Recuperado de http:// repositorio.cepal.org/bitstream/handle/11362/1417/S2010990_ es.pdf;jsessionid=1AE90FAB397D1BCD8B46BC5F9873B603? sequence $=1$

Consejo Nacional de Ciencia y Tecnología (2014). Programa Especial de Ciencia, Tecnología e Innovación 2014-2018. Recuperado de http://www.siicyt.gob.mx/index.php/ normatividad/nacional/631-3-programa-especial-de-ciencia-tecnologia-einnovacion-2014-2018/file

Consejo Nacional de Ciencia y Tecnología (2015). Agenda de innovación de Baja California. Resumen ejecutivo. Recuperado de http://www.agendasinnovacion.org/wpcontent/uploads/2015/01/Agenda-Baja-California.pdf

Gandlgruber, B. (2007). Coordinación, instituciones y empresas. (Tesis doctoral). Universidad Autónoma Metropolitana, México.

García-Galván, R. (2011). Revisión de los elementos teórico-conceptuales en torno a la cooperación interfirma e interorganizacional. Análisis Económico, 26(62), 185-208.

García-Galván, R. (2014). Teoría económica institucional de la empresa y de la cooperación. España: EAE. 
García-Galván, R. (2018). El papel de las instituciones y de la colaboración universidadempresa en el desarrollo: evidencias de la UAEMÉX y la UABC. Paradigma económico, (10), 81-118.

Gibbons, M., Limoges C., Nowotny, H. Schwartzman, S., Scott, P., \& Trow, M. (1997). La nueva producción del conocimiento. Barcelona: Ediciones Pomares-Corredor.

Gobierno del Estado de Baja California (2016). Plan Estatal de Desarrollo 2014-2019 BC (Actualización).Recuperadodehttp://www.copladebc.gob.mx/PED/documentos/ Actualizacion\%20del\%20Plan\%20Estatal\%20de\%20Desarrollo\%202014-2019. pdf

Gobierno del Estado de Baja California (2015). Programa de Educación de Baja California 2015-2019. Recuperado de http://www.educacionbc.edu.mx/see/ programasectorial/pebc20152019.pdf

González, L. (2003). Cooperación y Empresas. Retos, Presente y Futuro. Madrid: Thomson.

Greif, A., \& Christopher, K. (2011). Institutions: Rules or Equilibria? En N. Schofield y G. Caballero (Eds.), Political Economy of Institutions, Democracy and Voting (pp. 1343). Berlin: Springer-Verlag.

Hodgson, G.M. (2007). Economía institucional yevolutiva. México: Universidad Autónoma Metropolitana.

Latour, B. (1992). Ciencia en acción: cómo seguir a los científicos e ingenieros a través de la sociedad. Barcelona: Editorial Labor.

Ley de Ciencia y Tecnología (2015). México. Diario Oficial de la Federación, DOF 8-12-2015. Recuperado de http://www.diputados.gob.mx/LeyesBiblio/pdf/242_081215.pdf

Ley General de Educación (2018). México. Diario Oficial de la Federación, DOF 1901-2018. Recuperado de https://www.sep.gob.mx/work/models/sep1/ Resource/558c2c24-0b12-4676-ad90-8ab78086b184/ley_general_educacion. pdf

Ley General de Responsabilidades Administrativas. (2016). México. Diario Oficial de la Federación, DOF 18-07-2016. Recuperado de http://www.diputados.gob.mx/ LeyesBiblio/pdf/LGRA.pdf 
Ley de Educación del Estado de Baja California (2015). Periódico Oficial, 31 de julio de 2015. Recuperado de http://www.ordenjuridico.gob.mx/Documentos/Estatal/ Baja\%20California/wo19522.pdf

North, D. (1993 [2006]). Instituciones, cambio institucional y desempeño económico. México: Fondo de Cultura Económica.

North, D.C., Wallis, J.J., \& Weingast, B.R. (2009). Violence and Social Orders: A Conceptual Framework for Interpreting Recorded Human History. Cambridge: Cambridge University Press.

Organización de las Naciones Unidas (ONU). (2016). Agenda 2030 y los Objetivos de Desarrollo Sostenible Una oportunidad para América Latina y el Caribe. Recuperado de http://www.sela.org/media/2262361/agenda-2030-y-los-objetivos-dedesarrollo-sostenible.pdf

Presidencia de la República (2013). Plan Nacional de Desarrollo 2013-2018. Recuperado de http://itcampeche.edu.mx/wp-content/uploads/2016/06/Plan-Nacional-deDesarrollo-PND-2013-2018-PDF.pdf

Searle, J.R. (2005). What is an institution? Journal of Institutional Economics, 1(1), 1-22.

Secretaría de Educación Pública (SEP). (2013). Programa Sectorial de Educación 2013-2018.

Recuperado de http://www.sep.gob.mx/work/models/sep1/Resource/4479/4/ images/PROGRAMA_SECTORIAL_DE_EDUCACION_2013_2018_WEB.pdf

Vertova, G. (2014). The State and National Systems of Innovation: A Sympathetic Critique. Working Paper Collection No. 823, Levy Economics Institute, University of Bergamo. Villasana, M. (2011). Fostering university-industry interactions under a triple helix model: the case of Nuevo Leon, Mexico. Science and Public Policy, 38(1), 43-53. 


\title{
Capítulo 9
}

\section{La cooperación tecnocientífica IES-SP en Baja California desde la percepción de los profesores-investigadores}

\author{
Marcela Morales Páez, Juan Carlos Vázquez Almaraz \\ y Juan Carlos Rodríguez Macías
}

Desde 1970, en los países desarrollados (principalmente en Estados Unidos) se ha venido realizando investigación empírica sobre la cooperación entre Instituciones de Educación Superior y el sector productivo (IES-SP); en México, los esfuerzos sistemáticos datan de mediados de 1990. Por ejemplo, en 1996, la Asociación Nacional de Universidades e Instituciones de Educación Superior (ANUIES) y el Consejo Nacional de Ciencia y Tecnología (CONACYT) realizaron un diagnóstico sobre la vinculación, aplicando una encuesta a 247 IES, cuyos resultados fueron publicados en 1998 (Casalet y Casas, 1998; López, 2005). Otro caso es el de García-Galván (2013), quien indagó cuestiones como: naturaleza de la investigación realizada, fuentes de financiamiento, colaboración tecnocientífica y productividad en innovación, y factores que favorecen u obstaculizan dicha colaboración.

En la región noroeste de México, López (2002) realizó un estudio cuyo propósito fue investigar la vinculación IES-SP, a partir de la opinión de 219 investigadores. También en el noroeste del país, Bajo (2006) realizó un estudio cuyo objetivo fue "dar a conocer evidencias empíricas acerca de las características de la relación IES y sectores productivos para el aprovechamiento de nuevos conocimientos y su contribución al desarrollo de la región o el país" (p. 20). La investigación incluyó la revisión documental, así como la realización de entrevistas con responsables de oficinas de vinculación, 
responsables de proyectos de investigación de cada IES, y responsables de empresas relacionadas con los proyectos. En el ámbito estatal, destacan las tesis de maestría de Montes (2002) y Carro (2004), quienes se enfocaron en el estudio de la vinculación de las unidades académicas de la Universidad Autónoma de Baja California (UABC). En tanto, la tesis doctoral de Jáuregui (2012) tuvo como objeto la vinculación de la UABC con el sector agropecuario bajacaliforniano. Finalmente, Alcántar, Arcos y Mungaray (2006) integraron los temas de la vinculación y el posicionamiento de la UABC con su contexto.

Los antecedentes empíricos, regionales y estatales, dan cuenta de la insuficiente consolidación de las instituciones y organizaciones relacionadas con las actividades de cooperación IES-SP (Bajo, 2006; Carro, 2004; Montes, 2002), así como de la situación crítica en cuanto a la asignación de los recursos públicos a las IES (Bajo, 2006) -que impactan en el nivel de la colaboración-. Lo anterior, sustenta la importancia de un estudio que solvente el desconocimiento de las condiciones generales en las que se lleva a cabo la cooperación IES-SP actualmente en Baja California, ya que dicho desconocimiento repercute tanto en insuficientes capacidades de investigación e innovación a nivel regional (Bajo, 2006; García-Galván, 2013), como en una pobre cooperación tecnocientífica (CT) con el entorno productivo (Cabrera, 2015).

En síntesis, a pesar de los avances en la investigación, sigue sin ser claro el fenómeno; esa vaguedad en el entendimiento impacta en que las IES no pongan la atención suficiente en los recursos, las capacidades y las habilidades de investigación requeridas para establecer lazos colaborativos, sin los cuales, el impacto en el SP no deja de ser limitado.

Desde la perspectiva del institucionalismo contemporáneo integrado, las condiciones generales de la cooperación tecnocientífica IES-SP incluyen factores como las instituciones, organizaciones, convicciones personales, cultura académica, infraestructura tecnocientífica y capital humano. Siendo los profesores-investigadores los actores que interactúan directamente en las actividades de cooperación tecnocientífica, el objetivo de este capítulo es conocer la percepción de los profesores-investigadores de las IES de Baja California acerca de las condiciones en que se llevan a cabo las actividades de cooperación tecnocientífica IES-SP. 
En el contexto actual, el papel de las IES se torna decisivo como promotor de desarrollo económico y social de las naciones. Al ser las universidades el último eslabón de escolarización formal, previo a la inserción laboral, los sistemas de educación superior y sus funciones sustantivas, están intrínsecamente ligados a los procesos económicos y sociales (Rama, 2010). Por lo tanto, las actividades de investigación aplicada y generación de tecnología, realizadas por las IES, deberían considerar las necesidades del SP -sin subordinar su agenda a la de las empresas-.

Si bien, es cierto que la tendencia mundial, sobre todo en países desarrollados, ha sido fortalecer los vínculos IES-SP, en los países en desarrollo, este proceso no se ha podido consolidar (Thomas, Davyt, Gomes y Dagnino, 1997). Tal situación implica la necesidad de un análisis minucioso de la trayectoria de la cooperación IES-SP en México, con el fin de establecer mecanismos alternativos que aceleren la integración de las aportaciones hechas desde las IES hacia el SP. Tales mecanismos están relacionados con la revisión de los arreglos institucionales, las transformaciones al interior de las IES producto de las tendencias mundiales, la capacidad instalada (recursos tecnológicos, equipamiento, capital humano, capacidades y habilidades de investigación avanzada), y el papel que pueden jugar los actores del entorno, especialmente del sector productivo.

\section{Enfoque teórico}

Desde hace varias décadas, existe una tendencia mundial al incremento de las relaciones que se dan entre las IES y el sector productivo; esta tendencia es causada tanto por factores endógenos como exógenos a las IES (Thomas et al., 1997; Etzkowitz 1998, 2002; Etzkowitz, Webster, Gebhardt y Cantisano, 2000; Bodas, Argou y Mirra, 2013; Perkman et al., 2013; Wanda, 2015). Al principio, las IES tenían una relación indirecta con el SP mediante la formación profesional para el trabajo. La primera revolución académica ${ }^{1}$ dio paso a relaciones más directas, pero todavía unidireccionales, a través de la prestación de

1 Para ser agentes activos - más allá que meramente agentes formales de innovación - las universidades debieron experimentar una primera revolución: la incorporación de la investigación como misión académica (Etzkowitz et al. 2000). 
servicios y de investigación subcontratada. Más recientemente, dio inicio una interacción bidireccional en la que las IES aportan conocimiento científico, el cual es utilizado por el SP como insumo para las innovaciones tecnológicas y, en correspondencia, el SP aporta recursos económicos u otros (infraestructura, laboratorios, acceso a equipos industriales) para desarrollar la investigación (Etzkowitz, 1998; Etzkowitz et al., 2000; García-Galván, 2008). En este capítulo, esta interacción será denominada cooperación IES-SP.

Las investigaciones que abordan la cooperación tecnocientífica IES-SP se han realizado desde distintos enfoques teóricos, entre los que destacan: a) los sistemas de innovación (SI) (Edquist, 2001; Freeman, 1995; Lundvall; 1992; Vertova, 2014); b) el modo 2 de producción de conocimiento (Etzkowitz y Leydesdorff, 2000; Gibbons et al., 1997); c) el modelo de la triple hélice (Etzkowitz 1998; 2002; Etzkowitz et al. 2000; Baumol, 2005); y d) el institucionalismo contemporáneo integrado (Gandlgruber, 2007; García-Galván, 2008; 2012; 2013; Taboada, 2004).

\section{Los sistemas de innovación}

Edquist $(1997 ; 2001)$ definió un sistema de innovación (SI) como aquel que incluye factores económicos, sociales, políticos y organizacionales, entre otros; los cuales influencian el desarrollo, difusión y uso de las innovaciones. En consecuencia, para Edquist, el propósito principal del enfoque de los SI es identificar dichos factores, también denominados actividades o funciones. Además, las instituciones son consideradas como elementos clave en todas las versiones del enfoque de los $\mathrm{SI}$, debido a que las mismas forman y son formadas por las acciones de las organizaciones y las relaciones entre ellas. Por su parte, Vertova (2014), establece el concepto del sistema nacional de innovación como la principal herramienta teórica para considerar e integrar la importancia del ambiente económico a la posibilidad que presentan las empresas para innovar. Dicho concepto se ha utilizado con dos fines: el descriptivo -al mostrar las diferencias entre la habilidad de los países para innovar y colocarse a la vanguardia tecnológica- y el normativo -al dar sugerencias sobre las políticas que deben ser generadas para apoyar las actividades innovadoras de las empresas-. 


\section{El modo 2 de producción de conocimiento}

Para Gibbons et al. (1997), el modo 2 de producción de conocimiento es una consecuencia de los cambios ocurridos en las últimas décadas tanto en la ciencia y la tecnología como en las ciencias sociales y las humanidades. Según dichos autores, esta forma de producir conocimiento incluye aspectos adicionales a la determinación del tipo de conocimiento que es producido, por ejemplo, el contexto en el que es producido, los agentes que lo producen, y la organización y control de calidad de este. Con respecto a la importancia del SP en la generación de conocimiento, dicho autores destacan el hecho de que el conocimiento especializado representa una ventaja competitiva para las empresas, las cuales, al no poder solventar los altos costos de la producción de este, se ven en la necesidad de establecer relaciones de cooperación con universidades, gobierno e inclusive otras empresas. También hacen énfasis en que las instituciones deben volverse más permeables a su entorno para que el modo 2 de producción de conocimiento pueda funcionar adecuadamente. Por su parte, Etzkowitz y Leydesdorff (2000) mencionan que el modo 2 de producción de conocimiento debe ser considerado como un sistema emergente, como una híper-red que se apoya en otras redes, a partir de las cuales este se construye, como las disciplinas, las industrias y los gobiernos nacionales.

\section{Modelo de la triple hélice}

Para Etzkowitz (1998), la dinámica de la sociedad ha cambiado, desde una estructura de fuertes fronteras entre esferas institucionales y organizaciones separadas, hacia un sistema más flexible, con cada esfera tomando el rol de otra: la universidad es una empresa creadora -a través de las facilidades de incubación de otras empresas-; la industria es educadora -a través de la generación de compañías universitarias-; y el gobierno es una empresa capitalista -a través de diversos programas de inversión-.

La tesis central del Modelo de la triple hélice establece que la universidad puede jugar un papel más relevante en la innovación dentro de las sociedades basadas en el conocimiento. Dicho modelo describe la red subyacente de comunicaciones y expectativas que guían la reconstrucción de los arreglos institucionales entre universidades, industrias y agencias gubernamentales (Etzkowitz y Leydesdorff, 2000). 


\section{Institucionalismo contemporáneo integrado}

Este enfoque es el marco propicio para realizar estudios inter, multi y transdisciplinares, ya que incorpora elementos teóricos y metodológicos desarrollados en distintas ramas de las ciencias sociales, entre ellas: economía, ciencias políticas, psicología social, psicología organizacional, sociología y antropología; con el objetivo de comprender el papel de las instituciones -las cuales están inmersas en un contexto social, político y económico-. Debido a su consistencia teórica, y a las herramientas analíticas que de él se derivan: la teoría de los costos de transacción, la teoría de las capacidades dinámicas, y la teoría evolucionista de la empresa (García-Galván, 2008), el presente estudio se abordará desde el enfoque del institucionalismo contemporáneo integrado, retomando -cuando se considere relevante- algunas aportaciones de las otras perspectivas aquí presentadas.

Así, a partir de la revisión de las perspectivas de la cooperación IES-SP y de las herramientas teórico-analíticas del institucionalismo contemporáneo integrado, se justifica la pertinencia de incorporar el estudio de la cooperación tecnocientífica IES-SP al marco teórico de las instituciones y el cambio institucional (García-Galván, 2008).

\section{Estrategia metodológica}

Para recuperar la percepción de los profesores-investigadores acerca de las condiciones y procesos relacionados con la cooperación tecnocientífica, se utilizó la técnica de la encuesta, la cual se implementó a través de un cuestionario administrado en línea en la plataforma Google forms. El instrumento aplicado consta de tres ámbitos: individual, organizacional e institucional; e incluye un total de 24 ítems: 16 de opción múltiple, 2 de respuesta construida y 6 escalas.

Los participantesfueron profesores-investigadoresadscritosalasIESseleccionadas (representan el 97.15\% (817 de 841) del padrón de beneficiarios del Sistema Nacional de Investigadores (SNI) para el año 2017 en Baja California)² de los cuales se obtuvieron 774 correos (94.73\% de 817 ). De las 774 invitaciones a participar en la encuesta, se

2 El padrón de beneficiarios SNI se encuentra en la liga https://www.conacyt.gob.mx/index.php/el-conacyt/sistema-nacional-de-investigadores 
obtuvieron las respuestas de 184 profesores-investigadores. Las fases y actividades del proceso de encuesta se presentan en la tabla 1.

\section{Tabla 1}

Fases y actividades del procedimiento

\begin{tabular}{|c|c|c|}
\hline Fases & Actividades & Fecha \\
\hline $\begin{array}{l}\text { Plan Nacional } \\
\text { de Desarrollo } \\
2013-2018\end{array}$ & $\begin{array}{l}\text { Revisión del marco teórico. } \\
\text { Desarrollo de los ítems e integración del cuestionario. }\end{array}$ & $\begin{array}{l}\text { agosto y } \\
\text { septiembre } \\
2017\end{array}$ \\
\hline $\begin{array}{l}\text { Validación del } \\
\text { cuestionario }\end{array}$ & $\begin{array}{l}\text { Obtención de evidencias de validez del cuestionario a través del } \\
\text { jueceo de expertos (uno en psicometría y dos en cooperación } \\
\text { tecnocientífica). }\end{array}$ & octubre 2017 \\
\hline $\begin{array}{c}\text { Preparación } \\
\text { de la aplicación }\end{array}$ & $\begin{array}{l}\text { Determinación de la población objetivo. } \\
\text { Integración de la base de datos con los nombres de los profeso- } \\
\text { res-investigadores de las IES seleccionadas. }\end{array}$ & $\begin{array}{l}\text { noviembre y } \\
\text { diciembre } \\
2017\end{array}$ \\
\hline Pilotaje & $\begin{array}{l}\text { Capacitación en el uso de la aplicación Google forms. } \\
\text { Pilotaje del cuestionario en línea. }\end{array}$ & enero 2018 \\
\hline $\begin{array}{l}\text { Aplicación } \\
\text { y captura }\end{array}$ & $\begin{array}{l}\text { Recopilación de los correos electrónicos de los participantes. } \\
\text { Aplicación del cuestionario en línea. } \\
\text { Integración de la base de datos. }\end{array}$ & $\begin{array}{l}\text { Febrero } \\
\text { Marzo y abril } \\
\text { Mayo } 2018\end{array}$ \\
\hline $\begin{array}{l}\text { Análisis } \\
\text { de los datos }\end{array}$ & Obtención de estadísticos descriptivos. & Julio 2018 \\
\hline
\end{tabular}

\section{Discusión y resultados}

Como parte de las características de los participantes en la encuesta se aprecia que, del total de profesores-investigadores, el $72 \%$ son hombres y una tercera parte son mayores de 50 años. Dos terceras partes de los encuestados se concentran en una sola institución (UABC). También podemos encontrar en los resultados que los académicos señalan que colaboran con otros investigadores, incluso cerca del $45 \%$ lo hacen con, entre 3 y 6 pares. 
Antes de comentar los siguientes resultados obtenidos, es necesario señalar que el Conacyt divide el conocimiento en siete áreas, en las cuales pueden trabajar los investigadores afiliados al SNI, a saber: I. Fisicomatemáticas y Ciencias de la Tierra; II. Biología, Química y Ciencias de la Vida; III. Medicina y Ciencias de la Salud; Humanidades y Ciencias de la Conducta; V. Ciencias Sociales; VI. Biotecnología y Ciencias Agropecuarias; y VII. Ingenierías. Dado que el objetivo es examinar la cooperación tecnocientífica (CT) IES-SP, se podría pensar que esta debería ocurrir entre ambos sectores en áreas de aplicación y de interés para la región. Es decir, en este caso podría plantearse una vinculación en la biotecnología y las ciencias agropecuarias o en biología o química. Los resultados muestran que, según la percepción de los académicos, el 24\% de esta colaboración en realidad ocurre en el área de las Ciencias Sociales y un punto porcentual menos ocurre en fisicomatemáticas y ciencias de la tierra. En el primer caso, además, cerca de la mitad de los investigadores tienen más de 10 años de experiencia en la investigación.

Con referencia al ámbito individual, es fundamental identificar con qué agentes o con qué otras instituciones están colaborando los investigadores académicos. En este caso, los resultados muestran que, del total de investigadores, el 55\% realizan mayor interacción con investigadores de otras instituciones educativas y, poco menos de una quinta parte lo hace con empresas. Dado que, como se había señalado, la participación de los investigadores de la UABC es la más cuantiosa, vale la pena indagar cuál es el tenor en dicha institución en esta interacción. En este caso, los resultados muestran un comportamiento cercano al general, es decir, poco más de la mitad de los encuestados colaboran con investigadores de otras instituciones educativas y una quinta parte lo hacen con empresas. Pero, la pregunta que surge es: ¿qué motiva este tipo de interacción general y en la UABC?

Por otra parte, el principal nivel geográfico en el que se realizan las actividades de CT es el nacional, con 29.35\%; además, la difusión y divulgación del conocimiento (asistencia a congresos, seminarios, coloquios) es la principal forma de CT, elegida por casi el $60 \%$ de los participantes. Asimismo, casi el $70 \%$ de los profesores-investigadores consideran que los colegas de su unidad académica valoran positivamente la CT. 
En lo relativo al ámbito organizacional, destaca que casi el $80 \%$ de los encuestados considera que la apertura de una oficina exclusiva para apoyar las actividades de CT coadyuvaría en dichos procesos; lo cual concuerda con los hallazgos de Bajo (2006). Con respecto al principal factor externo que más influye positivamente en la $\mathrm{CT}$, destaca la demanda del entorno con $37 \%$, y las políticas nacionales que favorezcan la misma, con $30 \%$. En contrapartida, el principal factor externo que influye negativamente en la CT es la discrepancia entre necesidades de demandantes y la institución (36.4\%), seguida de la renuencia a invertir en investigación por parte del gobierno (26\%).

Asimismo, los ingresos económicos extraordinarios son el principal incentivo que exponen los profesores-investigadores para llevar a cabo actividades de CT (30.43\%), quedando en segundo lugar el incremento de su reputación como investigador (28.8\%). Con respecto al mayor obstáculo organizacional, los encuestados señalan, en primer lugar, el exceso de carga laboral con $44.57 \%$ y, en segundo lugar, el exceso de trámites burocráticos, con $19.57 \%$.

Finalmente, en el ámbito institucional, los participantes mencionan que las bolsas en unidades académicas para apoyar proyectos (26.09\%) serían la mejor estrategia para mejorar la CT. En contraparte, el mayor obstáculo institucional para el desarrollo de las actividades de CT es la falta de fomento de la cooperación tecnocientífica, con $39.67 \%$; seguida del cobro de overhead ${ }^{3}$ a los contratantes de servicios, con $19 \%$.

Por otra parte, en la escala para medir la percepción sobre las características del marco institucional, destaca que más de dos terceras partes (67.39\%) consideran que el modelo educativo de su institución exhibe elementos relacionados con la cooperación tecnocientífica. Sin embargo, poco más de la mitad (53.26\%) de los profesoresinvestigadores no consideran que la reglamentación de las actividades de cooperación tecnocientífica de su institución sea adecuada; esta discrepancia, pone de manifiesto la falta de coherencia entre ambos elementos del marco institucional. Asimismo, el 93.48\% está de acuerdo o totalmente de acuerdo en que es importante integrar a los

3 Los gastos administrativos overhead son todos aquellos que la empresa, en este caso la institución educativa, debe pagar para mantenerse en funcionamiento. 
profesores-investigadores en la revisión de la normatividad en materia de cooperación tecnocientífica.

\section{Conclusiones}

Como una primera aproximación a estos resultados, podemos indicar las siguientes conclusiones:

- Como soporte teórico-empírico del instrumento utilizado para conocer la percepción de los profesores-investigadores de las IES de Baja California acerca las condiciones en que se llevan a cabo las actividades de cooperación tecnocientífica IES-SP se incluyeron diversos aspectos relacionados con el ámbito individual, organizacional e institucional.

- Entre los hallazgos relevantes destaca que, en general, existe una predisposición positiva hacia la realización de actividades de CT por parte de los profesoresinvestigadores que respondieron la encuesta; sin embargo, la mayor parte de dicha cooperación se lleva a cabo con otras instituciones educativas y, en menor medida, con empresas.

- En el ámbito organizacional, se hace evidente la necesidad de que el gobierno adopte una actitud de mayor apoyo hacia la CT, tanto a través de financiamiento directo como de la generación de políticas públicas que coadyuven al fortalecimiento de esta.

- Finalmente, las respuestas de los participantes ponen de manifiesto la importancia de armonizar los distintos elementos del marco institucional (reglamentos, planeaciones, modelo educativo), así como de integrar a los profesoresinvestigadores en el proceso de dicho cambio institucional, con el fin de generar una mayor consistencia entre el discurso de apertura hacia la CT y la puesta en marcha de este. 


\section{Referencias}

Alcántar, V.M., Arcos, J.L., \& Mungaray, A. (2006). Vinculación y posicionamiento de la Universidad Autónoma de Baja California con su entorno social y productivo. México: UABC/ANUIES.

Bajo, A. (2006). Vinculación e innovación en la región noroeste de México. México: Universidad Autónoma de Sinaloa.

Baumol, W.J. (2005). Microtheory of Entrepreneurship: more exists than is recognized. The emergence of entrepreneurial economics. Research on technological innovations management and policy, 9, 27-35.

Bodas, I.M., Argou, R., \& Mirra, E. (2013). University-industry collaboration and innovation in emergent and mature industries in new industrialized countries. Research Policy, 42, 443-453.

Cabrera, M.R. (2015). De la ciudad intensiva en conocimiento a la ciudad innovadora. Aportaciones de las comunidades científicas a los ecosistemas de innovación. México: Universidad Autónoma de Baja California.

Carro, H. (2004). Diagnóstico de la vinculación en la Universidad Autónoma de Baja California: entrevistas a directores de unidades académicas (Tesis de maestría). Universidad Autónoma de Baja California, México.

Casalet, M., \& Casas R. (1998). Un diagnóstico sobre la vinculación Universidad-Empresa CONACYT-ANUIES. México: ANUIES.

Edquist, C. (Ed.). (1997). Systems of innovation. Technologies, institutions and organizations. London: Routledge. Recuperado de https://charlesedquist.files.wordpress. com/2015/06/science-technology-and-the-international-political-economyseries-charles-edquist-systems-of-innovation_-technologies-institutions-andorganizations-routledge-1997.pdf

Edquist, C. (2001). The System of Innovation Approach and Innovation Policy: An account of the state of the art. Trabajo presentado. DRUID Conference, Aalborg University, Denmark. 
Etzkowitz, H. (1998). The norms of entrepreneurial science: cognitive effects of the new university-industry linkages. Research Policy, 27, 823-833.

Etzkowitz, H. (2002). The Triple Helix of University - Industry - Government Implications for Policy and Evaluation (Working paper). Suecia: SISTER.

Etzkowitz, H., \& Leydesdorff, L. (2000). The dynamics of innovation: from National Systems and "Mode 2 " to a Triple Helix of university-industry-government relations. Research Policy, 29, 109-123. Recuperado de http://paca-online.org/cop/docs/ Etzkowitz+Leydesdorf_The_dynamics_of_innovation_-_a_triple_helix.pdf

Etzkowitz,H.,Webster, A., Gebhardt, C., \&Cantisano, B.R. (2000). The future of the university and the university of the future: evolution of ivory tower to entrepreneurial paradigm. Research Policy, 29, 313-330.

Freeman, C. (1995). The 'National System of Innovation' in historical perspective. Cambridge Journal of Economics, 19, 5-24. Recuperado de http://www. forschungsnetzwerk.at/downloadpub/1995_Freeman_NSI_historial_ perspective.pdf

Gandlgruber, B. (2007). Coordinación, institucionesyempresas (Tesis doctoral). Universidad Autónoma Metropolitana, México.

García-Galván, R.(2008). Análisisteórico dela transferencia deconocimientos universidadempresa mediante la colaboración. Revista Economía: Teoría y práctica, 29. Recuperado de http://www.revistas-conacyt.unam.mx/economiatyp/index.php/ ETYP/article/view/293/192

García-Galván, R. (2012). Cooperación tecnológica interfirma y empresa-universidad: el sector biofarmacéutico en México (Tesis doctoral). Universidad Autónoma Metropolitana, México. Recuperado de http://tesiuami.izt.uam.mx/uam/aspuam/ presentatesis.php? recno $=206180389 \&$ docs $=206180389$.pdf

García-Galván, R. (2013). ¿El conocimiento universitario puede promover el desarrollo industrial? Percepción sobre las promesas de la biotecnología en México. En E. Gaona \& D. Velázquez (Coords.), Conocimiento para el crecimiento económico (pp. 87-103). México: Universidad Autónoma del Estado de Hidalgo. 
Gibbons, M., Limoges C., Nowotny, H., Schwartzman, S., Scott, P., \& Trow, M. (1997). La nueva producción del conocimiento. Barcelona: Ediciones Pomares-Corredor.

López, S. (2002). La vinculación y los investigadores. Perfiles Educativos, 24(98), 76-95. Recuperado de http://www.redalyc.org/pdf/132/13209806.pdf

López, S. (2005). La vinculación de la ciencia y la tecnología con el sector productivo: una perspectiva económica y social. México: Universidad Autónoma de Sinaloa.

Lundvall, B.A. (Ed). (1992). National Systems of innovation: Towards a theory of innovation and interactive learning. Londres: Pinter.

Jáuregui, F. (2012). Vinculación y gestión del conocimiento en la interacción UniversidadEmpresa. El caso de la UABC-Sector agropecuario de Baja California (Tesis de doctorado). Universidad Autónoma de Baja California, México.

Montes, C. (2002). La vinculación de la Universidad Autónoma de Baja California vista desde sus unidades académicas (Tesis de maestría). Universidad Autónoma de Baja California, México. Recuperado de http://iide.ens.uabc.mx/images/pdf/ tesis/MCE/Tesis\%20MCE\%20CMontes.pdf

Perkman, M., Tartari, V., McKelvey, M., Autio, E., Broström, A., D’Este, P., ..., \& Sobrero, M. (2013). Academic engagement and commercialisation: A review of the literature on university-industry relations. Research Policy, 42, 423-442.

Rama, C. (2010). La irrupción de nuevos modelos socieconómicos, paradigmas educativos y lógicas económicas de la educación. Universidades, 60(46), 3-16. Recuperado de http://www.redalyc.org/pdf/373/37318636002.pdf

Taboada, E. (2004). ¿Qué hay detrás de la decisión de cooperar tecnológicamente? Propuesta teórica integradora para explicar la cooperación tecnológica interfirma (Tesis de Doctorado). Universidad Autónoma Metropolitana, México. Recuperado de http://tesiuami.izt.uam.mx/uam/aspuam/presentatesis. php?recno=12398\&docs=UAMI12398.PDF

Thomas, H., Davyt, A., Gomes, E., \& Dagnino, R. (1997). Racionalidades de la interacción universidad-empresa en América Latina (1955-1995). Educación Superior y Sociedad, 8(1), 83-110. Recuperado de file:///C:/Users/Hp/Downloads/289-10321-PB\%20(1).PDF 
Vertova, G. (2014). The State and National Systems of Innovation: A Sympathetic Critique. Levy Economics Institute Working Paper Collection No. 823. University of Bergamo, Italy. Recuperado de http://www.levyinstitute.org/pubs/wp_823.pdf

Wanda, O. (2015). Determinants of university-firm R\&D collaboration and its impact on innovation: A perspective from a low-tech industry. Research Policy, 44, 13411359. 


\section{Capítulo 10}

\section{¿Qué valoran los empleadores en los egresados de educación superior en Baja California?}

Dalia Lizzett Acosta Cárdenas, Juan Carlos Rodríguez Macías, Rodolfo García-Galván y Alicia Alelí Chaparro Caso-López

México es parte de la transformación mundial que se da a partir de la globalización, pero ese cambio es tan acelerado que por el momento no se aprecian las consecuencias ni el alcance que tendrá (Santibáñez y Cruz, 2000). Por ejemplo, con el avance de la tecnología tienden a extinguirse los puestos de trabajo más simples y comienzan a incrementarse aquellos que tienen funciones más complejas. Esto provoca que los empleadores aumenten sus estándares para contratar a nuevos profesionistas a quienes se les exigen competencias cada vez más especializadas (Gottfredson, 1997; Zalaquett y Turner, 1997, como se citó en Castro, 2004). Ante esta situación, la educación superior mexicana tiene el desafío de formar a jóvenes con competencias que les permitan integrarse, desarrollarse y mantenerse en los mercados laborales (Estrella y Ponce León, 2006). Al respecto, la opinión de los empleadores puede ayudar a la definición de los requerimientos asociados a la globalización económica y a la apertura comercial (Crespo, Cuamatzi y González, 2009). Con esta información, las universidades pueden revisar la pertinencia curricular, adecuar los planes de estudio, así como la incorporación de los desafíos del contexto regional en los programas educativos de las diferentes áreas de conocimiento (Damián, Montes, Arellano, 2010). Es decir, es preciso examinar y predecir cuál será el futuro de los egresados por medio de la interacción con el mercado laboral, pero sin limitarse únicamente a ella (Ordorika, 2014). No se trata de que la formación 
profesional tenga como objetivo adaptar a los trabajadores a los efectos de los cambios, sino de anticipar con medidas proactivas las habilidades que necesitarán los egresados en el futuro (González, 1993).

Dado lo anterior, surgió la siguiente pregunta de investigación ¿cuáles son las cualidades que más valoran los empleadores en los egresados de educación superior en Baja California? El estudio se centró en identificar las características formativas que posibilitan la empleabilidad de los egresados de Instituciones de Educación Superior (IES) en Baja California.

\section{Desarrollo}

Alcanzar una mayor escolaridad es considerado por la sociedad mexicana como un factor determinante para el desarrollo económico, pues esta situación permite acceder a empleos con mejores condiciones. Desde esta perspectiva, el papel de la educación superior es funcionar como un motor de movilidad social y debería disminuir las desigualdades sociales y económicas de nuestro país. Sin embargo, para un conjunto muy amplio de jóvenes que egresan de estudios superiores esta condición ya no se cumple, debido a que el nuevo orden mundial genera nuevas condiciones de mercado (Mora y Oliveira, 2012). Para explicar la relación que existe entre los jóvenes que egresan de la educación superior y la empleabilidad existen varias aproximaciones teóricas, para este caso, se eligió a la economía de la educación.

La economía de la educación aborda los aspectos e implicaciones económicas de los fenómenos educativos (Pineda, 2001). Dentro de este campo de conocimiento, hay distintas explicaciones, pero solamente se abordaron dos aproximaciones teóricas que encajan mejor con la realidad de Baja California; por un lado, la teoría del capital humano y, por otro lado, la teoría del filtro. Estas teorías que surgen de la Economía incitan a cuestionar cuál es el papel de la educación superior en relación con la inserción laboral de sus egresados, por lo que impulsó la realización de estudios, investigación y evaluación sobre los programas educativos, procesos de formación, trayectorias laborales y el seguimiento a los egresados. 
La teoría del capital humano tiene como principales representantes a Theodore Shultz, Gary Becker y Mark Blaug. Esta teoría se centra en la importancia que tiene la formación de las personas sobre la producción y el crecimiento económico, y considera que la educación es un bien de inversión. Según Garrido-Trejo (2011) la educación superior en México está fundamentada en esta teoría, pero en los resultados solo ha beneficiado a un reducido grupo en cada uno de los sectores y ramas de la economía, y de la sociedad. Esta teoría tiene limitaciones para explicar la relación entre educación y el trabajo. Es por ello necesario recurrir a la contribución que han hecho otras perspectivas emergentes ya que buscan cubrir dicha insuficiencia explicativa (Pineda, 2001).

Ante tales limitaciones, la teoría del filtro o de selección elaborada por Kenneth Arrow, Michael Spence y Joseph Stiglitz en la década de 1970, señala que el mercado de trabajo necesita de un conjunto de indicadores para tomar decisiones de contratación, por ejemplo, el nivel educativo alcanzado, obtención de grados académicos y altas calificaciones; si ello sucede, las empresas utilizarían a la educación como un filtro para seleccionar a sus trabajadores. Una de las críticas de esta corriente es que lo importante no es estudiar para ampliar conocimientos y adquirir habilidades y destrezas, sino que se accede a la educación para obtener un documento que acredite la capacidad del individuo (Oroval y Escadibul, 1998).

\section{Contexto del estudio}

En México hay empleadores que declaran tener dificultades para cubrir las vacantes que ofrecen; por otro lado, exponen que muchos de los egresados de educación superior no cuentan con las competencias necesarias para desempeñar sus funciones (Organización para la Cooperación y Desarrollo Económico [OCDE, 2017]). Respecto a esta situación, en el Plan Nacional de Desarrollo 2013-2018 aparece que la falta de capital humano es resultado de una vinculación inadecuada entre el sector productivo y el educativo, por lo tanto, la educación superior debe estar en estrecha vinculación con la investigación y la producción del país (Gobierno de la República, 2013). Otras razones para incentivar la vinculación entre los dos sectores son las siguientes: (a) desconocimiento de las 
necesidades y requerimientos profesionales y laborales actuales (Márquez, 2011); (b) desequilibrio en la composición de la matrícula, mientras hay una excesiva concentración en pocas carreras con destinos laborales saturados, hay otras que son muy poco solicitadas (Camarena y Velarde, 2009); y, (c) existe una alta proporción de egresados universitarios que no logran colocarse en el mercado laboral (Vargas, 1998).

La educación superior ${ }^{1}$ en Baja California sigue un modelo por competencias y existen 87 Instituciones de Educación Superior (IES) que concentran una matrícula de 135,826 estudiantes en modalidades escolarizadas, no escolarizadas y mixtas (Sistema Educativo Estatal [SEE], 2018). En el estado se ofertan 223 carreras, pero, a pesar de la diversidad de opciones, $38.5 \%$ de la matrícula se ubica en 10 licenciaturas ${ }^{2}$, siendo Derecho la que tiene más afluencia de estudiantes (SEE, 2018). Asimismo, en el ciclo escolar 2017-2018 hubo 19,902 egresados, de los cuales $38 \%$ no han cumplido con los requisitos de titulación, lo que puede representar un obstáculo en la búsqueda y adquisición de un empleo formal (SEE, 2018).

Respecto al empleo de las personas que cuentan con estudios de educación superior ${ }^{3}$, la población ocupada ${ }^{4}$ corresponde a 255,589 personas (INEGI, 2018a) mientras que la población desocupada con las mismas características es de 10,040 personas (INEGI, 2018b). Son bastantes las personas que no están empleadas en alguna actividad económica, pero, incluso si cuentan con un empleo remunerado, muchos se encuentran en condiciones laborales precarias o de baja calidad (OCDE, 2017).

1 La educación superior en Baja California comprende los niveles de técnico superior, licenciatura universitaria, tecnológica, normal y posgrado. Los tipos de sostenimiento son autónomo, privado, federal, estatal y federal transferido.

2 Las diez licenciaturas que concentran al 38.5\% de la matrícula de educación superior en Baja California son: Licenciatura en Derecho (9.5\%); Administración de empresas (4.6\%), Ingeniería Industrial (4.3\%), Psicología (4.2\%), Arquitectura (3.1\%), Medicina (3.1\%), Contaduría (2.9\%), Enfermería (2.8\%), Cirujano Dentista (2.2\%) e Ingeniería en Mecatrónica (2.2\%).

3 Se consideró a la población de Baja California que tiene entre 20 y 29 años en el segundo trimestre de 2018 (INEGI, 2018a).

4 La población ocupada comprende a las personas que trabajaron con una remuneración y como mínimo una tercera parte de la jornada laboral (INEGI, s.f.). 


\section{Método}

Para realizar el estudio se entrevistó a tres jefes de departamento con el fin de indagar cuáles son las cualidades que favorecen la empleabilidad de los egresados de educación superior desde la perspectiva de los empleadores. Se eligió a los jefes del departamento de recursos humanos, quienes son los responsables de reclutar y coordinar las acciones de contratación de personal dentro de las empresas.

Los datos para identificar a las empresas se tomaron del Directorio Estadístico Nacional de Unidades Económicas (DENUE) del INEGI. Se eligieron tres empresas que pertenecen al sector manufacturero y actualmente están en crecimiento. Tienen más de 20 años colocadas en el estado de Baja California y tienen sedes en Estados Unidos, China y México. La estructura organizacional de las tres empresas está dividida por departamentos (compras, ventas, producción, calidad, recursos humanos y contabilidad).

Las participantes son mujeres con estudios de licenciatura y son las titulares del departamento de recursos humanos de las empresas. Al momento de ingresar a este puesto contaban con experiencia previa en el área de recursos humanos. Las principales actividades que realizan son reclutamiento, contratación, capacitación, fomento del clima laboral, seguridad e higiene y trámites administrativos, por ejemplo, la elaboración de nóminas.

Las entrevistas que se realizaron fueron semiestructuradas porque facilitan la investigación cuando hay personas que disponen de poco tiempo para contestar (Bernard, 1988 como se citó en Tarrés, 2008). Para construir la guía de entrevista se construyeron dos dimensiones con base en la pregunta, el objetivo de investigación y la literatura revisada. La primera dimensión se llama características de la fuerza laboral y la segunda dimensión es percepción sobre las Instituciones de Educación Superior. En total fueron 20 preguntas de respuesta construida las que conformaron la guía de entrevista. Finalmente, cada una de las entrevistas duró aproximadamente 45 minutos y fueron audiograbadas.

Para el tratamiento de los datos de las entrevistas se utilizó la técnica de análisis de contenido deductivo considerando las dimensiones y categorías establecidas en la guía de entrevista. 


\section{Resultados}

Los resultados obtenidos se presentan conforme a las dimensiones y categorías que se establecieron en la guía de entrevista.

\section{Características de la fuerza laboral}

La primera dimensión tiene el objetivo de conocer cómo se realiza la selección de sus colaboradores y cuáles son los criterios que toman en cuenta al seleccionar o rechazar a un prospecto. Las categorías son: a) medios para reclutar personal; b) vacantes sin cubrir en la empresa; c) proceso de selección de personal; d) características de los candidatos; e) razones por las que se rechaza a un candidato; f) actitudes que buscan en los prospectos; $g$ ) habilidades escasas en los candidatos; y h) capacitación.

a) Medios para reclutar personal. El medio principal para captar personal para la empresa es Internet, ya sea a través de sitios web diseñados con ese propósito o por medio de las redes sociales. En segundo lugar, tienen contacto con las bolsas de empleo estatales, y en ocasiones, por medio de recomendaciones de otras personas.

b) Vacantes sin cubrir en la empresa. Las participantes declararon que se les dificulta cubrir posiciones en los departamentos de producción, control de calidad y ventas. Las razones por las que no encuentran el personal son distintas, pero destaca la falta de candidatos con la formación requerida para el puesto.

c) Proceso de selección de personal. El primer filtro que utilizan para la selección de personal es la revisión del currículum vitae porque analizan que la experiencia laboral corresponda con el perfil que se requiere para el puesto. Posteriormente, se cita a una entrevista inicial a aquellos candidatos seleccionados con el responsable de recursos humanos a fin de preguntar cuestiones personales, socioeconómicas, experiencia laboral y algunas preguntas teóricas sobre el puesto. Si cumplen con estos requisitos se cita a una segunda entrevista con quien será el jefe directo y éste pregunta sobre conocimientos específicos del puesto. 
d) Características de los candidatos. Se expresó que lo primero que buscan en un prospecto es que cuente con los conocimientos para desempeñar el puesto que solicita y esta característica la detectan en el currículum vitae; sin embargo, los participantes expresaron que los candidatos muchas veces no saben redactar el currículum. Otras características que consideran son el desenvolvimiento del candidato durante la entrevista, su actitud y los valores que demuestre, además de la apariencia personal, "no tiene que ser el más elegante pero que sea presentable".

e) Razones por las que se rechaza a un candidato. La principal causa de rechazo es que el candidato no demuestre que posee el perfil para el puesto, es decir, "Ia falta de conocimiento primordialmente". Las participantes coincidieron al decir que, actualmente, "Ia competencia por un empleo está muy cerrada y llega alguien mejor calificado". Otra de las participantes especificó que "y ahí la actitud que demuestre el candidato durante la entrevista puede hacer la diferencia entre ser seleccionado o no, aunque no cuenten con mucha experiencia, se evalúa los comentarios sobre propuestas, tipos de análisis y calidad de las participaciones". Al respecto, otra participante expresó que "al momento en que lo están entrevistando [al candidato], aunque no tengan la experiencia suficiente, pero ya están proponiendo, están analizando, ya están participando".

f) Actitudes que buscan en los prospectos. Las participantes coincidieron en que se busca mucha responsabilidad, compromiso, dedicación, flexibilidad, innovación, iniciativa, que pueda "solucionar problemas y trabajar bajo presión".

g) Habilidades escasas en los candidatos. Las participantes coincidieron que una habilidad muy escasa entre los empleados es una actitud proactiva, la falta de comunicación "correcta" y la capacidad de análisis. Otra, es el dominio del idioma inglés oral y escrito, pues deben comunicarse con clientes de ciudades extranjeras.

h) Capacitación. A todos los empleados de nuevo ingreso se les dan cursos de inducción. Para ciertos puestos hay más capacitaciones, por ejemplo, a ingeniería se les ofrecen certificaciones por parte de la empresa para recibir actualizaciones. 
Un participante expresó "a veces se ha enviado personal a Estados Unidos porque se tienen que certificar en el producto que nosotros hacemos, se tienen que capacitar en ciertos conocimientos que se requieren para hacerlo". Otra persona comentó que "antes los mandamos a Estados Unidos, pero ahora viene alguien para acá, sobre todo para nuevos procedimientos y actualizaciones". Para el personal de exportaciones también se ofrecen actualizaciones y capacitaciones porque surgieron cambios en las normas de operación a partir de diciembre de 2017. Para el departamento de contabilidad y recursos humanos las capacitaciones son locales, por parte del Colegio de Contadores y la Secretaría del Trabajo. Hay otros empleados que tienen la iniciativa de actualizarse por su cuenta y deciden estudiar alguna maestría. En algunas empresas, según la trayectoria del empleado, se les apoya económicamente cuando deciden estudiar un posgrado.

\section{Percepción sobre las Instituciones de Educación Superior}

La finalidad de esta dimensión fue conocer la opinión que los empleadores tienen sobre la formación que reciben los egresados de las IES, así como de las IES de la localidad. Las categorías son: a) principales instituciones de las que egresan los trabajadores; b) opinión de la calidad educativa de las IES estatales; c) problemas a los que se enfrentan los egresados; $\mathrm{y} d$ ) recomendaciones a las IES para que los egresados se incorporen, se mantengan y desarrollen dentro del mercado laboral.

a) Principales instituciones de las que egresan los trabajadores. De las 87 IES que existen en el Estado, los tres participantes mencionaron sólo a dos universidades públicas y una privada. Las universidades públicas fueron la Universidad Autónoma de Baja California y los Institutos Tecnológicos -hay campus en Ensenada, Mexicali y Tijuana-. La universidad privada que mencionaron es el Centro de Enseñanza Técnica y Superior (CETYS Universidad) la cual cuenta con una fuerte vocación tecnológica.

b) Opinión de la calidad educativa de las IES estatales. No hay una opinión contundente al respecto de las IES estatales. Una participante comentó que "no es la 
Institución, no creo que una sea mejor que otra, son iguales las instituciones, es la persona en sí la que define el resultado".

c) Problemas a los que se enfrentan los egresados. Los participantes han detectado varios problemas. El más mencionado fue la competencia que hay para incorporarse al mercado laboral, ya que hay pocas oportunidades para muchos egresados. Otro problema es la falta de experiencia de los egresados: "hay muchas carreras donde no se puede trabajar [al mismo tiempo que se estudia], lo cual le resta muchas competencias con alguien que si podía combinar el trabajo con el estudio".

d) Recomendaciones a las IES para que los egresados se incorporen, se mantengan y desarrollen dentro del mercado laboral. Los participantes hicieron dos recomendaciones. Primero, se debe estar al "pendiente" de las actualizaciones, tener iniciativa y pensar en las mejoras que se pueden implementar. La segunda recomendación estuvo relacionada con el trabajo, "que les permitan trabajar y estudiar (...), hay gente que lo hace y son gente que se logra colocar más rápido".

\section{Conclusiones}

Con los resultados que surgieron de este estudio, se logró conocer las características que más valoran los empleadores al momento de contratar a un egresado de educación superior. Como profesionistas que se desempeñan en un puesto profesional, el dominio de los conocimientos propios de su disciplina es la característica más importante que se busca en un prospecto. El medio para valorar esos conocimientos es el currículum vitae, de tal forma que, este documento constituye el primer filtro para la selección de los candidatos. Por lo tanto, los solicitantes que no logren elaborar un documento donde consigan expresar cuál ha sido su formación académica y profesional, son excluidos de inmediato. Esto coincide con la teoría del filtro o de la selección, ya que el currículum vitae se convierte en un indicador para tomar la decisión de contratar al candidato más apto, y que, a su vez, represente menos inversión en su capacitación.

Aunque los conocimientos son sumamente importantes, los empleadores declaran que las actitudes que demuestren los candidatos son mejor valoradas, ya que son 
decisivas para incorporarse y mantenerse en el empleo. El momento para demostrar responsabilidad, compromiso, dedicación, flexibilidad, innovación, iniciativa, resolución de problemas es durante la entrevista, por eso, esta técnica sigue siendo la favorita de los empleadores, a pesar del auge en el desarrollo de pruebas psicométricas y en los avances tecnológicos.

El papel que juegan las tecnologías de la información y la comunicación (TIC), en especial Internet, en el proceso de reclutamiento de egresados de educación superior es esencial. Esto hace necesario que los profesionistas egresen con un muy buen dominio de las competencias tecnológicas pues aquel candidato con más y mejores habilidades en el manejo de los medios digitales y de búsqueda de información tendrá más posibilidades de encontrar vacantes.

Por otro lado, hay vacantes en las empresas que no se cubren porque faltan profesionistas que cumplan con el perfil que se solicita. Esta declaración contrasta con el número de egresados que no se encuentran ocupados en un empleo formal, a su vez, se relaciona con la alta concentración de la matrícula y la preferencia por las carreras tradicionales del área de ciencias sociales y administrativas que tienen destinos laborales saturados. En el caso de Baja California, hay una alta vocación económica de la industria de la transformación, pero son pocas las personas que se deciden por una carrera que se relaciones con esta actividad económica.

Esta situación parece indicar que las IES están olvidando la importancia de mantener una vinculación sólida con las empresas y la sociedad. Es necesario fomentar la comunicación e interrelación entre estos sectores, de tal manera que se logre una recomposición estructural en las carreras que se ofertan y reducir el desequilibrio en la composición de la matrícula de educación superior y la disminución del número de egresados que no logran colocarse en el mercado laboral o que, a pesar de mantenerse ocupados, se encuentran subempleados, sobre todo que se fomente el ingreso a carreras más afines a la vocación productiva de Baja California.

Se requiere iniciar líneas de investigación sobre la opinión de los empleadores para comprender los retos, desafíos y oportunidades que hay en Baja California, e 
incorporar ese conocimiento al diseño y adecuación de planes de estudio alineados al contexto. A corto plazo, se puede utilizar la información para actualizar sus técnicas y métodos de enseñanza incorporando las tendencias del mercado, para que los estudiantes adquieran una visión más completa de la realidad. 


\section{Referencias}

Camarena, B., \& Velarde, D. (2009). Educación superior y mercado laboral: vinculación y pertinencia social ¿Por qué? y ¿Para qué? Estudios sociales 17, 105-125. Recuperado de http://www.scielo.org.mx/scielo.php?pid=S018845572009000300005\&script=sci_abstract

Castro, A. (2004). Las competencias profesionales del psicólogo y las necesidades de perfiles profesionales en los diferentes ámbitos laborales. Interdisciplinaria 21(2), 117-152. Recuperado de http://www.scielo.org.ar/scielo.php?script=sci_ arttext\&pid=S1668-70272004000200001

Crespo, S., Cuamatzi, M., \& González, M. (2009). Opinión de los empleadores sobre el perfil del licenciado en enfermería de la Facultad de Estudios Superiores Zaragoza. Ponencia presentada en X Congreso Nacional de Investigación Educativa (COMIE), Veracruz, Veracruz. Recuperado de http://www.comie.org.mx/congreso/ memoriaelectronica/v10/pdf/carteles/0182-F.pdf

Damián, J., Montes, E., \& Arellano, LI. (2010). Los estudios de opinión de empleadores. Estrategia para elevar la calidad de la educación superior no universitaria. RINACE 8(3) 180-203. Recuperado de http://www.rinace.net/reice/numeros/arts/ vol8num3/art11.pdf

Gobierno de la República (2013). Plan Nacional de Desarrollo 2013-2018. Diario Oficial de la Federación, DOF 20-05-2013. Recuperado de http://www.dof.gob.mx/nota_ detalle.php?codigo $=5299465 \&$ fecha $=20 / 05 / 2013 \&$ print $=$ true)

Estrella, G., \& Ponce León, M. (2006). Impacto Laboral de egresados universitarios y opinión de empleadores. México: UABC. Recuperado de http://www.uabc.mx/planeacion/ reportesdeestudios2004/reporteempleadores.pdf

Garrido-Trejo, C. (2011). Funcionalidad técnica de la educación y demanda de profesionales. Zona metropolitana de Toluca, 1995-2005. Convergencia Revista de Ciencias Sociales, O(55). Recuperado de http://convergencia.uaemex.mx/article/ view/1131/1700 
González, L. (1993). Nuevas relaciones entre educación, trabajo y empleo en la década de los 90. Revista Iberoamericana de la Educación 2. Recuperado de http://rieoei. org/oeivirt/rie02a03.htm

Instituto Nacional de Estadística y Geografía. (s.f.). Glosario completo. Recuperado de http://www.inegi.org.mx/est/contenidos/espanol/sistemas/cem07/texcom/ glosario/glosario.htm

Instituto Nacional de Estadística y Geografía. (2018a). Encuesta Nacional de Empleo. Población ocupada. Recuperado de http://www.inegi.org.mx/ Sistemas/Olap/Proyectos/bd/encuestas/hogares/enoe/2010_PE_ED15/ po.asp?s=est\&proy=enoe_pe_ed15_po\&p=enoe_pe_ed15

Instituto Nacional de Estadística y Geografía (INEGI). (2018b). Encuesta Nacional de Empleo. Población desocupada. Recuperado de http://www.inegi.org.mx/ Sistemas/Olap/Proyectos/bd/encuestas/hogares/enoe/2010_PE_ED15/pda. asp?s=est\&proy=enoe_pe_ed15_pda\&p=enoe_pe_ed15

Márquez, A. (2011). La relación entre educación superior y mercado de trabajo en México. Una breve contextualización. Perfiles Educativos 33 (número especial), 169-185. Recuperado de http://www.ses.unam.mx/integrantes/uploadfile/amarquez/ AMJ2011_LaRelacionEntreESyMercado.pdf

Mora, M., \& Oliveira, O. (2012). Las vicisitudes de la inclusión laboral en los albores del s XXI: trayectorias ocupacionales y desigualdades sociales entre jóvenes profesionistas mexicanos. Estudios Sociológicos de El Colegio de México, 34(102), 3-42. Recuperado de http://estudiossociologicos.colmex.mx/index.php/es/ article/view/157/157

Ordorika, I. (2014). Renovar las políticas de acceso a la educación superior. Revista de la educación superior, 43(170), 5-8. Recuperado de http://publicaciones.anuies.mx/ pdfs/revista/Revista170_S1A1ES.pdf 
Organización para la Cooperación y el Desarrollo Económico (OCDE). (2017). Diagnóstico de la OCDE sobre la Estrategia de Competencias, Destrezas y Habilidades de México. Resumen Ejecutivo. Recuperado de http://www.oecd.org/mexico/Diagnosticode-la-OCDE-sobre-la-Estrategia-de-Competencias-Destrezas-y-Habilidades-deMexico-Resumen-Ejecutivo.pdf

Oroval, E., \& Escadibul, O. (1998). Economía de la educación. Madrid: Encuentro Ediciones. Pineda, P. (2001). Economía de la educación: una disciplina pedagógica en pleno desarrollo. Teoría de la Educación 12(14), 143-158. Recuperado de https://gredos. usal.es/jspui/bitstream/10366/71891/1/Economia_de_la_Educacion_una_ disciplina_.pdf

Santibáñez, R.J., \& Cruz P.R. (2000). Mercados laborales fronterizos. En R. Tuirán (Coord.), Migración México-Estados Unidos, Opciones de política (pp. 169-178). México: SEGOB/CONAPO/SER. Recuperado de http://www.conapo.gob.mx/work/models/ CONAPO/migracion_internacional/MigracionOpPolitica/04.pdf

Sistema Educativo Estatal (SEE). (2018). Principales cifras estadísticas. Anuario de datos e indicadores Educativos ciclo 2017-2018. Recuperado de http://www.educacionbc. edu.mx/publicaciones/estadisticas/2018/publicaciones/Cuadernillo\%2020172018.pdf

Tarrés, M.L. (2008). Observar, escuchar y comprender. Sobre la tradición cualitativa en la investigación social. México: COLMEX/FLACSO.

Vargas, Z.F. (1998). Formación profesional en América Latina. Buenas perspectivas, varios desafíos. Encuentro Iberoamericano de responsables de la formación profesional. Seminario sobre Formación Profesional y Empleo. Recuperado de http://www.oei. org.co/iberfob/méxico 


\section{Capítulo 11}

\section{Análisis del procedimiento para evaluar programas educativos en la educación superior de México a partir del modelo CIPP de Stufflebeam}

Nancy Noemí Gutiérrez Anguiano, Leticia Berenice Castillo García, Alicia Alelí Chaparro Caso-López y Rodolfo García-Galván

A partir de la década de los ochenta, en México, se formalizó la evaluación de las instituciones de educación superior (IES) (Gómez y Herrera, 2007). Ante este nuevo cambio, en 1989, se creó la Comisión Nacional de Evaluación (CONAEVA), como un organismo dedicado a la creación y operación del sistema nacional de evaluación de la educación superior. Asimismo, en esta década, la Organización de las Naciones Unidas para la Educación, la Ciencia y la Cultura (UNESCO) y la Organización para la Cooperación y el Desarrollo Económico (OCDE) determinaron políticas internacionales para la regulación de los procedimientos de evaluación y acreditación de programas educativos, con el fin de asegurar la calidad en la educación superior.

La expansión del sistema educativo a nivel superior y el crecimiento de la matrícula son temas preocupantes no solamente para el gobierno sino para el sector social y laboral, respecto a la calidad de la educación que se brinda en las IES. Al respecto, De la Garza (2013) mencionó que existe una incertidumbre por asegurar que todos los estudiantes universitarios realicen sus estudios profesionales en programas educativos de buena calidad. Ante esta inquietud, las autoridades educativas han unido esfuerzos con organismos nacionales e internacionales para evaluar y acreditar programas educativos en las universidades del país, como un plan estratégico para reconocer fortalezas y de- 
bilidades, con el fin de promover la mejora continua. Además, con el reconocimiento de buena calidad en los programas educativos, las universidades están ganando prestigio y aceptación social, no sólo en el ámbito nacional sino también en el internacional.

En México, existen dos organismos encargados de evaluar la calidad de los programas educativos en la educación superior: los Comités Interinstitucionales para la Evaluación de la Educación Superior (CIEES) y el Consejo para la Acreditación de la Educación Superior (COPAES).

Acosta (2014), Gómez y Herrera (2007) y Ramírez (2016) precisaron que los CIEES fueron la primera estrategia de acción implementada en 1991 por la CONAEVA, para acreditar programas educativos, aunque posteriormente, en el siglo XXI, se dedicaron a diagnosticar y pre-acreditar programas. Por su parte, el COPAES, creado en el año 2000, es una instancia no gubernamental avalada por la Secretaría de Educación Pública (SEP), cuyo objetivo es la acreditación formal de programas educativos y organismos evaluadores. Con este cambio de roles entre el COPAES y los CIEES en el proceso de acreditación, las IES son evaluadas a través de dos procesos que permiten identificar aspectos de mejora en sus programas, organización y gestión institucional, recursos y servicios.

De acuerdo con Gómez y Mora (2011), la evaluación externa ha tenido mayor auge a medida que las autoridades de las IES han comprendido la importancia de evaluar y acreditar programas educativos como un medio que no sólo permite la obtención de recursos económicos, sino que produce también un cambio significativo en la calidad del proceso educativo. Algunas de las áreas del proceso educativo que reciben un impacto tras el procedimiento de evaluación y acreditación son: el plan de estudios, la infraestructura, los servicios administrativos, la labor de los docentes, entre otros.

Dada esta nueva perspectiva sobre los beneficios de un proceso de evaluación y acreditación, las IES están optando por someterse a un proceso de evaluación externa por alguno de los organismos evaluadores. Tanto los CIEES como el COPAES disponen de comités de expertos que evalúan distintas disciplinas como: Arquitectura, Diseño y Urbanismo; Artes, Educación y Humanidades; Ciencias Agropecuarias; Ciencias Naturales y Exactas; Ciencias de la salud; Ciencias Administrativas; e Ingeniería y Tecnología. 
La evaluación, en el transcurso de un proceso diagnóstico y de acreditación, ayuda a que en las IES se logre un avance en la mejora del procedimiento de autoevaluación y sistematización respecto a la atención en áreas de oportunidad (De la Garza, 2013; Gómez y Mora, 2011). Con la información recuperada en el proceso de evaluación por los CIEES y el COPAES, los responsables en las IES pueden preparar un plan estratégico hacia la mejora continua de sus servicios. Con este plan se espera el aumento de la calidad del proceso educativo, mediante la atención de las observaciones (deficiencias identificadas durante el proceso de autoevaluación interna y externa) y las recomendaciones emitidas por los organismos evaluadores (Ramírez, 2016).

De acuerdo con García-Cabrero (2010), evaluar un programa educativo requiere de una revisión de indicadores y adoptar un modelo de evaluación que permita reconocer los aspectos clave que deben ser valorados para distinguir aspectos susceptibles de mejora en los que se debe intervenir. Aunque no existe un consenso en la literatura especializada acerca de qué modelo es mejor, se ha identificado que el modelo CIPP de Stufflebeam ha sido ampliamente utilizado en la evaluación de programas educativos en las IES. Dicho modelo se caracteriza por ser un referente sistemático, dedicado al análisis de: insumos, estructura, proceso y resultados. En este tipo de modelo se prioriza la atención al contexto en el que se desenvuelve y organiza el programa educativo, así como los insumos destinados (recursos materiales, humanos y financieros) y los resultados adquiridos hacia el logro académico e impacto social.

Con base en lo expuesto, se puede afirmar que evaluar los programas educativos no sólo proporciona a las IES un incremento de financiamiento o un mayor prestigio, sino que se concientiza y promueve una cultura de actualización y valoración continúa sobre el funcionamiento del programa. Asimismo, se reconoce la necesidad de revisar los programas educativos, mediante un modelo fiable con estándares e indicadores que permitan verificar el logro eficiente y eficaz de las acciones que se implementan para mejorarlo -como es el caso del modelo CIPP de Stufflebeam-.

En consecuencia, el presente capítulo tiene como propósito analizar el procedimiento para evaluar programas educativos en la educación superior de México, a partir del modelo CIPP. 


\section{Procedimiento de evaluación empleado por CIEES y COPAES}

para evaluar y acreditar programas educativos

La evaluación de un programa educativo se caracteriza por ser de tipo mixto. Al respecto, Jornet, Leyva y Sánchez (2009) señalaron que las evaluaciones mixtas hacen una combinación de los propósitos, consecuencias y resultados de una evaluación sumativa y formativa. En este caso, los pares académicos realizan recomendaciones de mejora para el programa educativo $y$, finalmente, los resultados se apoyan en una decisión cuantitativa. De acuerdo con Bezies, Olvera y Enciso (2011), De la Garza (2013), Márquez y Zeballos (2017), el proceso de evaluación de un programa educativo tiene los siguientes fines:

- Promover una cultura de actualización y evaluación continua de los programas educativos y las IES

- Establecer recomendaciones para el mejoramiento de la calidad educativa en las IES

- Asignar recursos extraordinarios a las IES públicas ${ }^{1}$

- Dictaminar la calidad de un programa por medio de la acreditación, con base en los términos definidos por los CIEES y el COPAES

- Reconocimiento público respecto a las expectativas en la calidad de los programas educativos de las IES, lo que otorga prestigio y aceptación social

A partir de las normas que regulan los CIEES (2018a) y el COPAES (2016) se asegura que, en el transcurso de un proceso de acreditación, la evaluación será de carácter confidencial, transparente y formal. Asimismo, en este procedimiento se emplea una metodología flexible que permita evaluar cualquier tipo de programa educativo, por lo que no tendrá relevancia el tamaño, el financiamiento e incluso la ubicación de la IES. Para recibir el reconocimiento de acreditación, los programas educativos deben cumplir

1 Por ejemplo, en el 2001, a través del Programa Integral de Fortalecimiento Institucional (PIFI), el cual se transformó, en el 2014, en el Programa de Fortalecimiento de la Calidad en Instituciones Educativas (PROFOCIE); y hacia el 2016, se transformó en el Programa de Fortalecimiento de la Calidad Educativa (PFCE). 
con ciertos indicadores dedicados específicamente a revisar la calidad de las distintas áreas que conforman el proceso educativo de un programa perteneciente a la educación superior. La evaluación y acreditación por parte de los CIEES y el COPAES se divide en cinco etapas: autoevaluación de la institución; visita de evaluación; dictamen; entrega de informe de evaluación y visita de seguimiento.

\section{Etapa 1. Autoevaluación de la institución}

En esta etapa, el responsable del programa educativo deberá entregar al comité evaluador un informe general sobre el estado que guarda el programa educativo ante la revisión de ciertos estándares. Para evidenciar la configuración, acciones y organización del programa, se deben conformar carpetas con evidencias de mínimo cinco años que respalden los datos presentados en el informe. Los argumentos del informe y las carpetas habrán de constituirse con la información cuantitativa y cualitativa necesaria respecto a todas las áreas del proceso educativo del programa. Estos documentos de evidencias deben presentarse en el orden como vienen señalados los estándares e indicadores en cada una de las categorías a revisar (tabla 1), como se estípula en el marco de referencia de los CIEES y el COPAES.

Además, en este proceso de autoevaluación, el responsable del programa tiene que enunciar por cada estándar las virtudes y deficiencias que corresponden a la categoría revisada, así como las acciones que los encargados del programa deben seguir para asegurar la calidad futura.

Para evaluar los programas educativos existen 10 categorías esenciales (COPAES, 2016), a partir de dichas categorías se enuncian estándares e indicadores con el fin de valorar si un programa atiende los fundamentos básicos a considerar para brindar los servicios adecuados. Las categorías son las siguientes:

1. Personal académico. Involucra estándares relacionados con el reclutamiento, selección y contratación de docentes, tanto de tiempo completo como de asignatura. Además, se consideran aspectos relacionados con la actualización disciplinar y pedagógica, distribución de la carga académica, promoción y evaluación del desempeño docente. 
2. Estudiantes. Comprende los estándares dedicados a los criterios de selección e ingreso, trayectoria escolar (aprobación-reprobación, abandono escolar, etc.) y el tamaño de los grupos respecto a la capacidad de las aulas por semestre. Asimismo, se revisa el índice de rendimiento escolar por cohorte generacional que va del primer semestre (ingreso de los estudiantes) hasta el cuarto semestre de la carrera, así como la eficiencia terminal e índices de titulación.

3. Plan de estudios. Alude a la valoración de los estándares correspondientes a la fundamentación del modelo educativo que persigue el programa, los perfiles de ingreso y egreso para los estudiantes, las normas y lineamientos para la permanencia, egreso y revalidación, así como la flexibilidad curricular. También se evalúan estándares acerca del programa de unidades para el aprendizaje, la evaluación, difusión y actualización del plan de estudios del programa.

4. Evaluación del aprendizaje. Implica estándares vinculados con los mecanismos para la evaluación continua y los estímulos de rendimiento académico que son otorgados a los estudiantes por su desempeño.

5. Formación integral. Abarca estándares que tienen relación con actividades artísticas o culturales, físicas y deportivas, de orientación profesional y psicológica, así como la promoción de participación en eventos sobre el desarrollo de emprendedores.

6. Servicios de apoyo para el aprendizaje. Involucra estándares acerca del funcionamiento y acciones que se llevan a cabo entre los servicios de tutorías, asesorías académicas y biblioteca.

7. Vinculación y extensión universitaria. Alude a los estándares relacionados con la organización, planificación y evaluación de servicios que son realizados por los estudiantes en el sector público, privado y social, como: servicio social, prácticas profesionales y bolsa de trabajo. Además, se trata de estándares que hacen referencia al intercambio académico y seguimiento a egresados.

8. Investigación. Constituye el conjunto de estándares acerca de las líneas y proyectos de investigación con los que se dispone en el programa educativo, así como 
los recursos, difusión e impacto dedicados a la transferencia de los resultados en el área de la investigación.

9. Infraestructura y equipamiento. Comprende los estándares vinculados con la suficiencia de espacios, sistemas y recursos, para el desarrollo de eventos y la realización de actividades académicas y administrativas.

10. Gestión administrativa y financiamiento. Abarca los estándares correspondientes a la planeación, valoración y organización del sistema institucional de evaluación. Además de estándares relacionados con los recursos humanos, administrativos, financieros, de apoyo y servicios por los que dispone el programa educativo.

Tabla 1

Categorías para la evaluación de programas educativos por los CIEES y el COPAES

Categorías de los CIEES (diagnóstico)
Categorías del COPAES

(acreditación)

\begin{tabular}{|ll}
\hline 1. Propósitos del programa & 1. Personal académico \\
\hline 2. Condiciones generales de operación del programa & 2. Estudiantes \\
\hline 3. Modelo educativo y plan de estudios & 3. Plan de estudios \\
\hline 4. Actividades para la formación integral & 4. Evaluación del aprendizaje \\
\hline 5. Proceso de ingreso al programa & 5. Formación integral \\
\hline 6. Trayectoria escolar & 6. Servicios de apoyo para el aprendizaje \\
\hline 7. Egreso del programa & 7. Vinculación-extensión \\
\hline 8. Resultados de los estudiantes & 8. Investigación \\
\hline 9. Resultados del programa & 9. Infraestructura y equipamiento \\
\hline 10. Personal académico & 10. Gestión administrativa y financiamiento \\
\hline 11. Infraestructura académica & \\
\hline 12. Servicios de apoyo & \\
\hline
\end{tabular}

Nota: Los colores representan la relación que guardan las categorías entre los organismos evaluadores. Fuente: Elaboración propia, a partir de Comité para la Evaluación de Programas de Pedagogía y Educación (2015), Comités Interinstitucionales para la Evaluación de la Educación Superior (2018b) y Consejo para la Acreditación de la Educación Superior (2016). 


\section{Etapa 2. Visita de evaluación}

Para esta etapa, los organismos evaluadores asignan un comité de tres expertos en el área de conocimiento, con el propósito de que realicen una visita a la institución para evaluar el programa, a partir del informe y las carpetas con los documentos de verificación de cada categoría. Durante la visita, el comité llevará a cabo diversas entrevistas para conocer la percepción de los diversos agentes que están involucrados en el programa educativo, con el fin de conocer la optimización y suficiencia de este. Los agentes educativos que aportan información ante ciertos cuestionamientos son:

- Equipo directivo, personal administrativo y coordinador de la licenciatura. Responden acerca de cómo es la contratación y formación continua de los académicos que laboran en el programa educativo, la infraestructura, la gestión del programa educativo, la implementación de actividades de formación integral para los estudiantes, el uso de recursos, la vinculación con el sector laboral, el proceso de ingreso y egreso, entre otros

- Docentes. Son cuestionados sobre el proceso de enseñanza, el progreso de los estudiantes, el uso de recursos y estrategias didácticas, su participación en actividades que se organizan, directa o indirectamente, para el programa educativo, los mecanismos de formación continua que se les brinda, por mencionar algunos ejemplos

- Estudiantes. Expresan su opinión respecto a la suficiencia de recursos e infraestructura en la universidad, el servicio que reciben por parte del personal administrativo (equipo directivo, de los diversos departamentos y/o coordinaciones, biblioteca, centro de cómputo, etc.), la calidad de la enseñanza y el trato que reciben de sus maestros, entre otros aspectos

- Egresados. Se les pregunta sobre el trato que recibieron en la universidad durante su estancia hasta el egreso, de qué forma los conocimientos adquiridos en el programa educativo les ayuda en el campo laboral e incluso si continúan sus estudios al realizar un posgrado, por mencionar algunos ejemplos 
- Empleadores o personas que se encuentren en el sector laboral del área de conocimiento al que pertenece el programa. Se les cuestiona acerca de la eficacia, capacidad y compromiso laboral que disponen los egresados que ingresan a trabajar en sus empresas

\section{Etapa 3. Dictamen}

En esta etapa, con base al informe que el comité evaluador elabore durante la visita, se emitirá un dictamen con el cual se determinará si el programa educativo se acreditará o no. Para este procedimiento, se considerará el cumplimiento de argumentos y evidencias en cada uno de los indicadores que conforman los criterios de las áreas del proceso educativo a evaluar (categorías). Asimismo, se consideran las fortalezas y debilidades identificadas en el programa, así como la viabilidad de las acciones propuestas para la mejora por los responsables del programa.

De acuerdo con el CEPPE (2015) y el COPAES (2016), para que un programa quede acreditado debe cumplir satisfactoriamente con el 100\% de los indicadores clasificados como esenciales (aspectos indispensables que garantizan la calidad) en el marco de referencia para la acreditación. Además, se debe cubrir favorablemente con el 50\% de los indicadores necesarios (aspectos que impulsan el desarrollo de la calidad) y el $25 \%$ de los recomendables (indicadores que auxilian la optimización del programa).

\section{Etapa 4. Entrega de informe de evaluación}

Una vez dictaminado el resultado del proceso de evaluación, se entrega al responsable del programa educativo un informe en el cual se incluyen las valoraciones en cada una de las categorías respecto a sus criterios e indicadores. Asimismo, se entregan las recomendaciones de mejora que sugieren los expertos, para que los responsables del programa educativo optimicen su atención hasta el momento para la siguiente evaluación.

\section{Etapa 5. Visita de seguimiento}

A esta etapa corresponde la revisión del cumplimiento de las recomendaciones realizadas por los expertos del COPAES, planteadas en el informe final de acreditación. Además, 
se considera la atención y evidencias que se siguieron y cumplieron entre las acciones de mejora planteadas por el encargado del programa educativo. Durante la visita, los expertos -en el área del conocimiento al que pertenece el programa educativo- revisan no sólo la atención a las recomendaciones, sino también posibles o nuevas deficiencias, con el fin de aportar más sugerencias de mejora en cada una de las áreas del proceso educativo del programa.

De acuerdo con Rodríguez (2014), acreditar un programa educativo debería ser el resultado de una exhaustiva evaluación y seguimiento sistemático sobre el cumplimiento y pertinencia de las funciones esenciales hacia las necesidades sociales, por lo que la pertinencia tendría que ser un criterio importante de evaluar en un programa educativo. Con la acreditación se permite que los directivos de las universidades confirmen y amparen la calidad de sus recursos humanos y servicios profesionales ante la sociedad, en virtud de demostrar voluntariamente los avances significativos en sus programas hacia el logro de un conjunto de estándares de pertinencia para el nivel educativo. Sin embargo, entre los indicadores de cumplimiento propuestos por los organismos evaluadores (CIEES y COPAES), se identificó que no se logran abordar varios aspectos importantes entre los estándares de evaluación. Por ejemplo:

- En el seguimiento a egresados, no se cuestionan y valoran los mecanismos de comunicación que se tienen con los estudiantes egresados. Asimismo, no se discute si la universidad provee cursos para la capacitación profesional de los egresados y si estos tienen participación en algunas actividades de la universidad hacia la toma de decisiones respecto a la mejora del programa educativo

- Para el criterio sobre los recursos humanos administrativos, de apoyo y de servicios, no se valora la existencia de un sistema para la evaluación de la atención y disponibilidad del personal de apoyo al área administrativa correspondiente a la dirección, subdirección y administración de la universidad

- Entre los criterios no se aborda acerca de la gestión y aseguramiento del progreso de los estudiantes en el dominio de un idioma extranjero, como un recurso indispensable para la titulación, así como para ingresar a un programa de posgrado 
- No se presentan criterios sobre los recursos, implementación, seguimiento y evaluación de la educación a distancia (asignaturas semipresenciales y a distancia)

Aunado a lo anterior, respecto a la deficiencia identificada de aspectos por abordar entre los criterios de evaluación por organismos acreditadores, también se pueden apreciar algunas disyuntivas en el procedimiento de evaluación. Por ejemplo, de acuerdo con Rodríguez (2014), en los inicios de las acreditaciones se percibía dicho proceso como un reto hacia la certificación de un alto reconocimiento, con la certeza de que el programa cumplía con todos los estándares y fundamentos básicos de calidad y pertinencia de la educación superior. No obstante, ante la demanda de perseguir el certificado de acreditación, cada vez es más frecuente que los organismos evaluadores aprueben programas educativos con una variada y vasta cantidad de aspectos por mejorar en un transcurso de 3 años (en la etapa de seguimiento) y 5 años (en la etapa de re-acreditación). Por lo tanto, a partir de esta perspectiva del autor, se ponen en duda el reconocimiento de dichas certificaciones como programas educativos de buena calidad. Entre otros inconvenientes del proceso de acreditación de los organismos evaluadores se aprecia que:

- Dado que la evaluación es por medio de la revisión por pares académicos, dicho proceso no es del todo objetivo, como se especifica en la metodología de los organismos evaluadores previamente mencionados

- Debido a que la visita de evaluación se lleva a cabo por medio de un comité evaluador con al menos tres miembros, es importante considerar que, para una óptima revisión de la veracidad de la autoevaluación del programa educativo, dicha valoración sea a través de distintos cuerpos colegiados, realizando una exploración más exhaustiva de los estándares y criterios

- El mecanismo de selección de participación de los estudiantes, docentes y egresados no se especifica en el marco de evaluación de los CIEES y el COPAES, por lo que se debería definir un mecanismo más riguroso y no bajo el criterio de los responsables del programa educativo, puesto que se corre el riesgo de presentarse una invitación por conveniencia de los agentes educativos antes mencionados 
Con base en la descripción del procedimiento de evaluación y acreditación de organismos como CIEES y COPAES, así como las deficiencias identificadas en el proceso de evaluación, se hace indispensable revisar si la metodología de los organismos evaluadores corresponde con los módulos del modelo CIPP de Stufflebeam, el cual es un referente ampliamente utilizado para evaluar programas educativos.

\section{Comparación entre el procedimiento de evaluación de CIEES y COPAES con el modelo CIPP}

El modelo de CIPP (por sus siglas en inglés), creado por Stufflebeam y Shinkifield (1987), es un referente que permite la evaluación de programas educativos bajo el enfoque de la toma de decisiones. En este modelo, la evaluación representa un medio dirigido hacia el perfeccionamiento, para conocer el estado acerca de cómo se encuentra el objeto evaluado con el fin de que se reconozcan áreas susceptibles de mejora, que al atenderlas se convierten en fortalezas (Guerrero y Can, 2015). Para Rodríguez (2007), este modelo representa una perspectiva hacia la valoración global e integradora acerca de la eficacia de un programa, mediante cuatro tipos de evaluación: contexto, entrada, proceso y producto. Las fases del modelo CIPP se describen a continuación, de acuerdo con Bausela (2003) y Stufflebeam (2003).

\section{Evaluación de contexto}

Representa una revisión diagnóstica que ayuda a identificar las fortalezas y debilidades que comprenden las características del entorno en el que se desarrolla el programa educativo. Con este ejercicio se establecen criterios para definir metas hacia la mejora y juzgar los resultados obtenidos. Para evaluar el contexto de un programa educativo se requiere analizar bases de datos, informes y registros, así como realizar entrevistas y reuniones con el fin de explorar el estado actual del programa. De acuerdo con Rodgers (1979 como se citó en Bausela, 2003), la finalidad en esta fase del modelo es: identificar los objetivos del programa y reconocer los obstáculos que impiden su logro. 
Con base en lo expuesto en este proceso del modelo CIPP, se interpreta que existe una coincidencia con los propósitos de la etapa 1, Autoevaluación de la institución, en el procedimiento de evaluación de programas educativos empleado por los CIEES y el COPAES. Esta correspondencia se debe a que las características entre ambos procesos tienen relación con la revisión que emplean los responsables del programa respecto al contexto, el estado global actual del mismo, por la tarea de diagnosticar problemas y establecer metas para generar los cambios requeridos.

\section{Evaluación de entrada}

Consiste en establecer un plan de acción hacia la atención de las necesidades, a través de la utilización de los recursos disponibles en el programa para cumplir con sus objetivos. El cometido en esta fase contribuye a determinar estrategias, recursos (materiales o humanos), financiamiento y tiempo, para realizar los cambios necesarios y superar los obstáculos identificados en la evaluación de contexto. Además, con este proceso se pretende ayudar a los administradores y coordinadores del programa a examinar propuestas de estrategias alternativas que ayuden a eliminar las circunstancias que interfieran con el progreso del programa, mediante la revisión del estado de la práctica.

A partir de la información descrita, se aprecia una similitud entre las características de este proceso de evaluación del modelo CIPP con la etapa 2, Visita de evaluación, del procedimiento que llevan a cabo los CIEES y el COPAES. La coincidencia entre ambos procesos de evaluación se debe a que su finalidad es la revisión puntual de cada uno de los argumentos presentados en el proceso de autoevaluación, para generar un plan estratégico para la atención de las debilidades identificadas, considerando estrategias alternativas, limitaciones y recursos utilizables para el programa.

\section{Evaluación de proceso}

Alude a la comprobación de información necesaria para justificar que el programa, tal y como está constituido, funciona eficazmente. La finalidad de esta evaluación es asegurar que el diseño e implementación del programa no presente defectos. En esta evaluación 
se requiere que el evaluador supervise y elabore un registro sobre las condiciones contextuales, los aspectos del funcionamiento y los factores que conforman el programa, con el propósito de proporcionar una retroalimentación respecto a la interpretación de los resultados hacia una toma de decisiones.

De acuerdo con las características descritas, se considera que existe concordancia entre este proceso del modelo CIPP con la etapa 3, Dictamen, y la etapa 4, Entrega del informe de evaluación, en el procedimiento para evaluar programas por parte de los CIEES y el COPAES. La correspondencia entre ambos procesos guarda relación debido a que la finalidad es la retroalimentación que el organismo evaluador otorga al encargado del programa educativo, con el fin de mejorar la calidad de sus servicios, mediante una descripción extensa sobre la calidad juzgada, tras el trabajo de los evaluadores y la percepción de diversos agentes educativos.

\section{Evaluación de producto}

Hace referencia al juicio de valor sobre los logros del programa. Su finalidad es recuperar información acerca de la satisfacción y atención a las necesidades de todas las personas relacionadas con el programa. Para este proceso se deben evaluar tanto los resultados positivos como negativos, así como los efectos del programa educativo entre los sectores académico (personal administrativo, docentes, estudiantes, etc.), social (individuos de la comunidad, gobierno, etc.) y laboral (egresados, empresarios, etc.).

Conforme a lo expuesto en este proceso del modelo CIPP, se identifica que existe concordancia con el propósito de la etapa 5, Visita de seguimiento, del procedimiento de evaluación empleado por los CIEES y el COPAES. Esta similitud corresponde a que tienen relación con la revisión acerca de cómo se atendieron las acciones de mejora (propuestas por el responsable del programa) y de qué forma se siguieron las recomendaciones de los organismos evaluadores.

En la tabla 2, se presentan las similitudes entre las fases del modelo CIPP y las etapas del proceso de evaluación diagnóstica por CIEES y de acreditación por COPAES. 
Tabla 2

Similitudes entre los procesos de evaluación en el modelo CIPP, CIEES y COPAES

\begin{tabular}{|c|c|}
\hline Modelo CIPP & Evaluación por CIEES y COPAES \\
\hline 1. Contexto & 1. Autoevaluación de la institución \\
\hline 2. Entrada & 2. Visita de evaluación \\
\hline \multirow{2}{*}{ 3. Proceso } & 3. Dictamen \\
\hline & 4. Entrega del informe de evaluación \\
\hline 4. Producto & 5. Visita de seguimiento \\
\hline
\end{tabular}

\section{Conclusión}

Con base en los resultados presentados, se identificó una coincidencia entre las fases del modelo CIPP y las etapas del proceso de evaluación y acreditación de CIEES y COPAES. Además, se encontró lo siguiente:

- La metodología de evaluación de programas educativos que siguen los organismos evaluadores como CIEES y COPAES, se centran en un proceso que inicia con una autoevaluación del programa, a fin de conocer su estado actual, seguido de una visita de evaluación en la que se revisan los aspectos probatorios de la revisión diagnóstica y, posteriormente, tener una retroalimentación y revisión de los organismos especializados en la evaluación de programas educativos a través de estándares, criterios e indicadores. Dicha metodología guarda relación con el modelo hacia la toma de decisiones propuesta por Stufflebeam y Shinkifield (1987), sólo que en dicho modelo las denominaciones de las fases no describen las acciones por implementar en el proceso de evaluación

- Los resultados que se producen entre el modelo CIPP de evaluación y el modelo de CIEES y COPAES son los mismos. Por una parte, se exponen los motivos por los cuales el programa educativo debe atender a ciertos criterios esenciales para asegurar la calidad de sus servicios; y, por otra parte, se proponen recomendaciones viables con el propósito de resolver y/o disminuir las debilidades del programa 
- Con la información recabada entre el modelo CIPP y el que llevan a cabo CIEES y COPAES se obtienen resultados y evidencias similares. En ambos casos se plantea la necesidad de realizar un análisis de autoevaluación, se realiza un informe general del programa, respaldado con evidencias normativas y el registro de las actividades. Además, se genera un plan estratégico de acción para solucionar deficiencias y atender recomendaciones que serán objeto de revisión para asegurar su puntual y eficaz atención hacia la mejora del programa educativo y los servicios de la universidad

- $\quad$ Se aprecia la necesidad de incorporar, en los marcos de evaluación de CIEES y COPAES, indicadores relacionados con la comunicación y atención de egresados, la implementación de la educación a distancia y la revisión de mecanismos vinculados con la calidad de los servicios administrativos del personal directivo

- Queda la disyuntiva respecto a si el procedimiento de evaluación en las instituciones de educación superior en México atiende y es pertinente con las necesidades sociales. También, si la certificación por CIEES y COPAES está sujeta a una revisión exhaustiva de los criterios pertinentes para considerar que un programa educativo es de calidad, es decir, que no haya aspectos sustanciales pendientes hacia una segunda revisión, y que esta sea a través de diversos cuerpos colegiados 


\section{Referencias}

Acosta, A. (2014). Evaluación y acreditación de programas educativos en México: revisar los discursos, valorar lo efectos. Revista de la Educación Superior, 43(172), 151-157. Recuperado de https://goo.gl/nohyQL

Bausela, E. (2003). Metodología de la Investigación Evaluativa: Modelo CIPP. Revista Complutense de Educación, 14(2), 361-376. Recuperado de http://revistas.ucm.es/ index.php/RCED/article/view/17241

Bezies, P., Olvera, B., y Enciso, A. (noviembre, 2011). La autoevaluación de programas educativos en la UAEH: un medio para la mejora de la calidad. Trabajo presentado en el XI Congreso Nacional de Investigación Educativa, Ciudad de México.

Comités Interinstitucionales para la evaluación de programas educativos de educación superior (CIEES). (2018a). Proceso general para la evaluación de programas educativos de educación superior. México: CIEES.

Comités Interinstitucionales para la evaluación de programas educativos de educación superior (CIEES). (2018b). LOS CIEES actualizan la metodología para la evaluación de programas de educación superior. Recuperado de https://goo.gl/7jHnxF

Comité para la Evaluación de Programas de Pedagogía y Educación (CEPPE). (2015). Marco de referencia para la acreditación de programas universitarios. Recuperado de https://goo.gl/noih3A

Consejo para la Acreditación de la Educación Superior (COPAES). (2016). Marco General de Referencia para los Procesos de Acreditación de Programas Académicos de Tipo Superior. Recuperado de https://goo.gl/grqmTz

Dela Garza, J. (2013). La evaluación de programas educativos del nivel superior en México. Avances y perspectivas. Perfiles Educativos, 35(Especial), 33-45. Recuperado de https://goo.gl/mXYY9X

García-Cabrero, B. (2010). Modelos teóricos e indicadores de evaluación educativa. Sinéctica, (35), 1-17. Recuperado de https://goo.gl/1XaXL3

Gómez, M., \& Herrera, S. (2007). La Función de los Organismos Evaluadores que Coadyuvan en el Proceso de Evaluación para el Desarrollo de los Programas de 
Educación Superior y Facilitan la Obtención de Recursos Federales. Primera Revista Electrónica en América Latina Especializada en Comunicación, (55). Recuperado de Recuperado de https://goo.gl/VFck3b

Gómez, J., \& Mora, M. (2011). Los modelos de evaluación aplicados a los programas educativos de educación superior: una perspectiva bibliotecológica. Investigación Bibliotecológica, 25(53), 13-29. Recuperado de http://rev-ib.unam.mx/ib/index. php/ib/article/view/27467

Guerrero, J., \& Can, A. (2015). La evaluación del programa educativo en el nivel superior. Opción, 31(2), 557-572. Recuperado de https://goo.gl/35uVNf

Jornet, J., Leyva, Y., \& Sánchez, P. (2009). Dimensiones de clasificación de los procesos de evaluación educativa. En J.M. Jornet, \&Y.E. Leyva (Comp.), Conceptos, metodología y profesionalización en la evaluación educativa (pp. 65-75). México: INETE.

Márquez, E., \& Zeballos, Z. (2017). El Impacto de la Acreditación en la Mejora de la Calidad de los Programas Educativos que Ofrece la Universidad Autónoma de Tamaulipas: Un Estudio de Caso. Revista Iberoamericana de Evaluación Educativa, 10(2), 65-83.

Ramírez, L. (2016). La evaluación de la educación superior: Un campo de tensiones. Fides et Ratio-Revista de Difusión cultural y científica de la Universidad La Salle en Bolivia, 11(11), 125-138. Recuperado de https://goo.gl/UkCPV5

Rodríguez, M. (2007). Aplicación del modelo de evaluación CIPP al programa de ciencias de una escuela del distrito escolar de Juana Díaz (Tesis de maestría). Universidad Interamericana de Puerto Rico.

Rodríguez, I. (2014). La acreditación de los programas educativos, ¿eleva la calidad de educación? Revista Iberoamericana de Producción Académica y Gestión Educativa, (2), 1-13.

Stufflebeam, M. (2003). The CIPP Model for Evaluation. En T. Kellaghan, D.L. Stufflebeam, \& L.A. Wingate, International Handbook of Educational Evaluation (pp. 31-63). Great Britain: Kluwer Academic Publishers.

Stufflebeam, D.L., \& Shinkfield, A.J. (1987). Evaluación sistemática. Guía teórica y práctica. Barcelona: Paidos/MEC. 
Qartuppi, S. de R.L. de C.V. está inscrita de forma definitiva en el Registro Nacional de Instituciones y Empresas Científicas y Tecnológicas (RENIECYT) con el número 1600052.

Qartuppi, S. de R.L. de C.V. es miembro activo de la Cámara Nacional de la Industria Editorial Mexicana (CANIEM) con número de registro 3751.

Apuntes de investigación educativa

ISBN 978-607-98270-9-0

DOI 10.29410/QTP.19.05

Esta publicación digital se terminó de producir en abril de 2019. Su edición y diseño estuvieron a cargo de:

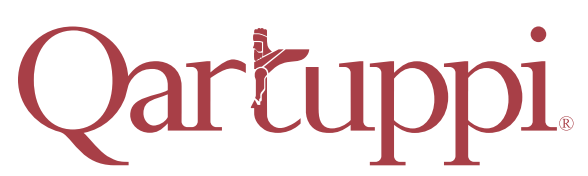

Qartuppi, S. de R.L. de C.V. http://www.qartuppi.com 
Esta obra muestra las revisiones, reflexiones, críticas y hallazgos en torno a la educación, producto del trabajo de investigación en distintos niveles educativos, con distintas aproximaciones metodológicas para estudiar distintos fenómenos. En ese sentido, esta obra pretende dos alcances: compartir el conocimiento generado por un grupo de investigadores y ser un insumo para la enseñanza de la investigación educativa. De esta manera, se pueden encontrar desde capítulos con un enfoque teórico/conceptual hasta capítulos empíricos o de análisis crítico. Se presentan contenidos vinculados a los distintos niveles educativos, desde básico hasta superior. Así, se construye una compilación de elementos individuales que resultan valiosos tanto por su contenido, como por lo que a través de ellos puede ejemplificarse en el ámbito de la investigación educativa.

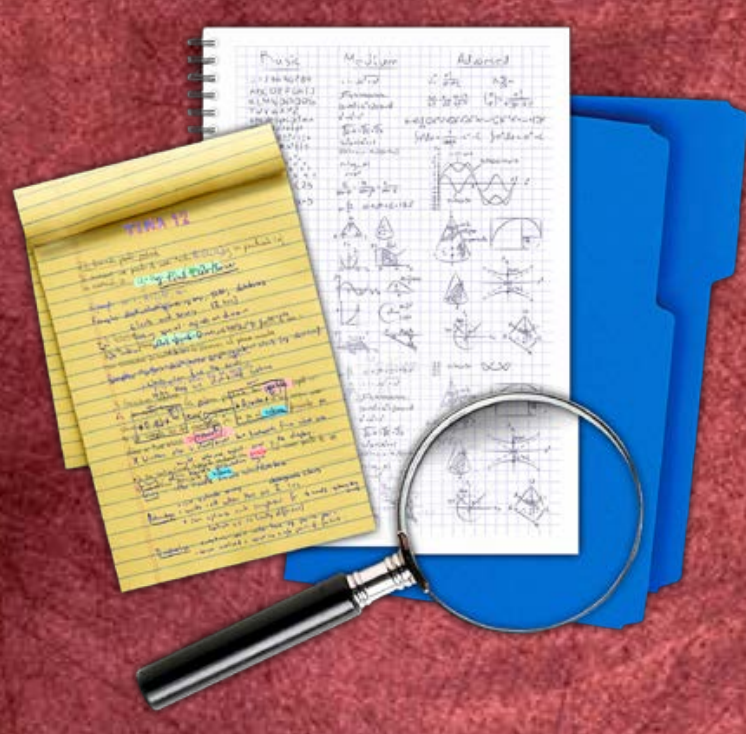

Qartuppi

ISBN 978-607-98270-9-0

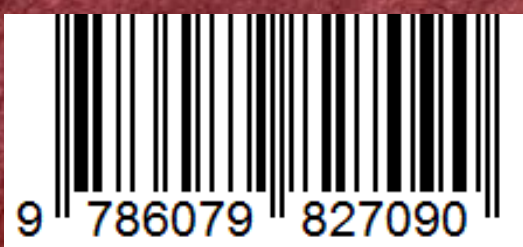

